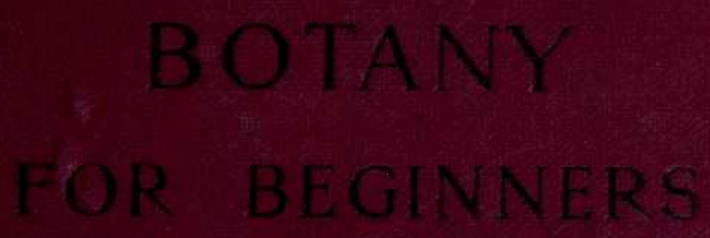

ERNEST EVANS

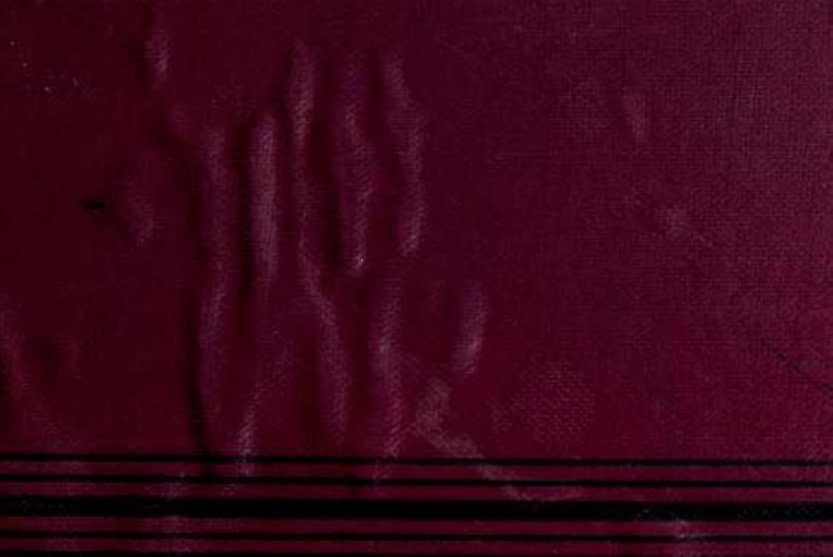


PRESENTED

To

THE UNIVERSITY OF TORONTO

BY

He Opp Clark Poupauy 
Examination copies of the accompanying Book have just reached us from the Publishers. We have pleasure in sending one to your address.

THE COPP, CLARK COMPANY, LIMITED

9 Front St. West, TORONTO 





\section{BOTANY FOR BEGINNERS}


s.:xixis 


\section{PREFACE}

IT is now generally accepted by educationists that experimental work is an essential part of instruction in any branch of physical or natural science. Too much importance cannot be attached to knowledge gained direct from Nature; and it is gratifying to know that many questions now set by public examining bodies are designed to test the student's own observations and experience. As an instance of this, it is worth pointing out that in the syllabus for Botany, published by the Department of Science and Art, the examiners remark :-

"The examination will be especially directed towards ascertaining the amount and character of the practically acquired knowledge possessed by the students."

To provide students with a means of obtaining such knowledge, this little work has been prepared in the spirit of the foregoing remarks, as a guide to beginners in the practical study of plants. The attempt is often made to study Botany without the practical examination of plants, and it has produced on the popular mind an impression that the subject is uninteresting. This is the result of the old method of teaching Botany by means of ideals or definitions; the new method is to examine the plants from as many points of view as possible, and to draw conclusions from actual observations. Studied in this way, the subject becomes one of living interest, instead of being merely a collection of technical names and terms. It is with the idea of placing in the hands of all who are interested in the study of plants a book which shall be a guide and companion during a first course that the present volume has been prepared. 
Though the book has been primarily designed to cover the syllabus of the Department of Science and Art, it is by no means a "cram-book" for that particular examination, and a thorough knowledge of its contents will not only lay the foundation for further work, but should enable a student to pass any elementary examination in Botany with distinction. The book should also be useful to teachers in elementary schools, in assisting them to prepare object lessons with plants for the instruction of their pupils.

Teachers are recommended to see that the students perform the experiments, and keep a complete record of the results obtained. Most of the plants necessary for the experiments can be easily obtained; the others can be grown in the school grounds. A small collection of fruits, seeds, dried and mounted plants, should be kept in all schools.

It is hoped that the introduction into this book of a series of carefully graded experiments with simple apparatus will prove useful to many students and teachers, and will be the means of making botanical science a more popular subject in the future than it has been in the past.

Many of the illustrations have been prepared, after careful consideration, by my friend and colleague Mr. W. E. Holt, to whose skill I am much indebted. Figures 128 to I3I have been drawn by my former student, Mr. H. Wright, A.R.C.S. The figures marked S. have, by the kindness of the publishers, been placed at my disposal from Strasburger's Text Book of Botany.

The questions at the ends of the chapters will serve to test whether students have clear ideas on the subjects dealt with. Those with years indicated are from papers set at the Science and Art Department's examinations ; and T. signifies Training College questions.

In conclusion, I desire to acknowledge my indebtedness to Prof. R. A. Gregory and Mr. A. T. Simmons, B.Sc., for many valuable suggestions and much help during the preparation of the manuscript, and the passage of the work through the press.

ERNEST EVANS.

Mechanics' Institute and Technical

SCHOOLS, BURNLEY. 


\section{CONTENTS}

CHAPTER I

INTRODUCTION . .

\section{CHAPTER II}

MORPHOLOGY_-STUDY OF THE BODY OF A PLANT .... $\delta$

CHAPTER III

ANATOMY - STUDY OF THE SHOOT ........ 16

CHAPTER IV

THE STUDY OF THE SHOOT (continued). ....... 34

CHAPTER V

ANATOMY -STUDY OF ROOTS ............ $5^{\mathrm{I}}$

CHAPTER VI

SECTIONS, HOW TO PREPARE AND EXAMINE THEM .... . 61

CHAPTER VII

THE HISTOLOGY OF THE CELL. ........... 74

CHAPTER VIII

THE HISTOLOGY OF THE TISSUES $\ldots \ldots \ldots \ldots . \ldots 92$

CHAPTER IX

THE HISTOLOGY OF THE SHOOT AND ROOT ........ IO3 


\section{CHAPTER $\mathrm{X}$}

THE PHYSIOLOGY OF NLTRITION

CHAPTER XI

THE ABSORPTION AND MOVEMENT OF WATER IN THE PLANT

CHAPTER XII

THE PHYSIOLOGY OF GROWTH AND MOVEMENT

CHAPTER XIII

FLOWER AND INFLORESCENCES . . . . . . . . . I64

\section{CHAPTER XIV}

THE TERMS USED IN DESCRIBING THE FLOWER. . . . . I78

CHAPTER XV

THE DEVELOPMENT AND MORPHOLOGY OF THE FLOWER . . I93 CHAPTER XVI

POLLINATION AND FERTILISATION . . . . . . . . 206

CHAPTER XVII

THE MORPHOLOGY OF SEED AND FRUITS, AND THEIR DISTRIBUTION

CHAPTER XVIII

THE PHYSIOLOGY OF REPRODUCTION . . . . . . . . 237

CHAPTER XIX

THE CLASSIFICATION OF PLANTS.

CHAPTER XX

CLA3SIFICATION OF PLANTS (continued)........ 265

CHAPTER XXI

PLANT DESCRIPTION 


\section{BOTANY FOR BEGINNERS}

\section{CHAPTER I}

INTRODUCTION

Definition.- The branch of science the object of which is the study of the plant, from-as many different points of view as possible, is termed Botany. All its laws can be proved by observation and experiment, and it is consequently known as one of the concrete sciences. If we wish to include all plants it is impossible to clearly define what is meant by a plant, because the higher plants differ in many respects from the lower, and so many exceptions to any rule we may state present themselves. It is true that in olden times our forefathers divided all forms of life into animals and plants, but we find we cannot, with the knowledge of to-day, draw a clear boundary line between them. It is easy to recognise the difference between an oak tree and a horse, but when the lower forms of life are examined no clear division can be drawn between animals and plants. All living things are built up of the same kind of material, viz. - protoplasm. Protoplasm has been called the physical basis of life, because life is never found apart from it. There appears to be no difference between the protoplasm obtained from animals and that obtained from plants. In fact, what we speak of as the tree of life is forked, the animals being found on one side and the plants on the other, 
and both of them spring from the lowly forms which are found at the base.

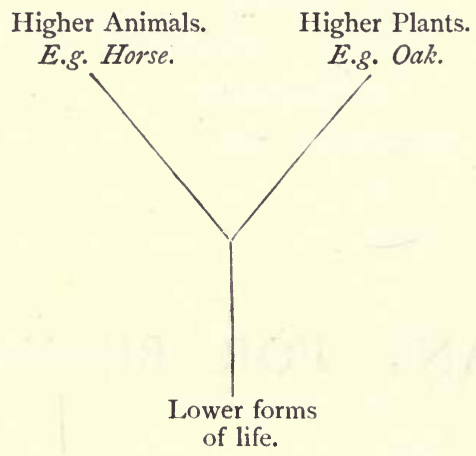

Living and Non-living Bodies.-It will be well to at once consider the question of the differences between living and non-living bodies; and here a fairly clear boundary line can be drawn.

I. Living bodies are characterised by the nature of their external form. Their shape is definite, and bounded more or less by curved surfaces. Non-living bodies are either amorphous, that is without shape ; or crystalline, that is bodies with a definite shape. Crystals are bounded by flat surfaces meeting in sharp edges.

2. Living bodies are able to reproduce their kind, but nonliving bodies have not this power of reproduction.

3. Living bodies take in food, which supplies material for growth, the growth taking place from the inside. Non-living bodies cannot take in food, but they can increase in size if placed under suitable conditions. The growth or increase in size of a crystal always takes place on the outside, not internally like the growth of either animals or plants.

The Object of the Plant.- Plants, then, are living things, and we must learn to treat them as such. Plants produce seeds, but not, as the reason is sometimes stated, for the use of man, but so that the continuity of the particular race of plants can be kept up. The living, working, struggling plant, has only 
one object in life, that is, to reproduce its kind. All the parts of the plant are designed with this object in view ; the shape, colour, and perfume of the flowers, and all the various contriv-
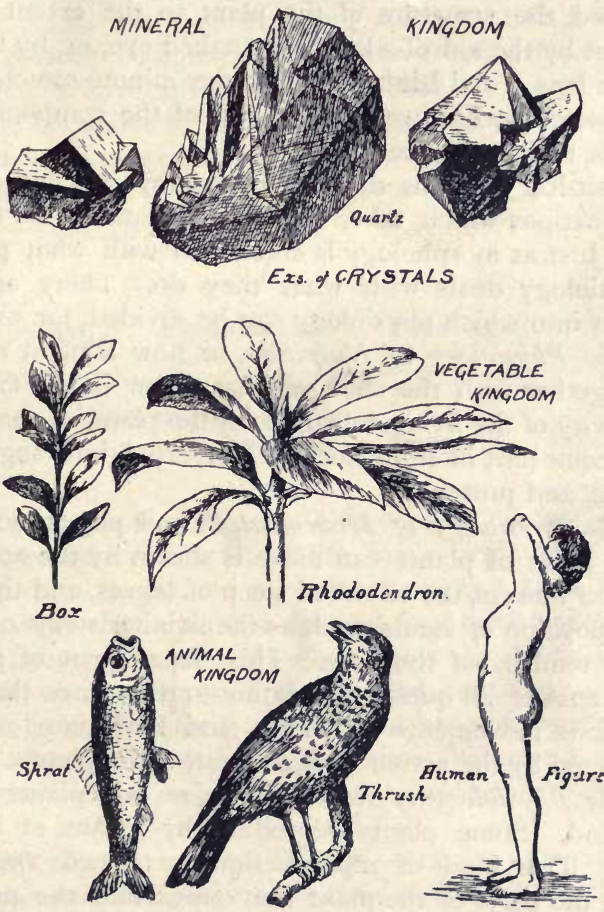

Fig. I.-Illustration of the difference in the external forms of the mineral, vegetable, and animal kingdoms.

ances with which plants are endowed, are to be regarded as means towards accomplishing this reproduction.

Scope of Our Lessons. - We shall have to consider the plant from the following points of view :-(i) Morphology, or the science of form and structure ; (ii) Physiology, or the science of function; (iii) Classification, or the science of relationship. 
Morphology.-That portion of the study of living things which deals with the shape and structure of the various organs of plants or animals is termed morphology. Morphology is divided into anatomy, which means, as far as our lessons are concerned, the structure of the plant to the extent it can be made out by the aid of a knife, the naked eye, or by the aid of a simple lens ; and histology, or the minute structure of the various organs which require the use of the compound microscope for their complete study.

Physiology.-This division of botany is concerned with those functions which, taken together, constitute the life of the plant. Just as morphology is concerned with what plants are, so physiology deals with what they do. There are several divisions into which physiology can be divided, for example :-

I. The Physiology of Nutrition, or how a plant obtains its food, together with the changes that go on in the food due to the activity of the living substance of the plant, so that the food may become part of it, or become converted into sugar, starch, cellulose, and proteids.

2. The Physiology of Movement, or how plants move. That various parts of plants can move is shown by the opening and closing of flowers, the so-called sleep of leaves, and the changes in the position of stems, such as the twining stems of the hop, and the tendrils of the vine. This department of physiology tries to answer all questions relating to the causes that produce the various movements of plants, and how these movements are affected by the action of light, heat, and moisture.

3. The Physiology of Reproduction, or how plants reproduce their kind. Some plants reproduce by means of bulbs and tubers. This kind of reproduction is termed vegetative, because the parts of the plant that enter into the process are only portions produced by the vegetative functions of the plant. In far the greater number of cases, plants reproduce their kind by means of seeds. This kind of reproduction is termed sexual.

Classiflcation.-The province of classification is to point out the relationship between different plants. Many methods of classification have been devised, and many of them are known as artificial systems.

One of the best known is that of Linnæus, which is based on 
the number and arrangement of the parts of the flower. All the various artificial systems have been superseded by that called the Natural System, which is based on the resemblances and differences of plants. The natural system of classifying plants is the most perfect yet used, though it is not up to the present complete, because the relationships between different plants have not been fully worked out.

To make the above divisions of our subject yet more clear to the reader we arrange them in a tabular form, which should be carefully learnt.

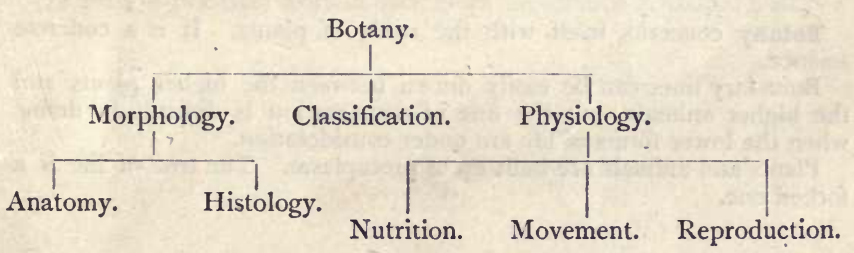

Life-History of a Plant.-Every plant possesses what is termed a life-history, that is, its life has a beginning, it passes through certain stages, old age comes on, and at last it dies. All the changes that a plant undergoes from birth to death make up its life-history. In all the higher plants the life-history commences witl the germination of the seed, continues as that of the seedling, is prolonged as the plant becomes mature, then flowering takes place, seeds are produced, the parent dies, and the continuity of the race is kept up by the young plant in the seed.

Necessity for Practical Work.-Having now given some idea of the scope and aims of botany, and the boundary lines which mark off the different divisions of the subject, the importance of practical work must next be insisted on.

No true knowledge of natural history can be obtained without practical work; and there is no doubt that such work is well adapted for cultivating the powers of observation and attention to details, attainments which are likely to prove of value in whatever walk of life the student may afterward find himself.

Botany is one of the best subjects with which to commence the study of science, because the necessary materials for 
practical work are abundant, and the instruments required in the early stages are very simple.

Full instructions will be found for carrying out the experiments given in the following pages, and if the student will only perform them, and carefully make notes of the results obtained, he will, after working through the book, have a good working acquaintance with elementary botany.

\section{SUMMARY.}

Botany concerns itself with the study of plants. It is a concrete science.

Boundary lines can be easily drawn between the higher plants and the higher animals, but the line of demarcation is difficult to define when the lower forms of life are under consideration.

Plants and animals are built up of protoplasm. The tree of life is a forked one.

Difference Between Living and Non-living Bodies.

\section{Living.}

I. Their shape is definite.

2. Can reproduce their kind.

3. Can take in food and grow internally.

The one object of the plant is to reproduce its kind.

\section{Non-Living.}

I. Either of no definite shape or crystalline.

2. Cannot reproduce their kind.

3. Cannot take in food and can only grow from the outside.

Scope of the Subject.

\section{Morphology}

the science of shape and structure. It is divided into-

Anatomy or structure made out without the use of the compound microscope.

Histology or structure made out by the use of a compound microscope.

\section{Physiology is}

the science of function, or what a plant can do. It is divided into-

Physiology of nutrition.

Physiology of movement.

Physiology of reproduction.

\section{Classification.} is the science of rela. tionship.

Embracing plant description, and placing the plant in its true position in the natural system. 


\section{Questions on Chapter I}

(I) Define the term botany. What are the objects of botany?

(2) What is meant by a concrete science? Why is botany placed among the concrete sciences ?

(3) Can a clear boundary line be drawn between the higher animals and the higher plants? If so, why?

(4) Into what divisions can botany be divided? Why is botany divided into the divisions you mention?

(5) Give a short account of the natural system of classification.

(6) What is meant by the life-history of a plant?

(7) Why is practical work of such great importance in natural history? 


\section{CHAPTER II}

MORPHOLOGY.-STUDY OF THE BOIY OF A PLANT

Parts of a Plant.-If any ordinary plant, such as a wallflower or mustard plant, be examined, we find that it consists of certain well defined parts.

These parts are known as root and shoot; the shoot can again be divided into stem and leaf.

The root and stem are continuous, and together form the axis of the plant. The root is called the descending axis, and the stem the ascending axis. By the repetition of these parts a plant is built up. From a morphological point of view, these parts of a plant are termed its members, and they can be classified under four main heads, as follows :-

I. Root-structures.-These are as a general rule found at the base of the plant. They serve to fix it to the soil, and to take in water and minerals. The root of the mustard plant may be mentioned as a typical instance.

2. Stem-structures. - These may be aërial, as in the stem of the oak, that is, those which grow upwards into the air ; or, they may be found beneath the soil, as in Solomon's Seal, when they are called subterianean stems. In some cases, like the strawberry, they creep along the surface of the ground, when they are known as creeping stems. From the stem both leaves and buds are developed as lateral outgrowths.

3. Leaf-structures.-Leaves are, as a general rule, thin, and green or brightly coloured. They are produced by the stern. 
4. Hair-structures.-These may grow from all parts of the plant and may be short, or long and silky. All hair structures agree in being developed from the epidermis or skin-like coverings of the plant. Some hair-structures serve to keep off unwelcome guests, like ants; others again, like those of the horse chestnut, secrete or form a kind of glue to protect the young buds from cold; while some, like the dandelion, take part in scattering the seeds.

Organs.-From a physiological standpoint the parts of a plant are spoken of as its organs. An organ is a structure which is able to perform some special work, e.g., the root is an organ because it fixes the plant to the soil.

ExPT. 1.-Obtain a nearly full-grown Wallflower plant, and examine it. Observe-

(i) The shoot is erect and branched, and the older part is hard and woody. The upper part of the shoot is green, and the lower part of it is covered with a pale-brown bark.

(ii) That the shoot can be divided into stem and leaf-the leaves being outgrowths of the stem.

(iii) That the stem branches, and the branches rise from the space between the stem and leaves. The space between the leaf and stem is called the axil

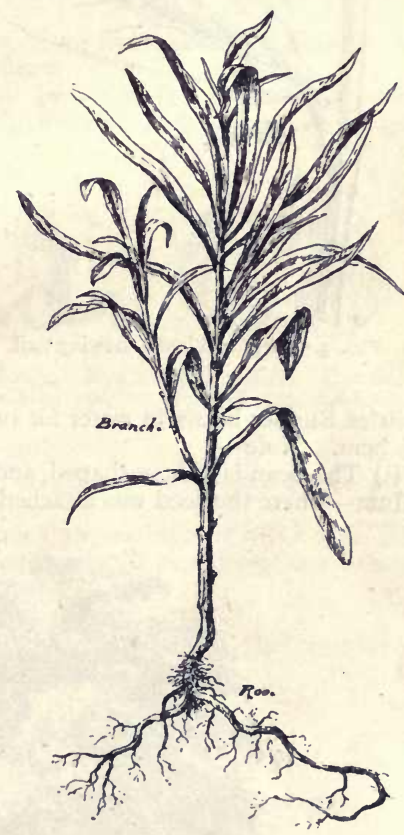

Fig. 2.-Wallfower Plant. of the leaf (Fig. 3).

(iv) That the leaves are green, thin, veined, and lance-shaped.

(v) The shoot is hairy, the hairs lying very close to the surface. Pass the leaf through the fingers and note what the hairs feel like.

(vi) That the main root is nearly colourless and tapers from the point where it joins the stem to its apex. Springing from the main root will be seen a very large number of secondary roots, or root branches, which help to fix the plant to the soil. 
The stock, or any ordinary plant will do for this experiment.

The body of the wallflower is built up of the same members as are found in an oak tree (Fig. 4), a potato, or many other plants.

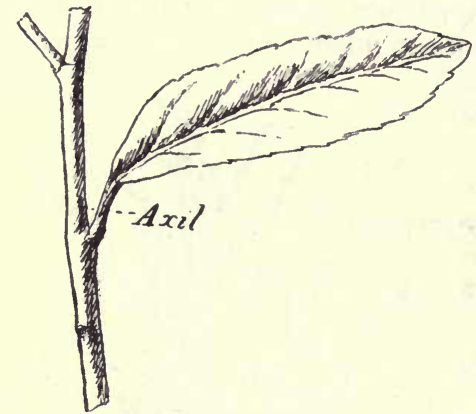

FiG. 3.-Stem and leaf; showing axil.

The Parts Present in a Seed.-Most flowering plants are produced from seeds, and at this point it will be well to consider the structure of seeds. The same parts can be found in a seed as have been recognised in the wallflower, along with other parts which belong to the parent plant.

The Structure of a Bean.-

Expt. 2. - Soak a , few Scarlet Runner beans in water for twenty-four hours, and examine one of them. Note-

(i) The bean is kidney-shaped, and along one side is a dark scar-the hilum - where the seed was attached to its stalk.

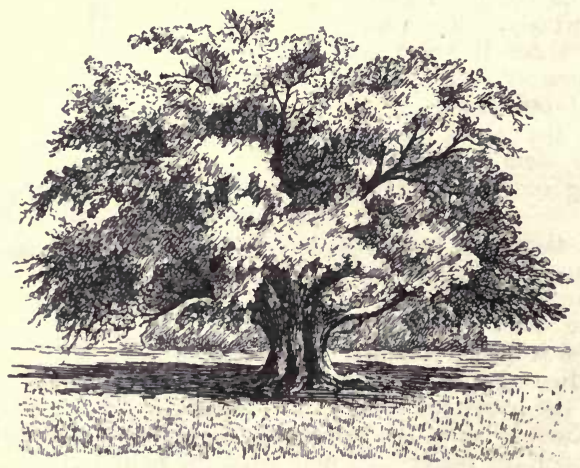

Fig. 4.-Oak Tree.

(ii) The small hole near the hilum-the micropyle. It can be seen best by wiping the seed and gently squeezing it, when water will ooze out. 
(iii) If the point of a penknife or a pin be inserted opposite to the hilum, the seed-coats can be removed. The seed-coat, or Spermoderm, consists of two layers; the outer is known as the testa, and the inner is called the tegmen.

(iv) The seed-coats surround a whitish mass, which may fall in pieces ; this is the young plant or embryo.

(v) If the embryo is examined there will be found along the side near to the micropyle a small body, called the radicle, the apex of which points towards the micropyle.

(vi) Now separate the white mass, along the middle line, into its two divisions-the seed-leaves or cotyledons.

(vii) Between the cotyledons will be found the plumule or young stem, which is continuous with the radicle, and if you use a lens
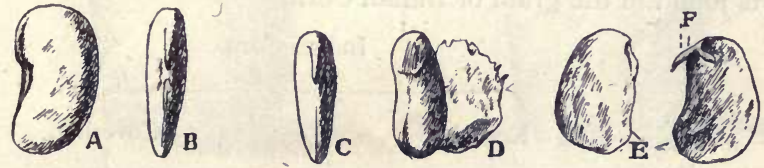

Fig. 5. - Bean Seed. $A=A$ side view of seed. $B=$ Showing radicle. $C=$ Bean, with seed coats stripped off. $\mathrm{D}=$ Seed coats. $\mathrm{E}=$ The two cotyledons. $\mathbf{F}=$ Plumule.

you will be able to see a number of minute leaves growing from the plumule.

(viii) It care be taken in examining the embryo, it will be noticed that the radicle, plumule, and cotyledons are all joined together to form the body of the embryo.

We can represent the relations of the parts of the bean seed as follows :-

Bean.

young root. or seed leaves. or young stem. -

\section{Structure of a Grain of Wheat.-}

ExPT. 3.-Take a few grains of Indian Corn, and soak them in water for a few hours, and examine in the following way:-Cut the grain lengthwise with a sharp knife, and look at half of it with a hand lens. Observe-

(i) The covering, which is made up of several layers, only two of 
which correspond to the testa and tegmen of the bean. The other layers belong to the fruit, for the grain of wheat is in reality a fruit (p. I9).

(ii) The micropyle is hidden by the coverings of the fruit and cannot be seen, but at one end of the grain a firmer portion will be found, which is the embryo, and above the embryo a softer portion, the endosperm, can be distinguished. This is reserve food material for the use of the young plant.

(iii) On the cut surface of the embryo, in contact with the endosperm, a single cotyledon will be found; and on the outside of this an upper portion, the plumule, and a lower portion, the radicle, can be made out.

The following table will show the relation of the different parts found in the grain of Indian Corn.

Indian Corn.

Kernel.

\section{I}

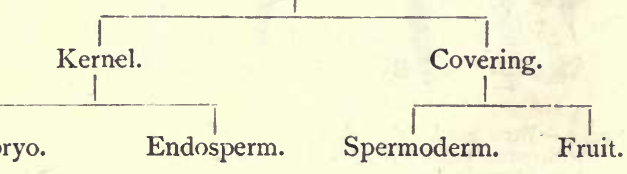

Radicle. Cotyledon. Plumule.

Dicotyledons and Monocotyledons. - In both the Bean and Indian Corn seeds, the embryo consists of radicle, plumule and cotyledons, but the number of cotyledons differs.

The Indian Corn has only one cotyledon, but the Bean possesses two. Those plants which possess two cotyledons are referred to as Dicotyledons, and those with only one as Monocotyledons. The Bean belongs to the former, and the Indian corn to the latter.

Germination of Seeds.-The early stages of the development of the embryo are spoken of as germination. If the seed is examined during germination, we can clearly see how the various parts which are found in the embryo act during that process.

Expт. 4. - Obtain a few Mustard seeds, and place them on a piece of flannel stretched on a saucer. Keep the flannel damp and warm. Examine the seeds from day to day, and notice :-

(i) That they begin to sprout. This is the result of the moisture and heat. At one place a small swelling appears, which is due to the radicle pushing its way through the micropyle. 
(ii) In a few days the radiete will have grown into the primary or main root, and from it a large numbgr of secondary roots develop.

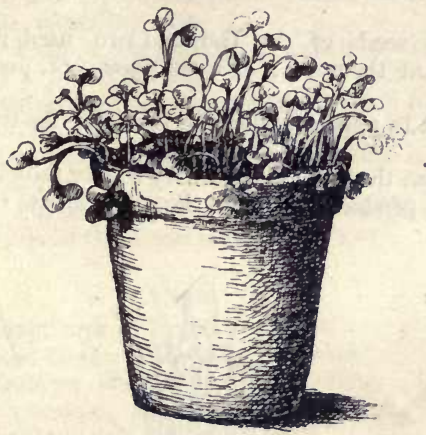

FIG. 6.-Pot of Mustard seedlings, showing cotyledonary leaves.

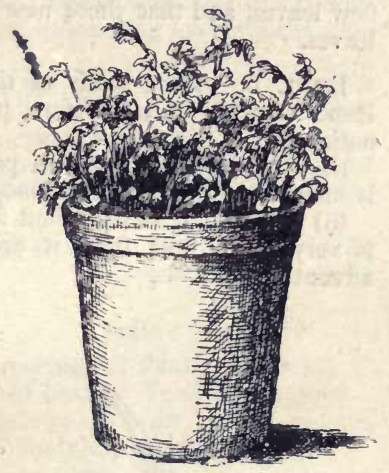

F1G. 7.- Pot of Mustard seedlings, showing secondary leaves.

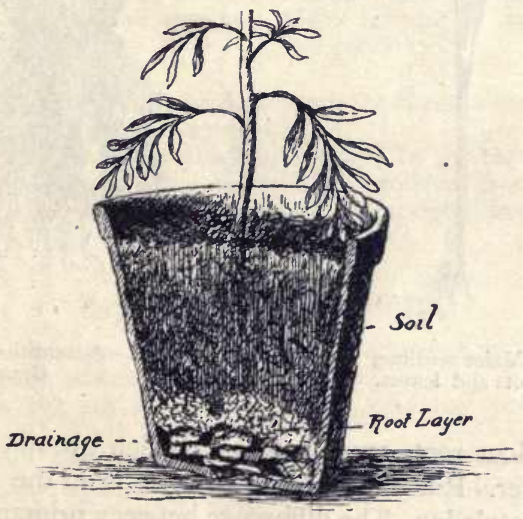

Fig. 8.- How to pot a plant.

(iii) The plumule grows upwards towards the light and the cotyledons are green.

ExPT. 5. - Take a few of the young Mustard plants used in the last experiment and a plant pot with soil in, and with a penholder make a 
few holes in the soil. Plant the mustard seedlings, firmly pressing the soil to the roots. Water the soil and place the pot on a window sill. Examine every day, and notice that the apex of the stem gives off new leaves, and that these new leaves are very different from the seed leaves.

ExpT. 6. - Take some of the seeds of the Indian Corn used in Experiment 3, and, as before, plant them in a box or plant pot, and notice that-

(i) The plumule is the first part to appear above the soil, and its tip is surrounded by the cotyledon.

(ii) Carefully remove a plant from the soil ; the primary root or radicle is very short, and from it are produced a very large number of adventitious roots.

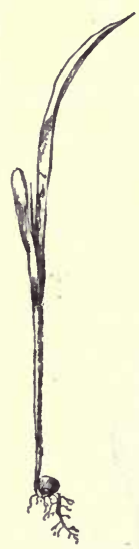

F1G. 9.-A Maize seedling, showing roots and leaves.

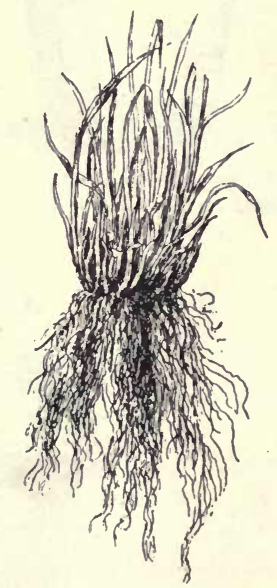

FIG. ro.-Adventitious roots of a Grass.

Adventitious roots are those roots which are not produced in regular order. Roots are also given off from the plumule just above the cotyledon. The difference between primary, secondary, and adventitious roots is well seen in the mustard and in the Indian corn. Primary roots are always formed by the elongation of the radicle; the secondary roots grow from the radicle, in regular order; but adventitious roots are produced from the stem, or some part of the plant other than the primary root. 


\section{SUMmary.}

Parts of a Plant. - The body of a plant is built up of root and shoot. The shoot is divided into stem and leaf. The axis of the plant is built up of the root and stem. The root is the descending axis and the stem the ascending axis.

From a morphological point of view, we speak of the various parts of a plant as members; these members are classed as root-structures, stem-structures, leaf-structures, and hair-structures.

The members are termed organs if we treat them from a physiological standpoint. The wallflower plant is built up of the same parts as the oak tree.

Parts in a Seed.-The following tables show the parts present in the seeds of the Bean and Indian Corn.

\section{Bean.}

Coverings of Fruit. Absent.

Seed-Coats. Testa and tegmen.

Embryo is built up of radicle, plumule, and two cotyledons.

Endosperm. Absent.

Marking in seed coat the hilum.

Opening. Micropyle.

This is a Dicotyledonous plant, because it possesses two cotyledons.
Indian Corn.

Coverings of Fruit. Present. Seed-Coats. Testa and tegmen. Embryo is built up of radicle, plumule, and one cotyledon.

Endosperm. Present.

Marking in seed coat, not seen. Opening. Micropyle, not seen.

This is a Monocotyledonous plant because it only possesses one cotyledon.

By the germination of the seed we mean the changes that a seed goes through during its early development.

A Primary Root is a root which is produced by the elongation of the radicle. A secondary root is a root which is produced from the primary root. Adventitious roots are roots which are produced from any part of the plant and without any regular order.

\section{Questions on Chapter II.}

(I) Define the term member. Name the members which can be found in any plant you may select.

(2) What is the use of a root? What kinds of roots are there? (I88I.)

(3) Suppose a piece of the axis of some flowering plant were shown to you, what appearances would enable you to decide whether it was part of the root or of a stem? (I882.)

(4) Describe the structure of a grain of wheat, and the mode of its germination. (I888.)

(5) Describe and compare the seeds of the bean and of the wheat. (1887.)

(6) From what part of a stem does a branch grow? Illustrate your answer by a sketch. 


\section{CHAPTER III}

\section{ANATOMY-STUDY OF THE SHOOT}

Shoot.-Stems and leaves are so intimately connected that it is impossible to treat of one without reference to the other. The term shoot is therefore used to include both the stem and its leaves. At the apex of the shoot there is, as a general rule, the growing point, from which the leaves and branches are produced. The leaves increase in size faster than the stem, which causes them to overlap the apex, forming a bud. The structure of the tip of the shoot can be made out by the aid of a hand lens. The growing point will be found at the apex of the shoot and it is surrounded by a number of minute leaves.

Expr. 7.-Take a twig of the Horse Chestnut, and make a longitudinal section so as to pass through the apex.

Examine the section by the aid of a hand lens. A series of leaves, the largest on the outside and the smallest near the centre of the bud, will be found, and protected from injury by these overlapping leaves, the growing point will be fairly easily made out.

Buds.-A bud is an undeveloped shoot, and from it leaves and branches may be produced. Buds receive different names according to the parts of the plant which may be produced from them. If a bud develops into a branch it is known as a stembud, if foliage leaves are formed from the bud it is called a leaf-bud; a flower-bud is one which produces a flower.

Buds are often named after their position on the shoot. If the bud is found at the end of the shoot it is called a terminal bud; when it grows in the axil of a leaf, an axillary bud; if the bud springs from any other part of the shoot it is known as 
an adventitious bud, but these are very rare though the tendrils of the vine are produced from such buds.

Some buds may be latent or dormant, i.e., remain undeveloped for a long time. These may become active when the ordinary buds have been destroyed by frost or accident. Trees in spring may have their leaves destroyed by frost, but after a few weeks a new set of leaves are developed, which are formed from latent buds. Latent buds may thus

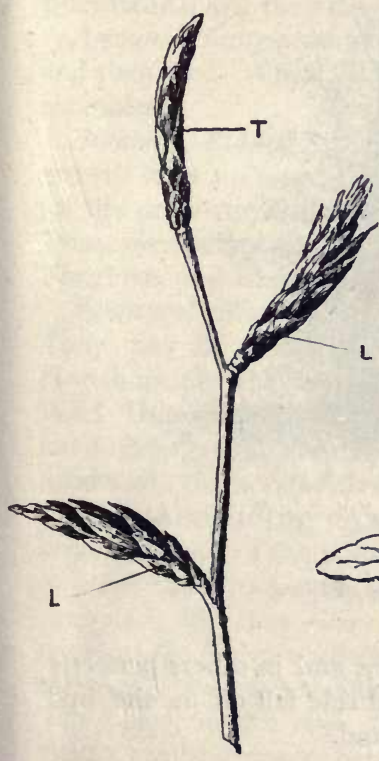

FIG. Ir.-Twig showing ; T, Terminal buds; L, Lateral buds.

ᄂ save the life of the tree. Even when in the dormant state these buds increase in size and give rise to balls such as are often seen, under the bark, in the Beech, Chestnut, and Lime. Latent buds also give rise to the
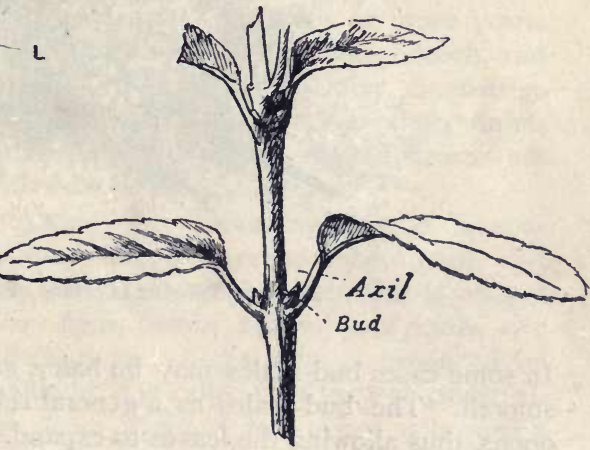

Fig. 12.-Stem and leaves, showing buds in the axils of leaves.

knots which are found in timber. If the main shoot of the Oak and Beech be cut down, a dense outgrowth of branches, formed from the base of the shoot, occurs ; this is called tillering. The new outgrowth is formed from the dormant and adventitious buds. It is a very common practice for farmers in the spring to roll the wheat which is sown in winter; this is to make it 
tiller. In other cases they have the young growing points eaten off by sheep to produce the same result.

Those buds which persist through the winter are protected with special bud-scales, which may be membranous or scaly in their texture. The bud-scales of the Oak are dry, those of the Horse-Chestnut sticky, from the secretion which they produce.

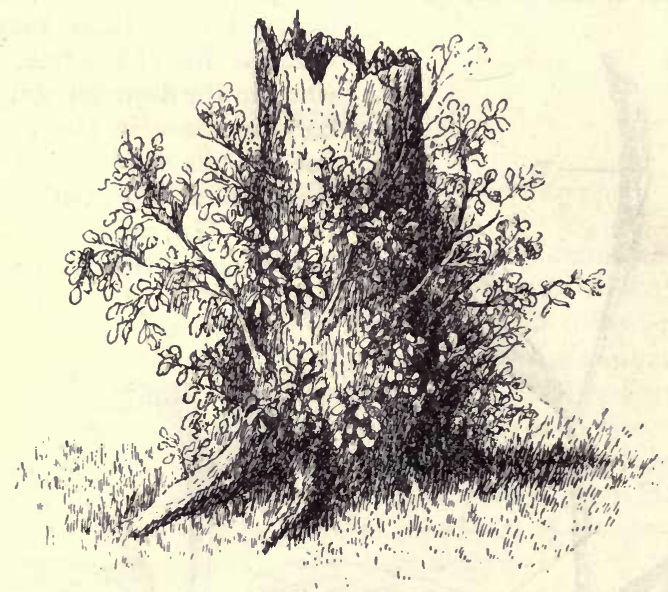

FIG. 13.-Tillering of Stump of Elm.

In some cases bud-scales may be hairy, and in others perfectly smooth. The bud-scales as a general rule fall off as the bud opens, thus allowing the leaves to expand.

ExPT. 8. - Obtain a small branch of the Hazel, and note the position of the buds. That at the apex of the branch is the terminal bud, those behind are the lateral ones.

ExpT. 9. - Take a twig from any tree in winter, and keep it in water in a warm room. Note-

(i) It will produce leaves from the leaf-buds; if flower buds are present, flowers may be produced.

(ii) This experiment shows that the materials necessary for the development of the leaves and flowers are stored up in the tree, and when the necessary temperature is obtained development takes place. 
ExpT. 10. - Cut sections through the apex of the buds of the Horse Chestnut and Sycamore. Note-

(i) The overlapping scale leaves.

(ii) The young foliage leaves.

(iii) The apical growing point.

(iv) The arrangement of the different parts should be shown in a sketch.

Kinds of Plants.-Plants may be annual, biennial, or perennial, i.e., they may last one, two, or more years.

Annual Plants produce seeds during the first year of growth and then die. Wheat, Barley, Peas, Beans and Mignonette, are examples.

Biennial Plants are those which during the first year of growth store up reserve materials, these substances being used for the production of flowers and seeds in the second season. Thus, biennial plants must live two years. Turnip, Cabbage, Foxglove, and Beet, are typical examples.

Perennial Plants live and grow for three or more years. They may be trees or shrubs, such as the Oak, Beech, and Hawthorn; or they may be herbs, like the Daisy, Snowdrop, Wild Hyacinth, and Primrose. The herbaceous perennials have underground stems from which the leaves and flowers are produced; the aërial parts die down each season.

The Ascending Axis.-The ascending axis is a very important part of the plant; though leaves may be absent, and in a few cases roots may not be developed, the stem is always present. The stem bears buds, leaves, flowers, and fruits, and connects the leaves with the roots. If the stem is produced by the elongation of the plumule, it is called primary or normal. The place on the stem from which a leaf arises is termed a node, and the space between two nodes is termed an internode. In some cases the nodes are thickened, as in the Stitchwort, and in a few cases adventitious roots may spring from them, as in the Ivy.

Herbaceous Stems.-The ascending axis may be soft and green, and die down at the end of the season, when it is called a herbaceous stem. Herbs are plants which fulfil their life-history in a single season; they are also called annuals. Annuals, such as the Stock, Oats, and Indian Corn, also produce seeds at the end of their period of growth. 
Shrubby Stems differ from those named above in being hard and woody. They are larger than herbaceous stems ; but smaller than the stems of trees. A shrub is a dwarf tree with a number of permanent woody stems, which divide from the bottom. A shrub differs from a tree $(a)$ in the stems being more slender, and $(b)$ in not growing more than twenty feet high. The following are typical shrubs :-Box, Heath, Rose, Rhododendron, Gooseberry and Currant.

\section{HERBACEOUS. SHRUBBY,ANoWOOOY STEMS.}

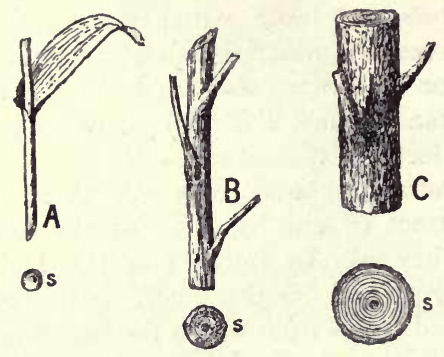

FIG. 14.-Diagram illustrating herbaceous, shrubby, and wooly stems. $\mathrm{A}=$ Herbaceous. $\mathrm{B}=$ Shrubby. $\mathrm{C}=$ Woody. $\mathrm{S}=$ Section.

Woody Stems are large, and last for a number of years ; they show rings of growth if cut across. Our forest trees such w the Oak, Beech, Fir, Lime, and Ash have woody stems.

Aërial Stems grow above the ground, as those of the Oak, Wallflower, and Foxglove. Several forms of aërial stems are distinguished :-

The Runner is a stem which creeps along the surface of the ground, and produces adventitious roots from its underside, and leaves from its upper surface, e.g., the Strawberry (Fig. 15).

The Off-set is a stem which is produced from the parent stem; it creeps along for a short distance and then takes root, e.g., the House-leek (Fig. 16).

The Stolon is a branch which takes root at its end, thus producing a new plant, e.g., Couch-grass (Fig. 17), Gooseberry, and Currant. 
The Sucker is an aërial branch given off by an underground stem ; it runs for a short distance beneath the surface, and then strikes upwards, forming a new plant, e.g., the Rose and Mint.

Subterranean Stems grow beneath the surface of the ground, and are often termed, in popular language, roots.

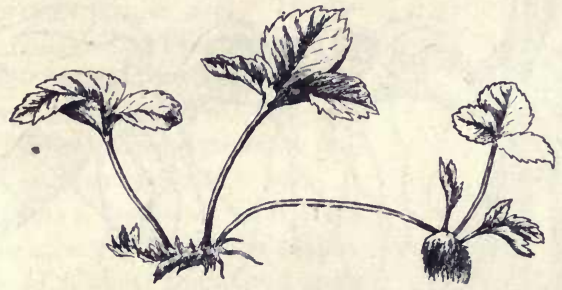

FIG. 15.-Runner of Strawberry.

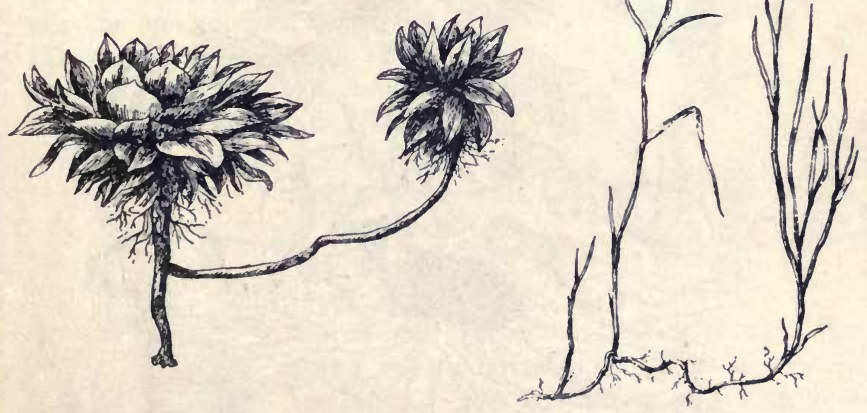

FIG. 16. -The Off-set of the House-leek. Fig. 17.-The stolon of the Couch-grass.

Many perennial plants are able to exist throughout the winter by means of underground stems.

The Rhizome is a creeping underground stem which produces both roots and leaves. The roots are produced from the undersurface of the stem, and the leaves from the upper. Rhizomes 
differ from roots in producing leaves and buds. Solomon's Seal and the Iris produce rhizomes (Fig. 18 ).

The Tuber is a swollen underground stem, and in it there is stored up large quantities of reserve materials for the production

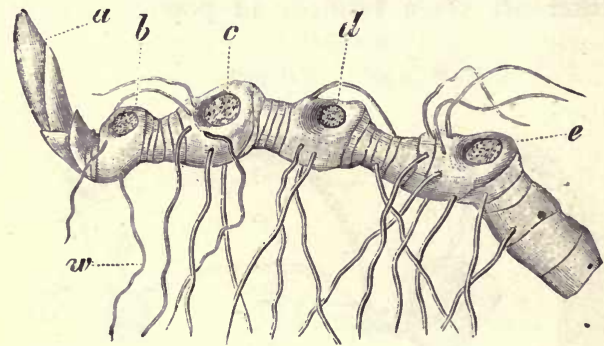

FIG. 18. - Rhizome of Solomon's Seal. $a=$ bud of next year's aërial growth ; $b=$ scar of this year's growth; $c, d, e$, scars of previous year's aërial growth; and $z=$ roots.

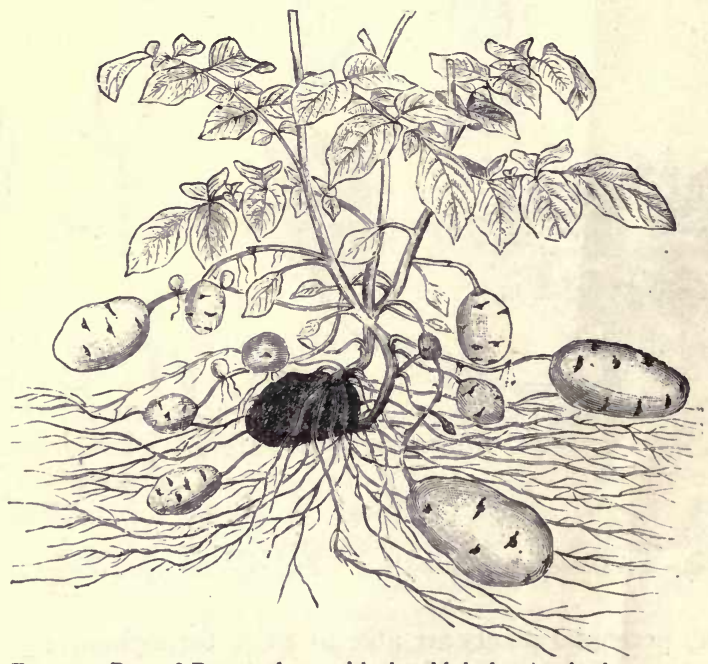

FIG. 19.- Part of Potato plant, with the old dark tuber in the centre. (One-third natural size.)

of a new plant. The Potato tubers are produced from the ends of stolons, and thus are formed a little distance from the parent 
plant. The so-called eyes that are found on the outside of a potato are in reality buds, from which the next year's growth will take place. The parent plant dies after the production of tubers, but not before large stores of reserve materials have been accumulated in the tubers for future use. If the aërial branches of the Potato plant be covered up with soil, their growth will be checked and they will produce tubers. The Jerusalem Artichoke and the Earth-nut also produce tubers.

The Bulb is a modified stem often met with in monocotyledonous plants. It consists of a short thickened stem with a large number of crowded, overlapping leaves. These leaves contain a large quantity of reserve material for the growth of the next season's plant. In the Onion the leaves sheathe one another, but in the Tiger Lily they only overlap. The bulb is closely allied to the tuber. The Onion, Wild Hyacinth, and Daffodil are examples of plants that produce

bulbs.

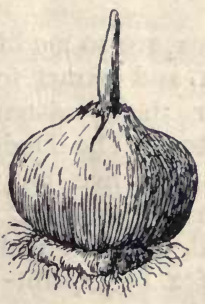

FIG. 21.-Corm of Crocus.

The Corm is a very solid fleshy stem with fewer

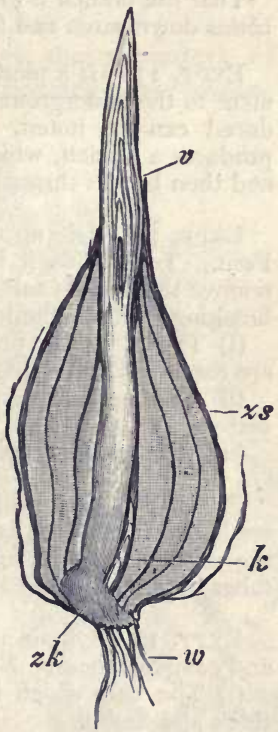

FIG. 20.-Longitudinal section of bulb of Tulip. $z k$, modified stem; $z s$, scale leaves; $v$, terminal bud ; $k$, young bud ; $w$, roots.

leaves than the bulb. In the Crocus it is a solid, rounded, main axis, full of reserve materials. The Snowdrop and Gladiolus spring from corms.

EXPT. I1.-Obtain from a gardener a piece of the runner of a Strawberry plant. Note-

(i) How the runner gives off roots.

(ii) How the leaves are produced. The leaves are developed from the upper surface of the stem and from the nodes; the roots spring from the lower surface of the stem. 
ExpT. 12. - Take a few plants of the Couch grass-which can be found in most meadows and in cornfields, and examine them. Select one which shows the stolon best. Note-

That the branch is given off above the level of the ground, and then bends downwards and forms a root at the end:

ExPT. 13. - If a piece of a sucker of a Raspberry plant with its attachment to the underground stem be obtained, the way in which it is produced can be noted. It will be seen that the underground stem produces a branch, which runs for a short distance beneath the ground and then breaks through the soil and comes to the surface.

ExpT. 14.-Dig up a rhizome, either of Solomon's Seal or a Bracken Fern. To do this it is necessary to have a good trowel with which to remove the surface soil. Follow the stem so as to uncover it without breaking it, and examine. Note-

(i) The old scars produced by the leaves of previous years. These are caused by the dying down of the leaves.

(ii) The new leaves, which will break through the ground next season.

(iii) The growing point, which is protected by scale leaves.

ExPT. I5.-Take a Potato tuber and examine it. The eyes, which are buds, will be seen as small dark spots. If a young tuber be examined, the minute scale leaves round the growing point will be seen. Cut a tuber in two and notice how thick and fleshy it is.

Expr. 16. - Obtain a.bulb of the Daffodil and a Crocus corm. Examine and compare them. Note-

(i) The bulb which is made up of scale leaves, many of which are thick and fleshy.

(ii) In the corm the stem is far larger than in the bulb, but the leaves are not so numerous.

Parasitic Stems.-In a few cases stems are so modified that they can fix themselves to another plant, and extract from it those materials which are necessary for their existence. Plants of this description are called parasites. The Dodder is a good example of such a plant; it can live on the Clover, the Nettle, and the Willow. When the seeds of the Dodder germinate a long filament is formed, the free end of which moves round and round in search of a host plant-as the plant upon which it lives is called-and when a suitable plant is found it twines closely about it like a climbing plant. Suckers are produced from those parts of the filament which are in close contact with the host, and these pierce the host, and work their way inwards, to obtain food. 
EXPT. 17.- If a specimen of a plant can be obtained, which has been attacked by the Dodder, it should be examined. Note-

(i) How the Dodder climbs round the host.

(ii) How the suckers are produced.

Climbing Plants.-Plants climb over the shoulders of their weaker brethren for two reasons; $(a)$ because their shoots are far too weak to support their own weight, and $(b)$ to expose their leaves to light. Climbing plants present four divisions, viz.: (I) Those which climb by the aid of rootlets, as the Ivy. (2) By the use of hooks, as the Bramble and the Yellow Bedstraw. (3) By twining stems, as the Convolvulus and the Hop. (4) By sensitive organs which come in contact with any structure and clasp it, as the Clematis and the Vine.

\section{Rootlet-Climbers.-} The Ivy climbs by means of adventitious roots which are produced from the stem. When these come in contact with a wall or the bark of a tree they give out a fluid, which by drying up causes the

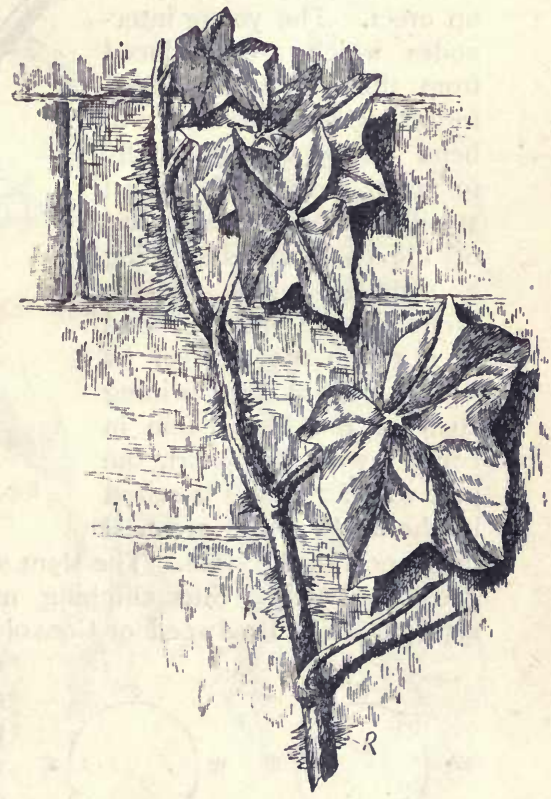

FIG. 22.-Ivy climbing up a wall. $\mathrm{R}=$ Aërial roots. stem to adhere to the support. The rootlets are produced on the shady side of the stem, and in older stems may not all be fixed to the support, but may be dried up, forming shaggy beards (Fig. 22).

Hook-Climbers. - The Bramble is able to support itself by weaving its way through the trees which grow in its neighbourhood. It is able to do this because it produces hooks, by the aid 
of which it fixes itself to walls, trees and shrubs. Cleavers, which is a struggling, rough and matted plant found in hedges, is another good example of a plant which climbs by means of hooks (Fig. 23).

Stem-Climbers. - When the stem of the hop plant comes out of the ground its first two or three internodes grow up erect. The young internodes which are produced from the top of the firstformed portion commence to bend slowly and gracefully to one side and travel steadily round to every point of the compass, describing a complete circle in the direction the minute hand of a watch moves over its face. Should the twining stem of the Hop come in contact with a support, the part which it strikes is seized

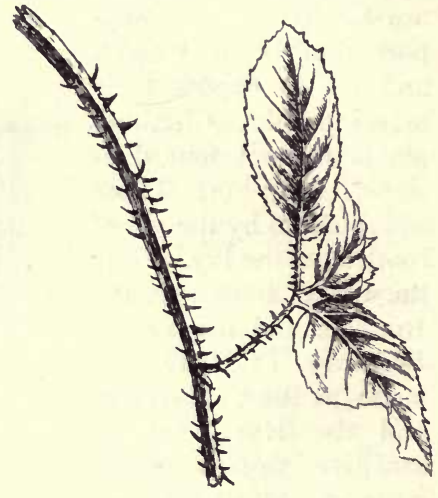

Fig. 23.-The hooks of the Bramble. by the hooks which are well developed on the stem. The stem still grows at the apex and goes on twining, thus climbing more and more about the support. The Bindweed or Convolvulus also climbs by means
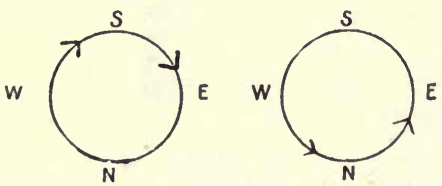

FIG. 24.-Diagram illustrating how plants twine. The left-hand figure shows how the Honeysuckle twines to the right; the right-hand figure how the Convolvulus twines to the left. of twining stems, but these climb in the opposite direction to the Hop, i.e., towards the left. The stems of the Hop and Honeysuckle turn round from the west through the south towards the east; this is called twining to the right. The Scarlet Runner and the Bind-weed turn round .from the west through the north towards the east; this is termed twining to the left (Fig. 24).

Plants which Climb with Sensitive Organs.-This 
division can be subdivided into two classes, viz., leaf-climbers and tendril-climbers.

A good example of a leaf climber is the familiar Clematis. The upper, younger internode of the Clematis goes wandering round and round in slow circles after the manner of the twining

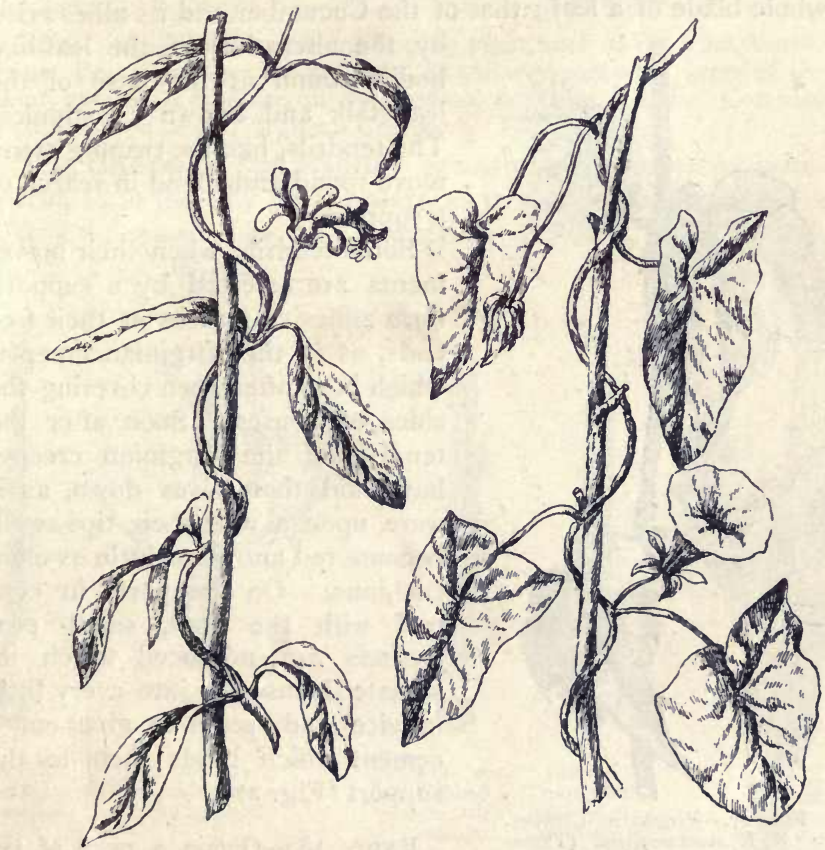

FIG. 25.-Climbing stem of Honeysuckle. (One-fourth nat. size.)

Fig. 26.-Climbing stem of Convolvulus. (One-fourth nat. size.)

plants. This brings the leaves in contact with the stems, twigs, or the trellis-work erected by the hand of man. Such objects as these are seized slowly but surely by the leaf-stalks of those leaves which come in contact with them. The leaf stalks are sensitive and turn round the object touched.

A tendril is another structure which is sensitive to touch and 
is used for climbing. These organs, with their ready response to any contact and their power of turning round and clinging to objects, are the most highly developed in the class of climbing plants. Tendrils are formed from various parts of plants; thus, in the Passion flower it is a whole branch transformed; the tendril of the Vine is a flower-stalk; that of the Sweet Pea, the whole blade of a leaf ; that of the Cucumber and its allies arise

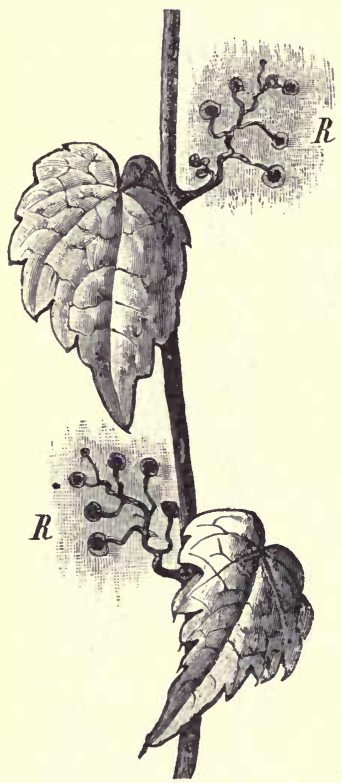

FIG. 27.-Virginian Creeper.

$\mathrm{R}, \mathrm{R}$, stem tendrils. ('Three. fourths nat. size.) by the alteration of the leaf-like bodies found at the base of the leaf-stalk and known as stipules. The tendrils, like the twining stem, move round and round in search of a support.

Some tendrils, when their movements are arrested by a support, form adhesive masses at their free ends, as in the Virginian creeper, which is so often seen covering the sides of houses. Soon after the tendrils of the Virginian creeper have laid themselves down, as it were, upon a wall, their tips swell, become red and form little swollen cushions. On the parts in contact with the wall, small projections are produced which insinuate themselves into every little crevice and seem to give out a cement which binds them to the support (Fig. 27).

Expt. 18.-Obtain a piece of Ivy from an old wall; examine it. Note the following points-

(i) That a portion of the wall has come away with the roots.

(ii) That the roots grow on a portion of the stem which is turned away. from the light.

(iii) That the root dries up, and forms a beard on the stem.

Expт. 19. -Examine branches of the Rose or Bramble. Notice-

(i) The prickles; pull one or two off and see how much of the branch comes away with them.

(ii) Prickles may be used for protection as well as for climbing. 
ExPT. 20. - Obtain a portion of the Hop-plant or Honeysuckle with its support. Note-

(i) How and in what direction the stem has moved. Compare with a piece of the Scarlet Runner and Bindweed.

(ii) Note the difference in the direction of twining.

EXPT. 21.-Obtain from a hedgerow or garden a piece of Clematis showing the sensitive leaf-stalks. Examine how the stalks clasp the support.

ExPT. 22.-Obtain a tendril-bearing plant, such as the Vine, Vetch, Sweet Pea, Cucumber, or Bryony. Examine to see what parts of the plant have been modified in the production of the tendril. Compare with a portion of the Virginian Creeper.

The Shape of the Stem.-Stems may be round or cylindrical, as in the Lily ; triangular, as in the flower stem of the Daffodil ; square, like the Deadnettle; or ribbed, like the Wallflower (Figs. 28-32).

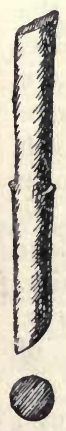

FIG. 28.

Round stem, with section.

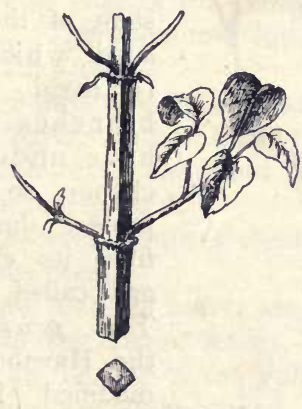

FIG. 29. Square stem, with section.

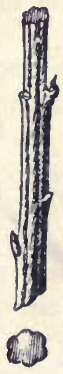

Fig. 30. Ribbed Triangula stem, with stem, with section. section.
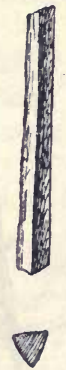

Fig. 3 t.

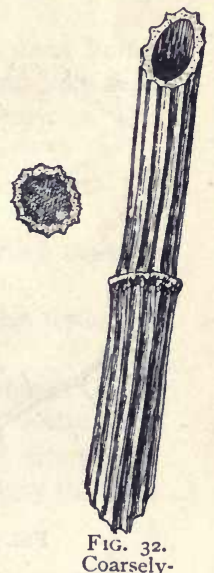

Coarsely. ribbed stem, with section.

Some stems are solid at the nodes, but hollow at the internodes, e.g. Fool's-Parsley. Others are solid throughout as in the Wallflower.

Surface of the Stem.-Stems differ not only in their shapes but also as regards the nature of their surfaces. Many stems are completely covered with hairs, prickles, or thorns. If the surface is smooth, it is termed glabrous; if hairs are present, hairy. 
The Wallflower is covered with spindle-shaped hairs, and upon the Stock branched hairs are found.

In the Stinging Nettle large hairs for protection are found. When the tip of such a hair enters the finger it breaks off and a fluid is injected into the wound causing a well-known smarting sensation.

The surface of a stem may be covered with prickly structures, which may be produced by the modification of hairs, or other structures. The hooks on the stems of the Hop, Cleavers, and Borage are true

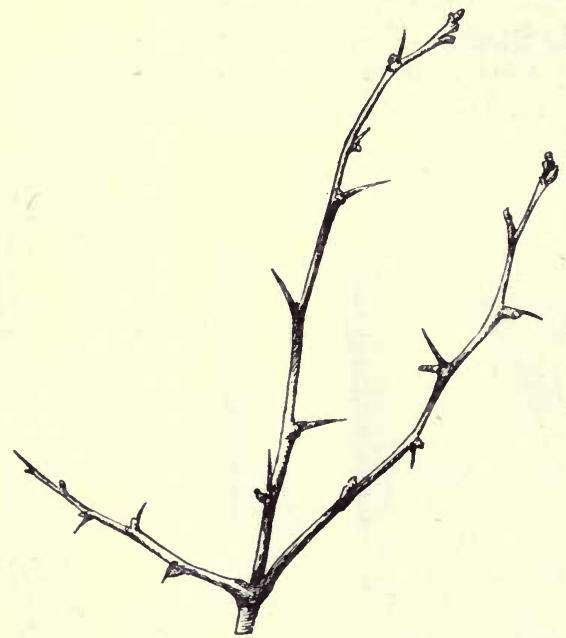

FIG. 33.-Spines on the Hawthorn. hair-structures, because they are developed from the surface layer of the plant. The structures found on the stem of the Sloe, and which are formed from branches which have undergone change so as to protect the plant from its enemies, are called thorns. The prickles of the Hawthorn are modified leaves ; they are, as a rule, termed spines. The prickles of the

Bramble and Rose are formed not only by the development of the surface covering of the plant, but also by a deeper layer which takes part in their formation. The name emergences may be given to them.

EXPT. 23.-Cut across the stems of the following so as to show their shape :- Wallflower (old stem), and flower stems of the Daffodil, Lily, Deadnettle, and Mignonette. Compare their shapes and notice if the stems are solid or hollow.

ExpT. 24.-Examine as many stems as possible to see if they are 
smooth or hairy. Similarly describe the surface of every stem met with. If this is done for a few weeks, the reader will have a very valuable series of notes.

EXPT. 25. - Collect a few branches of the following plants : Hawthorn, Rose, Sloe, Bramble, Hop, Cleavers, Borage, and prickly Comfrey. Examine and make notes of the size of the prickles, thorns, spines, and emergences found on them. Sections should be made through the stem so as to show the connection of the covering with the underlying parts.

Leaves.-Leaves are developed as lateral outgrowths from the growing point of the stem. They are often said to be flattened out stems. They may be deciduous, that is, they may fall off from the stem each year ; or persistent, remaining on the tree for a number of years. The Oak produces the former kind of leaves and the Holly the latter.

Leaves are developed in regular order, the older ones being found on the base of the young twig and the younger ones near the apex. There are four kinds of leaves which grow on the stem. They are :-

Foliage-leaves, or the ordinary green leaves of the plant.

Scale-leaves, or those found covering the bud.

Bracteate-leaves are found close to the flower, which they as a general rule protect.

Floral-leaves; some of these are coloured, and the flower is built up by them.

All these kinds of leaves are not found on every plant. Most plants possess foliage leaves, but the Dodder has only scale leaves. In the Lily of the Valley, the foliage leaves, bracts and floral leaves are all developed. In the Wallflower only the first and last are found.

ExpT. 26. - Collect branches of the Oak and Fir in winter. Notice that the twigs of the Oak are without leaves, but the Fir is well covered with them.

\section{SumMary.}

Shoot.-Built up of stem and leaf. The growing point is at the apex, and is surrounded by leaves.

A bud is an undeveloped shoot. There are three kinds of buds, viz., stem-buds, leaf-buds, and flower-buds. The bud at the apex of a stem is called the terminal bud, and those behind lateral, and if the latter 
are produced in the axils of the leaves they are axillary buds. An adventitious bud is one which is produced out of the regular order. A latent or dormant bud is one which remains undeveloped.

Tillering is a term which is used to describe what takes place when a plant produces a large number of branches from the base of the stem.

Plants can be divided into (I) Ammal plants; these only live a single season. (2) Biennial plants; these during their first year of growth produce foliage leaves and store up food, and during the second season produce flowers and seeds. They only live two years. (3) Perennial plants live three years or more.

The ascending axis produces leaves, and connects the leaves with the roots. The places on the stem from which leaves spring are termed nodes, and the space between two nodes is called an internode.

Stems. - There are three kinds of stems.

Herbaceous.

Soft and green, and die down each year.
Shrubby.

Hard and woody, not above twenty feet high.

\section{Woody.}

These are hard and strong, and grow above twenty feet high.

Aërial Stems grow above the ground. They can be divided into: The Runner, which creeps along the ground, like the Strawberry. The Offset creeps along the ground for a distance from the parent, then roots. The Stolon is a branch which takes root at its end. The Sucker is given off from an underground stem. The Erect Stem grows upright like the Oak.

Subterranean Stems grow beneath the ground and can be divided into: The Rhizome, which creeps along beneath the ground and pro: duces both roots and leaves. The Tuber is a swollen underground stem which grows from the end of a stolon. The Bulb is a fleshy underground bud, and is modified for the storing up of food for future use. The Corm is a solid, fleshy, underground stem.

Parasitic Stems are produced by parasites. A parasite is a plant which is too lazy to earn its own living, so lives on a host plant. The Clover Dodder is a good example of such a plant.

Climbing Plants. - There are four classes of these plants. They are as follows: Rootlet Climbers, like the Ivy. Hook Climbers, like the Bramble. Stem Climbers, like the Hop and Convolvulus. Plants which climb with sensitive organs; they can be divided into $(a)$ leaf and $(b)$ tendril climbers.

Stems. - They may be round, square, ribbed, and triangular. They may be smooth or hairy. The surface may be covered with spines or emergences.

Leaves are produced as outgrowths of the growing point of the stem. There are four kinds of leaves found growing on the stem : Folinge Leaves are the ordinary green leaves of the plant. Scale Leaves are found on the roots and young buds. Bracteate Leaves are found at the base of the flowers. Floral Leaves are modified leaves which go to build up the flower. 


\section{Questions on Chapter III.}

(I) Of what use to the plant is the stem? How can you distinguish a stem from a root?

(2) What are the essential differences between a node and an internode? Illustrate your answer by examples. (1884.)

(3) What is a rhizome, and how does it differ from a root? Explain the mode of annual growth in length of the rhizome of Solomon's Seal. (1885.)

(4) State what is meant by annual, biennial and perennial plants, giving examples. (1886.)

(5) What do you know about-
(a) The runner,
(c) The tuber,
(b) The rhizome,
(e) The bulb,
(d) The offset,
(f) The corm?

(6) What kinds of stems are there? Give examples.

(7) Where is the growing point of a shoot found, and how is it protected from injury?

(8) If all the leaves on a Currant bush be plucked in spring, what will happen?

(9) How are the knots found in timber produced?

(Io) Define the term "tillering." When and how does tillering take place?

(I I) What is a parasite? Give an account of the mode of life of the Dodder.

(12) Give examples of plants which climb by means of tendrils, and explain how the tendrils act. (I887.)

(13) Give a classification of climbing plants. Why do plants climb? How do they clinib?

(14) What is the structural difference between a prickle (as in the Rose) and a spine (as in the Blackthorn)? (188r.) 


\section{THE STUDY OF THE SHOOT (Continued)}

Parts present in a Perfect Foliage Leaf.-In a perfect leaf the following parts are present.

The blade or the fully expanded portion of the leaf.

The petiole or the stalk of the leaf.

The Sheath which forms the base of the leaf. It is wider than the petiole, and may sheathe the stem.

In most cases the blade is present; when other parts of the leaf are absent, the leaf is said to be sessile, as in the Wallflower: If the sheath is not developed, but

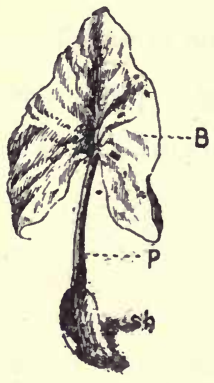

FIG. 34.-Perfect leaf of Arum. $\quad B=$ blade; $\mathbf{P}=$ petiole; $s k=$ sheath. the blade and petiole are present, the leaf is called petiolate, as in the Cherry. If all the parts are present, as in the Pilewort and Arum, the leaf is perfect. Outgrowths may be produced from the base of the leaf, as in the Rose and the Pea; these are termed Stipules. If stipules are present the leaf is said to be stipulate, and if they are absent exstipulate.

The Venation of Leaves. - The veins of a leaf form the framework by which the softer parts are supported; they also bring the sap from the stem and distribute it to the cells of the leaf. Leaves may either be parallel or reticulate-veined. The former arrangement is found in monocotyledonous plants and the latter in dicotyledonous. In a parallel-veined leaf, the veins run parallel to one another from the base of the blade to 
the apex, and they are connected by smaller cross veins, as in the leaf of the Lily of the Valley. The reticulate-veined leaf differs from the parallel-veined leaf in possessing one or more midribs, from which veins are produced eventually uniting with one another to give the leaf the appearance of net-work. The Oak bears such a reticulate-veined leaf (Fig. 36).

If the leaf only possesses one mid-rib, the leaf is said to be $u n i$ costate. When the leaf is divided into a number of divisions, and each lobe possesses a mid-rib, it is said to be multicostate. The leaves of the Oak, Beech, Poppy, and Dandelion, are unicostate, while the leaves of the Monkshood, Castoroil plant, and Fig, are multicostate.

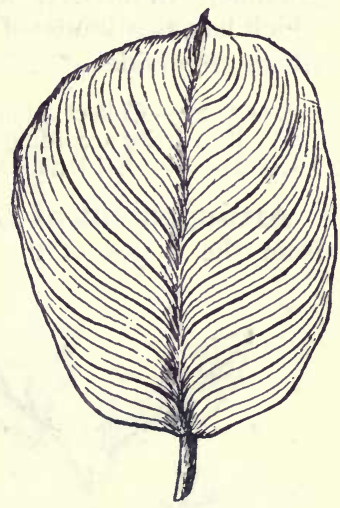

FIG. 35.-Venation of a leaf.

'The veins of a leaf give it strength ; it depends upon the mode of life of the plant what kind of leaves will be produced. Plants which grow in a very

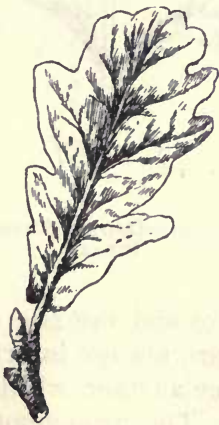

FIG. 36.-Unicostate leaf of Oak.

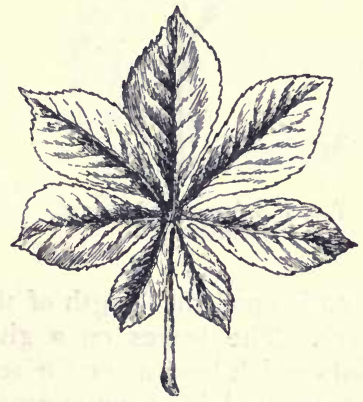

FIG. 37.-Multicostate and palmate leaf of the Horse-Chestnut.

exposed position generally have narrower leaves than those which grow in sheltered places. Water plants with submerged 
leaves have the veins finely divided so as to give mechanical support, as well as to expose as great a surface to the water as possible. In the case of marsh plants like the water Crowfoot, which has two kinds of leaves, it is only the submerged ones which are divided.

EXPT. 27. - Collect a number of leaves and arrange them into-

(i) Two series according to their venation.

(ii) The two divisions, unicostate and multicostate.

Arrangement of Leaves on the Stem.-Leaves grow from the nodes of the stem, and the arrangement of these

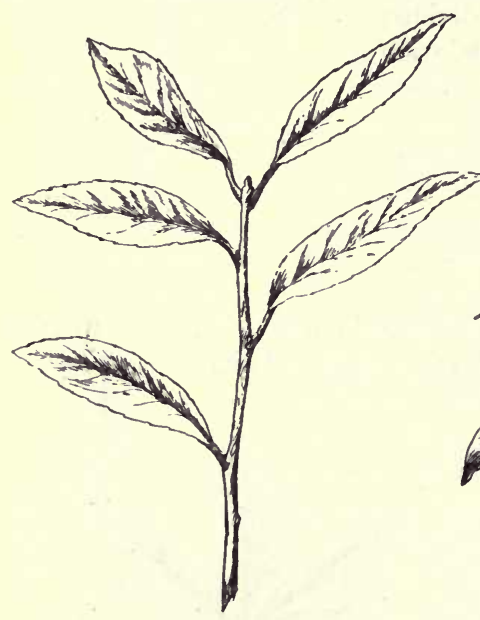

FIG. 38.-Alternate leaves of Rhododendron.

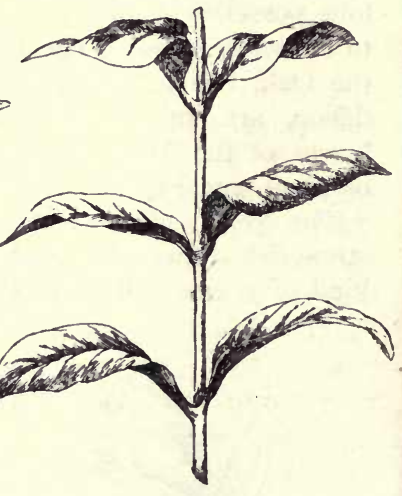

FIG. 39.-Opposite leaves of Privet.

depends upon the length of the internodes and the size of the leaves. The leaves on a given plant are always inserted at points which bear a certain relation to one another, which may be expressed in a numerical manner. The arrangement of leaves on a stem is often spoken of as phyllotaxis. If one leaf only is produced at a given node, and from the node higher up the stem but on the opposite side another springs the phyllotaxis is said to be alternate, as in the Wallfower. 
When two leaves spring from the node and face each other, the arrangement is called opposite; if the leaves higher up are placed at right angles to the first pair, the arrangement is called decussate - the Deadnettle is a good example of this. If more than two leaves are produced at a node, they are termed whorled leaves. The Bed-straw and Cleavers illustrate this arrangement.

The most common arrangements of leaves are the alternate, opposite, and whorled. The socalled alternate arrange-

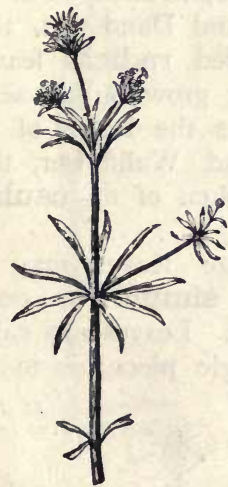

FIG. 40.-Whorled leaves of Cleavers.

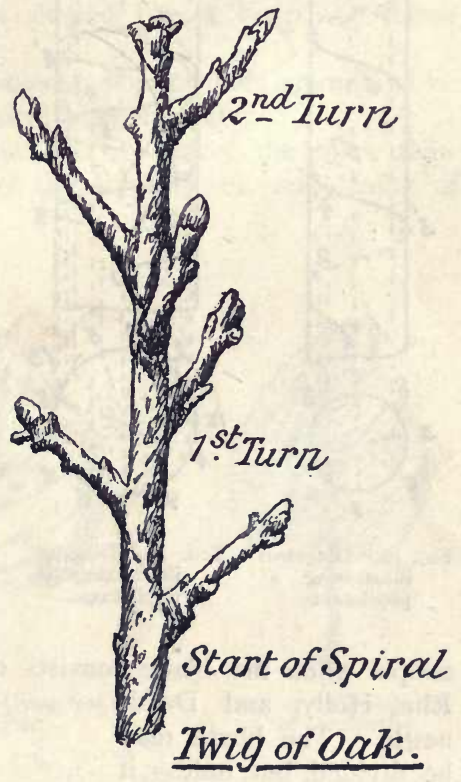

FIG. 4I.-Diagram illustrating $\frac{2}{5}$ phyllotaxis of Oak.

ment can be further investigated by drawing a spiral round the stem from one leaf until the leaf vertically above is reached. In the case of the Wallflower or Oak the spiral goes round the stem twice before the leaf vertically above is reached, and five leaves, not counting the leaf at which the spiral commenced, are touched by the spiral. This is known as a $\frac{2}{5}$ arrangement. The same phyllotaxis is found in the Pear, Poplar, and Walnut. In the Plantain the leaves form a $\frac{3}{8}$ phyllotaxis. 


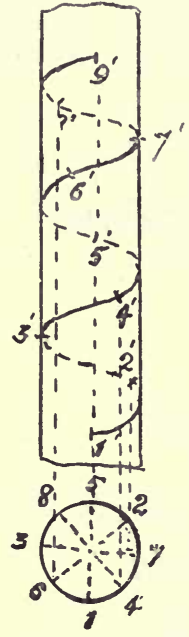

FIG. 42.-Diagram illustrating $\frac{5}{8}$ phyllotaxis.

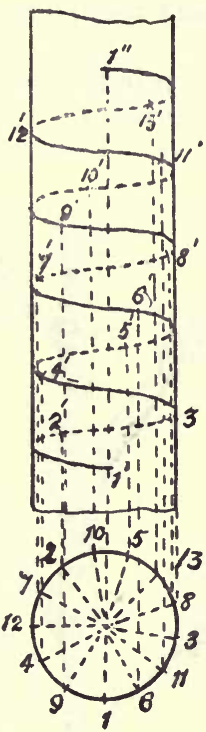

FIG. 43.-Diagram illustrating $\frac{5}{13}$ phyllotaxis.

EXPT. 28.-Collect and examine branches of the Oak, Wallflower, Deadnettle, Bedstraw, and Elm. Determine their phyllotaxis, and mark on the stem the leaf-cycle or the cycle made in passing from one leaf to the leaf vertically above. This can be done with a piece of coloured chalk, and if the leaves are also numbered the arrangement will be seen at a glance.

Different Kinds of Foliage Leaves.-When the leaves spring from an underground stem, as in the Daisy and Dandelion, they are called radical leaves. If they grow on an aërial stem, as the leaves of the Oak and Wallflower, they are spoken of as cauline leaves.

Foliage leaves may be either simple or compound. Leaves are called simple when the blade consists of a single piece, as in the Elm, Holly, and Deadnettle. The blade may be divided, but, unless it is cut down to the midrib, it is still a simple leaf. Compound leaves are cut into a number of distinct pieces, as in the Pea and the Ash. Each separate part of such a leaf is called a leaflet.

Simple Leaves. Leaves vary much in shape or general outline.

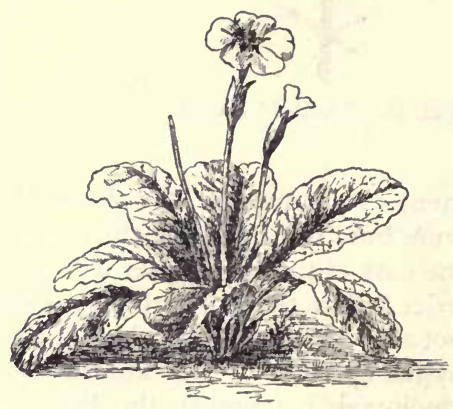

FIG. 44.-Radical leaves of the Primrose. 
Simple leaves receive the following names, according to the shape of the blade :-

Lanceolate, when the leaf is from two to four times as long as it is broad and tapers at both ends, e.g., Wallflower (Fig. 45).

Ovate, when the broadest part is nearer the base than the apex, e.g. Guelder-Rose (Fig. 46).

Cordate, when the base is shaped like a heart, e.g. Lime (Fig. 47).

Sagittate, when the base possesses pointed ends extending like an arrow backwards, e.g. Convolvulus (Fig. 48).

Obovate, when the broadest end is nearer the apex than the base, e.g. as in some of the Rock-Roses, and leaflet of Wood-Sorrel (Fig. 49).

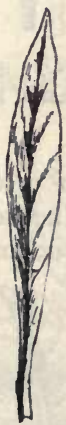

FIG. 45.-Ianceolate leaf of Wallflower.

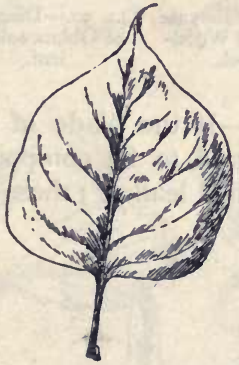

Fig. 46.-Ovate leaf of Lilac.

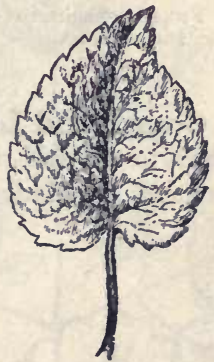

FIG. 47.-Cordate leaf of Deadnettle.

Oblanceolate, when the lanceolate leaf has a wider part which is nearer the apex than the base, e.g. Dog Violet and Spurge Laurel (Fig. 50).

Spatulate, when the leaf is like a spoon, with a rounded portion near the apex, e.g. Daisy.

Reniform, when the leaf is kidney-shaped, e.g. Ground Ivy (Fig. 52).

Linear, when the leaf is very long and narrow, e.g. most Grasses (Fig. 5.3).

Elliptical, when the leaf is oval, e.g Apple (Fig. 54). Acicular, when shaped like a needle, e.g. Fir. 
Many of the above terms are used to describe the shapes of the leaflets of compound leaves.

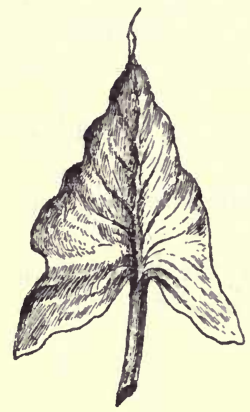

FIG. 48.-Sagit tate leaf of Arum.

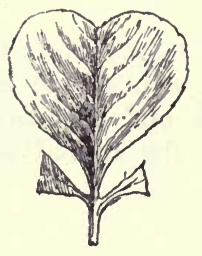

FiG. 49.-Obovate leaflet of Wood. Sorrel.
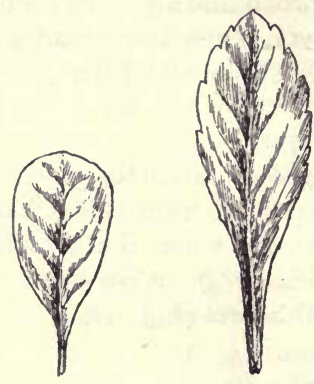

FIG. 50.-Diagram Fig. 5I.-Spatulate of Oblanceolate leaf of Daisy. leaf.

Compound Leaves.-If the blade of the leaf is divided down to the mid-rib it is said to be compound. The separate parts of the blades are called leaflets; these are given off from

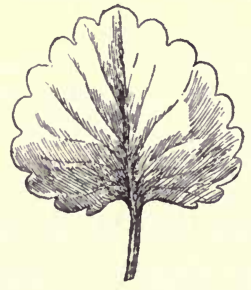

FIG. 52-Reniform leaf of Ground Ivy.

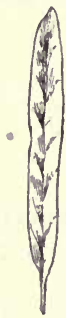

FIG. 53.-Diagram of linear leaf.

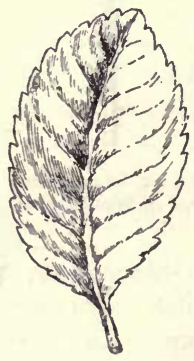

FIG. 54.-Elliptical leaf of Apple.

the mid-rib. The leaflets separate from the mid-rib or petiole in the same way that the entire leaf separates from the stem, i.e., without tearing. They may be pinnately or palmately divided. The following are examples of the latter kind. 
Ternate or trifoliate, the leaf is built up of three leaflets, as in the Clover and Wood-Sorrel (Fig. 55).

Biternate, when the leaf is ternate, but each division is divided again ; in fact, three leaflets divided into three leaflets, as in the Baneberry or Herb Christopher.

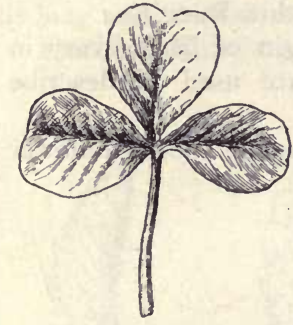

FIG. 55.-Ternate leaf of Wood-Sorrel.

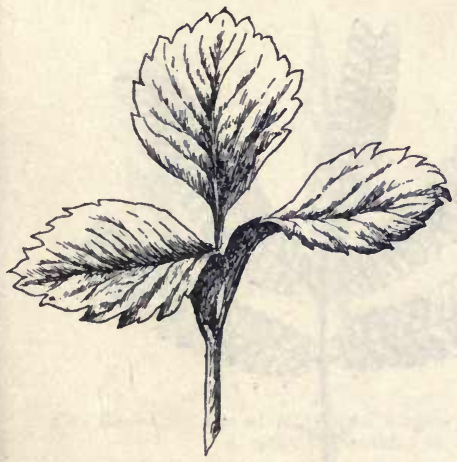

Fig. 56.-Ternate leaf of Strawberry.

Palmate, when the leaflets radiate from the leaf-stalk like fingers from the palm of the hand, e.g., HorseChestnut (Fig. 37).

When the leaflets are arranged along each side of the midrib, they are said to be like a feather or pinnate.

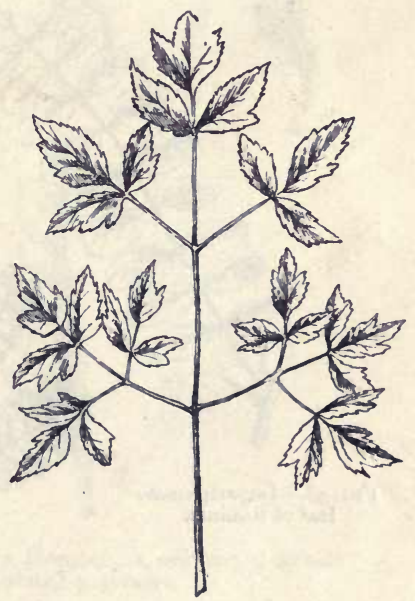

FIG. 57.-Biternate leaf of Baneberry.

There are two kinds of pinnately divided leaves-those with an equal number of leaflets along each side of the mid-rib, and those with an odd leaflet. The former are called paripinnate, and the latter imparipinnate.

Paripinnate, when there are an equal number of leaflets on each side of the mid-rib, as in the Bitter Vetch. 
Imparipinnate, when there is an odd leaflet, as in the Rose and Robinia (Fig. 58).

Bipinnate, when the leaflet is again divided, as in the common Meadow Rue and Acacia (Fig. 59).

Tripinnate, when the division is carried a little farther and each part is in three, as in the Lesser Meadow Rue.

The Margin of Leaves.-The margin of leaves vary in different plants. The following terms are used to describe them :-

Entire, if the margin is undivided, as in the Wallflower (Fig. 60).

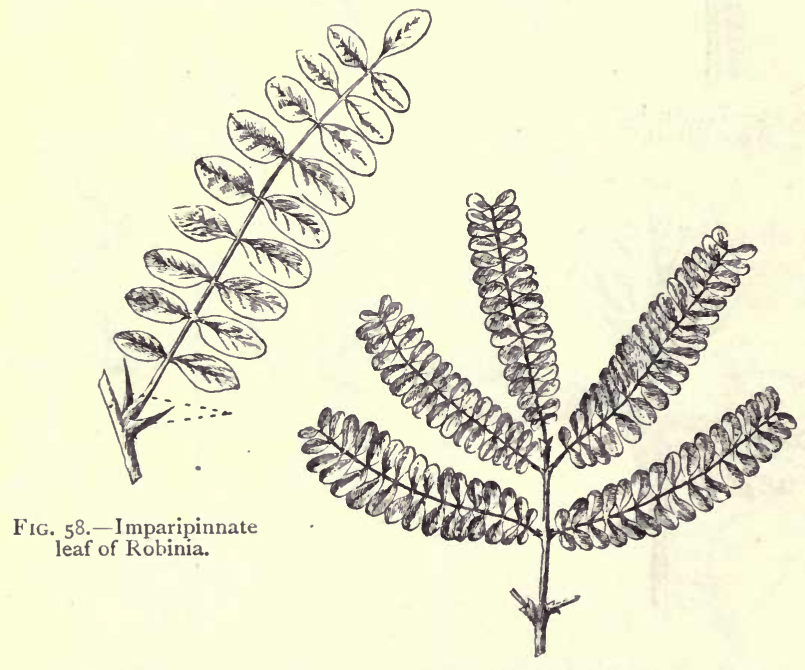

FIG. 59.-Bipinnate leaf of Acacia.

Serrate, if the margin is divided up into teeth-like divisions, like a saw, and they point towards the apex, the above term is used, e.g., Deadnettle.

Biserrate, if the teeth are again divided, as in the Elm. Crenate, if the teeth are rounded, as in the Ground Ivy. Dentate, if the teeth point outwards, as in the Guelder Rose. 
Ciliated, if the margin is fringed with fine hairs like the Beech.

Spiny, if the teeth are long and very sharp, as in the Holly.

Apex of the Leaf.-The apex of the leaf may be sharply pointed, when it is called acute ; if blunt, Obtuse ; and if the end is long and pointed, acuminate (Fig. 6I).

Further Kinds of Simple Leaves.-When the leaf is
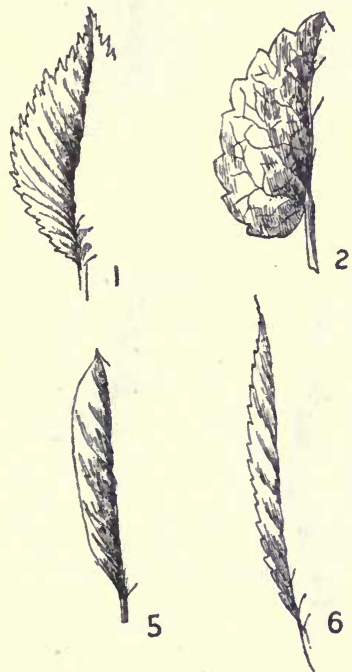

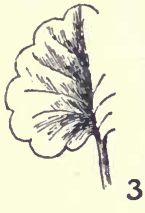

34

4

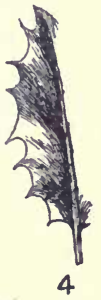

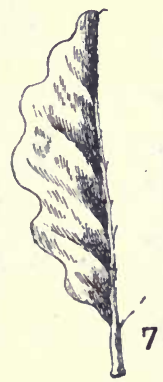

Fig. 60.-Diagram of margin of leaves. x, biserrate; 2 , serrate ; 3 , crenate ; 4 , spiny; 5 , entire ; 6 , dentate ; 7 , sinuate.

split up into a number of divisions, and these do not cut down to the mid-rib, the following terms are used :-

Palmatisect, if the ends extend nearly to the base, e.g., Monkshood.

Palmatifid, if the cuts extend about halfway from the margin to the base of the leaf, as in the Castor Oil plant.

Palmate, if in the palmatifid leaf the number of divisions is five, as in the Maple. 
Pinnatisect, if the divisions extend nearly to the mid-rib, as in the Poppy.

Pinnatifid, if the cuts extend about half way from the margin
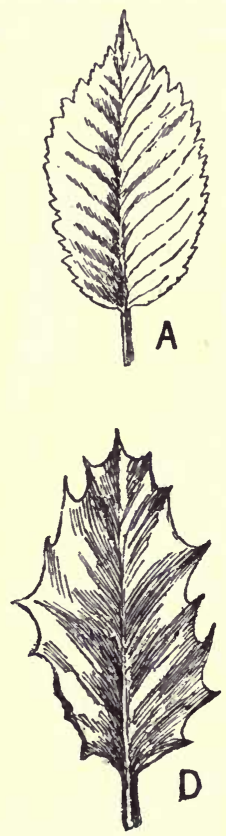
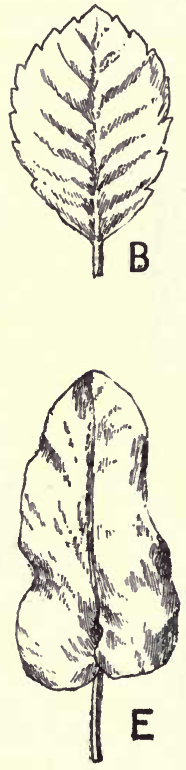
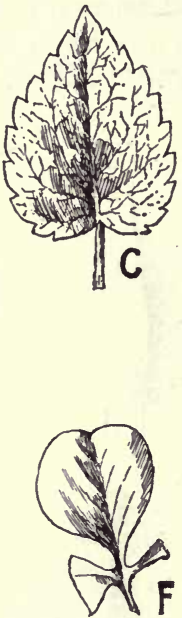

Fig. 6r.-Diagram of apex of leaves. A, acuminate ; B, obtuse ; C, acute ; $\mathrm{D}$, mucronate; $\mathrm{E}$, retuse; $\mathrm{F}$, emarginate.

to the midrib, as in the Welsh Poppy, and in some of the leaves of the Mignonette.

Lobed Leaves. These, according to the number of lobes, may be trifid, trilobed, five-lobed, \&c.

ExpT. 29. - Make a collection of leaves. Note and compare their shapes with the figures in the book.

The leaves can be dried by pressing them with heavy weights between the leaves of a blotting book or even between sheets of note paper. If the sheets of paper be changed every day until the leaves are perfectly 
dry, the leaves can be mounted on sheets of card board, or on special papers such as the following :-

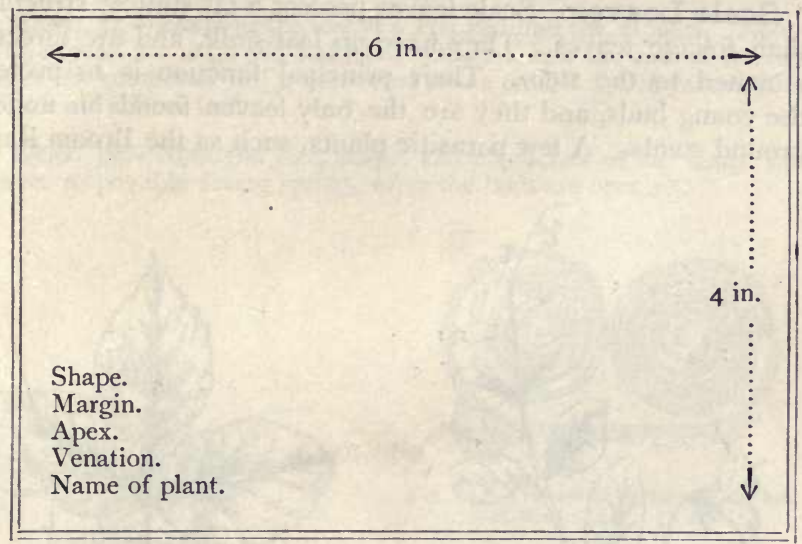

EXPT. 30.- Try and cut out in paper the different forms of any leaves which may be obtained. This can be done by laying the leaf on a sheet of white paper and tracing on the paper with a fine pointed pencil the outline of the leaf. Cut along the lines so made with a sharp pair of scissors. The name of the leaf and its shape can be marked on the model. The pupil will soon discover how difficult it is to describe the leaf with accuracy, and will also apprehend the greater truth that there are probably not two leaves alike.

Expr. 31.-Examine every leaf, spine, and tendril you can obtain.

Stipules.-Theše, as we have already seen, are outgrowths at the base of the leaf. The texture and colour of stipules vary ; thus, if their function is to protect the young leaves in the bud, they may be brown or yellow in colour; if they are used for assimilation, that is, to provide nourishment for the plant, they are green in colour, and large and leaf-like in form.

There may be two stipules, one on each side of the leaf, as in the Pea and Pansy. In some of the Bed-straws the stipules are large and are often mistaken for leaves ; in fact, they appear to form whorls with the leaves. The stipules are membranous in the Rose leaf, where they are represented by a series of teeth along each side of the base, and are called adnate stipules. Where 
the stipules unite in the leaf-axil they are called axillary, as in the Pea (Fig. 62).

Scale Leaves.-Scale leaves possess a far simpler structure than foliage leaves. They have no leaf-stalk, and are directly attached to the stem. Their principal function is to protect the young buds, and they are the only leaves found on underground stems. A few parasitic plants, such as the Broom Rape

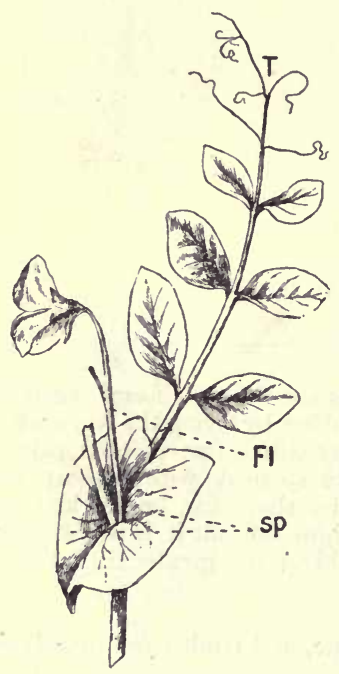

Fig. 62.-Leaf of Pea. Fr, flowerstalk ; SP, stipules ; T, tendrils.

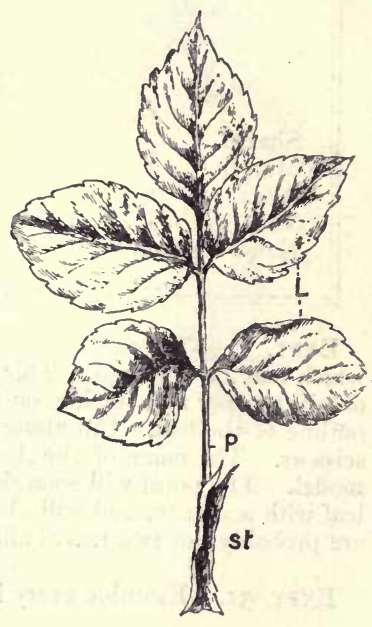

FrG. 63.-Leaf of Rose. L, leaflets; $\mathrm{P}$, petiole ; st, stipules.

which grows on the roots of plants, do not possess any other kinds of leaves.

Bracteate Leaves.-Bracteate leaves resemble scale leaves both in structure and function. They grow at the base of the stem upon which the flowers are produced. When present the plant is said to be bracteate, if they are absent, ebracteate. Bracts may be scaly, leafy, meinbranous, woody, or coloured. When the bracts are arranged in a circle, as in the Dandelion, they form an involucre. If the bracts form a solid cup, as in the 
acorn, they form a cupule. When a single bract is large and protects a series of flowers it is called a Spathe, e.g., the Arum.

Expт. 32.-Examine the leaf of a Pea and find the stipules. NoteThe stipules are large and leaf-like. Observe how the end of the midrib of the compound leaf is converted into a tendril. Compare with the stipules of a Rose leaf.

ExpT. 33.- Note the size, shape, and characters of as many scale leaves as possible during spring, when the buds are opening.

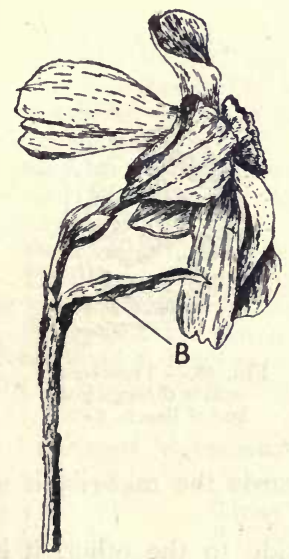

Fig. 65.-Bracteate leaf of Narcissus. B, bract.

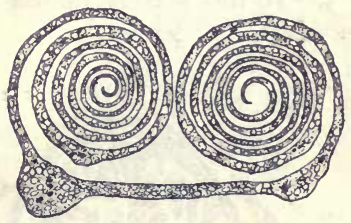

FIG. 64.-Transverse section of leaf-bud of Water Lily. ( $\times$ 6.)

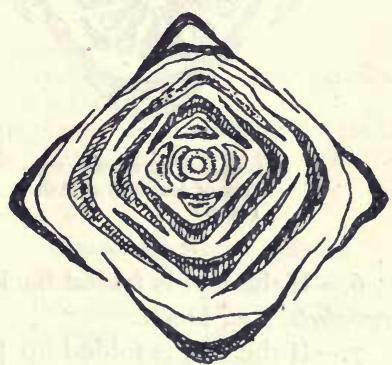

FIG. 66.-Transverse section through leaf-bud of Lilac. $(\times 5$.

Floral Leaves.-Floral leaves are modified leaves which go to build up the flowers of a flowering plant.

Vernation.-The way in which the young leaves are folded in the bud is called vernation or prafoliation. This differs in different plants, and will be considered under two heads, viz., (a) the folding of the individual leaf in the bud ; and (b) the folding of the several leaves in the bud. 
The arrangement of the individual leaf in the bud is shown below in a tabular form :-

I.- If the leaf is not folded at all, the vernation is plane.

2.- If the leaf is folded along the mid-rib, it is conduplicate, e.g., Bean.

3.- If the leaf is folded into a number of longitudinal or oblique pleats, it is plicate, e.g., Beech.

4.- If the leaf is folded in all directions, it is crumpled, e.g., Poppy.

5. - If the leaf is folded inwards towards the mid-rib, it is involute, e.g., Violet.

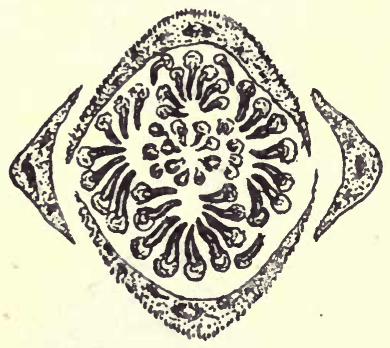

Fig. 67.-Transverse section of leaf-bud of Ash. $(\times 7$.

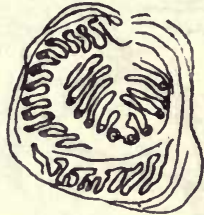

FIG. 68.- Transverse section through leafbud of Beech. ( $\times 6$.

6.- If the leaf is folded backwards towards the mid-rib, it is revolute, e.g.; Dock.

7.- If the leaf is folded up from one side to the other, it is convolute, e.g., Banana.

The arrangement of the several leaves in the bud is shown below :-

I. - If the leaves in a bud just touch by their margins, the vernation is valvate.

2.--If the leaves in a bud overlap each other, it is imbricated.

3.-If the leaves in a bud overlap each other in regular order, it is tristed or contorted.

4. - If the outer conduplicated leaves in a bud enclose those within in regular order, it is equitant. 
5.- If half of one conduplicated leaf enfolds another, it is semi-equitant.

6.-If one convolute leaf is rolled around another, it is supervolute.

EXPT. 34.-Cut a transverse section of any leaf-buds met with. Note-

(i) The arrangement of the individual leaves in the bud.

(ii) The arrangement of the several leaves in the bud.

(iii) The arrangement of the parts in the buds. Show it by sketches.

\section{SUMMARY}

A Perfect Ieaf consists of a sheath, petiole, and blade. If the blade is the only part present, the leaf is said to be sessile, and fetiolate when the blade and petiole are developed.

Stipules are outgrowths at the base of the leaf. Leaves can be exstipulate

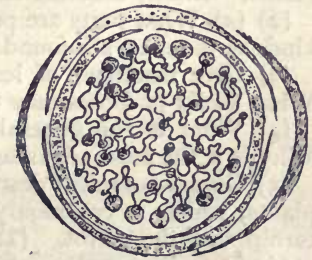

FIG. 69.-Transverse section of leaf-bud of Sycamore. $(\times 4$. or stipulate.

Venation of leaves-two kinds-parallel-and reticulate.

Phyllotaxis is the arrangement of leaves on a stem. The common arrangements are alternate, opposite, and whorled.

Foliage Leaves may be simple or compound. In the former the blade is not divided down to the mid-rib, but in the latter kind the blade is cut up in separate or distinct parts.

\section{Simple leaves may be}

Lanceolate. Oblanceolate.

Ovate.

Cordate.

Sagittate.

Spatulate. Acicular.

\section{Compound leaves may be}

Ternate. Paripinnate.

Biternate. Imparipinnate.

Palmate. Bipinnate.

Tripinnate.

The Margin of Leaves may be-(1) Entire, (2) Serrate, (3) Biserrate, (4) Crenate, (5) Dentate, (6) Ciliated, (7) Spiny.

The Apex may be-(I) Acute, (2) Obtuse, (3) Acuminate.

The Margin may be divided as-(1) Palmatisect, (2) Pinnatifid, (3) Pinnatisect, (4) Palmatifid, (5) Palmate, (6) Lobed.

Stipules may be leaf-like, or membranous.

Scale Leaves. - These are found to be modified leaves; they protect the buds from injury.

Bracteate Leaves. - These are found at the base of the flowers, and may form an involucre, cupule, or spathe. 
Floral Leaves. - From these various parts of the flowers are formed. They can be divided into four kinds.

Vernation or Præfoliation is the folding of the leaves in the bud.

\section{Questions on Chapter IV.}

(I) What is a leaf? Excluding the leaves forming the flower, we have three kinds occupying different positions on the stem in the higher plants. Briefly describe these.

(2) (a) What parts are present in a perfect foliage leaf? (b) What kinds of venation are found in leaves?

(3) Give instances of leaves which are only imperfectly developed. What useful purposes may they serve in such cases? (1882.)

(4) What is the general plan of arrangement of leaves on a stem? Why is it the most advantageous to the plant? (I88I.)

(5) Give a botanical description of the part, in each of the following plants, which is commonly used as food: the potato, the onion, the turnip, and the carrot. (1887.)

(6) Describe, with examples, the principal forms of compound leaves. What is the difference between a simple and a compound leaf? (189o.)

(7) Explain, with examples, the following terms :-Bract, stipule, pinna, petiole, peduncle. (I896.)

(8) What are stipules? Describe the stipules of the Rose and the Sweet Pea.

(9) How do the leaves of the Oak differ from the leaves of the Clover?

(Io) Describe the general structure of the leaf-bud, explaining the meaning of the term "vernation." What is the usual position in which buds are developed on the stem? (I89I.) 


\section{CHAPTER V}

\section{ANATOMY-STUDY OF ROOTS}

Descending axis.-The descending axis, or root, is the part of the plant which grows downwards, fixes it into the soil, and takes from the ground water in which minerals are dissolved. The root can be distinguished from the stem in the following way :-

Root.

I. The root produces neither leaves nor buds.

2. The root as a rule grows downwards.

3. The growing point of a root is protected by a sheath which is called the Root cap.

4. The root produces small hairs, which absorb from the soil the water and minerals required by the plant for its growth.

5. Roots grow away from the light.
Expr. 35.-Dig up a Deadnettle and examine it. Note-

(i) The roots bear neither leaves nor buds.

(ii) The stem produces both.

(iii) The hairs on the stem, which are close set and are used to protect the plants from cold currents of air and from insect pests.

(iv) The very minute and soft hairs on the roots. These can be best seen if the root be held up between the eye and the light and looked at through a hand-lens. 
Expr. 36. - Take a few Beans and soak them in water for twentyfour hours. With a sharp knife cut longitudinal slices from the radicle and place them on a glass slip, such as is used for microscope work. Hold the glass slip between the eye and a strong light and place the hand-lens up to the eye. Move the sections first

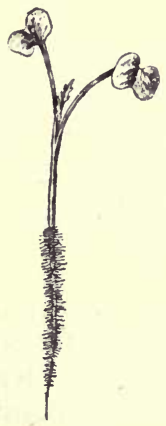

FIG. 70.-A Mustard seedling, showing root - hairs and cotyledons. towards the lens and then away from it, until they appear clear. Near the apex of the radicle a dark inner portion and an outer lighter part can be made out. The dark portion is the growing point, and the lighter part the root-cap.

The Primary Roots.-The root procluced by the elongation of the radicle is termed a primary root. When the primary root persists and continues to grow it is called a tap-root. The Oak, Bean, and Wallflower produce tap roots. Branches are produced from the primary root in regular order, the oldest being found towards its base, i.e., near the apex or growing point.

The Secondary Roots. - The lateral branches of the primary root are termed secondary roots. They differ from the branches of the stem in not being produced in the axil of leaves, nor from buds; but they are formed in regular order. Each plant produces a definite number of rows of rootlets, which are arranged longitudinally, the roots in each row being accurately one above the other. The secondary roots grow horizontally or somewhat obliquely, not straight down like primary roots, and in this way the roots between them parcel out the soil. In the Wallflower there are four rows of roots, which strike out north, south, east and west, and it is clear that between them there is always unoccupied ground. This unoccupied ground is worked by roots produced from secondary roots and known as tertiary. They have no definite direction of growth, but spread outwards, upwards, and in all directions, thus reaching every part of the vacant soil.

EXPT. 37.-Obtain a Wallfower plant with perfect roots. Wash the roots in water so as to remove the soil.

Examine the roots and observe-

(i) The primary root.

(ii) The secondary roots forming four rows.

(iii) The tertiary roots growing from the secondary roots. 
ExPT. 38. - Compare the roots of the Deadnettle, or any other plant which can be obtained, with the Wallflower, and note the number of rows of secondary roots.

Adventitious Roots. - The roots which are produced without any definite orcler from stems, leaves and roots are termed adventitious. In most monocotyledonous plants the primary root is either very short or ceases to grow soon after it leaves the seed. Its place is taken by an immense number of adventitious roots which spring from the stem. When gardeners place cuttings in the soil, they are said to "strike" when they

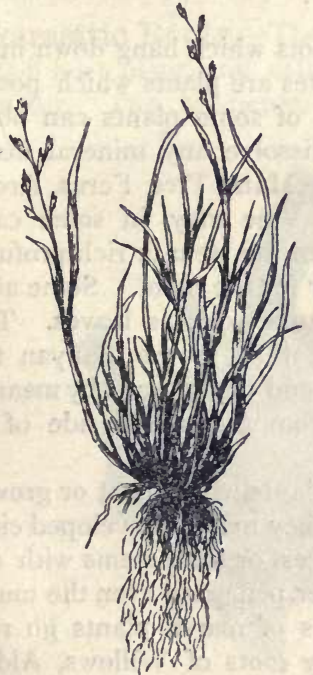

FIG. 7x. - The fibrous roots of a Grass.

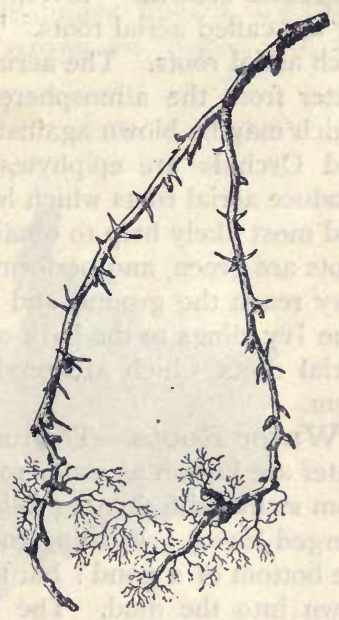

FIG. 72.-Branches of a Gooseberry bush producing adventitious roots.

take root. This is brought about by adventitious roots being produced from the nodes of the stem which is pushed into the soil.

Clinging Roots.-When adventitious roots are used for climbing as in the Ivy, they are called climbing or clinging roots. Roots of this kind are very highly developed in many tropical plants like the Orchids. 
Such roots simply cling to the bark of trees, they take nothing from the plant on which it grows. Some water plants produce a large number of roots which float in the water and help to support or moor the plant. The Duckweed, which grows in many of our ponds, is a good example.

ExPT. 39. -Dig up a Grass plant from a field, and examine the roots. Note-

(i) The tap-root is either absent or very short.

(ii) A large number of roots, which seem to come from either the top of the root or from the stem, and grow without any regular order, can easily be made out. They are called adventitious roots. They are also fibrous roots.

Aërial Roots.-Adventitious roots which hang down in the air are called aërial roots. Epiphytes are plants which possess such aërial roots. The aërial roots of some plants can obtain water from the atmosphere and dissolve any mineral matter which may be blown against them. Many Tree Ferns, Aroids, and Orchids are epiphytes. The Vine may, in some cases, produce aërial roots which hang from the stem in rich profusion and most likely help to obtain water for the plant. Some aërial roots are green, and perform the same work as leaves. They may reach the ground and take root as in the Banyan tree. The Ivy clings to the bark of trees and to old walls by means of aërial roots which are produced from the shady side of the stem.

Water Roots.-The roots of plants which float or grow in water are known as water roots. They may be developed either from stems with floating foliage leaves, or from stems with submerged leaves. Floating roots never penetrate even the mud at the bottom of a pond : but the roots of marsh plants go right down into the mud. The ordinary roots of Willows, Alders, and Elms, growing along the sides of streams, often grow from the bank into the water in which they float. Water roots do not produce root hairs.

ExPr. 40.-Obtain a Hyacinth bulb, and place it in a vase of water. Make up the loss of water which will take place by a solution ${ }^{1}$ containing-

Potassium nitrate . I gram. Calcium phosphate $\frac{1}{2}$ gram.

Sodium chloride . . $\frac{1}{2}, "$ Water ... I litre

Calcium sulphate. . $\frac{1}{2}, \quad$ Iron chloride . . a few drops

Magnesium sulphate. $\frac{1}{2}, ”$

1 Any chemist will make up this solution. 
Such a solution contains everything necessary for the growth of a plant. Note how the bulb produces water roots, which obtain from the solution the substances required by the plant for its growth. Observe the growth of leaves and flowers. This experiment shows that roots, which under natural conditions live in soil, can change their mode of life and become water roots.

ExpT. 41.-Cut a slip from any plant, (the garden Geranium will do), so as to leave at least three nodes with leaves and one without. Place the slip in a bottle with some of the solution used in the last experiment.

Observe that roots develop in the water from the nodes. Keep the bottle warm; it will soon be filled with roots. These roots are adventitious and aquatic.

Parasitic Roots. - The roots of those plants which penetrate a host plant, and extract nourishment from it, are called parasitic. The Mistletoe, which grows on Apple, Fir, and

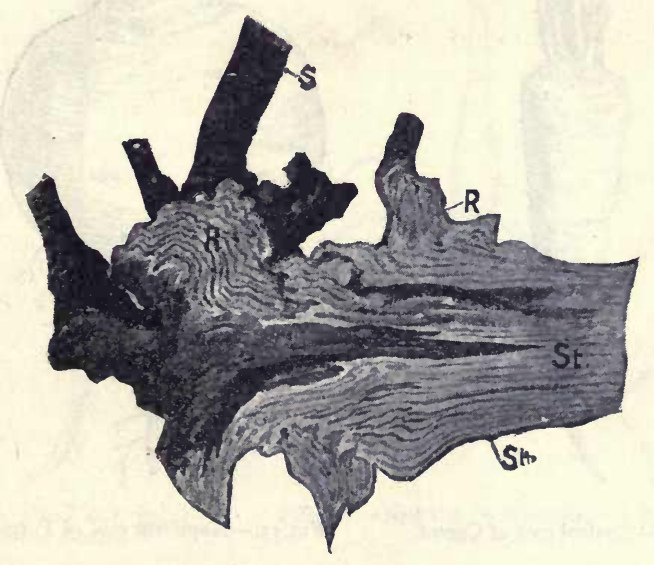

Fig. 73.-St, stem of Apple. S, shoot of Mistletoe; R, roots of Mistletoe. (One-twelfth nat. size.)

Poplar trees is a parasite. Mistletoe is very plentiful in our homes about Christmas time, and most persons know its berries. Thrushes feed on these berries, and the seeds enclosed in the fruit are protected from the digestive juices by a hard covering.

They consequently pass out of the digestive tube without undergoing any change; the droppings of the Thrush are 
generally voided from the upper branches of trees and carry the seeds with them. The droppings and the seeds which are enclosed in them cling to the branches. The seeds germinate and the radicle which is produced is pressed closed to the bark and cemented there (Fig. 73).

The Eye-bright, so common in fields, produces suckers on its root which attach themselves to the roots of grasses and extract nourishment from them. The Yellow-rattle, Lousewort, Cow-

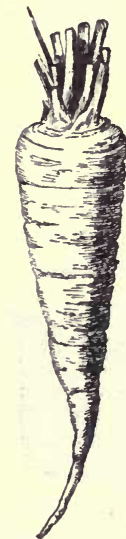

FIG. 74.-Conical root of Carrot.

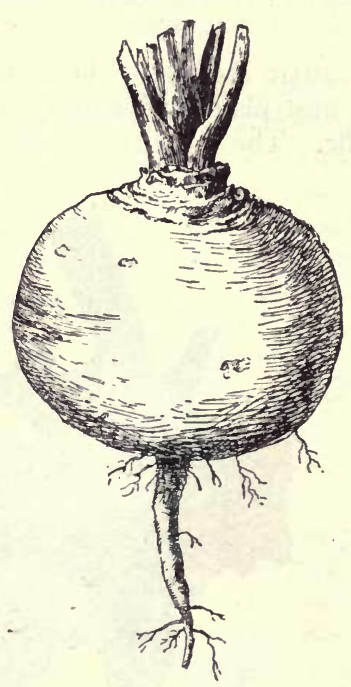

FIG.75.-Napiform root of Turnip.

wheat, Toothwort, and Broom-Rape, are all parasites growing on the roots of plants.

EXP'T. 42.-Pull up a few plants of Eye-bright and examine their roots. Find the suckers, which appear as little white knobs on the roots; they are always found on the secondary roots.

Modified Roots.-Roots may be modified for the storing up of reserve materials, often becoming large and fleshy, as in the 
case of the Turnip. Roots of this description belong to biennial plants. The principal shapes of modified roots are as follows :

I.-Conical, when broad near the stem and tapering towards the tip, as in the Carrot (Fig. 74).

2.-Napiform, when shaped like a Turnip. The Swede usually has, at the crown of the root, a neck from which the leaves spring. This is absent in the Turnip (Fig. 75).

3.-Fusiform, when the root tapers both near the stem and towards the apex, e.g., Radish (Fig. 76).

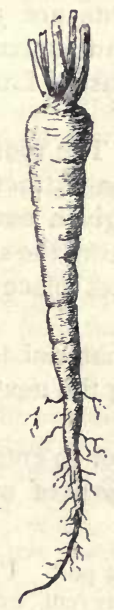

Fig. 76.-Fusiform root of Radish.

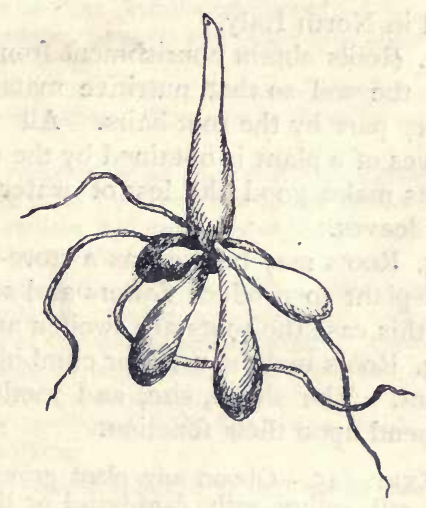

Fig. 77.-Nodular or tubercular root of Pilewort.

4.- Tubercular, when the rootlets are swollen and round, as in the Pilewort (Fig. 77).

ExPT. 43.-Obtain the roots of the Turnip, Carrot, and Radish. Make sketches illustrating their shape, and mark on them the reduction in size which you make. This can be done by measuring the size of the root, and then the drawing. If these be compared, the reduction can be found. The pupil should do this in all sketches made.

ExPT. 44.-Dig up, either in March or April, the roots of the Pile- 
wort. This plant can be distinguished from the common Buttercup, because-

(i) Its leaves are cordate and perfect ; in the Buttercup the leaves are very much divided, and the segments are lobed.

(ii) The petals vary in number from eight to ten; in the Buttercup there are only five. Examine the roots and note the swollen fibres; these are used for storing up reserve materials. These are tubercular roots.

Uses of Roots.-Roots perform various functions which can be arranged in a tabular form.

r. Roots fix the plant in the soil. The roots can anchor a tree like the Oak so that the strongest wind cannot blow it over. In many cases the roots of grass-like plants are used by engineers, to bind together the soil along an embankment, and so keep it from falling, as on the West Coast of Lancashire and in North Italy.

2. Roots obtain nourishment from the soil. The roots parcel out the soil so that nutritive materials can be extracted from every part by the root-hairs. All the water given out by the leaves of a plant is obtained by the root-hairs from the soil. The roots make good the loss of water which takes place through the leaves.

3. Roots may be used as a store-house for material to enable the plant to produce flowers and seeds during the next season. In this case the roots are swollen and large.

4. Roots may be used for climbing, floating, or to enter a host plant. The shape, size, and method of growth of roots will depend upon their function.

EXPT. 45.-Obtain any plant growing in a plant pot. Cover over the soil, either with card-board or tin-foil, to prevent evaporation from the pot. Place the plant beneath a glass globe, and expose to light in a window sill. Note that the inside of the glass is soon covered with moisture. This is given out by the leaves, and the loss can only be made good by the water taken in by the roots.

Movements of Roots.-The younger portions of the roots are all in a constant state of motion. When the radicle leaves the seed it commences to move, and so long as life lasts the tip of the root will go on moving round and round in search of certain substances or conditions. The force exerted by a young radicle when growing is very great; in twenty-four hours it causes a downward pressure equal to lifting a weight of a 
quarter of a pound. Roots not only move in the direction of least resistance, but also towards damp and away from dry soil.

The use of these movements to the plant cannot be overestinated. If the root made its way through the soil in a perfectly straight line, not half the favourable spots for food would be touched; the spiral or circular movements of the root ensure its contact with the best sources of food in the soil. The tip of the root is also very tender and liable to be injured, and the movement from side to side enables it to find the path along which there is least danger to the growing point.

Expr. 46.-Take a few Beans or Peas and germinate them on damp sawdust. When the radicle appears through the micropyle, turn the seeds over so that the radicle points upwards. Under another radicle place a piece of glass. Notice how the radicles act.

ExpT. 47.-Using the Beans or Peas germinated above,

(i) Cut off the root-tip of a radicle, so as to separate it just above the growing point.

(ii) Place a piece of post card on one side of the tip of a radicle, and on the other side a piece of tissue paper. This can be done by using a solution of shellac.

(iii) Cut slices from a few radicles, so as to remove a longitudinal layer from one side. Great care must be taken not to fix the card too far away from the tip or the radicle will turn towards the card, not away from it. Make notes of the results.

ExpT. 48. - Replace one of the sides of a box with a piece of glass. Fill up the box with alternating layers of sand, sawdust, clay, and peat. Sow mustard seeds or the seeds of any quick growing plants. Cover up the front of the box with a piece of cardboard. Keep the box warm and damp. When the seed leaves are well up in the air, place the box on a window sill. Remove the cardboard from day to day, to see how the roots are placed against the glass.

ExPT. 49. - Take the bottom out of a box, and nail on in place of the bottom a piece of wire netting with holes of about a quarter of an inch in diameter. Fill the box up with soil, placing the largest particles at the bottom. Grow plants as in Expt. 48. Hang the box up in a window and keep the soil moist. Note-

(i) The roots will pass out through the wire netting.

(ii) Many, if not all, will bend up and pass again into the box. This shows that the radicle or roots like darkness better than light. In fact, nearly all roots grow away from the light.

\section{SUMMARY.}

Roots can be divided into-

Primary roots. - A primary root is produced when the radicle goes on growing. Thus, all primary roots are produced by the elongation of 
radicles. Those roots which are formed from the primary roots are called secondary roots. When roots grow out of the secondary roots they are known as tertiary roots.

Other kinds of Roots. - Adventitious roots are produced from stems, leaves, and roots without any regular order. Clinging roots are adventitious roots used to fix a plant to a support. Aïrial roots hang down in the air and take water from it, or enable a plant to climb. Water roots are produced by water-plants, and do not produce root-hairs. Parasitic roots penetrate into a host-plant and extract nourishment from it. Modified roots have undergone a change, so as to serve as a store. house of reserve material.

Shapes of Roots. - May be conical, napiform, fusiform, tubercular, fibrous.

Uses of Roots.-(a) They anchor the plant to the soil. (b) They obtain nourishment from the soil. (c) Food may be stored up in them. (d) They may be used for climbing, \&c.

Movements of Roots. - Ronts are always moving from place to place, so as to find food and the line of least resistance.

\section{Questions on Chapter V.}

(I) Describe and explain, with reference to examples, the peculiarities of the roots of biennial plants. (1890.)

(2) What is a growing point ? How does the growing point of a root differ from that of the stem? (1889.)

(3) Briefly describe, giving examples, the principal kinds of roots; and explain what are the functions which the various kinds of roots are specially adapted to perform.

(4) How do roots parcel out the soil? Give examples.

(5) Give sketches showing (a) conical, (b) napiform, (c) fusiform roots.

(6) What is an adventitious root? Mention plants which produce such roots, and give an account of their function.

(7) What is a parasite? How do the seeds of the Mistletoe find their way to the host plant? How does the seed act when it germinates?

(8) What is a root parasite? Give examples.

(9) Of what use is a root? In what circumstances may a plant exist without one?

(I0) Explain why the root of a turnip first grows faster than the stem, and then stops while the stem grows.

(II) Give an account of experiments which you have performed to show how roots move.

(12) In preparing sketches you have to show the scale. What is meant by the scale, and how can it be determined? 
SECTIONS, HOW TO PREPARE AND EXAMINE THEM

Sections.-To fully investigate the internal structure of a plant or its members, it is necessary to cut sections of the plant in various directions. A piece cut out of a stem is called a section. If the stem is cut across at right angles to its long axis it is called a transverse section. When the stem is cut along its long axis, the section made is termed longitudinal. There are two kinds of longitudinal sections, radial and tangential. A radial longitudinal section is one which passes through the organic centre of the stem. A tangential section can be made lengthways through the stem, but does not pass through the centre. This is illustrated by Figs. 78, 79, 80 and $8 \mathrm{r}$. When a piece is cut out of a stem in the plane A, Fig. 78 , the section is transverse. Such a section is shown in Fig. 79. If the cut is made through $B$,

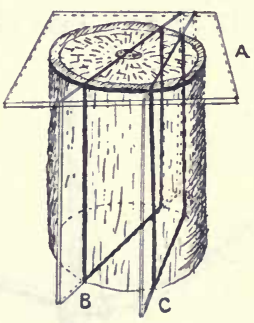

FIG. 78. - Diagram illustrating how to cut sections. A cut along the line $\mathrm{A}$ gives a transverse section : along plane $\mathrm{B}$, a radial section: and along $\mathrm{C}$, a tangential section. Fig. 78 , it passes through the organic centre, and is a radial longitudinal section, as shown in Fig. 80. The tangential section can be made through the plane C, Fig. 78 . This is shown in Fig. 8I.

To make good sections either a very sharp knife or a razor will be necessary. The shape of the blade will depend upon the size of the proposed section; if the area of the section is small, a hollow-ground razor or knife will give the best results, but for 
large flat sections a cutting instrument with a flat side must be used. The section when made may be so thin that light can

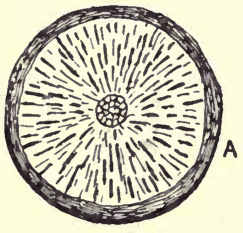

FIG. 79.-A transverse section, cut through A, Fig. 78 .

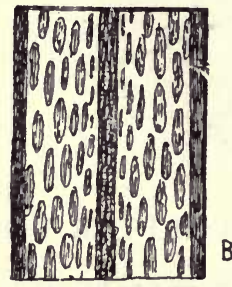

Fig. 80.-A radial section, cut through $\mathrm{B}$, Fig. 78 .

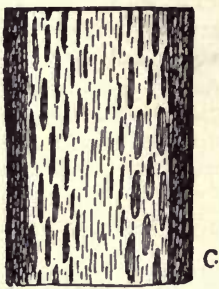

FIG. 8r.-A tangential section, cut through C, Fig. 78 .

pass through it, when it is said to be transparent. If the section is thick and no light can pass through it, it is called opaque.

EXPT. 50.-Take a long kidney potato and cut sections from it; they can be made in three directions, as fol-

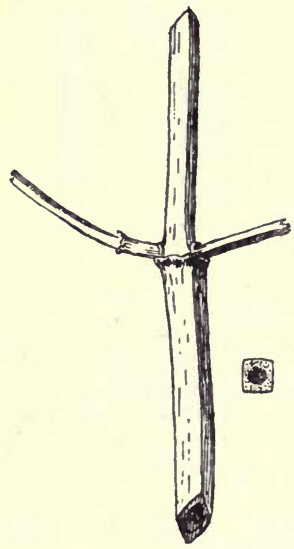
lows-

(i) At right angles to its long axis; this will be a transverse section.

(ii) Parallel to its long axis, and passing through the centre; this will be a radial longitudinal section.

(iii) Parallel to its long axis, but not passing through the centre; this will be a tangential section.

\section{Mounting Specimens. - After} the sections have been cut they must be mounted on ordinary microscopic slips. These are pieces of glass three inches long by one wide. All fresh specimens can be mounted in water for examination by the microscope, but for examination by a hand lens the dry FIG. 82.-Transverse section object can often be used. Great care through a square stem. must be taken to have both the microscopic slip, and objects used in preparing the specimens, perfectly clean, for the slightest amount of dirt will spoil the section. In mounting the object in fluid only a small drop of it should be used, just sufficient 
to cover the object. For examination under the microscope, the section must be covered with a cover-glass; these can be obtained of different sizes, the one in general use being $\frac{7}{8}$ of an inch in diameter.

If the plant from which the sections have to be prepared has been kept in spirits, they must be mounted either in alcohol or glycerine. The section must never be allowed to dry; if it does, air fills up the cells, and the air bubbles, as they are called, make the specimen appear very dark.

(I) Do not begin to cut sections until you are quite certain what kind you require. If the sections are to be viewed by the compound microscope, keep the razor or knife wet by dipping it before each cut into a glass of water for fresh specimens, and in spirits for materials which have been preserved in alcohol.

(2) Keep the microscope perfectly clean, and be careful that no mounting fluid finds its way on to the stage, lens, or any parts of the instrument.

(3) In mounting the specimen, only just sufficient of the mounting medium must be used to cover the object. When the cover-glass is put on, it must on no account be allowed to drop; one edge must first touch the mounting fluid and be slowly lowered into position, so as to spread out the medium and drive out the air. This can be done by using a needle or pin to support the cover-glass, and with the thumb and finger of the left hand guide it into position as the needle or pin is slowly withdrawn.

(4) Always keep the section wet so as to avoid air-bubbles. If airbubbles are found in a specimen, they may be removed by gently warming the slide by placing it over a jar containing hot water.

(5) If the specimen is intended for future use be careful to label it, and write on this label the name of plant, portion of plant, direction of section, mounting fluid, and date.

Exp'T. 51.-Take a glass slip, and with a dipping rod place a single drop of water in the centre. Now place a cover-glass over the drop of water. This can be done by using a needle or pin to support the coverglass, and with the thumb and finger of the left hand guide the coverglass into position, at the same time slowly withdrawing the needle or pin. After a few attempts the pupil will be able to spread out the drop so as to fill the entire space beneath the cover-glass.

\section{The Structure and use of a Hand-Lens.-A lens is a} transparent substance, usually formed of glass, and is shaped so as to change the direction of the rays of light which pass through it. A lens appears to magnify or diminish the size of objects seen through it. A hand-lens is a piece of glass, suitably mounted, which possesses the property of magnifying objects. 
One of the best and cheapest for botanical work is shown in Fig. 83. It is called a triplet, because there are three lenses mounted so that each one can be used by itself, or in combination with the others. To use such a lens to view a transparent object it is necessary to place the lens close to the eye and to move the specimen about until it appears bright and clear. The object is said to be in focus when it is best seen. If the specimen to be examined is opaque, the best way to observe it is to move both the lens and object until a good view is obtained. Transparent objects can be seen best with all the three lenses as

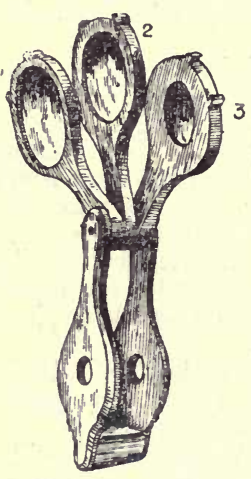

Fig. 83.-Diagram illus. trating hand-lens. $\mathrm{I}=$ low power. $2=$ medium power. $3=$ high power.

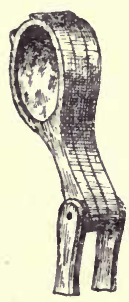

Fig. 84. Diagram showing position of lens when the highest power is used.

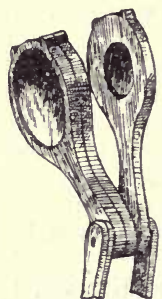

FiG. 85 . Diagram showing position of lens when medium power is used.

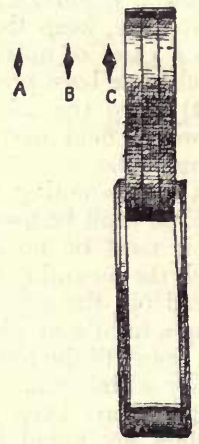

FIG. 86.-Diagram illustrating how to focus a hand-lens. A, the distance of the object from the lens when in focus with the low power; B, with medium; and C, with bigh power.

shown in Fig. 84, but if the objects are opaque, with either lenses I or 2 , or I and 2 combined, as in Fig. 85. In Fig. 86, the edges of the lenses are shown, and A, B, and C, indicates the relative distances at which a specimen may be viewed by I, I and 2 and I, 2, 3, respectively.

ExpT. 52.-Place a little cotton wool between two microscope slips, and with the hand-lens find out the position in which it has to be held so as to focus it with (i) the lower power, (ii) the medium power, (iii) the highest power. 
Cells. - If a thin transverse section of the stem of the sunflower be made, and examined with a hand-lens, a number of openings will be seen; these represent the elementary parts of the plant, and are called cells. The portion of the cell which surrounds the soft material is called the cell-wall, and in our section is the most prominent part of the cell. The soft material receives the name of protoplasm, and is the most important part of the cell. All plants are built up of cells, and these are arranged to form definite structures, which receive the name of tissues.

ExpT. 53.-Obtain a ripe Tomato and mount a small portion of the inner pulp without water, and examine with a lens. Note-the cells are very large and oval, the cell-walls are very thin, and a thin protoplasmic lining can be seen.

EXPT. 54.- - Sow some seeds of the Sunflower in soil, and when the stem is about six inches in length, cut transverse sections of it. These should be placed in a watch-glass with a fifty \% solution of alcohol to clear them. Mount the thinnest section in glycerine and examine with a lens. The cells are large and filled with protoplasm, and are arranged in definite groups,

ExPT. 55.-From a small Beetroot cut a thin transverse section, mount on a glass slip and examine with a hand-lens. Notice the cells are filled with coloured cell-sap. Place the section in alcohol for a few minutes and examine again ; the coloured cell-sap will have oozed out. This is due to the spirits having killed the protoplasm.

Expr. 56. - Cut a thin section from a Potato, mount and hold it on the blade of the knife so that a portion is exposed to the light; examine with a hand-lens. Note the cells appear as minute bodies, dark in colour, due to the air they contain.

Tissues.-If a transverse section of the stem of a Sunflower be made and examined (see Fig. 87), the cells are seen to be arranged in a certain definite manner. On the outside a single layer of cells is arranged to form a covering to the stem. This covering forms the epidermis. In all cases the cells which cover the plant, and protect the deeper parts from injury, form the epidermal tissue. Within the section a number of groups of cells can be seen forming a nearly complete ring ; these are separated from the epidermis by a layer of cells. This ring of cells forms the vascular tissue of the plant. The separate groups of cells are called vascular bundles. In the centre, and between the vascular ring and the epidermis, a 
number of cells can be seen. These fill up the interspaces, and can be called packing cells, or ground tissue.

All the higher plants are built up of tissues. These tissues consist of cells which are grouped together to perform special work. The three kinds of tissues found in the section of the

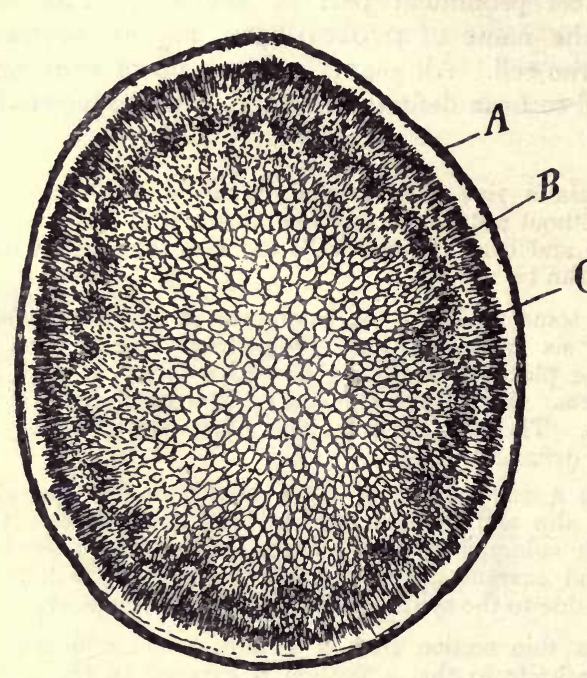

FIG. 87.-Transverse section of stem of Sunflower. $A$, epidermis ; $B$, cortex; C, vascular ring. $(\times 7$. stem of the Sunflower are also found in leaves, roots, and flowers.

ExP'. 57.--If the ground under a Holly Tree be searched during autumn a number of leaves in va. rious stages of decay will be found. Some will be found with the soft material de. cayed away, leaving a skelelon leaf. The veins of the leaf con. sist of very hard material, and have resisted the action of the atmosphere to a greater extent than the softer material which has

disappeared. The skeleton leaf consists of vascular tissue, as shown in Fig. 88, where a small quantity of the epidermis and ground tissue is shown near the apex of the leaf.

ExpT. 58.-Obtain an old Cabbage-stalk and cut a transverse section. Such a section is shown in Fig. 89. Examine it with the aid of a hand-lens, and note-

(i) The epidermis, this is shown at A, Fig. 89.

(ii) A ring of tissue is found between the centre of the stem, see B, Fig. 89, and the epidermis ; this is made up of vascular bundles.

(iii) In the centre a mass of tissue is found with a number of cavities in; this is the pith. Between the epidermis and the vascular cylinder a ring of tissue can be seen, which is called the cortex. These cells form the ground tissue of the plant.

(iv) On the outside of the stalk is seen a number of marks. 
These are the places where the leaves were inserted; they are called leaf scars (Fig. 89, D).

ExPT. 59.-Cut a transverse section of a twig of the Lime tree. Note-that the wood is made up of a number of rings. Each ring is niade up of $(a)$ a dark coloured layer and $(b)$ a light coloured layer. These are shown in Fig. 90. Each ring represents the amount of growth which has taken place in one year. The age of the tree can be told by the number of rings of wood present

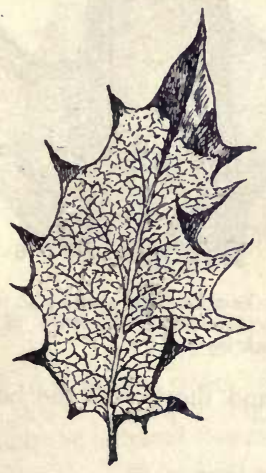

Fig. 88.-Skeleton leaf of Holly. (Half nat. size.)

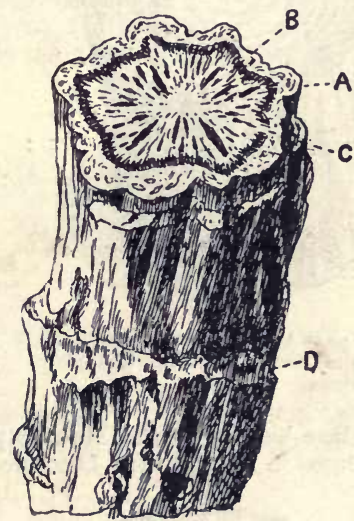

FIG. 89.-A piece of Cabbage stalk. $\mathrm{A}=$ epidermis $; \mathrm{B}=$ cortex $; \mathrm{C}=$ vas. cular tissue ; $\mathrm{D}=$ leaf scar.

ExPT. 60.-Cut in autumn a longitudinal section of the stem of the Horse-Chestnut so as to pass through the base of a leaf. Examine such a section with a hand-lens. Note-

(i) The base of the leaf which is connected with the stem (see A, Fig. 9I).

(ii) A layer of cork which consists of cells ; the layer passes right across (see B, Fig. 9r) the base of the leaf. This layer, when the leaf has performed all its work, separates the leaf from the stem and covers up the scar which is left.

ExpT. 61.-Cut a transverse section of the stem of the Maize, and mount it in glycerine. If the stem has been preserved in alcohol so much the better, because there will be a smaller number of air bubbles present, and the section will be far clearer. Examine with the low power of the hand-lens. Note-

(i) The primary cortex. This surrounds the vascular bundles and helps to support the plant in an erect position. 
(ii) The ground tissue which separates the vascular bundles, and in which they are embedded.

(iii) The vascular bundles which are scattered; they are not arranged in the form of a ring as in the Sunflower. The bundles are smallest

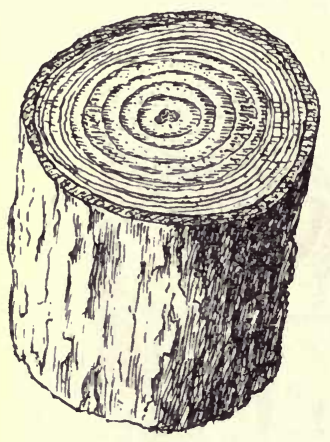

FiG. 90.-A piece of the stem or the Lime, showing annual rings. and most numerous near the primary cortex, and largest and few in number near the centre of the stem.

All plants with scattered vascular

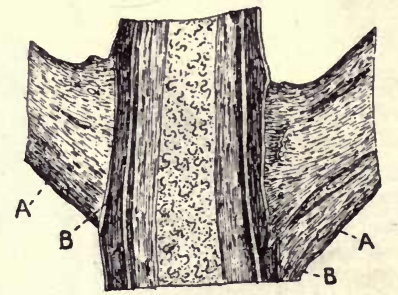

FIG. 9r.-Longitudinal section of stem of Horse-Chestnut. A, base of leaf; $\mathrm{B}$, cork layer. $(\times 3$.

bundles belong to the Monocotyledons, and those with the bundles arranged in a ring to the Dicotyledons.

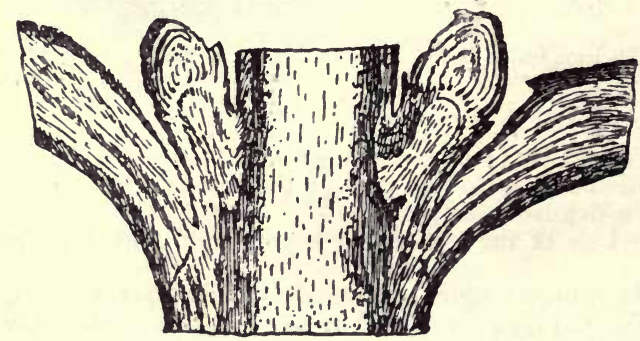

FiG. 92.-Longitudinal section of stem of Sycamore, showing leaf fall and buds in the axils of leaves. $(\times 4$.

Expr. 62. - Select an old root of the Maize from which a number of rootlets are growing. Cut transverse sections so as to pass through one of the young rootlets. Select one of the thinnest and mount in water or glycerine. Examine with a hand-lens. Note-

(i) The young rootlet which is found on one side of the section. (Fig. 93, R.) 
(ii) The way the rootlet springs from close up to the vascular bundles, and breaks through the cortex and epidermis.

ExpT. 63.-Dig up a few rhizomes of the Sweet Flag (Acorus). It can be found growing in ditches in Lancashire, Yorkshire, Somerset, Sussex, and in Scotland and Ireland.

Select a young one and cut transverse sections; choose a thin section

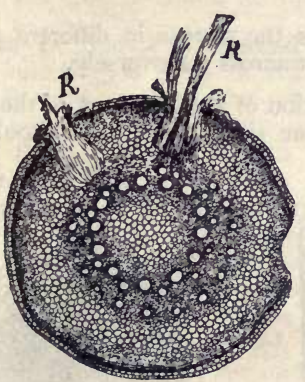

FIG. 93-Transverse section of the root of Maize. $R, R$, roots. (X12.) and mount it in glycerine. Examine, and note-

(i) The scattered vascular bundles (Fig. 94).

(ii) The vascular cylinder formed by the numerous vascular bundles.

(iii) A few roots which spring from close up to the vascular bundles may also be seen; in Fig. 94 they can be seen breaking their way through the external tissues.

Expт. 64.-From a stem of the Vegetable Marrow cut transverse sections. Select a thin one from these and mount it in water. Examine and note-

(i) The pith (which may have dropped out).

(ii) The vascular bundles in which there are a number of large open vessels.

(iii) The epidermis which presents a sinuous outline.

Expт. 65.-Make a thin transverse section through the wood of the Pine which has been kept in alcohol for some time to remove the resin. Mount in glycerine, and

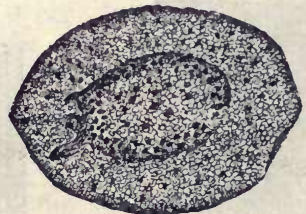

FIG. 94.-Transverse section of the rhizome of the Sweet Flag. $\left(\begin{array}{l}x \\ 2\end{array}\right)$ examine. Note-

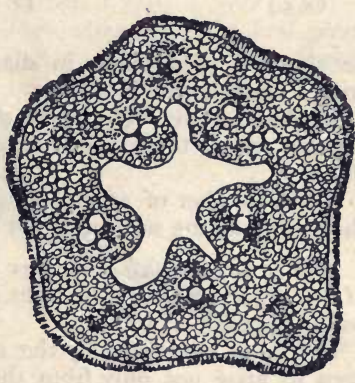

Fig. 95.-Transverse section of stem of Vegetable Marrow. The middle of section has dropped out. ( $\times$ 5.)

(i) The cells; these are small and close together (Fig. 97) in one part of the section, but large in the remaining portion.

(ii) The small thick walled cells are formed in late summer and autumn, 
the larger ones in spring and early summer. The small cells are dark coloured; these form the dark portion of the annual ring. The large cells are light coloured and form the lighter coloured portion of the annual ring.

ExPT. 66. - Cut a radial longitudinal section through a young stem of the Pine. Note-

(i) The cells are cut through lengthwise (Fig. 96), and some of them show a pitted arrangement.

(ii) A few fine lines will seem to cross the section in different parts ; these are the walls of cells which are cut across transversely.

ExpT. 67.- Prepare a transverse section of a young root of the Pine, which has been kept in spirits for some time. The root should not

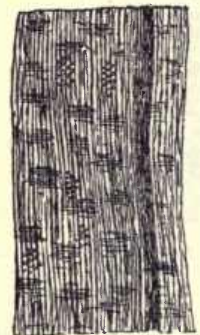

FIG. 96.-Radial section of wood of Pine. $(\times 5$.

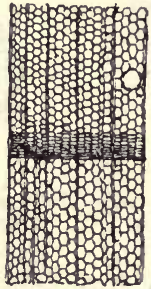

Fig. 97.-Transverse section of wood of Pine. $(\times 6$.

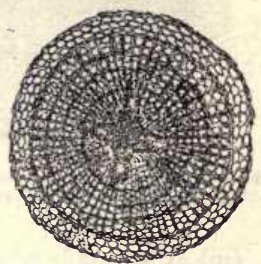

Fig. 98.- Transverse section of young root of Pine. $(x 7$.

be above $\frac{1}{8}$ of an inch in diameter. Mount in glycerine. Examine with a hand-lens. Note-

(i) Around the outer part a series of cells which are arranged in regular rows; these are cork cells, and form the protecting tissue of the root.

(ii) A number of annual rings which have the same appearance as those seen in the section of the stem of the Lime.

ExpT. 68.-Make a number of transverse sections through the stem of the Rose on which prickles are found. Select a thin section which passes through a prickle.

If this is examined by the aid of a hand-lens, the prickle will be seen to arise not only from the epidermis (Fig. 99), but also from a portion of the cortex.

ExpT. 69.--Obtain a leaf of the Rhododendron, and bleach it by placing it in alcohol for a few hours. Cut a thin transverse section. This can be done by placing the leaf between slices of Potato, Carrot, or Elder pith. If a sharp razor be used, and slices be cut across the embedding substance so as to pass through the leaf, a number of sections will be obtained. Place these in water or alcohol in a watch glass, and 
pick out the thinnest. Mount in glycerine. Examine with the high power of the hand-lens. Note-

(i) The mid-rib, which is the most prominent part of the section. In the centre of this a vascular bundle will be seen.

(ii) The epidermis which covers the whole surface of the leaf.

(iii) The ground tissue which comes between the lower epidermis and the upper.

How to Use a Compound Microscope The following is a set of rules to direct the student how to use the compound micro. scope :-

(1) Before commencing to use the microscope it must be examined to see if it is perfectly clean. If any mounting media or reagents find their way on to the stage, clean them off at once with a soft clean cloth.

(2) To examine the lenses, the light must be directed up through the tube by the mirror. If the eye-piece be rotated, and specks of dust move with it, they are on the lenses of the eye-piece. The lenses must be unscrewed, and the dust cleaned off with a soft silk rag. If the

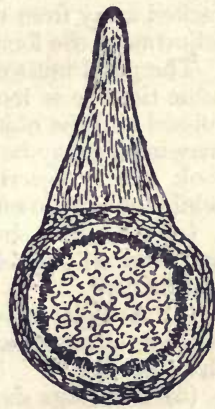

FIG. 99. - Transverse section of stem and prickle of Dog Rose. $(\times 4$. dust does not rotate with the eye-piece, it is on the objective, which must be cleaned in the same way. If either glycerine or Canada balsam is smeared on the objective, it must be cleaned by a jet of water directed on to it from a wash-bottle and then be carefully dried. Canada balsam is removed easily by alcohol or benzol.

(3) To examine a specimen on a slide-screw on the low power obiective. and move the mirror until the whole field is illuminated.

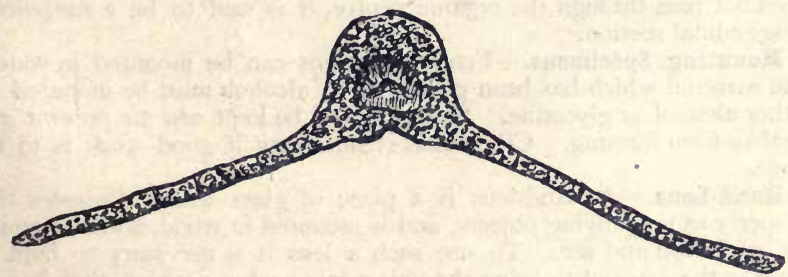

FIG. 100.-Transverse section of leaf of Rhododendron. $(\times 8$.

Then rack the tube down until it nearly touches the slide; if the tube is now racked up very slowly the object will come dimly into view. In most cases a good view can be obtained with a low power without using the finer adjustment, but if there is any difficulty the fine adjustment can be used. 
With a high power the method of finding the focus is the same, only greater care is required. If the $\frac{1}{6}$ objective is used, it can be racked down until the image of the objective appears to meet the objective when the specimen is nearly in focus. If the tube is gently racked away from the slide it will come into view, and with the finer adjustment the focus can be found.

The pupil must on no account rack the tube towards the object at the same time he is looking down it. If this is done the object may be missed and the objective may be forced through the slide. The section may in this way be damaged and the lens ruined. The best way is to look at the objective until it is nearly close to the object, and then, while looking down the tube, rack it away until the object becomes clear.

(4) An object should always be examined with the low power first, and after all possible detail has been made out with this, the high power can be used.

(5) A high power must never be used unless the object is covered with a cover-glass. This prevents the mounting media from touching the objective.

(6) Drawings shonld always be made of the objects examined. This practice compels attention to details, and tends to produce the habit of close observation. In drawing, a fine pointed pencil should be used, and the drawings made either on good cartridge paper or Bristol board. The drawings should always be made to scale.

\section{SumMary.}

Sections of a plant can oe made in three directions. If the section of the stem is made at right angles to its long axis it is called a transverse section. When the section is made in the direction of the long axis of the stem and passes through the organic centre, it is a radial longitudinal section. If the section passes lengthwise through the stem but does not pass through the organic centre, it is said to be a tangential longitudinal section.

Mounting Specimens.-Fresh specimens can be mounted in water, and material which has been preserved in alcohol must be mounted in either alcohol or glycerine. Sections must be kept wet to prevent air bubbles from forming. Cleanliness is necessary if good work is to be done.

Hand-Lens. - A hand-lens is a piece of glass which possesses the property of magnifying objects, and is mounted in wood, horn, or mietal for protection and use. To use such a lens it is necessary to hold it close to the eye and to bring the object into such a position that it can best be seen.

Cells. - Plants are built up of elements which receive the name of cells. A cell is surrounded with a cell-wall, and contains protoplasm.

Tissues are formed by the union of a number of cells. There are three kinds of tissues; they are-

Epidermal tissue;

Vascular tissue;

Ground tissue. 
The Compound Microscope is an instrument which consists of lens and accessory parts. Such an instrument is used for the examination of the minute parts of plants.

\section{Questions on Chapter VI.}

(I) What do you understand by the term "section"? What kinds of sections can be made from a stem?

(2) Write a set of rules to guide you in mounting sections.

(3) Why, in mounting sections, must a cover-glass be placed over the object ; and how is such a cover glass put on?

(4) Explain what is meant by air-bubbles, and how they find their way into sections.

(5) A hand-lens and a transparent section are given to you. How should the lens be used so as to examine the section?

(6) What is a cell ? Of what parts does a cell consist?

(7) A Tomato is given to you to make a preparation showing the cells. Explain how you would proceed to do this.

(8) Explain what is meant by the term "tissuc." What kinds of tissue can be found in plants?

(9) Give an account of the structure of the stem of the Sunflower, and compare it with the stem of the Maize.

(Io) Explain the term annual ring, as applied to woody trees. How is it that each ring is formed of a light coloured layer and a dark coloured layer? 


\section{CHAPTER VII}

THE HISTOLOGY OF THE CEII,

The Cell.-All parts of plants agree in being built up of microscopic elements which have received the name of cells (p.65). The cells which are present in a woody plant, such as the Oak, may be living or dead. Dead cells perform an important function in giving firmness and rigidity to the plant. They may also conduct water from the roots to the leaves, and protect the deeper parts of the plant from injury. Cells may be separate, as in the ripe pulp of the Tomato, but in most cases they are united to form a tissue. Cells vary very much in form and development, and upon this will depend the kinds of tissue which they may produce. It will be an advantage to begin by studying the individual cell.

The Structure of a Cell.-As living cells change with age it will be better to take a young cell and to follow it until it

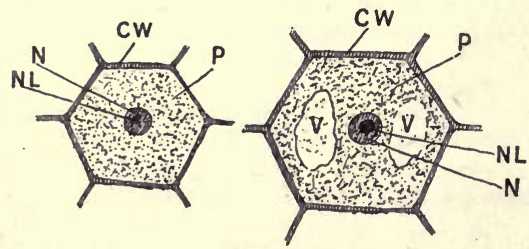

FiG. ror.-The left-hand.figure, a young parenchyma cell; the right-hand figure, an older cell. CW, cell-wall; P, Protoplasm; N, nucleus; NL; nucleolus; $\mathrm{V}$, vacuoles. becomes mature. In a young cell, such as can be seen in the cortical ( $p$. 66) tissue of the stem of most plants, the following three principal constituents can be distinguished. On the outside a mem-

brane separates the cell from others which surround it, and is called a cell-wall. In close contact with the whole surface of the cell-wall, and filling the entire cavity of the cell, is the protoplasm. Embedded in the protoplasm is a denser granular portion which is called the nucleus. 
Formation and Growth of the Cell-Wall.-The cellwall is verystrong and elastic, and is formed from and by the protoplasm, and its increase in thickness and area depends upon the vital activity of such protoplasm. The cell-wall may grow in area owing to the stretching caused by the pressure set up inside the cell, but throughout this increase in size new material is deposited to strengthen it. In some cases the stretched cellwall breaks, and the ruptured edges separate. The break is commonly repaired by the deposition of a plug of new material which connects the disconnected surfaces.

The cell-wall grows in thickness by the deposition of successive layers on the internal surface of the first-formed layer. This kind of growth is termed growth by apposition. The subsequent growth of the cellwall by the deposition of new material between the old is called growth by intussusception. As a general rule growth

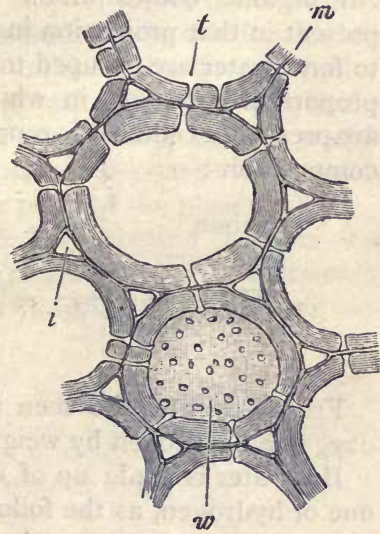

FIG. 102.-Cell with thickened wall. $m$, middle lamella; $t$, pit; $w$, pitted transverse wall. $\left(x_{300 .}\right)(\mathrm{S}$. in thickness does not take place until after a cell has reached its full size. When such a cell-wall is examined by the high power of the microscope, it exhibits a stratified appearance; this is owing to the constituent layers acting on the light differently. All the markings which are found on cell-walls are due to the unequal deposition of the new material during growth in thickness. The spiral, annular, and pitted walls, for example, which are found in the wood of most plants, are caused by this unequal growth.

The Chemical Composition of the Cell Wall.-If a few cells be treated with iodine-stain ${ }^{1}$ the cell-wall will assume a yellow colour, and the further addition of a single drop of

1 Iodine-stain is made by dissolving crystals of potassium iodide in distilled water until a strong solution is made and then adding crystals of iodine. If this is diluted with distilled water to the colour of brown sherry it is ready for use. The alcoholic solution is made in the same way, only alcohol is used instead of water. 
strong sulphuric acid causes the yellow colour to be replaced by a deep blue.

This reaction is characteristic of a substance termed cellulose. We may consequently conclude that the cell-wall consists principally of such cellulose. Cellulose consists of three chemical elements, known as carbon, hydrogen, and oxygen. All organic bodies which have the hydrogen and oxygen present in that proportion in which these elements are present to form water are grouped together as carbohydrates. The proportion by weight in which carbon, hydrogen, and oxygen are present in cellulose is represented by the following percentage composition :-

$$
\begin{aligned}
& \text { Carbon . . . . . . } 4444 \\
& \text { Hydrogen . . . . . 6 6 } 17 \\
& \text { Oxygen . . . . . . } 493^{8} \\
& 99.99 \text { (= } 100 \text { very nearly.) }
\end{aligned}
$$

From this it will be seen that there is eight times as much oxygen as hydrogen by weight in cellulose.

But water is made up of eight parts by weight of oxygen to one of hydrogen, as the following analysis shows :-

$$
\begin{aligned}
& \text { Hydrogen . . . . I I I } 136 \\
& \text { Oxygen . . . . 8 88.864 }
\end{aligned}
$$

Hence, we are justified in classing cellulose as a carbohydrate.

Mineral substances such as silica, carbonate of lime, and compounds of iron are also found deposited in cell-walls.

Chemical Changes which the Cell-wall may undergo.-I. A portion, or all, of the cell-wall may become cuticularised. This is caused either by a change in the cellulose, or by the deposition of cutin in the cell-wall.

The epidermal cells of some leaves afford a good example of cuticularisation. If a section of a leaf of the Rhododendron be touched with iodine and sulphuric acid, some of the layers of the wall of the epidermal cells will assume a deep blue colour; the colour is deepest in the inner layers, the outer layers not 
showing it at all. The external layer of the epidermal cells is called cuticle, which is almost impermeable to water.

The walls of corky cells have the same properties as cuticularised cell-yalls, and they give the same reaction with iodine. The corky walls consist of a substance called suberin. Both cutin and suberin contain about 74 per cent of Carbon.

2.-The cellulose of the cell-wall may, owing to the deposition of lignin in the wall, become lignified. A lignified wall gives a blue colour when treated with aniline chloride and hydrochloric acid. Lignification, while it makes the cell-wall harder and more elastic, does not prevent water being able to readily traverse it. Lignification takes place most largely in woody tissue, and to a less extent in other parts of the plant.

3.-In some cases the cell-wall may become more or less mucilaginous. This change is caused by the conversion of cellulose into mucilage, which may be either a form of cellulose or a form of gum.

ExPT. 70. -Obtain a small quantity of Spirogyra, which is found in ditches and ponds during summer. Mount some of it in water, and examine it under a low power of the microscope. Note-

(i) That the filament is surrounded by a cell-wall.

(ii) That each cell contains protoplasm.

(iii) That a nucleus is present in the protoplasm.

Place a small quantity of Spirogyra in a watch glass and cover it with iodine solution. Mount it in water and examine it first with a low power, then with a high power. Note-

(i) The cell-wall is but slightly stained yellow.

(ii) The protoplasm is coloured a deeper yellow or brown.

(iii) The nucleus is still more deeply stained than the protoplasm.

ExPT. 71. - Take a Date stone and scrape away the brown coat. Cut sections from the reserve material (which is cellulose) stored up in the seed. This can be done by using either the heel of the razor or a strong knife. Mount a thin section in glycerine, and examine first under a low power and then under a high power. Note-

(i) The thick cell-walls with a number of thin places called pits in them; the membrane which closes those pits is called the closing membrane, and is, in reality, the primary cell-wall. For this reason the closing membrane is sometimes called the middle lamella (Fig. Io2).

(ii) The granular protoplasm.

(iii) Soak a section for a few minutes in iodine, and mount in glycerine. The cell-wall is stained slightly yellow.

(iv) Mount another section which has been soaked in iodine and a drop of strong sulphuric acid. Examine it under a low power only. Observe how the cell-walls swell, lose their sharp outline, and assume 
a blue colour. (Siee that no sulphuric acid finds its way on to the microscope).

EXPT. 72. - Take some cotton wool and first soak it in alcohol for half an hour to drive out the air. Mount it in water. Examine it first under a low power, then under a high power. Note-

(i) The twisted filaments, which consist of single cells.

(ii) The thick colourless cell-walls.

(iii) The remains of the protoplasm seen clinging to the interior of the cell-walls.

(iv) Treat a small quantity with iodine solution-the walls stain slightly yellow.

(v) Add a drop of strong sulphuric acid after the cover-glass has been removed, when a distinct blue colour will be seen.

Evidently cotton consists principally of cellulose.

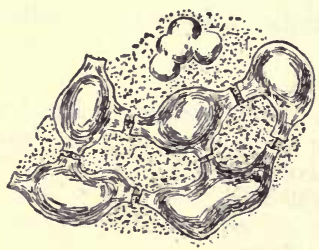

FIG. 103.-Section of endosperm of Date. $\left(x_{4}\right.$ oo. $)$

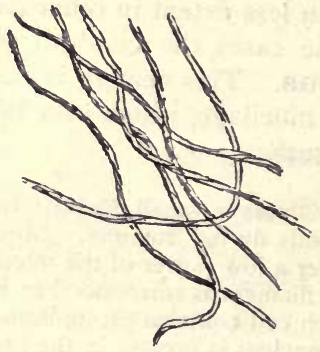

FIG. 104.-Cotton fibres.

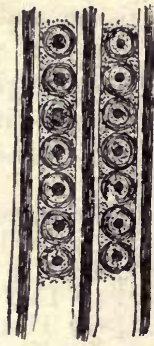

Fig. 105.-Longitudinal section of a Match, showing pits.

ExpT. 73.-Cut sections from a cork and soak them in alcohol. Mount the thinnest in water and examine with the microscope. Observe :-

(i) The cell-walls, which have a clear outline. The cells have lost their contents.

(ii) Treat another section with iodine solution, the walls stain yellow.

(iii) Treat another section with iodine and sulphuric acid, the walls stain yellow or brown, not blue; neither do they swell with sulphuric acid, but keep their outline.

EXPT. 74.-Cut sections from a wooden match and soak them in alcohol to remove the air bubbles. Mount a thin one in glycerine, and observe the cell-walls, which are seen to have a number of pits (Fig. 105).

(i) Treat a section with iodine ; it stains yellow.

(ii) Treat another section with iodine and sulphuric acid; it swells and stains brown.

Note.-A cellulose wall can thus be distinguished from a lignified or a corky wall because it gives a blue colour with iodine and sulphuric 
acid. A lignified wall is stained brown and swells, and a corky wall is stained brown but does not swell.

EXP'T. 75. - Soak some Linseed seeds in water, and note how they swell. The outer layers of the seed, which were hard and horny, have been converted into mucilage.

Make a section from a dry seed and mount in glycerine and water. Examine with a low power, and notice the wall swells and the striations on it become very clear.

The Protoplasm. - The protoplasm is the living and active part of the cell. It is a semi-solid material, which has embedded in it a number of granules, and is kept moist by the cell-sap, which saturates the whole of the cell.

It is probable that the protoplasm consists of a number of fibres which cross in all directions to form a net-work, the meshes of which are filled in with a more fluid substance.

In living cells the protoplasm is always in close contact with the cell-wali ; but if the temperature of the cells be raised to $120^{\circ} \mathrm{F}$, the protoplasm coagulates, i.e., sets like the white of an egg when boiled. In this state it loses all power of movement and dies. Alcohol or weak acids produce similar result.

The Composition of Protoplasm.-If a few cells are treated with iodine, the protoplasm is coloured brown. This is the same colour which the substances called proteids give with iodine, and it seems very probable that protoplasm is built up of proteids.

A proteid is a substance which contains Carbon, Hydrogen, Oxygen, Nitrogen, and Sulphur. The essential element of a proteid is nitrogen, and in some cases the name nitrogenous substance is used in place of proteid. The proportion of the above elements in living protoplasm is not known. If an analysis is made of protoplasm it is necessary to kill it in the process, and there may be a difference between the composition of living and dead protoplasm. Protoplasm certainly contains the same elements which are found in proteids. It is the most wonderful substance in the universe, because life is never found apart from it. There appears to be no difference between the protoplasm of plants and that of animals.

The Movement of Protoplasm.-The protoplasm of a plant cell possesses the power of movement. These movements can be observed in large cells with thin and transparent walls, cspecially when the colourless protoplasm contains a large number of granules. These granules are driven backwards and forwards with the stream, and they appear much as particles of 
mud would do in a swiftly moving river. When the granules in their movements go round and round the interior of the cell, the movement is called rotation.

In an old cell where the protoplasm does not completely fill the interior of the cell the spaces are termed vacuoles. Vacuoles are filled with cell-sap. The connection between the protoplasm in different parts of the cell is kept up by strands of protoplasm. In such a cell the granules move up one strand and down another, much as the blood corpuscles move in the blood stream. This latter movement, which is more complex than that of rotation is called circulation. The individual granules in the current can be seen to move with unequal rapidity, according to their sizes, the smallest moving fastest.

The currents in the protoplasm are apparently irregular, now advancing, now retreating, sometimes suddenly arrested, and commencing again with increased rapidity. The movements depend upon temperature. In winter, during frost, and in summer, during dry weather, they are arrested. In spring, when there is plenty of moisture and a fair amount of heat, they are seen at their best.

ExPT. 76.-Obtain a plant of the American Water Weed (Elodea) and mount a single leaf in water. Place a cover-glass on, and examine with a high power. Note-

(i) The cells and the granules in the protoplasm.

(ii) The movement of the granules; they move round and roundthis is rotation.

(iii) Gently'warm the slide over hot water. Examine again. The temperature being raised the granules move faster.

(iv) Now hold the slide either over a gas flame or a spirit lamp until the water boils. Examine again. There is no movement, the protoplasm has been killed.

Expт. 77. - Remove a portion of the epidermis of a Stinging Nettle and mount it in water; examine with the low power. Notice-

(i) The hairs; focus one in the centre of the field and, using the high power, observe-

(ii) The cell is wider at the base than at the apex of the hair ; examine the protoplasm, nucleus, vacuoles, and cell-wall.

(iii) The granules are seen in a state of motion; they move up one of the strands and down another-this is circulation.

EXPT. 78. - Remove a small portion from near the core of an American Apple. Mount in water and examine under a low power ; foçus a cell 
near the centre of the field and proceed to observe a single cell with the high power. Make out-

(i) The cell-wall, protoplasm, nucleus, and racuoles?

(ii) Treat with iodine solution; the protoplasm is stained brown, and the nucleus a very dark brown.

(iii) Treat a freshly prepared specimen with salt solution ( $2 \frac{1}{2}$ per cent.). The wall retains its original position and appearance, but the protoplasm contracts and leaves the walls. This is known as plasmolysis.

(iv) Wash out the salt solution with water and examine again; the protoplasm slowly regains its original position.

The contraction of the protoplasm is due to the salt solution attracting the water from the cell; and it regains its original position when water again is taken in.

The Nucleus.-The nucleus is a denser portion of the protoplasm; it stains a deeper colour when treated with iodine solution. In shape the nucleus is somewhat oval, and in its interior a distinct rounded body called a nucleotus may be present. It is built up of proteids, and contains a large quantity of phosphorus. A nucleus is present in all cells, and this seems to show that the presence of such a body is necessary to the life of the cell. It is always formed from a preceding nucleus. The exact function of the nucleus is not known, but in every case of cell-production the nucleus divides first. It has been suggested that the nucleus is the most important part of the cell, and that it forms the protoplasm which surrounds it.

The Difference between a Young and Mature Cell.-A very young cell is completely filled with protoplasm. As the cell increases in size the cell-wall grows faster than the protoplasm, causing cavities, which become filled with cell-sap, to appear in it. These cavities are called vacuoles, which in a very old cell may be very large.

The Contents of the Cell. - The cell always contains a number of other substances in addition to the protoplasm and the nucleus. In fact, at one time or another, it contains every element that the plant contains, for the protoplasm is the active material of the cell, and produces all the organic substances found in the plant. The vacuoles and all parts of the cell are saturated with cell-sap. The protoplasm contains granules, which, according to their nature, are variously known as chloroplists, leucoplasts, and chromoplasts. Starch and Aleurone grains are also found in cells, while futs and, in some cases, crystals of calcium oxalate may be present. 
The Cell-Sap is the watery fluid which saturates the protoplasm and the cell-wall, and also occupies the vacuoles ; it consists of water which holds in solution a number of organic and inorganic substances. The substances in solution are either on their way to be built up into protoplasm, or have themselves been formed by previously existing protoplasm. The organic substances present in cell-sap are sugar, organic acids, proteids, and in many cells colouring matter. The inorganic substances are chlorides and sulphates of potassium and sodium. Solid bodies, in addition to these dissolved substances, may also be present in the vacuole, e.g., starch grains, aleurone grains, and raphides or needle-like crystals of calcium oxalate.

Chloroplasts. - In the cells building up the green parts of plants a green colouring matter is present called chlorophyll. In all the higher plants the chlorophyll is found in the form of granules known by various names, as chlorophyll grains, chlorophyll corpuscles, or chloroplasts. A chloroplast is a small mass of protcplasm saturated with chlorophyll. This is shown to be the case when a cell which contains chloroplasts is treated with alcohol. The chlorophyll is dissolved out, and colourless grains are left behind; these are called leucoplasts.

It is only in those cells which are exposed to light that chlorophyll is developed. The conditions necessary for the development of chlorophyll, are :-

(a) a certain temperature, a few degrees above the freezing point ;

(b) light ; any light will do if it is only intense enough ;

(c) a small quantity of iron in the food of the plant. The necessity of iron for the development of chlorophyll is very interesting, for no iron is found in the chlorophyll itself. The iron is probably necessary in the chemical changes which result in the formation of chlorophyll.

From what has been said about light being necessary for the formation of chlorophyll, it will be understood why it is found only in the surface cells. The important function of chlorophyll, which can only be exercised in the presence of light, is to absorb the carbon dioxide in the atmosphere, and to split it up into carbon and oxygen. The oxygen is returned to the air, but the carbon combines with the elements of water to form sugar 
which is eventually converted into starch. The starch grains are formed inside the chloroplasts.

Chloroplasts ultimately undergo decay, when, as in the case of falling leaves, all that is left of them are a few yellow granules. During autumn the nutritive matters in the cells of the leaves are carried to other parts of the plant to be stored up for future

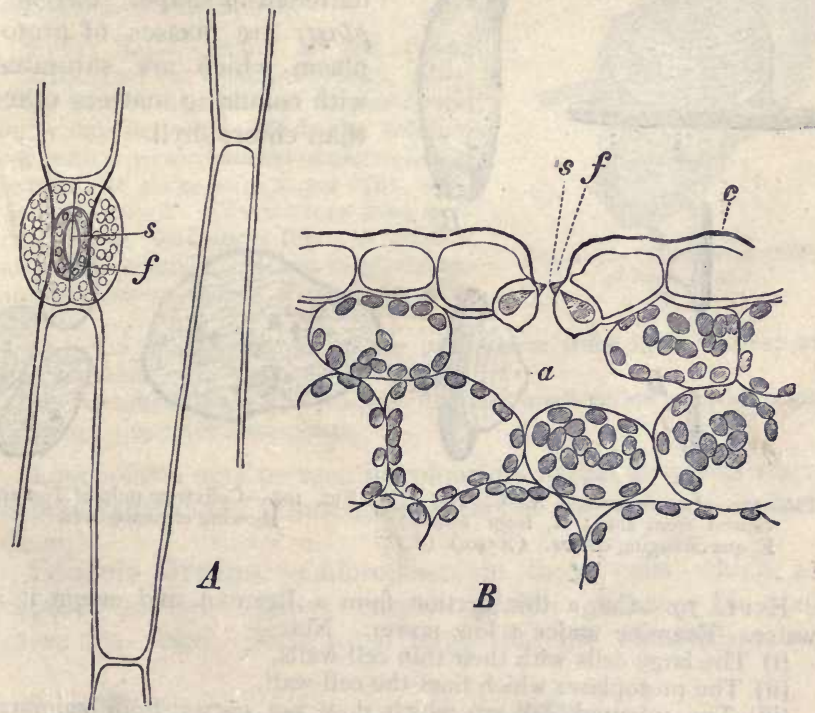

Fig. 106.-Epidermis from under side of a leaf of Iris, showing chloroplasts. $A$, surface view ; $B$, in transverse section; $s$, stoma ; $a$, air cavity $; f$, depression ; c, cuticle. $(\times 240).(\mathrm{S}$.

use ; and with these nutritive materials the greater part of the chloroplasts are removed. In the Copper Beech the chlorophyll is masked by colouring matter, which is dissolved in the cell-sap.

Leucoplasts. - In those cells not exposed to light, colourless granules are found ; these are called leucoplasts. Leucoplasts may be converted into chloroplasts if the cell in which they are present is exposed to light. The change of colour which a Potato may undergo when exposed to light is owing to some of 
the leucoplasts being converted into chloroplasts. The leucoplasts perform the important work of converting sugar into starch. The starch grains are produced on the outside of the leucoplasts, not inside as in the chloroplasts. They are of

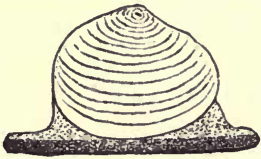

$A$

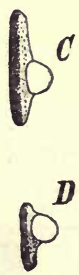

FiG. 107.-Leucoplasts. A, C, D, E, viewed from side; $B$, from above ; $\mathrm{E}$, one changing colour. $(\times 540$.$) (S.)$

a denser consistency than chloroplasts, and somewhat flattened in shape. Chromoplasts are masses of protoplasm which are saturated with colouring matters other than chlorophyll.
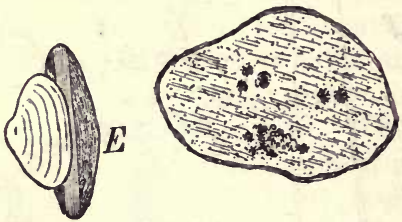

FIG. 108.-Cells from pulp of Tomato, showing chromoplasts.

EXPT. 79. - Cut a thin section from a Beetroot, and mount it in water. Examine under a low power. Note-

(i) The large cells with their thin cell-walls.

(ii) The protoplasm which lines the cell-wall.

(iii) The coloured cell-sap which does not escape from uninjured cells.

(iv) Dip a fresh section in alcohol for half a minute, before examining it. The coloured sap oozes out because the protoplasm has been killed.

ExPT. 80. - Obtain a few Fern Prothalli from a gardener. Mount a small one in water, and examine with a low power. Note-

(i) The cells crowded with chlorophyll corpuscles.

(ii) Many of the chlorophyll corpuscles are undergoing division, as is shown by their shape. Grains shaped like an hour glass are undergoing division.

(iii) Place a prothallus in a watch glass and cover with alcohol, and leave it for half an hour. Mount and examine. Note-The colouring matter has been dissolved out of the corpuscles, but they still retain their outline. 
Expt. 81.-Sow a few mustard seeds in two plant pots; keep the soil noist; place one in a dark place and the other in a light place. Observe from day to day. Note-

The stems and leaves of those plants kept in the dark are far longer than those grown in the light, but they are pale yellow or dirty white in colour.

Those grown in the light are bright green. Light is necessary for the de: velopment of chlorophyll,

ExpT. 82. - Obtain a few young Potatoes and cut them into slices. Place them in a weak solution of picric acid for a day or two. Wash the solution out with a weak solution of alcohol, and harden the slices in a 70 per cent. solution of alcohol. Cut sections from near the surface, and stain them in alcohol and iodine solution. Mount in glycerine, and examine under a high power.

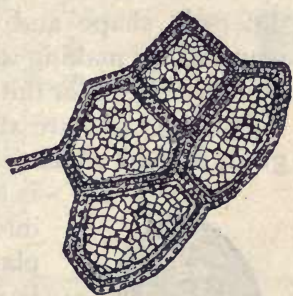

FIG. Iog.-Cells from prothallus of Fern. (20.) Note-

(i) Some of the granules in the protoplasm stain blue. These are starch grains.

(ii) Attached to some of the starch grains small yellowish bodies may be seen; these are leucoplasts.

Leucoplasts may be seen in colourless tissue in which starch is being stored up. Underground tubers and rhizomes contain them.

Starch Grains.-Chloroplasts in those cells which are exposed to light always contain starch grains. In many cases the starch grain is so large that the chloroplast only
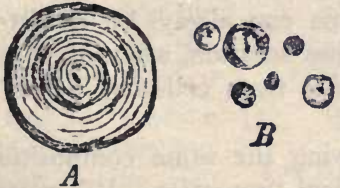

FIG. II0.-Starch grains of Wheat. $A$, large ; $B$, small grains. $\left(x_{540 .)}\right.$ (S.)

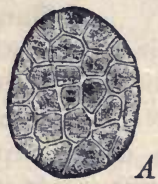

[i]
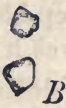

FIG. III.-Starch grains of Oats. A, compound grains; $\mathrm{B}$, isolated grains. $(\times 540$.$) (S.)$

surrounds it as a thin covering. Chloroplasts are always forming starch at the expense of the sugar which is produced by the constructive activity of the chlorophyll and the protoplasm. In the green parts of plants starch grains are very small because 
they are always undergoing a change due to the action of a ferment found in the cells. This ferment, which is called diastase, reconverts the starch into sugar. Large starch grains are only found in those parts of plants where they are stored up for future use. Each plant produces a starch grain which differs in shape and size from the grains produced by other plants. By making use of this fact, adulterations of foods can be detected under the microscope.

Starch grains are always striated. The organic centre of the grain around which it grows by the deposition of new material
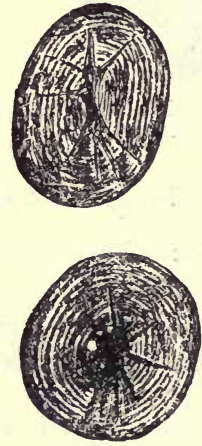

FIG. II2, - Starch grains from seedleaves of Bean. (X 540.) (S.) is termed the hilum. The hilum is produced by the activity of either the chloroplast or the leucoplast, and the successive layers which are deposited are also due to the same activity. Starch grains grow in the same way that a cell-wall grows in thickness, that is, by apposition or by intussusception. In some cases compound grains may be found in cells. These can be divided into two kinds, (a) those called spurious, which are produced by two or more grains coming together and uniting as a result of pressure, (b) true compound grains which are produced by the same leucoplast, and round which there are always a number of layers which bind the grains together.

Starch grains can always be detected in cells by treating them with iodine solution, when they give a deep-blue colour. They thus differ from cellulose which only gives a yellow colour with iodine.

Starch is a carbohydrate having the same composition as cellulose but differing in its physical properties. When treated with potash solution starch swells up, and if boiled with water will form a paste. If heated while dry, starch is converted into dextrine and becomes soluble.

Aleurone Grains.-Aleurone grains, or as they are sometimes called, proteid grains, are found in many seeds. Each aleurone grain is built up of a crystalloid and a globoid. The crystalloid is composed of albumen or proteids, and a 
globoid is formed of a double phosphate of lime and magnesia. If a section of a Castor Oil seed be made and examined by the high power of the microscope, the aleurone grains will be seen to be embedded in the protoplasm, which is also rich in oil. The proteids are stored up in plants principally in the form of aleurone grains. They are large in oily seeds
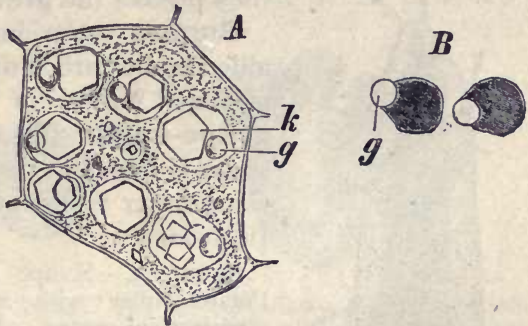

Fig. Ir3.-A, cell from the endosperm of the Castor Oil plant; $\mathrm{B}$, aleurone grains; $g$, globoid ; $k$, crystalloid. ( $\times 540$.) (S.)

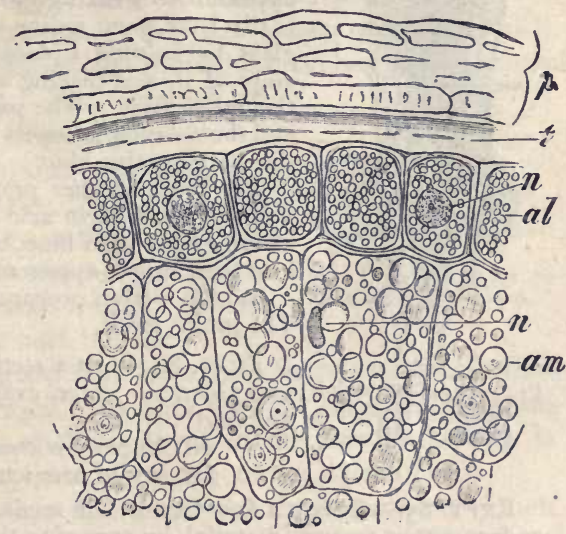

FIG. IJ4.-Section of grain of Wheat. $p$, pericarp; $t$, seed coat ; al, aleurone grains; $a \mathrm{~m}$, starch grains ; $n$, cell nucleus. of the seeds of the Castor Oil plant, Rape, Flax, and in the fruit of the Olive. The non-nitrogenous substances stored up as reserve material in the above plants occur as drops of oil. When the seeds germinate the fat is converted into sugar.

Raphides. - In most plants crystals of calcium oxalate are 
found. They are always found in vacuoles, and when needleshaped are called raphides. In many monocotyledonous plants

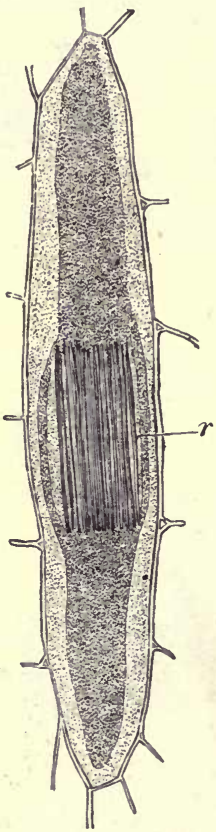

FI 3. I I5.-Cell, with a bundle of Raphides. ( $x$ I60.) (S.) they protect the plant from snails, slugs, \&c.

Sugars.-Various kinds of sugars and allied bodies are found in the cell-sap. The principal forms of sugar thus found are grape-sugar and cane-sugar. Grapesugar is found in the fruit of the Grape, and Cane-sugar is found in the Sugar-cane and Beetroot.

ExPT. 83.-Scrape a freshly cut surface of a Potato tuber with a knife, and mount the scrapings in water. Examine first with a low power and afterwards with a high power. Note-

(i) The numerous starch grains which appear very bright. Observe the hilum and the stratified appearance of each grain.

(ii) Run some iodine solution under the coverglass by holding a piece of blotting paper at one edge of it, and placing a drop of the solution on the other edge. The paper soaks up the water, and the solution takes its place. The iodine stains the starch grains blue.

(iii) Treat another preparation with chlor-zinciodine, ${ }^{1}$ which is an acid solution of iodine. The starch grains stain blue, but they also swell up and lose their bright appearance.

(iv) To a fresh preparation add potash solution. The grains swell.

EXPT. 84. - Cut a section from the Potato tuber and mount in water, examine with a high power and find

(i) A spurious compound grain.

(ii) A true compound grain.

EXPT. 85.-Obtain a few Castor Oil seeds, and expose the pearly endosperm or reserve material by removing the outer covering. Cut a thin section of the endosperm and mount in olive oil. Examine with th: high power. Note-

(i) The aleurone grains or proteids granules.

(ii) Find the crystalloid and globoid in the grain.

Expт. 86.-Cut sections from a cotyledon of the Almond, and mount in water.

Observe the bright-looking drops in the water; they are oil drops.

1 Chlor-zinc-Iodine (Schulze's solution) consists of a mixture of zinc dissolved in pure hydrochloric acid, and a small quantity of potassium iodide dissolved in water. It is an acid solution of iodine. 
Formation of New Cells.-It is necessary that new cells should be produced so as to ensure growth and also to continue the life of the plant. The mode in which new cells are produced will depend upon the kinds of organs in which the
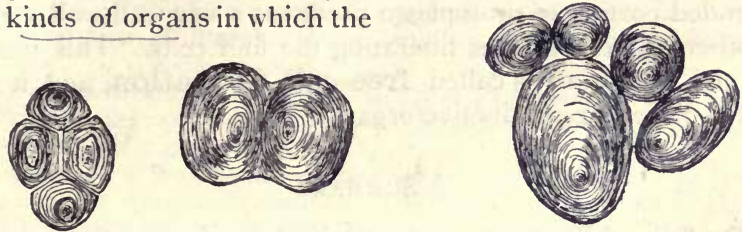

FIG. 116.-Starch grains from Potato. The left-hand figure shows a spurious compound grain; the middle a true compound grain; and the right-hand figure ordinary starch grains.

division takes place. Cell-formation goes on in two different sets of organs, viz., vegetative and reproductive.

The vegetative parts of a plant are those portions which are of service to the life of the individual, such as root, stem, branches and leaves. The method of cell-formation in all these organs is by simple division. In this case the nucleus first divides into two, the protoplasm then separates into two parts, and a cellwall is formed between the newly formed nuclei. Two cells are thus formed. These

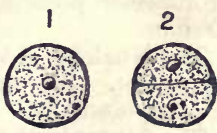

FIG. I17. - Diagram to illustrate cell division. cells are at first only half the size of the parent cell, but they grow and become as large as the cell from which they were formed. In this method of cell formation there is only a portion of the cell-wall of the new cell which is new, the remaining portions belonging to the parent cell.

The reproductive parts of a plant are those portions which are concerned in the propagation of the species. They are a tax on the individual which bears them, for such individual must find the whole of the material necessary to give the offspring a start in life. In all the higher plants this is done by the production of seeds, which produce new individuals, and so keep up the continuity of the species. Cell-formation in reproductive organs is characterised by a rounding off of the protoplasm : and no portion of the parent cell-wall aids in the formation of new daughter cells. 
The parent cell contains a nucleus, which, as before divides into two, and each part again divides, and thus there are four nuclei in the cell. The protoplasm now divides into four masses and each portion arranges itself around a nucleus. Each rounded portion of protoplasm produces a new cell-wall and the mother wall disappears, liberating the four cells. This method of cell formation is called free-cell formation, and it only takes place in reproductive organs.

\section{SUMMARY}

The Cell.-All parts of plants are built up of microscopic elements called cells, which may be living or dead.

The Structure of a Cell. - Each living cell consists of-

(I) The cell-zuall, built up of cellulose.

(2) The protoplasm, which lines the cell-wall.

(3) The nucleus, a denser portion of the protoplasm.

Changes which the Cell-wall undergoes. - It may become-(I) Cuticularised, (2) Lignified, (3) Mucilaginous.

Protoplasm. - The protoplasm is the living portion of the cell. It contains the elements carbon, hydrogen, oxygen, nitrogen, and sulphur. Protoplasm possesses the power of movement. It may rotale or circulate.

The Nucleus.-All cells possess a nucleus, and in it a nuclcolus may be present. It is built up of protoplasm, and contains a large quantity of phosphorus.

The Contents of the Cell. - The cell may contain-

Cell-sap.
Chloroplasts.
Leucoplasts.
Chromoplasts.

Starch grains.

Aleurone grains.

Fats.

Crystals.

Chloroplasts are masses of protoplasm containing a green colcuring matter called chlorophyll. The conditions necessary for the production of chlorophyll are-

(I) A certain intensity of light.

(2) A temperature above the freezing point.

(3) A small quantity of iron in the food.

The functions of the chloroplasts are-

(I) To absorb carbon dioxide from the air.

(2) To split up the carbon dioxide into carbon and oxygen.

(3) To form starch from sugar.

Leucoplasts are masses of colourless protoplasm. They form starch in those parts of the plants not exposed to light.

Chromoplasts are masses of protoplasm saturated with other colouring matter than chlorophyll.

Starch Grains are formed (1) by chloroplasts in organs exposed to 
light, (2) by leucoplasts in the underground stems, roots, \&c. Starch grains grow by afposition and intussusception.

The hilum forms the organic centre of the grain. Successive layers are deposited round the hilum, thus giving the grain a stratified appearance. A ferment (diastase) can convert starch into sugar. Starch grains may be simple, spuriously compound, or truly compound.

Composition of Starch.-It is built up of the same elements as cellulose. It is a carbohydrate.

Aleurone Grains. - The proteids found in plants are stored up as aleurone grains and proteid crystals. Each aleurone grain consists of a crystalloid and a globoid.

Formation of New Cells. - New cells are produced by (I) simple cell division, (2) free-cell formation. The former method takes place in vegetative organs, the latter in reproductive organs.

\section{Questions on Chapter VII}

(I) Describe the structure of a young cell, and explain how it differs from a full-grown cell.

(2) How is the cell-wall formed, and how does it grow in thickness?

(3) To what are the markings due which can be found in cell-walls?

(4) Give an account of the composition and properties of cellulose.

(5) Describe the structure of a living parenchymatous plant cell. What chemical elements enter into the composition $(a)$ of the cell-wall, (b) of the protoplasm?

(6) How can you distinguish by the aid of the microscope a cellulose wall from $(a)$ a lignified wall, $(b)$ a corky wall, $(c)$ a mucilaginous wall ?

(7) What is protoplasm? What do you know about the properties of protoplasm?

(8) What is meant by the circulation of protoplasm?

(9) Enumerate and give a brief account of the most important substances which are found in cells.

(10) What is a chloroplast? Where are chloroplasts found? What work can they perform which makes then useful to the plant?

(II) Give an account of the conditions which are necessary for the development of chlorophyll.

(12) What is a leucoplast? How may a leucoplast be converted into a chloroplast? Why are leucoplasts said to be starch builders?

(I3) What is the nature of starch? How is it formed, and what are its uses?

(I4) To what sulbstance do the green parts of plants owe their colour? State and explain the nature of the work which green parts of plants are alone able to perform.

(I5) What is an aleurone grain? Where are aleurone grains found?

(I6) How are new cells formed? What kinds of cell-formations are there?

(I7) Explain clearly how starch is formed in a Potato, and from what source it is derived. (1899.) 


\section{CHAPTER VIII}

\section{THE HISTOLOGY OF THE TISSUES}

Kinds of Cells.-All cells can be classed according to their shape into (a) Parenchyma, and (b) Prosenchyma.

A parenchyma cell is one in which the diameter of the cell is about the same in every direction. Cells of this description

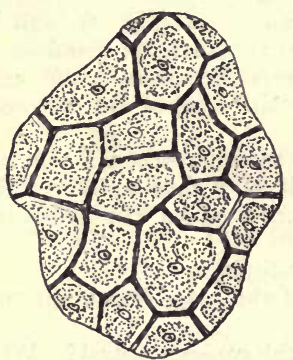

FIG. Ir8. - Parenchyma cell from fruit of Bean. $\left(x_{500 .}\right)$ are especially abundant in the succulent parts of plants. The ground tissue of a plant is composed of parenchyma cells, and in many cases they form a storehouse for reserve material, as in the turnip. When such cells are very numerous in an organ they are said to form parenchymatous tissue.

\section{A prosenchyma} cell is long and narrow. Cells of this description may lose their living contents and become filled with air and water. If a number of prosenchyma cells are placed end-toend so that the transverse walls are at right angles to the long side walls, the transverse walls may become perforated, and so form a vessel. The living contents of the cells become absorbed after the transverse walls are

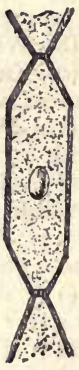

FIG. Irg.-Diagram of Prosenchyma cell. broken down, and eventually the fully formed ressels contain only air or water. The markings on the walls of the vessels supply the botanist with their characteristic names. 
If the walls are pitted (p. 78) they are called pitted-vessels. When the thickenings of the walls appear to form a spiral, the vessels are spoken of as spiral (Fig. I20). When the markings give to the vessel a reticulate or netted appearance, such vessels are termed reticulate (Fig. I20). If the transverse walls have been perforated by a single round opening while the rest of the walls remain to form thick rings the vessels are called annular. Vessels of the above kinds are found in the wood of all plants. The walls of all such
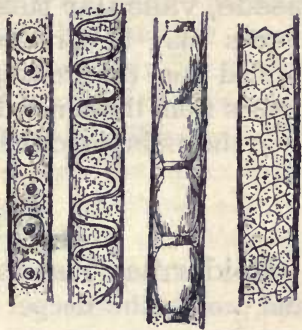

FIG. I20.-Pitted, spiral, annular, and reticulate vessels. vessels are lignified.

Sieve Tubes.-In the formation of the sieve vessels or sieve tubes the transverse walls are not completely broken down, but they are perforated by fine canals through which the protoplasm passes-for such vessels keep their living contents.

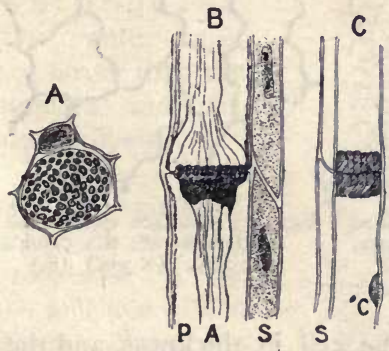

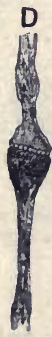

Fig. 121.-Parts of sieve tubes from Vegetable Marrow. A, surface view of sieve plate; B, C, longitudinal sections, showing sieve plates; $\mathrm{D}$, contents of sieve tube; $\mathrm{S}$, companion cells ; PA, protoplasm ; C, lateral sieve plate. ( $\times 270$.$) (After Strasburger.)$

The wall whiclı contains the perforations is called a sieve plate. In some plants the longitudinal walls may become similarly perforated so that sieve plates are also formed there. The walls of sieve tubes are always unlignified, and the vessels contain a watery cellsap. In close contact with the sieve tubes, and formed from the same cells during development, long narrow cells are formed, and these are called companion cells. The nuclei of the sieve tubes are broken up and disappear, but the companion cells keep both their protoplasm and nuclei.

Kinds of Tissues. - When a number of cells are intimately connected, and perform the same kinds of work, they are 
spoken of as forming a tissue. In the higher plants there are three kinds of tissue systems, they are called epidermal tissue, vascular tissue, and ground tissue. The above tissues may be primary or secondary. Primary tissues are formed from the growing cells of the embryo, and the secondary tissues from those new layers of growing cells which are formed from the embryonic cells.

\section{EPIDERMal Tissue}

Epidermal Tissue.-Those cells which cover the plant and protect the deeper parts from injury, form the epidermis.

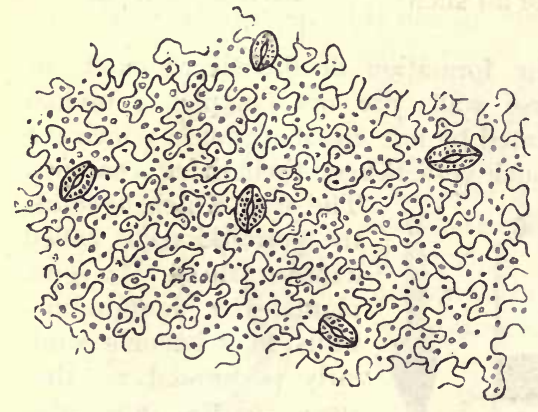

FIG. 122.-Surface view of the epidermis from under side of leaf of Balsam, showing stomata. (X r6o.) (S.)

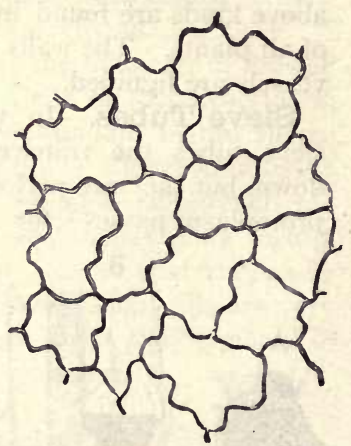

FIG. 123.-Surface view of the epidermis of the Dog's Mercury. ( $\times 300$.$) (S.)$

As a rule the epidermis is only one cell in thickness, and the cells do not contain any chlorophyll. The protoplasm of the epidermal cells is reduced to a very thin layer which lines the cell-walls, and the cavities of the cells contain a colourless cellsap. The outer wall of the epidermal cells forms a cuticle, which protects the deeper tissue from a too rapid loss of water.

Stomata are found in the epidermis of all those parts of plants which are exposed to the air. Each stoma is a minute opening between two cells which contain chlorophyll and are called guard-cells. The stoma is formed by a young epidermal cell becoming divided by a septum into two equal cells. 
The septum then splits open, the opening constitutes the stoma, and the cells form the guard-cells. The size of the stoma depends upon the movement of the guard-cells. The stomata are found on all the green parts of plants, but they are most

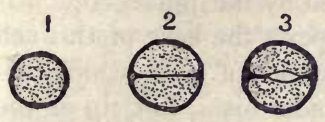

F1G. I24.- Diagram illustrating formation of stoma. I, young epidermal cell; 2 , division of cell; 3 , the cell-wall split to form the stoma.

numerous on the under side of the leaves. If both sides of a leaf are alike, the stomata will be equally developed on both the upper and lower surfaces. In those plants with floating leaves the stomata are found on the upper side only.

Stomata can open and shut by the change in the shape of the guard-cells. The interchange of gases between the interior of the plant and the external atmosphere-froin which interchange the plant obtains energy and food material-goes on through the stomata, which also give out watery vapour.

Some plants have openings in the epidermis by which they give out water in a liquid state. Such openings are called wat er-pores. The water - pores are larger than the stomata and are always open.

Hairs. - From the epidermis hairs are produced $(a)$ for protection (b) for the nutrition of the plant. When the hair consists of a single cell it is said to be unicellular; if a number of cells enter into the composition of a single hair it is termed

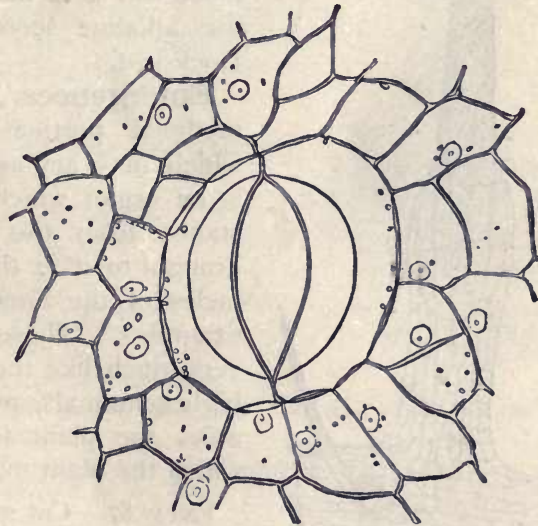

FIG. 125.-Waterpore, with a portion of epidermis from a leaf. $(\times 240$.$) (S.)$ a multicellular hair. The former are found on the roots of plants, where they take in water containing minerals in solution. The latter 
are found on the stem, leaves, and flowers of most plants. The unicellular root-hair is produced by the outgrowth of an epidermal cell.

On the surface of the stinging nettle a very large number of hairs are produced. If one is examined by the microscope it is seen to consist of a single cell at the apex ; the base of this cell

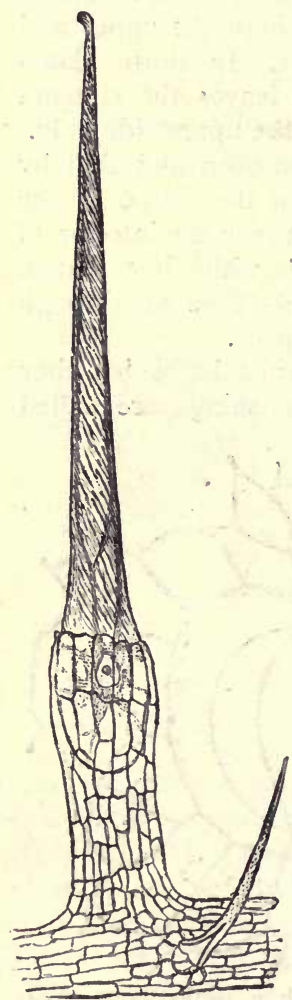

FIg. 126.-Stinging hair of Nettle. $(\times 60$.$) (S.)$ is fixed in a number of cells which belong to the epidermis. The tip of the hair of a stinging nettle is strengthened with silica, while the rest of the hair contains carbonate of lime. In the terminal cell a poisonous fluid is produced. When an animal touches the plant the stiff pointed hairs enter its skin and the poisonous fluid is poured into the wound. The well known smarting sensation which a person feels when "nettled" is due to this acid fluid. The well known method of rubbing the wound with a Dock leaf is to neutralise the acid with the alkaline secretion present in the Dock leaf.

Emergences. - Emergences are modified portions of the epidermis which may act as glands. A gland is an organ which secretes some substance from the materials which are brought to it in the cell sap. The tentacles of the Sundew are well known examples. These secrete a substance very much like the gastric juice of the higher animals, and this secretion enables the plant to digest any insects which the plant may catch.

EXPT. 87.-Cut sections from a Turnip or from a Potato; mount the thinnest in water. Note-

(i) The shape of the cells. They are parenchyma cells.

(ii) The contents of the cells. These consist principally of protoplasm and starch grains. 
Expr. 88.-Obtain either the stem of the Pumpkin or of the Cucumber; harden in alcohol. Cut either radial or tangential longitudinal sections. Stain in iodine solution, and mount a few in glycerine. Note-

(i) The sieve tubes, the transverse walls of which are clearly seen owing to the substance which surrounds them being stained dark brown, the wall only staining faintly yellow.

The substance which surrounds the sieve plates is called callus, and it is probably composed of cellulose. The amount of callus present will depend upon the age of the sieve tubes, and the season of the year.

(ii) The protoplasm which lines the tubes and is well developed just over the sieveplates.

(iii) The shape of the sieve tubes.

(iv) The companion cells. These are long and narrow and their nuclei can be clearly seen under the high power.

Expr. 89. - From the lower side of the leaf of the Wallflower pull off a small portion of the epidermis; this can be done by raising the epidermis with a knife and gently pulling at it; as a rule the edge of the piece of epidermis will be thin enough for examination. Mount in water, and examine it with the high power. Note-

(i) The sinuous outline of the cell-wall.

(ii) The spindle-shaped hairs which lie close to the surface of the leaf.

(iii) The stomata, which are very numerous. Each stoma is surrounded by a pair of sausageshaped cells - the guard-cells.

ExpT. 90.-Strip from the underside of the leaf of the Hyacinth (the leaf of any monocotyledonous plant will do as well) a small portion of the epidermis. Mount in water and

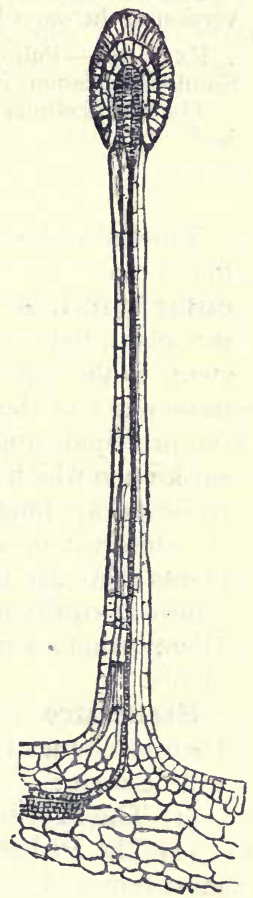

FIG. 127.-Digestive gland of the Sundew. $(\times 6 \circ).(\mathrm{S}$. examine first under a low power, then with the high power. Note-

(i) The epiclermal cells.

(ii) The stomata, which are very large and numerous.

Strip from the upper surface of the leaf a piece of epidermis and treat in the same way.

(iii) Compare its appearance with the lower epidermis and note in what ways they agree and how they differ.

ExpT. 9r.-Mount in water the root of a germinating Mustard Seed ; examine it under a low power. Note-

(i) The root-hairs ; these are unicellular, and are formed by the outgrowth of the cells of the epidermis. 
(ii) To some of the root-hairs particles of soil adhere.

This adhesion of the root-hairs to particles of soil is due to the conversion of the outer layer of the cell-walls into mucilage.

ExPT. 92.-Pull off a small piece of the epidermis of a leaf of the Sunflower; mount in water, and examine under a low power. Note-

The multicellular hairs which are scattered over the surface of the leaf.

\section{VASCULAR TISSUE.}

Vascular tissue.-If a skeleton leaf be examined it will be found to consist of a number of hard fibres ; these are the vascular bundles. These bundles form the conductive tissue of the plant, that is, they conduct water from the roots up the stem, to the leaves, and the elaborated sap from the leaves to those parts of the plant which need it. Such bundles are also the principal supporting tissue of the plant and form the framework upon which the softer parts are fixed. The bundles always resist decay longer than the other parts of the plant, and in a skeleton leaf or stem are the only parts present. In the higher plants there are two principal types of vascular bundles, they are known as open and closed bundles. Open bundles are found in Dicotyledonous plants and closed bundles in Monocotyledonous plants.

Structure of Bundles.-If a vascular bundle of the Dicotyledonous type be examined under the microscope, there will be seen :-

(I) The Xylem, which is nearest the centre of the plant.

(2) The Phloem, which is always the portion of the bundle most removed from the centre of the plant.

(3) The Cambium, which lies between the xylem and phloem.

Xylem.-The xylem is the woody portion of the bundle, and in the vascular bundle of the stem it is always found nearest to the pith. It consists of a number of vessels and parenchyma cells. The vessels which are found in the xylem are spiral (p. 93), annular (p. 93), reticulated (p. 93), and pitted (p. 93). The spiral vessels are the nearest to the pith, then come the annular vessels, and these two kinds together make up the first-formed xylem, called protoxylem. The reticulate vessels come next, and the pitted vessels are to be found close up to the cambium. Scattered about among the vessels, fibrous cells are to be found. These fibrous cells are long and narrow, and in 
some cases have sharp-pointed ends. Prosenchyma cells are also found mixed up with the vessels (p. 92).

In addition to the vessels and the fibrous cells a number of parenchyma cells occur mixed with the vessels ; these parenchyma cells never fuse together.

Phloem. - The phloem consists of two portions which are known as the soft- and hard-bast. The soft bast is found close to the cambium and consists of sieve tubes, companion cells, and parenchyma cells. The sieve tubes (p. 93) are long vessels which have their transverse walls perforated. Companion cells-which can always be recognised in a longitudinal section of the bast because they are long narrow cells filled with protoplasm, and each possessing a large nucleus-are found with the sieve-tubes. In transverse sections companion cells appear as if they were originally cut off from the same cells as the sieve-tubes. Mixed up with the sieve-tubes and companion cells a few parenchyma cells may be found ; these are known as phloem parenchyma.

The hard bast is composed principally of bast fibres, which are long narrow spindle-shaped fibres, much-like the fibres of wood. Parenchyma cells are to be found mixed with the bast fibres.

Cambium.-The cambium is found between the xylem and phloem. It consists of cells which do not as yet show the characters of either xylem or phloem. Those cambium cells nearest to the phloem pass gradually into it, while those nearest the xylem eventually become the xylem. The cells near the middle of the cambium are thin walled, and contain protoplasm. They are in a state of constant division, and thus form new cells. The new cells on one side pass into and form new xylem. Similarly, on the other side new phloem is produced. A tissue composed of cells which can divide in this way is called meristematic, because it is capable of dividing up and producing new cells.

Open and Closed Vascular Bundles.-Those vascular bundles which possess a cambium are said to be open because they can produce new tissue. If the bundles consist of xylem and phloem only, without a cambium, they are termed closed bundles, because growth in thickness of the bundle cannot go on. When the xylem and phloem are in contact on one side only, they are said to be collateral. 
The general arrangement of the elements in an open vascular bundle is shown below in a tabular form.

\section{Near Pith.}

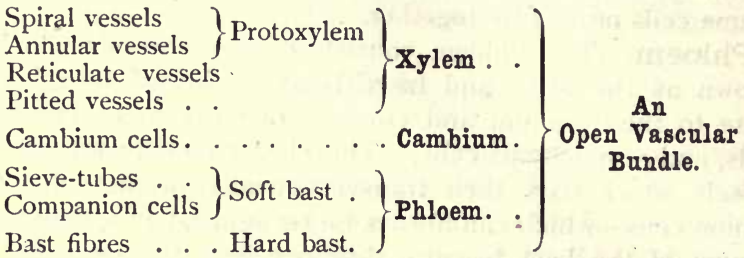

Bundle Sheath (Pericycle.)

The Monocotyledonous Type of Vascular Bundle.If a vascular bundle of a monocotyledonous plant be examined, there will be found two kinds of tissue present. They are :-

(I) The Xylem, which always points towards the centre of the stem.

(2) The Phloem, which is turned towards the exterior of the stem.

The structure of such a vascular bundle is much the same as in the dicotyledonous type, only the variety of vessels is not so great. The bundle is surrounded by a special sheath of thick walled cells.

The Course of Vascular Bundles.-If the bundle passes from the stem into the leaf, as most bundles do, it is called a common bundle, because it is common to both stem and leaf. The portion of the bundle in the leaf is termed a leaftrace. In a few cases the bundle never passes from the stem, and it is then spoken of as a cauline bundle.

The arrangement of the bundles in the stem depends upon the phyllotaxis (p. 36). If the arrangement of the leaves is $\frac{2}{5}$, the bundle which proceeds from the leaf will pass through five internodes before it joins on to the bundle below, as in the Wallflower.

If the leaves are decussate there will be four rows of leaves on the stem, and the bundle from any leaf will have to pass through two internodes only before it joins on to the bundle of the leaf below. Thus, the bundle which proceeds from a leaf will pass inwards for a short distance, then bend and pass down 
the stem until it joins on to the bundle below. The above are the arrangements in most dicotyledonous plants.

The course of the bundles in monocotyledonous plants is very irregular. The bundles from any leaf base pass into the stem towards the centre, then bend back and pass for some distance down the stem, when they join on to the bundles below.

ExPT. 93.-Obtain a piece of the stem of the Wallflower with a number of leaves on it, and trace out the course of the vascular bundles. To do this bisect it longitudinally so as to pass through the middle of a leaf; clear away the pith with a blunt knife. Note-

(i) That the bundle which enters the stem from the midrib of the leaf runs inwards for a short distance, then turns straight downwards, and ioins on to the leaf vertically below the first leaf.

(ii) That the bundle runs through five internodes without joining a bundle.

(iii) That there are two smaller bundles that act in the same way.

(iv) That in any section of the stem of the Wallflower there must be five large bundles and ten small bundles cut through.

Expr. 94. - Trace the course of the vascular bundles in the stem of the Deadnettle. Bisect the stem longitudinally, so as to pass through two leaves on the same side of the stem. Clear the pith away, and note-

(i) That the bundle which enters the stem runs inwards and then downwards, and joins on to the bundle of the leaf vertically below.

(ii) That the bundle only passes through two internodes before it joins on to the bundle below.

(iii) That in the stem of the Deadnettle there are four main vascular bundles, which correspond to the decussate arrangement of the leaves.

\section{The Ground Tissue.}

The Ground Tissue.-The tissue which is found in the centre of a stem and between the vascular bundles and the epidermis is called ground or fundamental tissue. It usually forms the principal part of the primary tissue of the plant, and can be arranged in three groups :-

The Pith within the ring of vascular tissue.

The Cortex between the ring of bundles and the epidermis.

The Medullary rays between the pairs of bundles.

The vascular bundles seem to be fixed in the ground tissue, which in a young stem appears to surround them. It may contain chlorophyll and be used for obtaining food.

While the epidermal tissue protects the internal parts of the plant and the vascular bundles perform the office of conduction and support, the ground tissue provides for the nutrition of the plant and forms a store for reserve material. 


\section{SUMMARY.}

Parenchyma cells are those in which the diameter is about the same in all directions.

Prosench jma cells are long and narrow.

Vessels are formed by the perforation of the transverse walls of cells which are placed end to end. The following are very common :-

Spiral vessels.

Annular vessels.
Reticulate vessels.

Pitted vessels.

Sieve tubes are formed from cells which have their transverse walls perforated to form sieve plates.

Tissues.-There are three tissue systems in a plant, viz. :-

Epidermal tissue, which covers and protects the deeper parts of the plant from injury.

Vascular tissue, which forms the supporting and conducting tissue of the plant.

Ground tissue, which fills in the spaces between the epidermal and vascular tissue.

Stomata are the small openings which are found between guard-cells in the epidermis of the aërial parts of plants.

Hairs may be either unicellular or multicellular. They may protect the plant from insect pests, or be used for taking in food.

Vascular bundles may be closed or open. If the bundle is open it will consist of (I) Xylem ; (2) Cambium ; (3) Phloem.

If the bundle is closed it will consist of (I) Xylem, and (2) Phloem.

The Course of Vascular Bundles depends upon the arrangement of the leaves on the stem.

\section{Questions on Chapter VIII.}

(I) How does a parenchyma cell differ from a prosenchyma cell?

(2) What is a vessel? How are vessels formed? Enumerate the different kinds which are found in wood.

(3) In what respects of structure and function do the vessels of the bast (sieve tubes) differ from those of the wood? (1892.)

(4) Describe fully the structure of a vascular bundle in the stem of a dicotyledon. Explain how such a bundle differs from that of a monocotyledon. (1894.)

(5) What is a stoma? On what parts of the plant are the stumata chiefly developed? How is a stoma formed?

(6) Give an account of the structure of the epidermis of a leat.

(7) What is a vascular bundle ? Of what parts does it consist ? ( 2898 .)

(8) What is the cambium? Explain where you would find it in the trunk of a tree, and what its importance is? (I898.)

(9) Describe the structure of a young parenchyma cell, and explain how it differs from that of a full-grown cell of the same kind. (I892.)

(Io) Explain what is meant by ground tissue. In what parts of a plant is ground tissue found?

(II) Give a short account of the longitudinal course of the vascular bundle in a dicotyledonous plant.

(I2) What kinds of hairs are found on plants? Of what use to the plant are hairs? 


\section{CHAPTER IX}

\section{The Histology of the Shoot and Root}

The Structure of a Dicotyledonous Stem.-A transverse section of a young dicotyledonous stem, when examined under the low power of the microscope, shows the following parts (Fig. 128). Externally the section is limited by a single layer of cells, many of which may produce hairs ; this is the epidermis. Inside the epidermis comes the cortex, bounded on the inside by a single row of cells called the endodermis. Inside the endodermis a broken ring of vascular bundles is found, which is surrounded on the

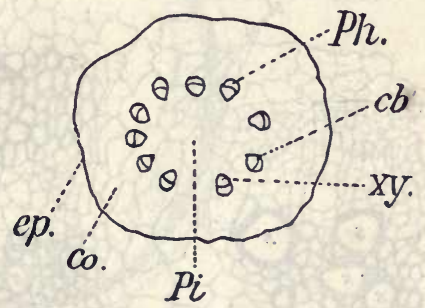

FIG. 128.-Transverse section of young stem of Sunflower, showing ten separate vascular bundles in the ground tissues. Ep, epidermis ; co, cortex ; $P i$, pith ; $P h$, phloem ; $c b$, cambium ; $x y$, xylem. outside by a layer of cells, known as the pericycle. The vascular bundles are divided from one another by a number of cells forming medullary rays. The centre of the stem is full of loose cells which form the pith.

\section{Outside.}

Epidermis

Cortex ... $\}$. Ground Tissue ...

Pericycle

Phloem .

Cambium

Xylem . .

Pith

Vascular Tissue

Transverse

Section of

Dicotyledonous

Ground Tissue

stem. 
In an old stem of the Sunflower the vascular bundles form a complete ring, and in such an old stem a complete ring of cambium passes through the bundles and across the medullary rays. Those parts of this cambium ring which lie between the vascular bundles are spoken of as forming the interfascicular cambium (p. 99). The interfascicular cambium is formed by the cells between the bundles becoming meristematic, i.e., they begin to divide up and so complete the ring. This portion of the cambium ring forms

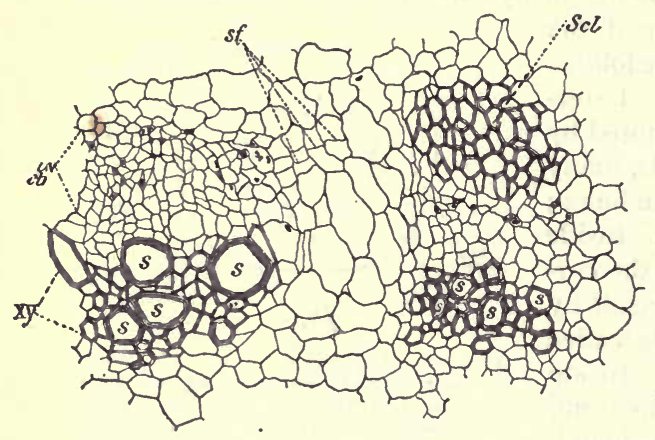

FIG. 129.-Transverse section of older stem of Sunflower, showing the first formation of interfascicular cambium. Ph. and $c b$, phloem and cambium; $x y$, xylem; $S c l$, sclerenchyma; $s$, spiral vessels; $s f$, interfascicular cambium.

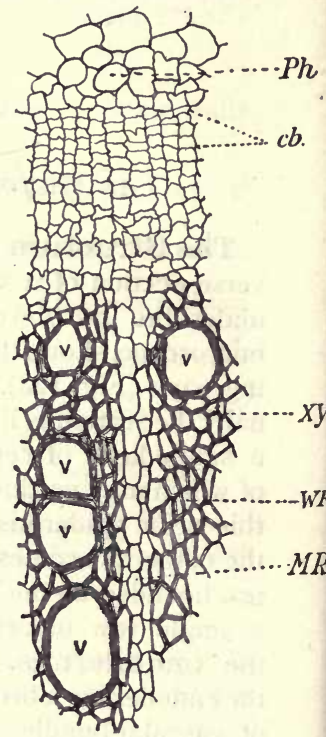

FIG. r30.-Transverse section of part of cylinder of old Sunflower stem; $P h$, phloem ; $c b$, cambium ; $x y$, xylem; $W F$, wood fibres; $M R$, medullary rays; $v$, vessels of xylem.

vascular elements which partly fill up the spaces between the bundles. The whole of the cambium during the active period of growth produces xylem on one side and phloem on the other. Thus, in an old stem the vascular cylinder is formed (p. 66).

ExPT. 95.-Cut transverse sections of a young stem of the Wallfower and mount in water. Look for a thin section, and note-

(i) The epidermis, a single row of cells which surrounds the cortex.

(ii) The cut ends of the vascular bundles.

(iii) The ground tissue forming the cortex and pith. 
ExP'. 96.-Transfer the thinnest section observed in Expt. 95 to alcohol, and let it remain for twenty minutes to bleach it. Now stain it with iodine solution, mount in glycerine, and examine a vascular bundle under the high power. Note-

(i) The endodermis, a single layer of cells containing starch. The starch grains stain blue.

(ii) The pericycle, a layer of cells inside the endodmeris.

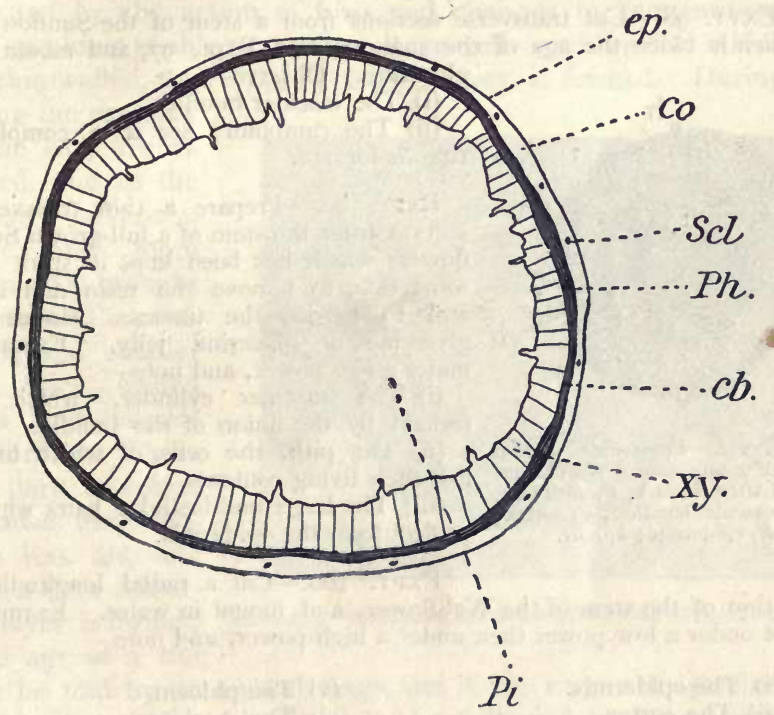

FIG. r31.-Diagram of old stem of Sunflower as seen in transverse section, showing an almost complete cylinder of secondary tissues, interrupted by medullary rays. ( $\times 6) E$.$p , epidermis ; c 0$, cortex; $S c l$, sclerenchyma patches; $P h$, phloem ; $c b$, cambium; $x y$, xylem; $P i$, pith.

(iii) The phloem inside the pericycle; the transverse walls of the sieve tubes will be stained yellow, and the perforations through which the strands of protoplasm pass may be stained brown.

(iv) The cambium, several layers of cells inside the phloem.

(v) The xylem between the cambium and pith. This can be easily recognised by the large cavities of the vessels.

(vi) The pith, which fills the interior of the stem.

Expт. 97.-Select a very young stem of the Sunflower. This can be obtained by germinating seeds, and planting out the young plants in plant pots. The stem should not be more than $\frac{1}{6}$ th of an inch in 
diameter. Cut transverse sections and mount in water. Examine under a low power. Note-

(i) The epidermis.

(ii) The cortex.

(iii) The vasscular bundles, which are not united.

(iv) The ground tissue between the bundles.

(v) The cambium, between the phloem and xylem.

ExPT. 98.-Cut transverse sections from a stem of the Sunflower, which is twice the age of the stem used in Expt. 97, and mount in

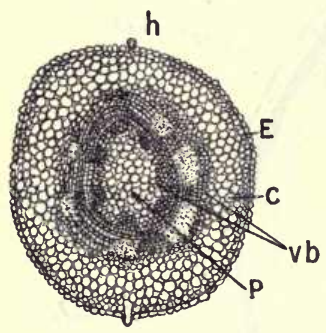

FIG. 132.-Transverse section of young stem of Wallflower. (After Scott.). $P$, pith; $v b$, vascular bundles ; $C$, cortex ; $E$, epidermis; $h$, hair. glycerine. Observe-

(i) The vascular bundles.

(ii) The cambium; see if a complete ring is formed.

ExPT. 99.-Prepare a thin transverse section from the stem of a full-grown Sunflower, which has been kept in spirit for some time to remove the resin and air, and to harden the tissues. Mount in glycerine or glycerine jelly. Examine under a low power, and note-

(i) The vascular cylinder, which is formed by the union of the bundles.

(ii) The pith, the cells of which have lost their living contents.

(iii) The large multicellular hairs which project from the epidermis.

Exp'T. 100.-Cut a radial longitudinal section of the stem of the Wallflower, and mount in water. Examine first under a low power then under a high power, and note-
(i) The epidermis.
(ii) The cortex.
(iii) The endodermis.
(iv) The pericycle.

(v) The phloem.

(vi) The cambium.

(vii) The xylem.

(viii) The pith.

\section{Growth in thickness of a Dicotyledonous Stem.-} In those perennial plants which possess open vascular bundles new additions are made to both the xylem and the phloem by the cambium which is between them. The xylem increases in size by additions to its outer surface, the phloem by additions to its inner surface, the central portion of the cambium remaining meristematic. Thus, every season new layers are produced, but far more xylem is formed than phloem. The rings which are seen in a cross section of the oak are produced 
by the action of the cambium and each ring marks a year's growth.

Each annual ring consists of a dark coloured layer and a light coloured layer. In spring, when the active period of growth commences, the pressure on the cambium is very little, because during the winter the bark and cortex have been ruptured by the action of frost and changes in temperature. The cambium is able to produce large cells and vessels which are thin-walled, thus a light coloured layer is formed. During spring the ruptures in the bark are repaired, and as the season advances, more and more pressure is brought to bear on the cambium, and smaller and thick - walled cells and vessels are formed. These are dark in colour because they contain less air, and thus a dark coloured layer is formed.

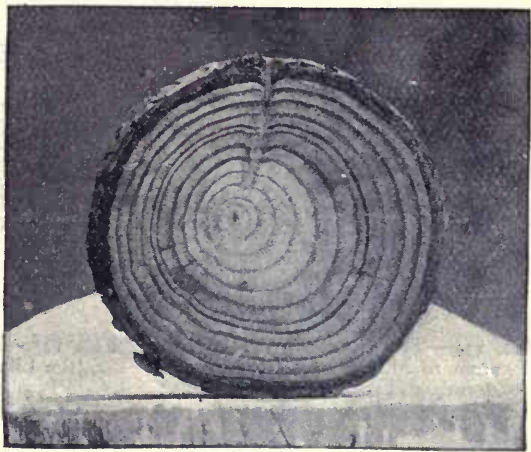

FIG. 133.-Section of Larch stem ; showing annual rings. The age of a tree

can be told by its annual rings, and if the rings are examined and compared the size of the layers will give us some clue to the kind of season when any ring was produced.

The Formation of Periderm.-In those plants which grow in thickness the epidermis is replaced by a new tissue which receives the name of periderm. The periderm is formed from the pericycle, which divides up into a number of rows of cells ; one of these rows forms the phellogen or cork cambium. The phellogen produces new cells on both its inner and outer surfaces; the cells on the inside keep their living contents and form the phelloderm ; those on the outside lose their living contents and their cellulose walls are converted into cork. The cork cells are impervious to water, and so cut off the supply of water to the cortex and epidermis ; these con- 
sequently dry up and aid in the formation of bark. The parts which form bark and periderm are shown below :-

Periderm $\left\{\begin{array}{l}\text { Phelloderm } \\ \text { Phellogen } \\ \text { Cork cells }\end{array}\right.$

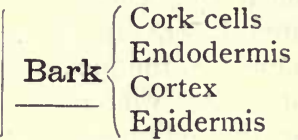

The primary phellogen after a time ceases its activity, and a deeper phellogen is formed. Still later, even this may discontinue

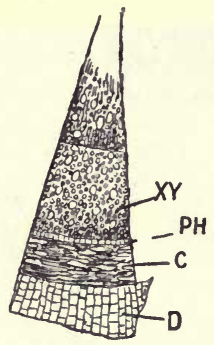

FIG. I34.-Transverse section through stem of Maple. D, dried up epidermis and cortex; $\mathbf{C}$, cork cells ; $\mathrm{PH}$, phloem ; XY, xylem. ( $\times$ I50.)

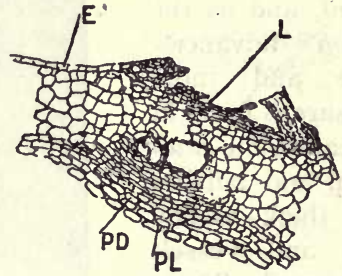

FIG. 135.-L, Lenticel from the stem of the Lilac. $(\times 25$.$) PD, phellogen ;$ PL, phelloderm; E, epidermis.

its function, until at last the new phellogens which are produced come to be formed in secondary bast. If the bark which is produced by these deeper phellogens is thrown off in scales it is called Scaly bark; this is found on the Pine and Plane tree. On the other hand, if the secondary bark forms complete rings which are concentric-ringed bark is formed, as in the Honeysuckle, Clematis, and Grape-vine.

Lenticels.-In the Periderm are produced small pores called lenticels. They are developed just beneath those places where the stomata existed in the epidermis. They are openings formed by the phellogen, which produces cells between which intercellular spaces are formed (Fig. 135).

ExpT. I0I.-Prepare sections of the flower stem of the White Lily, and if the stem is fresh, mount the thinnest section in water; if the material has been in spirit, mount in glycerine. Observe-

(i) The epidermis, a single layer of cells. 
(ii) The cortex, which is several layers of cells in thickness.

(iii) The pericycle, which is very strong and forms a thick ring.

(iv) The scattered vascular bundles, which are embedded in the ground tissue.

ExPT. 102. - Cut a transverse section of a two-year-old stem of the Wallflower. Mount in water, and examine under a low power. Note-

(i) The periderm, which is formed from the pericycle.

(ii) The bark, which is outside the phellogen or cork cambium.

\section{The Structure of a Monocotyledonous Stem.-If a} transverse section of a young stem of the Maize be made and examined by a low power the following parts will be seen, Fig. I36. On the outside an epidermis which consists of a single layer of cells. Immediately inside this, a broad band of thick-walled parenchyma forms the cortex. The cortex is a mechanical tissue and is the principal support of the plant. The remaining part of the stem is made up of scattered vascular bundles and ground tissue.

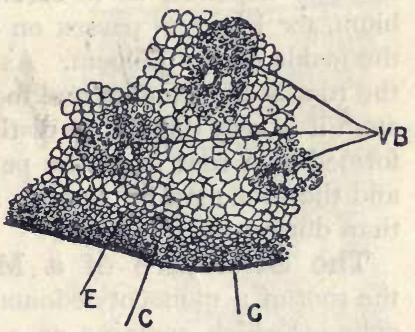

FIG. 136.-A portion of a transverse section of stem of Maize. (X 20.) E, epidermis; C, cortex; VB, vascular bundles. There is no cambium and

no growth in thickness can take place as a result of tha division of the cambium ring.

Structure of a Dicotyledonous Root.-If a transverse section of a very young tap-root of the Wallflower is examined the structure appears very different to that of the stem. On the outside the piliferous layer is formed; this is another name for the young epidermis of the root. Many of the cells of the piliferous layer are converted into root-hairs, hence the name. A root-hair is unicellular and is produced from a single cell of the epidermis. Inside the epidermis, and limited internally as in the stem by the endodermis, is the cortex. The centre of the root is occupied by a vascular cylinder which consists of two masses of xylem and two masses of phloem. The xylem masses alternate with the phloem masses. In the stem the protoxylem 
points towards the pith, in the root it points toward the cortex. The vascular cylinder is surrounded by the pericycle.

\section{Outside.}

Piliferous layer with root hairs

Cortex (parenchyma cells)

Endodermis (single layer of cells).

Pericycle (single layer of cells) . .

Phloem masses) (In wallflower two,

Xylem masses $\}$ which alternate). Inside.
Transverse section of

Dicotyledonous Root.

Growth in Thickness of the Root.-The roots of dicotyledonous plants in which the stem increases in thickness themselves also grow in thickness. The growth in thickness of roots depends, as in stems, upon the cambium. The cambium, see Fig. I28, passes on the outside of the xylem, and on the inside of the phloem. As growth goes on the structure of the root becomes more and more like the stem, until in an old stem it is very difficult to distinguish the two. Periderm is also formed in a root from the pericycle ; this cuts off the cortex, and the root may be smaller after the second year of growth than during the first year.

The Structure of a Monocotyledonous Root.-In the root of a monocotyledonous plant there is a large central cylinder which contains, as a general rule, a larger number of distinct bundles of wood and bast. In some roots there may be as many as twelve alternating masses of xylem and phloern. The structure is essentially the same, but because the cambium layer is absent, there is no growth in thickness.

ExPT. 103.- Select a young root of the Wallflower, and cut a thin transverse section from it, and mount in water. Examine under a low power. Note-

(i) The piliferous layer with its root-hairs.

(ii) The cortex, which is several layers of cells in thickness.

(iii) The endodermis, which is a single layer of cells surrounding the pericycle.

(iv) The pericycle, just within the endodermis.

(v) The alternating masses of phloem and xylem.

There are only two vascular bundles present.

EXPT. 104.-Obtain a bulb of the Hyacinth, and from one of the adventitious roots cut a thin transverse section, mount in water. Examine under a low power. Note-

(i) The central cylinder, which is limited by the endodermis and the pericycle.

(ii) The very numerous masses of xylem and phloem, which also show the alternating arrangement already seen in the Wallfower. 
The Structure of the Leaf.-Each leaf consists of the three tissue systems, but by far the largest portion is groundtissue. The whole of the leaf is covered by the epidermis, and between the upper and lower epidermis comes the Mesophyll. Fig. 138. The mesophyll is built up of palisade cells above, and spongy parenchyma below. Between the spongy parenchyma and the palisade tissue the vascular bundles run; these bring sap from the root to the cells of the leaf, and carry away the elaborated sap. The palisade tissue consists of regular, fairly elongated cells, which contain a very large number of chloroplasts, and only a few intercellular spaces. The spongy

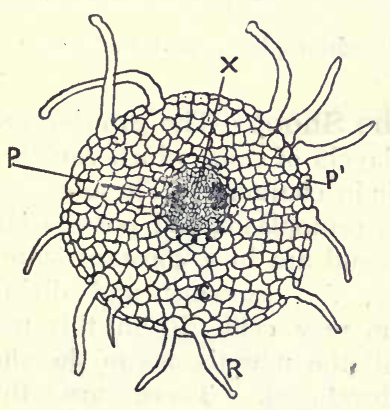

FIG. 137.-Transverse section of young root of Wallflower. (After Scott.) $\mathrm{P}$, phloem ; X, xylem ; C, cortex ; $\mathrm{P}$, piliferous layer ; $R$, root hair.

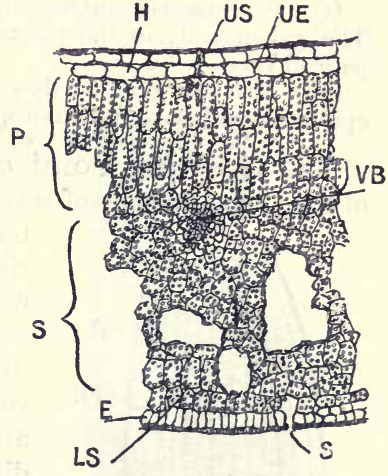

Fig. 138.-Transverse section of leaf of Rhododendron. ( $\times 250$.) US, upper side of leaf; LS, lower side of leaf ; $\mathrm{P}$, palisade parenchyma; $\mathrm{S}$, spongy parenchyma; VB, vascular bundle; $\mathrm{E}$, epidermis ; H, hypoderm.

parenchyma forms a loose tissue full of intercellular spaces. The cells of this tissue are not so well supplied with chloroplasts. The intercellular spaces of the leaf communicate with the stomata, so that any gas which may enter the stomata finds its way into the deeper parts of the leaf. The outside of the epidermis of the leaf is always of the nature of cuticle.

ExPT. 105.-.-Place a piece of the leaf of the Wallflower between little slabs of carrot, and with a sharp razor cut slices right across. Separate the transverse sections of the leaf so obtained in water in a 
watch glass. With a camel's hair brush mount the thinnest one in water, and examine first with a low power then with the high power. Note-

(i) The upper epidermis, a single layer of cells with an outer cuticle.

(ii) The palisade parenchyma, which consists of cells, cylindrical in form, with a few air spaces between them; the chloroplasts are very numerous in the cells.

(iii) The spongy parenchyma, which consists of loosely-arranged irregular cells with large air spaces between.

(iv) The lower epidermis with the stomata. Each stoma opens into a large intercellular space - the air chamber.

(v) That each stoma is a small opening between two guard-cells. Each guard cell is sausage-shaped and curved, the ends of the guardcells being firmly joined together.

(vi) The vascular bundles have the xylem above and the phloem belowe. The xylem ends in the palisade cells and the phloem in the spongy parenchyma.

(vii) That the guard-cells contain chloroplasts, and that the other epidermal cells have no chloroplasts.

The Growing Point of the Shoot.-The growing point of the shoot consists of several layers of cells, which are meris-

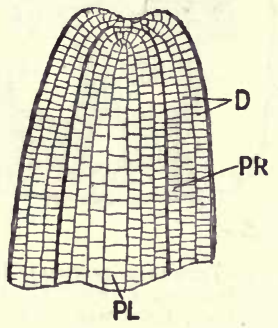

Fig. 139.-Diagram of the growing point of Shoot. $\mathrm{D}$, dermatogen; PR, periblem ; PL, plerome. tematic in character. These cells are rich in protoplasm, and possess large nuclei, and are in a constant state of activity, i.e., growing and dividing to form new cells. From this meristem all the new tissues of the shoot are developed. There are three distinct layers of cells at the apex, viz. :-

(I.) Dermatogen.-On the outer portion of the growing point a single layer of cells is present. These divide up by walls being formed at right angles to their surface. This layer gives rise to the epidermis of the young shoot, and is called the dermatogen.

(2.) Periblem.-Below the dermatogen a layer of cells is found, which, at the apex, may be only one layer of cells thick, but lower down may be several cells thick. This is the periblem or young cortex, for it forms the cortex.

(3.) Plerome.-Underneath the periblem is found a group of cells, which gives rise to the whole of the vascular cylinder of 
the stem, including the pith, the bundles, and pericycle. This layer receives the name of plerome.

Formation of Leaves.-Leaves are formed from the dermatogen and periblem. The dermatogen grows out and the periblem follows. From the dermatogen the epidermis only is formed, the mesophyll and vascular bundles being formed from the periblem.

Formation of Branches.-When a branch arises in the axil of a leaf, it is formed from the dermatogen and periblem, the plerome taking no part in it. Thus a branch is produced from the outer tissues of the stem, i.e., from the cortex and epidermis, and it is said to be formed exogenously.

The Growing Point of the Root.-All the new tissues of the root are produced from its apex. Though there are no

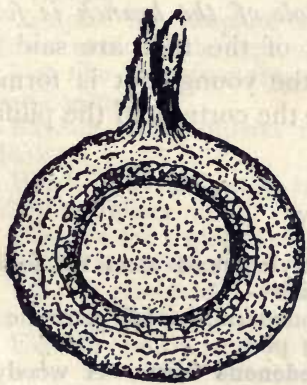

FIG. 140.-A transverse section of the stem of Ivy; showing origin of aèrial root. $(\times 8$.

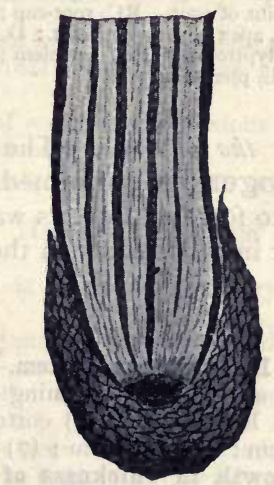

Fig. 141.-Root cap of Barley. (Magnified.)

leaves to be developed, there is a root-cap to form. If the young root of a Bean plant is held up to the light, two parts can be distinguished, a lighter outer portion and a darker inner portion. The outer portion is the root-cap, and the inner dark zone the growing point, which is protected by the root-cap. The growing point consists of three layers, as in the shoot. They are :-

(I.) The plerome, which forms the vascular cylinder.

(2.) The periblem, which forms the cortex. 
(3.) The calyptrogen (which is another name for dermatogen) forms the piliferous layer and the root-cap. . Cells are cut-off

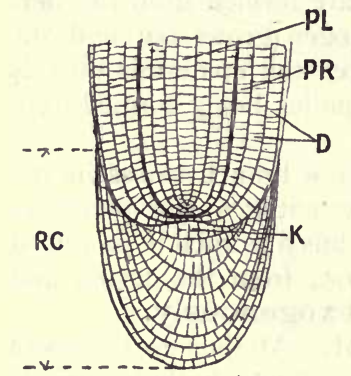

FIG. I42.-Diagram of growing point of root. RC, root-cap; $\mathrm{K}$, apex of growing point ; $\mathrm{D}$, calyptrogen; $\mathrm{PR}$, periblem ; PL, plerome. from the outside of the calyptrogen to form the root-cap. The root-cap by coming in contact with the sharp fragments in the soil protects the growing point from injury. It is worn away as it passes through the soil, and is repaired by the production of new cells by the calyptrogen.

Formation of Branches.The branches of the root are produced from the pericycle, or outer layer of the vascular cylinder. In the stem, as we have seen, the branches arise from the periblem and dermatogen, but in the root the whole of the branch is formed from the plerome. The branches of the root are said to be endogenously formed. When the young root is formed it has to force and eat its way through the cortex and the piliferous layer in order to reach the soil.

\section{Summary.}

A Dicotyledonous Stem.-In a dicotyledonous stem the following parts are present, beginning on the outside-

(I) Epidermis ; (2) cortex ; (3) endodermis ; (4) pericycle ; phloem; (6) cambium ; (7) xylem; (8) pith.

Growth in Thickness of a Dicotyledonous Stem.-A woody tree shows annual rings of growth which are produced by the activity of the cambium forming new xylem. Each ring consists of a dark coloured and a light coloured portion. The latter is produced in spring, the former in autumn.

Periderm is formed from the pericycle. The pericycle divides up and forms the phellogen or cork cambium, which forms on the inside a layer of cells which keep their living contents, and an outer ring of cells which lose their living contents. The former is called the phelloderm, and the latter the cork-layer.

Lenticels are openings found in the periderm.

A Monocotyledonous Stem differs from a dicotyledonous stem in having the vascular bundles scattered, and in no growth in thickness taking place.

Roots differ from stems in having alternating masses of phloem and 
xylem. Dicotyledonous roots grow in thickness by a cambium which forms new xylem and phloem. A monocotyledonous root only differs from that of a dicotyledon in having more masses of xylem and phloem and no secondary growth.

Leaves are outgrowths of the stem, and consist of -

(I) An upper epidermis; (2) palisade tissue ; (3) vascular bundles; (4) spongy parenchyma ; (5) lower epidermis with stomata.

Growing Point of Stem. - There are three layers of cells in the growing point of the stem, viz., (a) Dermatogen, which forms the epidermis ; (b) Periblem, which forms the cortex; (c) Plerome, which forms the vascular bundles and pith.

Growing Point of Root.-In the root there are three layers of cells from which all parts of the root are formed-(a) Plerome, which forms the vascular cylinder; (b) Periblem, which forms the cortex; (c) Calyptrogen, which forms the piliferous layer and root-cap.

\section{Questions on Chapter IX.}

(I) Describe the way in which the stem of a dicotyledonons tree grows in thickness, and explain how it is that its wood shows annual rings. (1889.)

(2) Compare the structure of the stem of a monocotyledonous plant with the structure of the stem of a dicotyledonous plant.

(3) Describe the structure of an ordinary foliage-leaf as seen in transverse section.

(4) Explain how periderm is formed. How does periderm differ from bark?

(5) What is a medullary ray? What is meant by primary and secondary medullary rays?

(6) Describe the structure of the growing point of the stem, and contrast it with that of the root. (1897.)

(7) What is cambium? What is its position in the stem of dicotyledonous plants, and what is its use? (I890 T.)

(8) Explain exactly how the root and the stem of any dicotyledonous plant differ from each other in structure, as seen in transverse section under the microscope.

(9) How does the branching of the stem differ from the branching of the root?

(10) How can the longitudinal course of the vascular bundles in any stem be determined?

(I I) What is a lenticel? On what parts of a plant are lenticels found?

(12) Describe the structure of the stem in any monocotyledon, as seen in longitudinal and in transverse sections.

(13) Briefly describe the chief anatomical differences between the stem of a monocotyledon and that of a dicotyledon. (I89r T.)

(14) The stem of an oak tree continues to grow in thickness so long as the tree lives, whereas the stem of a palm tree does not grow any thicker when once formed. Explain the cause of this difference. 


\section{CHAPTER $\mathrm{X}$}

THE PHYSIOLOGY OF NUTRITION

Physiology. - That division of botany which investigates the work which plants can perform is called physiology. Physiology shows us how each structure is adapted to the functions which a plant, or organs of a plant, can perform. In simple plants like Protococcus - which grows on walls, trunks of trees, and can live if it is only damp,-the entire body of the plant consists of a single cell, which performs all the work necessary both for the life of the plant and for the reproduction of its kind. In most multicellular plants, as we have seen, the constituent cells differ very much in structure, and this difference of structure is connected with the performance of some particular function.

In all the higher plants we obtain what is known as division of labour. Each special part of the plant has some special work to perform. The roots collect water and minerals; the leaves take in carbon dioxide; the stem conducts the water from the roots to the leaves; and the leaves from these materials form sugar, starch, cellulose, and proteids.

The striking attributes which especially characterise plants as living bodies, and by which they can be distinguished from nonliving bodies, are (i) that from time to time food is taken in and the plant grows, (ii) movements are carried out by the plant for its benefit, (iii) certain parts of the plant are separated, and these parts produce new individuals, i.e., reproduction takes place.

Nutrition.-Those processes which go on in a plant and by which it is able to form new material from the constituents 
of its food are spoken of as nutrition. The nourishment of the plant can only go on where food materials are taken in and so changed that they can become a part of the plant. If the foodsupply is not kept up the death of the plant is a foregone conclusion. Growth can only go on where the food-supply is in excess of that demanded for the production of the energy expended during its present activity.

The Composition of Plants.-The most abundant ingredient in a living plant is water. Many succulent plants, such as Turnips and Cabbages, contain more than 90 per cent. of water. Timber which is felled during the driest season of the year seldom contains less than 40 per cent. of water. If a plant is dried at a temperature of from $230^{\circ} \mathrm{F}$. to $248^{\circ} \mathrm{F}$. all water is expelled and the solid matter alone remains.

The solid matter of a plant can easily be made to burn, and the greater part will disappear in the form of gas, a white ash only being left behind. If the gases which are given off during the combustion of the solid matter of a plant are collected and examined, they are found to consist of carbon dioxide, water, ammonia, and a compound of sulphur. If these compounds are split up into their elements they are found to consist of Carbon, Hydrogen, Oxygen, Nitrogen, and Sulphur.

Without these five elements no plant can be produced, and they are called the combustible elements of the plant because they can be burnt off. Carbon may form as much as one-half of the dried substance of a plant. The nitrogen seldom exceeds 4 per cent. of the dry matter, and in far the larger number of cases is present in much smaller quantities, while the amount of sulphur present is still smaller. The remaining fraction of the solid part of plants is composed of oxygen and hydrogen, and a little mineral matter.

The ash of the plant is found, when analysed, to contain Phosphorus, Potassium, Calcium, Magnesium, and Iron, along with Silicon, Sodium, Chlorine, and slight traces of most other chemical elements. Silicon, Sodium, and Chlorine, are not necessary for the growth of the plant, but are taken in along with the water.

Chlorine seems to be necessary for the nutrition of Buckwheat, Barley, and Oats, for if these plants are grown in solutions which do not contain this element they do not flourish. 
The elements which are found in the ash of a plant are said to form the incombustible elements of the plant.

The Essential Chemical Elements of Plant Food.The elements which are essential for the life of a green plant are ten in number. They are as follows :-

$\begin{array}{ll}\text { Carbon } & \text { Phosphorus } \\ \text { Hydrogen } & \text { Potassium } \\ \text { Oxygen } & \text { Calcium } \\ \text { Nitrogen } & \text { Magnesium } \\ \text { Sulphur } & \text { Iron }\end{array}$

Water Culture.-The relative importance of the elements given above to the life of plants can be ascertained by the method of water culture. The plant is grown in distilled water in which certain salts have been dissolved. If the solution contains everything necessary for the growth of the plant, it is said to be a normal solution. By varying the salts in the solution in a number of experiments, and observing the effect produced upon the plants, we can draw certain conclusions as to the needs of plants.

The following can be taken as an example of a solution for water culture :-

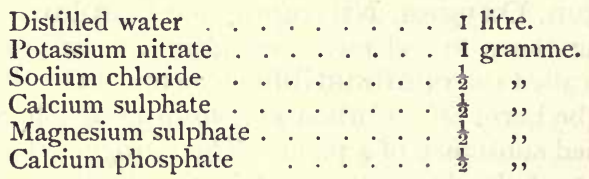

A few drops of a dilute solution of iron chloride should be added.

Seeds of any quick growing plant, such as Maize, Bean, Pea, or Buck-wheat, are germinated on danı saw-dust, and when the radicles are well-developed, the seedlings are washed in distilled water. A series of bottles with wide mouths are prepared, and the corks which fit the bottles are suitably split. The seedling is then placed in the split made in the corks with its roots hanging in the solution. A different solution is placed in each bottle. In one a normal solution is used as a test of the growing power of the others. If, for instance, the plant is grown in a solution which contains all the essential elements except iron the plant is of a pale yellow colour, because iron is necessary for the development of chlorophyll. If a mere trace of iron is 
added to the solution the plant changes its colour and becomes green. In fact, if some of the leaves are simply washed with a weak solution of iron they turn green.

When potassium nitrate is left out of the solution the plant is stunted in its growth.

Expr. 106.-Weigh a Turnip and place it in a hot oven for a few days, or until it is perfectly dry. Weigh again, and note the change in weight. The water in the Turnip has been driven off, and only the solid matter remains behind.

EXPT. 107.-Twist a piece of stout iron wire many times round two or three inches of a small branch, and burn the wood over a Bunsen or spirit flame upon a plate. Note-

(i) The residue of incombustible matter (the ash).

(ii) The bark produces the most ash.

(iii) The colour of the ash is white or grey.

ExpT. 108. - Burn a piece of dry wood in a jar full of air. This can be done by twisting a piece of wire round the woor to hold it with; then light the wood and hold it in the jar as long as it will smoulder. Pour into the jar a little lime-water. Note-

(i) The limewater in the bottle is clear and colourless.

(ii) The limewa ter becomes milky when shaken in the jar.

(iii) This being the test for carbon dioxide, show s that when wood is burnt in air, carbon dioxide is formed.

EXPT. 109.Germinate a few

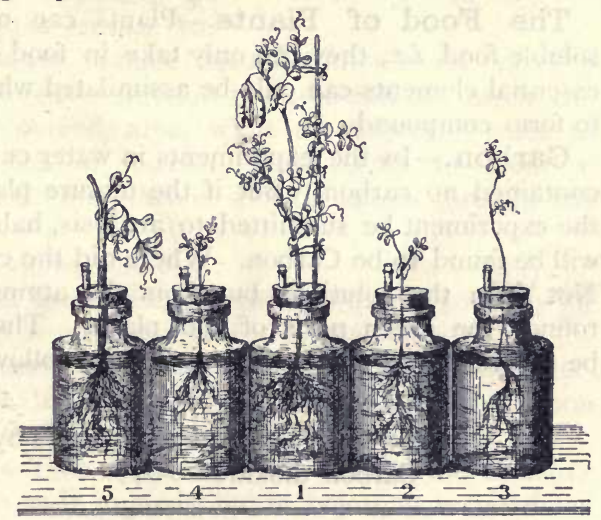

Fig. I43.-Water Culture.-No. I. Pea plant grown in normal solution. No. 2. Pea plant grown without potassium. No. 3. Pea plant grown without nitrates or ammonium salts. No. 4. Pea plant grown with soda instead of potash. No. 5. Pea plant grown without calcium.

Peas in damp sawdust. Obtain five wide-mouthed bottles with corks and split the corks so that the plants can be suitably fixed. When the Pea seedlings have their radicles about two inches in length, wash them in pure water and fix five of the best developed in slits in the 
corks. Mix five solutions for water culture, and number the bottles containing them from one to five.

(I) Let the first be the normal solution given on p. I 8 .

(2) Leave out the potassium nitrate from the second solution.

(3) Mix the third solution without the iron chloride.

(4) From the fourth leave out magnesium sulphate.

(5) In the fifth substitute sodium nitrate for the potassium nitrate.

Measure the plants from time to time. Note-

(i) How the plant grows in the first solution; the growth will be normal.

(ii) The plant which is grown without the potassium nitrate is stunted in growth.

(iii) The plant grown without iron is not green. Wash a leaf with a weak solution of iron chloride ; it will turn green.

(iv) The plant grown without magnesium sulphate is very stunted in its growth.

(v) The plant grown without potassium nitrate, but for which sodium nitrate is substituted, is also abnormal in its growth. This shows that sodium cannot take the place of potassium.

The Food of Plants.-Plants can only make use of soluble food, i.e., they can only take in food in solution. The essential elements can only be assimilated when they are united to form compounds.

Carbon.- In the experiments in water culture, the solutions contained no carbon. But if the mature plants at the close of the experiment be submitted to analysis, half their dry weight will be found to be Carbon. Where did the carbon come from? Not from the solutions, but from the atmosphere which surrounds the green parts of the plants. The atmosphere may be regarded as a mixture of gases in the following proportion :-

$$
\left.\begin{array}{lr}
\text { Nitrogen } & 79^{\circ} 00 \\
\text { Oxygen } & 20^{\circ} 96 \\
\text { Carbon dioxide } & 0^{\circ} .4
\end{array}\right\} \text { Parts by Volume. }
$$

\section{$100^{\circ} 00$}

The green parts of plants are alone able to take in carbon dioxide and decompose it into carbon and oxygen. That green plants give out oxygen can be shown by placing a few leaves of any water plant (Elodea or Water Cress will do) in water, and exposing them to bright sunlight, when bubbles of gas will be given off. If these bubbles of gas are collected and examined, they are found to consist of oxygen. If a green plant, or 
a portion of a green plant, be placed under a bell jar arranged over mercury, and containing a measured mixture of air and carbon dioxide, and be then exposed to light for a few hours, the volume of the gas under the jar will remain unaltered.

If after the experiment the gas is analysed, there will be found to be less carbon dioxide, but more oxygen than at the commencement of the experiment. This shows that the plant had taken in carbon dioxide and given out as much oxygen as the carbon dioxide taken in.

If a leaf which possesses no stomata on the upper surface has

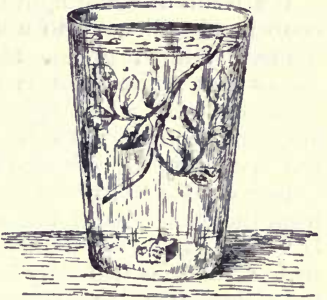

FIG. 144.-Stem and leaves of Water Cress giving out oxygen in water. The leaves and stem have been cut to allow of the escape of the oxygen.

a portion of its lower surface coated with wax or vaseline so that no air can enter through the stomata, no starch can be found in the covered area, while the adjacent parts of the leaf become rich in starch. This seems to point to the conclusion that the carbon dioxide enters through the stomata.

Recent research shows that :-

I. Under normal conditions, practically the sole pathway for carbon dioxide into or out of the leaf is by the stomata.

2. Under abnormal conditions, when the stomata or intercellular spaces are blocked, and the pressure of the carbon dioxide is great enough, it may pass through the cuticle.

Assimilation. - This term is used for all the nutritive processes which go on in animals, but in botany it is restricted to the taking in of carbon dioxide by the chloroplasts and subsequent changes which they produce in it. All the other processes of the plants depend upon the assimilation of carbon dioxide.

Conditions for Assimilation.-Assimilation by green plants can only take place under the following conditions :-

I. - A certain intensity of light (either sunlight or electric light will do).

2.-A certain temperature, at least a few degrees above the 
freezing point. Heat is as necessary here as in all other vital processes.

If a beam of white light is passed through a prism it is bent out of its course and split up into a number of colours. These colours are red, orange, yellow, green, blue, indigo, and violet. This experiment shows that white light is built up of several primary colours. The constituents of white light which the chloroplasts use for assimilation are just the reverse to those used in chemical processes. The rays of the spectrum, as the decomposed light is called, which act on the sensitive plate of the photographer, or decompose silver salts, are those from the violet end ; but the rays which are the most active in assimilation are the red, orange, and yellow. If a plant is grown under such conditions that only the red, orange, and yellow rays can reach it, the assimilation is nearly as active as in white light-for 90 per cent. of starch will be formed against 100 per cent. in white light. On the other hand, if a plant is grown so that only the violet and blue rays can pass through, assimilation falls very low, to from 5 to 7 per cent. only of the 100 in white light.

The changes by which carbon dioxide and water are converted into organic substances are not fully understood at present. We only know the final products, not the stages that lead up to them. The first substance formed in the plant by the constructive activity of the chloroplasts is some form of sugar. It is most likely cane sugar. If more sugar is produced than can be carried away in the sap, it is converted into starch by the chloroplasts.

If the green parts of any plants are exposed to light, assimilation commences, and starch appears in the chloroplasts. If assimilation ceases, as it does regularly at night, the starch disappears. The disappearance of the starch is due to a ferment called diastase, which is found in small quantities in various parts of plants. A ferment is a compound which can act on another substance, and convert it into a different material. Ferments may be living or non-living. The Yeast plant is an example of the former and diastase of the latter.

A very interesting experiment can be performed to show that assimilation has taken place in a green leaf. From a piece of tinfoil, cut out the word "Assimilation," and encase a leaf with it so that the word assimilation is on its upper surface. Allow the leaf to remain on the tree for a few days, and then bleach the leaf, and treat it with iodine solution. The word assimilation will appear on the leaf. The whole of the leaf, with the 
exception of where it had been exposed to light, is pale in colour. This shows that light is necessary for the formation of starch.

Only Green Plants can Assimilate.-Those plants which are destitute of chlorophyll must obtain their carbonaceous food in some other form. The Dodder and the Broom-rape obtain their carbon from the host plant (p. 24) upon which they live, hence they are said to be parasites. Some plants obtain the carbon which they require from decomposing vegetable matter; they are called saprophytes. The Bird's Nest Orchid is a good example.

ExpT. I10.-Place a little lime water in a saucer, and leave it on a table for an hour or two.

(i) The surface of the lime water will turn milky.

(ii) This shows that carbon dioxide exists in the air.

ExP'. III. - Prepare some carbon dioxide by acting on marble with hydrochloric acid. Fit up the apparatus shown in Fig. 145. Place a few pieces of marble or limestone in the flask and cover with water ; pour strong hydrochloric acid down the funnel till the action is brisk. Collect a bottle of the gas. This can be done by placing a delivery tube into the bottle. When the contents put out a light held just below the outside of the mouth of the bottle, it is full of carbon dioxide. Turn the bottle wrong side up, and place it over a branch with leaves which is placed in a glass of water. Expose to light for a few hours, and then test with a light. The light will burn. This shows that the leaf has taken in carbon dioxide and given

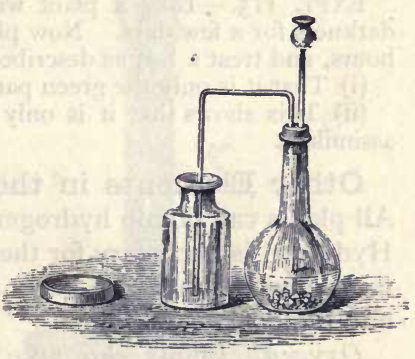

Fig. 145.-Diagram of apparatus for the preparation of carbon dioxide. out oxygen.

EXPT. I12.-Place a green plant under an orange or red coloured bottle. Expose to a bright light for a few days. Examine a leaf of the plant in the following way :-

(i) Dip the leaf in boiling water.

(ii) Bleach in methylated spirits till white.

(iii) Place in cold water to displace some of the spirits.

(iv) Cover with iodine solution. Note-

(v) The leaf will be coloured blue black. This shows that green plants use the rays of light from the red end of the spectrum.

If a red bottle cannot be procured, the experiment can be performed by building around the plant panes of red glass. 
EXPT. I 13.- Place a green plant under a blue bottle, and expose to light for a few days. Examine a leaf by the same method given in Expt. I I2. Note-

(i) The leaf does not turn so dark in colour with the iodine solution.

(ii) This is due to the blue glass cutting off all the rays except the blue and violet, and these are not the active agents in assimilation.

Experiments show that the active rays are those from the red end of the spectrum, but as white light contains all these rays in addition to blue and violet, there will be even more starch produced in white light than under the influence of the red, orange and yellow rays.

ExpT. 114.-Obtain a strip of tinfoil and fix it over a portion of a leaf, so as to protect it from the light. Leave the leaf on the plant for a few days. Treat the leaf in the way advised in Expt. I12. Note-

(i) The part of the leaf which has been covered with tinfoil is of a pale yellow colour.

(ii) The remainder of the leaf is of a dark blue colour.

(iii) This shows'that light is necessary for the formation of starch.

EXPT. I 15.-Take a plant with variegated leaves, and place it in darkness for a few days. Now place the plant in bright light for two hours, and treat a leaf as described in Expt. I I2. Note-

(i) That it is only the green parts of the leaf which colour blue.

(ii) This shows that it is only the green parts of plants which can assimilate.

Other Elements in the Food of Plants.-Hydrogen. All plants can obtain hydrogen from water and ammonium salts. Hydrogen is necessary for the life of the plant, for it enters into the composition, as we have seen, of cellulose, starch, proteids, and protoplasm.

Oxygen. Plants can take up oxygen in a free state, in combination in water, and in mineral salts.

Respiration.-Free oxygen is necessary for the life of nearly all living beings. The taking in of free oxygen and the giving out of carbon dioxide is spoken of as respiration. Every living cell in a plant requires oxygen for its activity.

It must be distinctly understood that respiration and assimilation are two distinct processes. Green plants are alone able to assimilate under the influence of light; they take in carbon dioxide and give out oxygen.

Respiration is carried on by all parts of plants no matter what their colour may be, and at all times, from the commencement of germination until the plants die. Oxygen is taken in 
by living plants and carbon dioxide given out both during light and darkness.

During assimilation the plant gains weight, but during active respiration there is a loss of material. The loss is caused by the oxygen uniting with the carbon compounds of the plant to form carbon dioxide. 'This loss of weight due to respiration supplies the plant with energy, by means of which it is able to assimilate. If a plant which is growing well be placed in an atmosphere of pure nitrogen, or hydrogen, or in air from which the oxygen has been absorbed, the active life of the plant ceases at once. It has been calculated that one hour's assimilation will counterbalance thirty hours' loss by respiration.

Heat is Produced by Respiration. - A thermometer surrounded by germinating seeds registers a

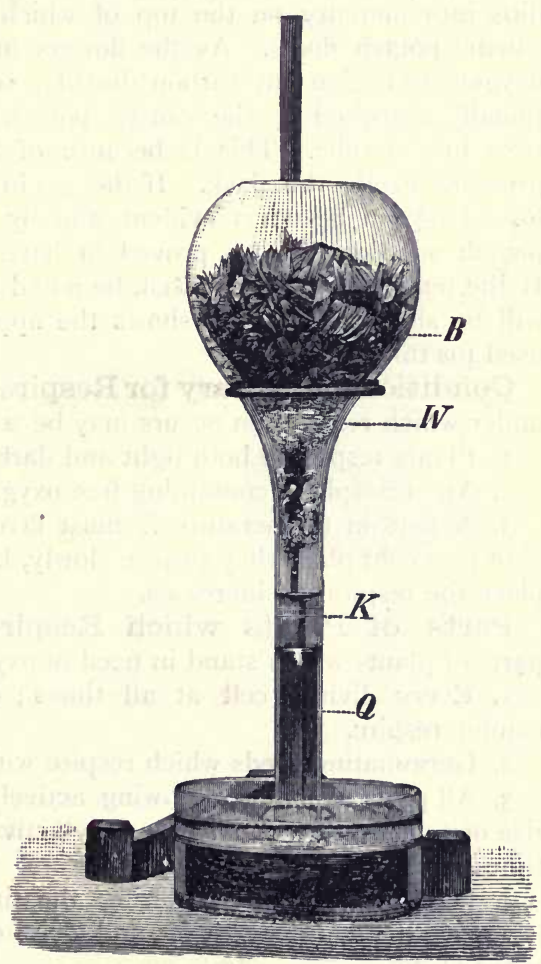

FIG. 146.-Experiment in respiration. $B$, an inverted flask containing flowers, which are held in position by cotton wool, $W ; K$, solution of caustic potash ; $Q$, mercury, which rises in the neck of the flask, because carbon dioxide is absorbed by the caustic potash solution. (S.) rise of temperature.

Flowers which are actively respiring produce both heat and carbon dioxide. This can be shown by placing a number of 
flowers in a flask and holding them in position by a plug of cotton wool pushed into the neck of the flask. Fit the flask in an inverted position on to a cork through which one end of a tube (open at both ends) passes. The other end of the tube dips into mercury on the top of which a strong solution of caustic potash floats. As the flowers in the flask use up the oxygen and give out carbon dioxide, since the latter is continually absorbed by the caustic potash solution, the mercury rises in the tube. This is because of the diminution of the pressure inside the flask. If the gas in the flask be tested, a loss of oxygen becomes evident, and by weighing, the caustic potash solution can be proved to have increased in weight. If the temperature of the flask be noted a rise of temperature will be shown. Fig. I 46 shows the apparatus which can be used for this experiment.

Conditions necessary for Respiration.-The conditions under which respiration occurs may be stated as follows :-

I. Plants respire in both light and darkness.

2. An atmosphere containing free oxygen is necessary.

3. A certain temperature is most favourable. If seeds are kept in a cold place they respire slowly, but if moved to a warm place the respiration increases.

Parts of Plants which Respire vigorously.-The parts of plants which stand in need of oxygen are :-

I. Every living cell at all times; dead parts of plants cannot respire.

2. Germinating seeds which respire with great vigour.

3. All parts which are growing actively. There is always a rise of temperature due to the very active respiration at these times.

4. Developing flowers; during the time of flowering there is a great demand for oxygen, and a rise of temperature always takes place.

Use of Oxygen.-Plants require oxygen for two purposes. In the first place it is necessary for the building up of cellulose, starch, sugar, proteids, and protoplasm. It is also necessary for respiration, for without it the plant cannot gain the necessary energy for the vital processes to be carried out.

Expr. II6.- Steep a few Peas in water for twenty-four hours, and place them on damp cotton-wool at the bottom of a bottle. Close the 
bottle with a tight-fitting cork, and keep the Peas warm for two days. Note-

(i) That when the cork is removed and a lighted taper put in, the flame is extinguished.

(ii) If a little lime-water is shaken in the bottle, it turns milky.

(iii) This shows that some or all of the oxygen has been used up by the germinating seeds, and that carbon dioxide has been given out.

ExPT. II7.- Place a few Peas on damp cotton-wool at the bottom of a bottle, and also place in the bottle a test-tube which contains a solution of caustic potash. Through the cork pass a glass tube bent into the shape of a U, as is shown in Fig. 147, and in the glass tube pour a little coloured fluid. Note-

(i) The liquid stands at the same level in both arms of the tube.

(ii) As the experiment goes on, the liquid rises in the arm of the tube which is in direct contact with the sair in the bottle.

(iii) The rise of the liquid is due to the oxygen in the bottle being used up by the germinating Peas, and the carbon dioxide which they give out being absorbed by the caustic potash. The pressure in the bottle being less than the pressure of the external air the liquid is forced towards the bottle.

(iv) At the close of the experiment the caustic potash tube can be weighed, and it will be found to have increased in weight.

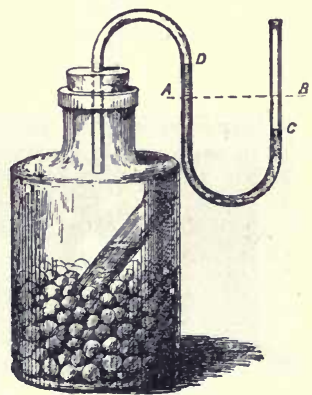

FIG. 147.-Diagram illustrating how germinating Peas use up oxygen and give out carbon dioxide. $A, B$, level of coloured liquid; $C, D$, the change in level due to oxygen being used. The carbon dioxide is absorbed by the caus. tic potash in the test-tube.

\section{ExpT. I 8.-Obtain two Potato}

tubers of the same weight. Place one to dry in a hot oven, and the other in a damp dark room. Examine both from time to time, and note-

(i) The one in the oven, because water is driven off, loses weight. When it is perfectly dry, weigh it, and record the change in weight.

(ii) The one in the damp dark room commences to grow and produces small pale leaves and small tubers.

(iii) After a time growth ceases, because the reserve material in the tuber has been used up.

(iv) Now take the old tuber, with the stems, leaves, and tubers which have been produced, and place them in a hot oven until all the water has been driven off.

(v) Weigh the dry residue. It is lighter than the residue obtained from the first tuber dried in the oven. This loss of weight is due to respiration. During the whole of the time of growth, oxygen was taken 
in and carbon dioxide given out ; but, the plant being in the dark, no chlorophyll was produced and no assimilation could go on.

(vi) This experiment shows that there is a loss of weight due to respiration, caused by the oxygen uniting with some of the carbon of the plant to form carbon dioxide.

ExPT. I 19.-Place some germinating Peas in a funnel, as shown in Fig. 148, so that they surround the bulb of a thermometer. Cover the

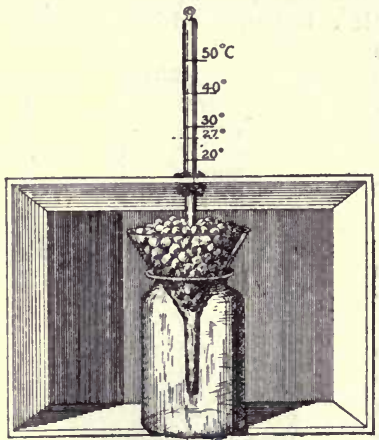

FIG. I48.-Diagram illustrating the rise of temperature due to respiration.

apparatus over with a cardboard box, and pass the thermometer through a hole in the box. Notethere will be a rise of temperature, due to the respiration which goes on.

\section{The Nitrogen of Plants.-} In the water culture experiment we found that the plant grown in the solution without compounds of nitrogen was stunted, and soon died. It died from want of nitrogen, though surrounding it on every hand there was plenty of free nitrogen. Plants cannot use the free nitrogen of the air. Nitrogen must always be presented to a plant in a combined form. Most green plants obtain the nitrogen necessary for their growth from the nitrates in the soil. Nitrates are mineral salts which contain nitrogen; they are found in all fertile soils. The nitrates of the soil may be dissolved by water, which is subsequently absorbed by the roots and is so introduced into a plant. Parasites obtain the nitrogen necessary for their growth from the hosts upon which they live.

Carnivorous Plants are able to obtain the greater portion of the nitrogen which they require for their growth from the animals which they are able to entrap.

The Sun-Dew (Fig. I 50), which grows on the moors in Lancashire, Yorkshire, North Wales, and many other parts of the United Kingdom, is a good example of such a plant. The name Sun-Dew has been given to the plant because, when the sun shines, it appears to be covered with dew. The leaves are covered with hairs called tentacles, on the end of which minute 
glands are developed. The glands secrete a fluid which is very much like the gastric juice of the higher animals. It is this

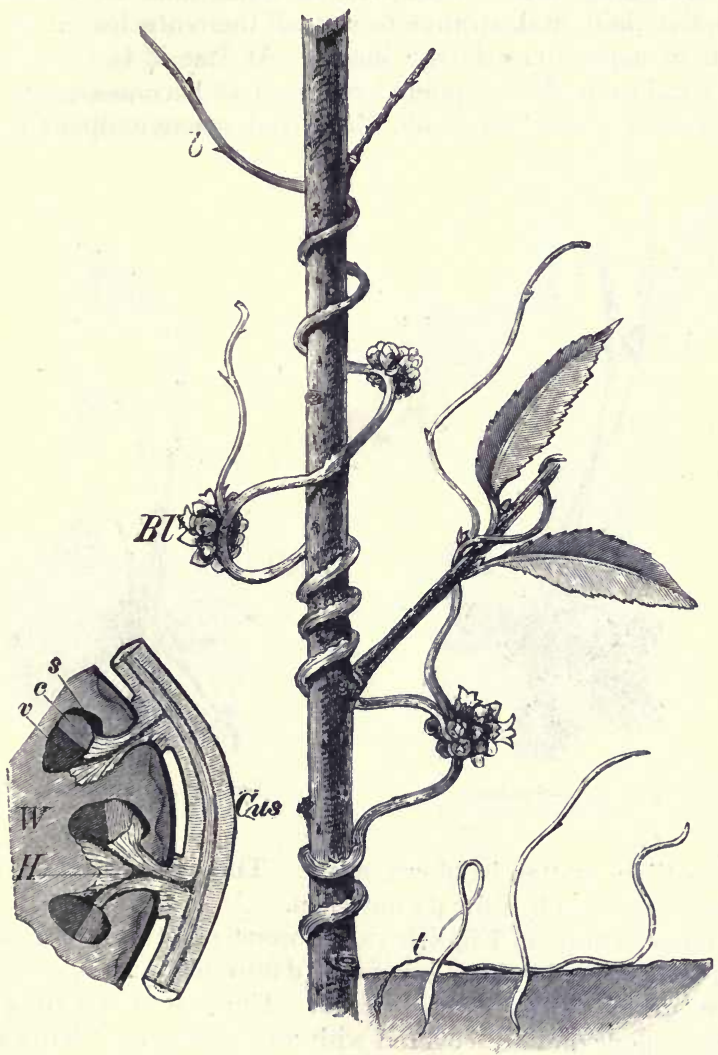

FIG. 149.- Dodder.-In the middle a plant of the Dodder is shown parasitic on a Willow twig; $b$, reduced leaves; $B l$, flowers. On the left a transverse secticn shows how the suckers enter the host plant. On the right, the filaments which are produced from the seeds are shown. (S.)

fluid which causes the plant to appear to be covered with dew. If a small insect sees the glistening fluid it comes towards 
it (doubtless with visions of honey), and a leg or a wing comes in contact with the end of a gland and the fluid holds it tight. The struggling insect smears itself more and more with the deceptive fluid, and, strange to say, all the tentacles on the leaf begin to move towards the insect. At last it is covered up. More and more fluid is poured out until all becomes quiet. The leaf remains closed for a few days, and when it opens a little

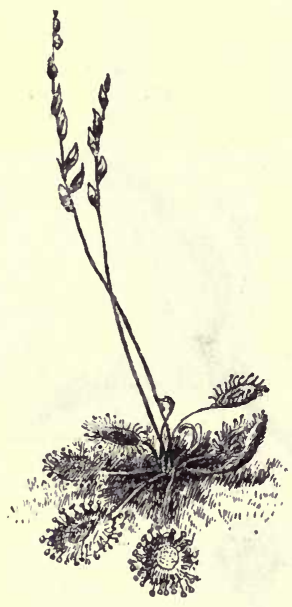

Fig. I50.-Sundew.

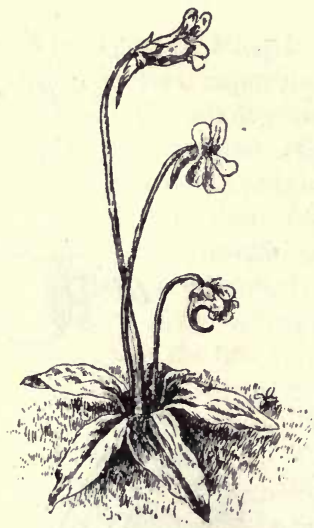

Fig. I51.-Butterwort.

indigestible matter is blown away. The remainder has been absorbed by the leaf for its nutrition.

Another common English carnivorous plant is the Butterwort (Fig. I5I), which grows in damp places. A rosette of leaves grows close to the ground. The leaves are of a dirty yellow colour and are covered with numerous small hairs which secrete a sticky fluid. The windl is always blowing the dead bodies of small animals about, and if one of these comes in contact with the fluid it adheres to it. The margin of the leaf, which is always somewhat curved, moves a little and pushes the body before it. The hairs secrete an acid fluid capable of 
decomposing the dead bodies, and thus the plant is able to obtain a portion of the nitrogen which it requires.

In many parts of the ditches, ponds, or pools in Scotland and Ireland an aquatic carnivorous plant is found. Growing from it are a large number of small bladders which vary in size from oneeighth to one-quarter of an inch in diameter. It receives the name of the Bladderwort (Fig. 152). Each bladder is full of water.

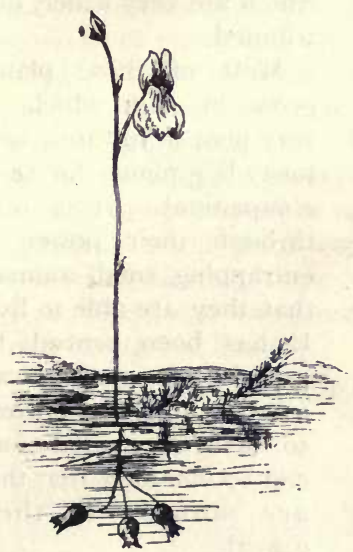

Fig, I52.-Bladderwort.

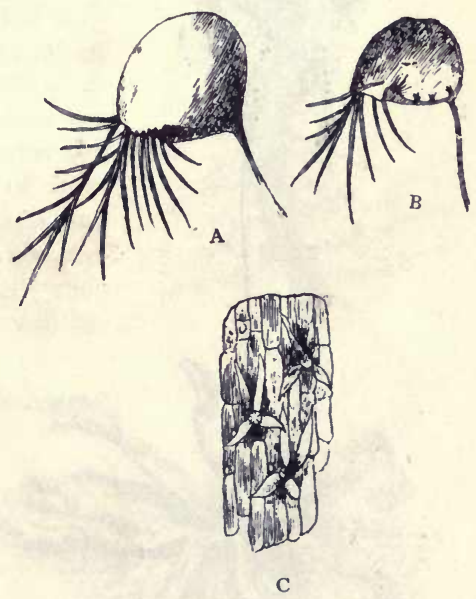

FIG. I53--A, bladder of Bladderwort ; B, section of bladder; C, wall of bladder, more highly magnified.

Entrance into the bladder is effected through the opening at one end. The opening is guarded by a valve which is a sort of a trap-door opening inwards and sloping towards the cavity. The valve is guarded internally by a number of stiff hairs, and the external opening is protected from large animals by long multicellular hairs. The bladder (Fig. 153) is lined with a number of cells which can absorb materials from the bladder.

The whole of the apparatus is a trap for small aquatic animals. They can enter but never return. The animal pushes against 
the door, which gives way and allows it to enter. It tries again and again to push the door open but it will only open inwards. After a time it dies; decomposition sets in, and the products are absorbed by the cells which line the bladder.

In most parts of the world there are carnivorous plants. Well-known examples are the Venus's Fly-trap (Fig. 154), which

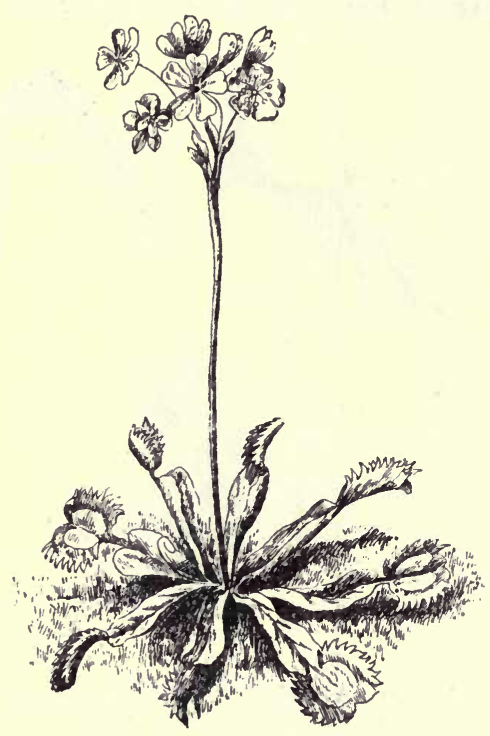

FIG. 154.-Venus's Fly-trap. grows in South America, and the Pitcher plants, which are very widely distributed.

Most of these plants grow in soil which is very poor in nitrates, with lowly bog plants for their companions. It is only through their power of entrapping small animals that they are able to live. It has been proved by experiments that if carnivorous plants are grown so that no animal food can be obtained that they are stunted in their growth.

Leguminous Plants - The members of the Bean family can obtain the nitrogen which they require in a different way

from most plants. If a Clover or Pea-plant is pulled up and the roots examined, they will be seen to be covered with a number of nodules, or root-tubercles, as they are called. These are produced by Bacteria, which are themselves minute plants. The Bacteria penetrate through the root-hairs into the cortex of the root, and so produce the tubercles. The Bacteria live in and around the tubercles in the soil, and take free nitrogen from the air in the soil, and build up this nitrogen into compounds, which are passed on to the plant. The plant most likely gives carbonaceous compounds to the Bacteria in return for nitrogen. 
The Bacteria form with the Leguminous plant a life partnership, which is called Symbiosis. That it is an advantage for the Leguminous plants to have the Bacteria living in the soil is certain, for those plants with the best developed tubercles thrive the best.

The relation of the Bacteria with the plants which belong to the Bean family is so well known that farmers can now obtain Bacteria to mix with the seeds of the above plants when sowing. This material which is mixed with the seeds receives the name of nitragin. If a little soil from a field where plenty of roottubercles are produced be taken and applied to a soil which will not produce root-tubercles, these will then be produced, and the plant will become strong and healthy.

Expr. 120.-Pull up a well-developed Clover plant and examine the roots. Note-

(i) The tubercles on the roots. These are shown in Fig. 155.

(ii) Cut a transverse section of a root so as to pass through a root tubercle and examine it with a hand-lens.

(iii) Mount a transverse section of a root having a root-tubercle in water.

(iv) Examine under a high power, and note the structure.

EXPT. 121. - Pull up a stunted Clover plant and examine the roots. Note-

(i) The roots have either only very few tubercles or they are entirely absent.

(ii) The general appearance of the plant.

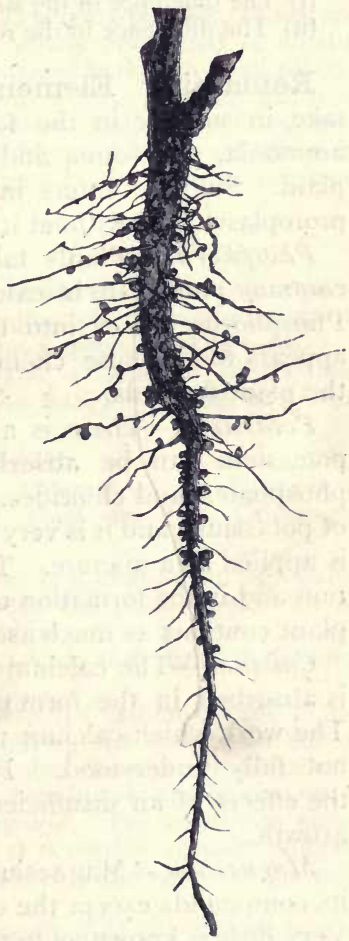

FiG. 155.-Root-tubercles on the roots of a Leguminous plant. (Reduced.) (S.)

(iii) Experiments 120 and 122 show that the tubercles exert a favourable influence on the growth of the Clover.

EXPT. 122. - Prepare two plant pots in the following way-(a) Fill one with rich soil from a field in which Clover grows to perfection; (b) fill the other one with sand which has been raised to a high 
temperature by placing in an old tin and applying heat to it. Sow a few Clover seeds in each ; give to $(a)$ water only, but to $(b)$ give the solution described on page i 8 . From time to time pull up a plant from each pot and examine. Note-

(i) The difference in the size of the plants.

(ii) The difference in the root-tubercles.

Remaining Elements in Plants.-Sulphur.-Plants take in sulphur in the form of sulphates. The sulphates of ammonia, potassium, and calcium are the most useful to the plant. Sulphur enters into the composition of proteids and protoplasm, and without it these materials cannot be formed.

Phosphorus.-Plants take in phosphorus as phosphates. A common phosphate is calcic phosphate, or phosphate of lime. Phosphorus enters into the composition of the nucleus, and appears to aid those chemical changes upon which the life of the plant depends.

Potassium.-There is a very large variety of forms in which potassium can be absorbed by plants, such as sulphates, phosphates, and chlorides. As a rule clay soils possess plenty of potassium, and it is very seldom that a compound of potassium is applied as a manure. This element is very active in assimilation and in the formation of protoplasm. The solid matter of a plant contains as much as $3 \cdot 5$ per cent. of potassium.

Calcium.-The calcium which a plant requires for its growth is absorbed in the form of sulphates, phosphates, or nitrates. The work which calcium plays in the economy of the plant is not fully understood. Plants cannot live without it, and the effects of an insufficient supply is shown by their retarded growth.

Magnesium.-Magnesium can be taken in by plants from all its compounds except the chloride, which seems to be injurious. Very little is known as to the use of magnesium, but our experiments in water culture show that it is necessary for the healthy growth of the plant.

Iron.-Green plants, as we have seen, require iron in their food for the formation of chlorophyll. This element can be absorbed from a variety of compounds, and it is only an essential element for the nutrition of green plants.

The Non-Essential Elements of Plant Food-A very large number of elements which plants take in with their food they can do without. 
Silicon.-This element is taken in by the roots of plants in the form of soluble silicates. It is very largely deposited in cell-walls, and probably protects the plant from the attacks of fungi which are unable to penetrate through external walls in which silicon is present. Wheat and all the cereal grains have a very large quantity of silicon in their ash ; the ash of wheat-straw contains as much as seventy per cent. of silicon.

Sodizm.- Sodium is one of the most widely distributed of all the elements, and it is no wonder that it is contained in the ash of all plants.

Chlorine. - The ash of all plants contains a little chlorine, but it is not essential for their nutrition. Buck-wheat, Barley and Oats seem to grow better if they are supplied with chlorine; Maize will grow in solutions without it. Chlorine and sodium, in the form of common salt, seem to keep plants healthý.

\section{SUMMARY.}

Physiology. - The division of botany which deals with what a plant can do is termed physiology. All the higher plants show division of labour, i.e., each part of the plant performs a special kind of work.

Nutrition. - The processes which enable a plant to obtain and change its food, thus enabling the plant to form new tissue, is spoken of as nutrition.

\section{The Essential Elements of Plant Food are-}
I. Carbon
2. Hydrogen
5. Sulphur
9. Magnesium
6. Phosphorus
3. Oxygen
7. Potassium
4. Nitrogen
8. Calcium

Water Culture.-When a plant is grown in a solution the ingredients of which are known, we can find out what the plant requires for its growth. This method is termed water culture.

The Food of Plants. - Plants can only take in their food in the form of compounds and in solution.

Carbon is obtained by green plants from the carbon dioxide of the atmosphere. Only the green parts of plants can decompose carbon dioxide. Carbon dioxide passes into the plant through the stomata.

Assimilation. - The absorption of carbon dioxicle and its conversion into organic compounds is called assimilation. The conditions necessary for assimilation to take place are-(I) A certain intensity of light ; (2) A certain temperature. The red parts of white light are the most active in assimilation.

Parasites and Saprophytes. - Plants destitute of chlorophyll take in their carbon in the form of carbon compounds other than carbon clioxide. Those plants which live on decomposing matter are called saprophytes.

The Hydrogen necessary for a plant is obtained from water and ammonium salts.

0xygen is required by a plant $(a)$ in a combined form as a food, and $+(b)$ in a free state for respiration.

Respiration.-All plants must have free oxygen for respiration. This oxygen unites with the carbon of the plant and forms carbon dioxice, which is given out by the stomata. Respiration and assimil. ation are two different processes; the plant gains by the first the energy necessary for assimilation and growth, by the latter it gains weight. 
Heat is produced by respiration. Plants respire (I) In both light and darkness ; (2) In an atmosphere containing free oxygen ; (3) At a certain temperature - $a$ few degrees above the freezing point.

The parts of plants which respire are-(I) Every living cell, (2) Germinating seeds, (3) The growing parts of plants, (4) The flowers.

Nitrogen. - Most green plants obtain the nitrogen necessary for their growth from the nitrates in the soil.

Leguminous Plants obtain most of the nitrogen for their growth through the agency of Bacteria, which grow in tubercles on their routs. They are said to live in Symbiosis with the Bacteria, i.e., there is a lifepartnership between them.

\section{Questions ON Chap'TeR X.}

(I) What is meant by plant physiology?

(2) Explain what you understand by "division of labour"?

(3) What do you know about-

(a) The amount of water found in plants?

(b) The solid matter of a plant?

(c) The ash left after the combustion of a plant?

(4) Enumerate the essential chemical elements which a green plant absorbs as food from the soil ? and briefly state what is the special use of each element. (I89I.)

(5) Explain why it is that starch-grains are formed in the chlorophyll corpuscles when a leaf is exposed to light and air.

(6) Explain how it is that a green plant cannot carry on its nutrition in darkness (1892).

(7) What part of its food does a green plant obtain from the air? In what form, and under what conditions, is it taken in? (I889.)

(8) What are the conditions necessary for the assimilation of carbon by green leaves? State the means by which you would prove that a given leaf had been assimilating carbon. (I89I T.)

(9) Give an account of the use of chlorophyll in the nutritive processes of plants. (1890 T.)

(I0) From what source and in what forms do plants usually absorb their nitrogenous food? Mention cases in which the nitrogenous food is absorbed from other sources and in other forms. (1887.)

(I2) Plants both absorb and give out carbon dioxide. State precisely the circumstances upon which each process depends. (I885.)

(13) In what respects does the nutrition of the leguminous differ from that of the other green plants? Explain the significance of this difference. (I896.)

(14) What is starch? Explain how it is that, if a green plant be kept for a day or two in darkness, no starch is to be found in its leaves. (1897.)

(15) How may the necessary chemical elements for the nutrition of a green plant be determined?

(16) What is the importance of carbon to a plant? From what source does a green plant get its carbon, and how is it assimilated? (1899.) 


\section{CHAPTER XI}

\section{THE ABSORPTION AND MOVEMENT OF WATER IN THE PLANT}

Absorption of Water and Minerals.-It is a wellknown fact that if plants are not supplied with water they cease to grow ; they droop, wither, and die. All the substances which a plant requires for its growth are taken from the soil with the exception of carbon, and this, as we have seen, is obtained from the air. That the roots are the organs which take in water is shown by the experiments in water culture. The parts of the roots active in absorption are the root-hairs, and the uncuticularised portions of the younger roots. Root-hairs are unicellular and thinwalled, the walls being lined with protoplasm. These root-hairs pass between the particles of the soil, and by their intimate connection therewith absorb water which contains minerals in solution. Even in a dry soil there is a certain amount of water round the particles, held there by capillary attraction. This water may pass from particle to particle by the same capillary

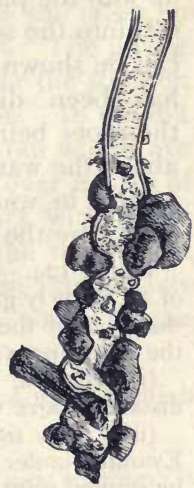

F1G. 156.-Tip of root-hair, with adhering particles of soil. $(\times 240).(\mathrm{S}$. force. Capillary attraction similarly causes water or tea to completely saturate a piece of sugar if one corner is wetted; it also determines the flow of oil up the wick of a lamp.

Ex1'1. 123.- Obtain two slips or pieces of window glass and a tumbler partly filled with a coloured liquid. Place the pieces of glass so that 
there is a little space between them, and dip them into the liquid in the tumbler. Note-

(i) The coloured liquid rises between the slips of glass.

(ii) The height to which it rises will depend upon the width of the opening between the slips. The greater the distance between the slips of glass the shorter the column of liquid; and the nearer they are together the higher the coloured water will rise.

(iii) The liquid rises by capillary attraction.

The finer the particles in the soil the more water will be held by it. The interspaces between the particles of the soil form so many capillary tubes, up which the water rises, and by which it is held.

Absorption.-The root-hairs make their way into the interspaces, and come into close contact with the water round the particles. The water gradually diffuses through the thin cell-wall of the root-hair, or uncuticularised portion of the root ; it thus reaches the interior of the root-hair and eventually passes up into the plant, while a little acid sap diffuses out from the cell into the soil. That plants do take in water by their roots can be shown by growing a plant in water in which a little cosin has been dissolved. The solution of eosin is taken in, the roots being stained internally for a considerable distance above the water. Only those substances in the soil which are soluble in water can be taken in by the plant. This can be shown by the following experiments.

ExP'r. 124. --Put a little powdered eosin in water, and place the roots of an actively growing plant so that they dip into the solution. Leave the roots of the plant in the solution for several hours, and examine in the following way :-

(i) Examine the root; it will be coloured externally for a short distance above where the water stood.

(ii) Cut a transverse section of the root and mount it in glycerine. Examine under the low power of the microscope ; the section is seen to be stained right through.

(iii) This shows that the soluble eosin can pass along with the water through the cell-walls.

ExPr. 125.-Place a little powdered carmine in water, and place the roots of an actively growing plant so that they dip into the mixture. Note-

(i) The carmine does not dissolve, but remains suspended in the water.

(ii) Cut a transverse section of the root and mount in glycerine. Examine with the low power of the microscope. Observe the carmine has not passed into the plant, for the section is not coloured.

(iii) It is only the soluble constituents which can pass through the cell-wall along with the water. 
Osmosis.- - Since nutrient substances must pass through the closed walls of cells in order to reach their interior, it follows that they must be in a soluble condition.

How is the interchange between the fluid in the plant and that in the soil brought about? The cell-sap in the plant is separated from the water in the soil by the permeable cell-walls.

The absorption of the solution from the soil is nothing more than a mixing of two fluids of different densities. The mixing of fluids through a permeable membrane is called osmosis, and for this to take place it is necessary for the fluids to be of different densities. There are two currents set up, one from the exterior of the plant to the interior called the endosmotic current, and one from the interior of the plant to the exterior, called the exosmotic current. Since the cell-sap is much richer in substances which set up osmotic currents than the water in the soil, or in other words is heavier bulk for bulk, a considerable endosmotic current of water from the soil is set up while very little of the cell-sap passes into the soil. The giving out of the acid cell-sap by the plant in exchange for the solution in the soil plays a very important part in absorption. In the soil is a variety of materials insoluble in pure water but which are dissolved in a weak acid. If a plant is grown over a slab of polished marble so that the roots come in contact with it, the acid sap in the cells of the younger portions of the roots leave their impression on the slab of marble. These impressions are produced by the acid cell-sap dissolving some of the marble.

Expr. 126. -(i) Dip a piece of blue litmus paper in a weak solution of sulphuric acid. Note-

(ii) It turns red.

(iii) Dip a piece of red litmus paper in a little caustic soda solution ; it changes its colour and becomes blue.

(iv) These tests are used to see if a substance is acid or alkaline.

ExpT. 127.-Pull up a grass plant $b$ / the roots and place a piece of blue litmus paper against the tip of a young root. Note-

(i) The paper gradually becomes red.

(ii) The roots are therefore acid.

Expr. 128.-Obtain a piece of limestone or marble and polish it by rubbing one side on a piece of flagstone. Place the polished limestone in a pot along with some soil, and plant a young scedling above the limestone. Keep the plant moist and place the pot where there is 
plenty of light. At the end of some twelve weeks pull up the plant, take the piece of limestone out, and wash it. Note-

(i) The markings on the limestone show where the roots have touched.

(ii) These markings have been produced by the acid sap which the roots gave out.

(iii) In the soil under ordinary conditions the acid sap performs the same kind of work.

\section{Conditions Necessary for Absorption.-}

I. - The air which surrounds the plant must have a certain temperature. There is a minimum temperature below which no absorption will take place, and a maximum above which this process will cease. Between these two extremes a temperature can be found for each plant at which the process is most vigorous, and this temperature is said to be the Optimum temperature.

2.- The soil (or culture solution) must also have a certain temperature before absorption can take place. The roots of a plant take in very little water in winter because the soil is very cold ; in summer a larger quantity is taken in because the soil is warmer.

3. - The strength of a culture solution has a very decided effect on absorption. If the solution is very strong the plant cannot take it in; absorption only goes on when the solution is very weak-the condition found in the soil in ordinary circumstances.

Plants give out Moisture. - Plants not only take in water but they also give it out. This is shown by the atmosphere of forests always being moister than places without vegetation. It has been calculated that a good-sized Oak tree will give out in a single day several gallons of water, and during the active life of a Sunflower plant, it will give out 200 times its dry weight of water. That plants lose water is shown by cutting a branch, weighing it, and placing it in a dry place. A second weighing in the course of a few hours will show it to have lost weight.

Transpiration.- The way in which the plant gives out the moisture must now be considered. This giving out of moisture by a plant in the form of vapour is called transpiration. It is only those parts of plants which are in contact with the air 
which can transpire. The following experiments will show that plants lose water:-

EXPT. 129.-Take up three well-developed Mustard plants by their roots and put one in a dry place, such as on a table in a warm room. Place another with its roots in water, and the third in a dark cupboard. Examine at the end of a few hours. Note-

(i) The plant placed on the table is withered.

(ii) The one in the dark cupboard is in a far better state than the first.

(iii) The plant in water is unaltered; the roots have taken water in as fast as it has been transpired.

(iv) Plants give out water more actively in a light than in a dark place.

EXPт. 130.-Obtain a potted plant, and cover the soil either with tinfoil or cardboard to prevent evaporation fron: it. Now place the pot and its contents on the pan of a scale and weigh it. Note-

(i) That the pot and its contents lose weight.

(ii) This must be due to the leaves and stem giving out moisture.

(iii) The longer it stays on the scale the lighter it becomes.

(iv) This experiment can be performed before a class even in winter, using either the electric light or gas.

EXPT. I3I. - Cover the soil of a potted plant with tinfoil or cardboard as before, and cover the plant with a bell jar, and place the whole arrangement in sunlight. Note-

(i) The inside of the jar is soon covered with moisture.

(ii) The moisture disappears at night.

(iii) There is only one source for the moisture, viz., the leaves and stems of the plant.

(iv) The moisture disappears at night because the plant no longer transpires; the moisture is condensed and runs down the jar.

\section{To Prove that a given Green-leaf is losing} Moisture.-

ExPT. 132.- Place some white blotting paper in a weak solution of cobalt chloride. Dry:the paper either by holding it before a fire or in clirect sunlight ; it turns blue.

Hold a piece of this paper near a leaf which is still on the tree. Note-

(i) That the paper slowly becomes red; the quicker the colour changes, the more moisture the leaf is giving out.

(ii) A similar piece of paper should be exposed to the air at the same time as a test of the atmospheric condition with regard to moisture.

EXPT. 133.--There is, as a rule, more moisture given off by the under side of a leaf than by the upper. This can be proved by fixing the leaf of the Oak or Beech with a piece of cobalt paper on each face and enclosing it between slips of glass. Note-

The one fixed to the lower side assumes the red colour far more quickly than the one on the upper side. 
The Organs of Transpiration.-The epidermal tissue of a plant is generally more or less cuticularised (p. 76), and the amount of water vapour which can be given out by the epidermis depends upon the degree of cuticularisation. In plants where the epidermis is covered by a well-developed cuticle, very little water vapour is given out. If the cuticle is very thin or absent, as in the case of water plants, the leaves droop and wither far more quickly than those with a well-developed cuticle. Those parts of plants which are covered with cork, or with wax, possess a protection against a too rapid loss of water. The Potato is covered with a thin layer of cork, which prevents loss of water through evaporation.

The principal organs by which water vapour is transpired by plants are the Stomata and the Lenticels. The stomata are very small, in fact so small that neither dust nor water can pass through them into the plant ; but their enormous numbers more than makes up for their small size. It is calculated that a Sunflower leaf contains some thirteen million stomata, and that an ordinary leaf of a cabbage may contain eleven million.

Changes in Size of the Stomata.-The stomata also regulate transpiration by changes in their size. They open in bright

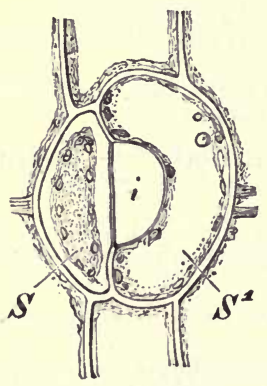

Fig. r57. - Diagram of Stoma. $S$, guard cell, with wall straight; $S^{1}$, guard cell, with curved lateral wall. (S.) light, and close in darkness or in foggy weather. The opening and closing depends upon the amount of light which they receive. The guard cells (p. 94) contain chlorophyll, and when light shines upon them the chloroplasts commence to assimilate and form sugar. In this process water is used up, and the cell-sap becomes denser; a current of sap is thus set up from the cells in contact with them to the guard cells. As more and more sap is absorbed by the guard cells, they become tense, or turgid, and being fixed, they shorten and become curved. The small opening which appears between them is called the stoma.

The stomata close in darkness because then the chloroplasts can no longer assimilate. The sugar which has been previously produced is removed by the movements of the sap, and the sap 
in the guard cells returns to its normal strength. Figures 157 and 158 show the opening and closing of the stomata.

Lenticels and Transpiration.-The lenticels (p. 108) which are formed in the periderm of a woody plant also give out water vapour ; but the quantity so lost can only be small. The lenticels communicate with the intercellular spaces in the plant, much in the same way as stomata communicate with the intercellular spaces in the leaf. In winter the lenticels are closed by ordinary periderm, but they are open in summer.

Force exerted by Transpiring Shoots.-If a branch is cut from a tree, and the cut end is placed in water, it will re-

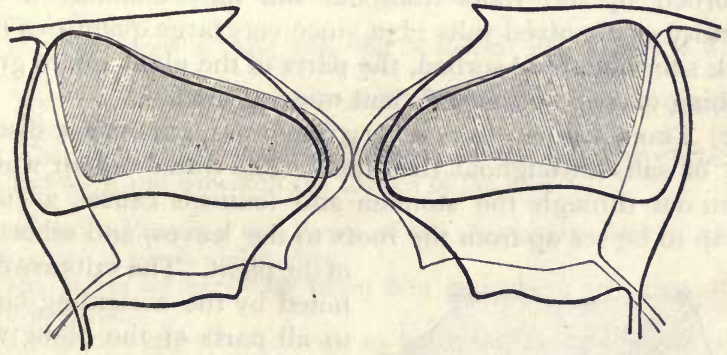

Fig. 158.-Stoma in transverse section. The darker lines show the shape of the stoma when open, and the lighter lines when closed. (S.)

main fresh. This shows that the branch can take in water by its cut end. The force which such a branch can exert while actively transpiring can be measured by the following experiment.

ExpT. 134. - Cut a branch from an Oak tree when the leaves are fully developed, and fix it in an air-tight manner in a glass tube filled with water, the lower end of which dips into a cup of mercury. Note-

(i) The volume of the water decreases.

(ii) The mercury rises in the tube.

(iii) This is caused by the suction exerted by the transpiring shoot.

(iv) The water in the tube disappears to make good that lost by transpiration.

(v) Thus the mercury is forced up the tube by atmospheric pressure.

\section{Conditions Necessary for Transpiration.-}

I. A certain intensity of light; the stronger the light the greater the transpiration. 
(2) The drier the air the more rapid the transpiration; this is shown by noting how soon a plant withers on a very dry day, and the fresh appearance of a plant on a damp, foggy day.

(3) A windy day is favourable to transpiration. If a plant is placed where there is a draught it fades more quickly than if placed where the air is still.

Why Plants Transpire.-The effects of transpiration on the economy of plants are very important and far-reaching. These effects may be summarised as follows :-

(I) Transpiration is the principal way in which plants get rid of the excess of water taken in by the roots. The solution absorbed by the roots from the soil only contains a small quantity of dissolved salts ; but since very large quantities of the weak solution are absorbed, the parts of the plant where growth is going on still obtain sufficient mineral matter.

(2) Transpiration plays a very important part in the distribution of salts throughout the plant. The water vapour which is given out through the stomata and lenticels causes a current of sap to be set up from the roots to the leaves, and other parts

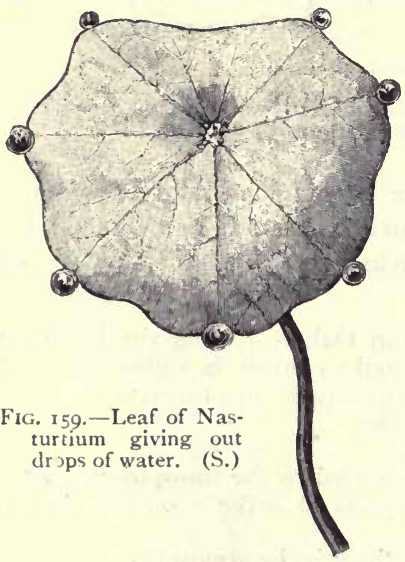
of the plant. The salts are distributed by the ascending current to all parts of the plant where they are required.

(3) Transpiration aids the absorption of water and salts by the roots. If a plant is growing in a water culture solution, and is covered by a bell-jar, the transpiration is continuously reduced, until at last it stops altogether. If the bell-jar is removed, transpiration increases again, because the water vapour can now escape.

Liquid Water Given out by Plants. - If the leaves of Grasses, Buttercup, Strawberry, Lady's Mantle, and most other plants be examined on a summer morning, drops of glistening water will be seen to hang from them. For a long time it was thought that these drops had been deposited on the leaves from 
the atmosphere. They were said to be drops of dew. But in far the larger number of cases the water has been pumped out of the water-pores. The roots have taken in an excess of water, which has been forced up the stem to the leaves. In these plants transpiration is reduced to a minimum, and the water exudes from the water pores, stomata, or through the epidermis. These drops are evaporated as the sun gains more and more power. A deposit of carbonate of lime, or some other mineral which encrusts the leaves, is often left behind, as in the London Pride, Gooseberry, and Currant.

Expr. 135.-Examine a leaf of the Lady's Mantle on a warm summer morning. Note-

(i) The leaf forms a little cup, and is shaped like a mantle with a number of lobes.

(ii) The cup of the leaf is often filled with water which has oozed out of every leaf-tooth.

(iii) That after emptying the leaf, drops of water ooze out of the end of the leaf-teeth and collect in the bottom of the leaf.

Expт. 136.-Examine the leaves of the Arum, also known as the Cuckoo-pint, or Lords and Ladies.

(i) The leaves are very long (from 6 to ro inches), and are hastatecordate in shape.

(ii) Drops of water can be seen to fall from the tips of the larger leaves at very short intervals.

ExPT. 137.- Place a bell-jar over some grass plants which are growing actively. Note-

(i) The leaves, which were dry to commence with, become in a short time covered with drops of moisture.

(ii) Remove the bell-jar, and the moisture evaporates into the atmosphere.

Root-Pressure.-If the stem of a vigorously-growing plant, such as the Indian Corn or Sunflower, be cut off just above the soil, and the cut surface be dried and examined by a hand lens, water is seen to ooze out of the cut vascular bundles. It is also a well-known fact, that if a vine is cut in spring, the cut stem will bleed; but if it is cut in summer, when the foliage leaves are fully developed and transpiring, it will not bleed. The power which the roots possess of forcing water up the stem is called root-pressure.

The amount of this pressure can be measured by cutting off the stem of a plant just above the surface of the ground, and 
fixing on the cut end a manometer (Fig. 160). The pressure is often sufficient to force the mercury up the tube to a height of

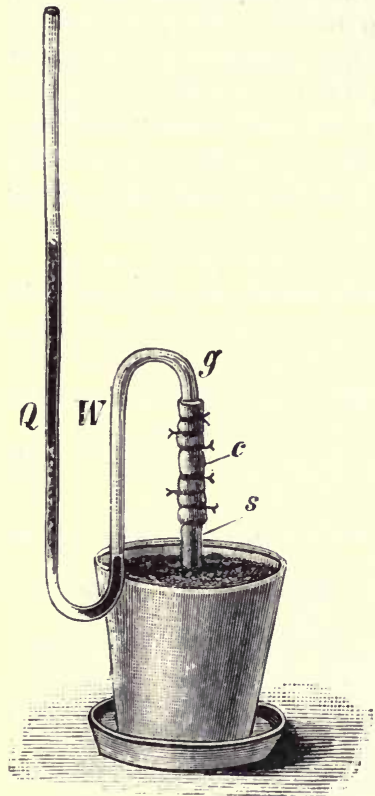

FIG. 160.-Apparatus for measuring root-pressure. The glass tube $g$ is joined to the cut stem $s$ by means of the rubber tubing $c$. The mercury $Q$ is forced up the tube by the water $W$, which is given out by the cut stem. (S.) several inches. In the Nettle the root-pressure observed has been found to be sufficient to support a column of mercury about 15 inches high.

How Root-Pressure is Set Up.--In spring the root-hairs are very active, taking in large quantities of water from the soil, which passes by osmosis into the cells of the cortex, and when these become filled with water it is forced into the vessels of the xylem. The force with which the water is pumped from the parenchyma cells of the cortex into the vessels of the xylem is produced by the activity of the root-hairs in absorbing more water than can be stored up in the cells of the root.

Thus the phenomenon of rootpressure depends upon the temperature of the soil (p. 140), for it is only when absorption is active that it can take place.

Exp'T. 138. - Cul off the stem of a Dahlia or Sunflower just above the soil, and fix to the cut end a hollow glass tube which contains a little coloured water. The fixing can be done by sliding the glass tube over the end of the stump and using rubber bands to hold it in place, and to pack the base of the tube. Note-

The water is pushed higher and higher up the tube against the pressure of the atmosphere. The weight of the water lifted will give the amount of the root pressure.

EXPT. 139.-In spring, cut off a branch of the Barberry. Note-

(i) A whitish fluid, the sap, oozes out of the cut end.

(ii) The sap is forced out by the root-pressure. 
How the Water Travels from the Roots to the Leaves.-The water which, as we have seen, is forced into the xylem vessels of the root finds its way to the deaves (as far as we know at present) up the interior of the vessels of the stem. Professor Dixon, and Jr. Joly, found that if they blocked up the interior of the vessels with paraffin-wax, only a little water found its way up the stem, and the leaves on the branch soon flagged. It would take far too long for the large quantity of water which the plant requires to pass either up the parenchyma cells, or through the cell walls. The water is able to move faster up the interior of the vessels than in any other direction.

The Transpiration Current.-The current of water which passes up the stem from the roots to the leaves, to make good that lost by transpiration, is called the transpiration

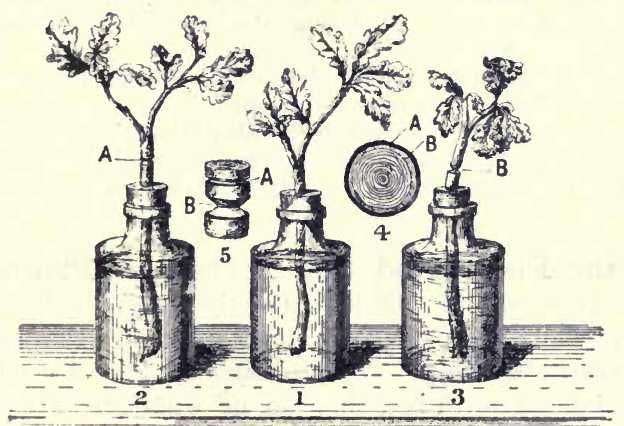

FiG. 161.-Diagram illustrating how the water moves up a stem. 1, A nornal branch from the Oak in water, the leaves of which are fresh; 2, a branch of the Oak with the tissues removed down to the new wood; 3 , a similar branch with the new wood taken out, the leaves are dried up; 4,5 , sections of the same.

current. This current travels up the stem of a woody plant, but only through the outer and younger rings (p. 107). The heart wood of an old tree never takes part in the conduction of water, but only the newer rings of the sap wood. The reason why the transpiration current ascends as it does in some trees to a height of over a hundred feet is not fully understood, and 
is one of the problems of plant physiology which requires solving.

The following experiments will demonstrate how the sap travels in woody plants.

ExPT. 140.-Obtain a woody plant, such as an Oak, which is growing in a pot. (a) From one branch remove a ring of tissue down as far as the new wood, i.e., cut away the bark cortex and phloem, and pack the wound with cotton wool to prevent the entrance of fungi. (b) From another branch remove a ring of the new wood, and replace the bark and cortex. Note-

(i) The leaves on the branch, which has only a ring of tissue removed, down to the new wood, are still green and fresh.

(ii) The leaves on the branch, which has had the new wood removed, have flagged; they ultimately die.

(iii) The water, which makes good that lost by transpiration, travels in the new wood, but neither in the cortex nor in the bark.

Expr. 14I. - In many parts of the country old trees may be seen which have lost their heart wood, as well as the outer tissues of the plant. When such a tree is encountered, the following observations should be made. Note-

(i) That leaves are still produced on the upper part of the old stem.

(ii) That the leaves are green and fresh.

(iii) These leaves must be supplied with water. This can only take place through the new wood, because the heart wood and the outer part of the tree have decayed. The water travels only through the new wood.

\section{How the Elaborated Sap Travels in Plants.-The} sap which is acted on in the leaves by the chlorophyll and protoplasm, and which becomes very rich in organic compounds, is called elaborated sap. This is distributed to those parts of the plant where growth is going on, or where reserve material is stored up. How is this elaborated sap distributed? If a leaf is examined the xylem will be found distributed over the upper surface of the leaf, and the phloem on the under side. The xylem brings water and minerals in solution to the cells of the leaf; when this has undergone the necessary changes, and is fit for the nourishment of the plant, it is carried away down the phloem. Different materials are produced in the leaf by the activity of the chloroplasts and protoplasm. These materials can be divided into proteids, fats, and carbohydrates (p. 85-7). Each of these is distributed in a different way throughout the plant. The proteid substances in the elaborated sap travel 
along the sieve tubes of the phloem, and from cell to cell by osmosis, to those parts of the plant where they are needed.

The carbohydrates (sugars) travel in solution along the parenchyma cells which surround the vascular bundles in the leaf and belong to the cortex of the stem.

The needs of the various parts of the plant cause the current to move to those places where material is being used up in the formation of new cells, or is being stored up as reserve material.

ExpT. 142.- From the plant used for Experiment 140, cut away from a branch a ring of tissue so as to remove the phloem. NoteThe branch below the cut will not increase in size unless elaborated sap is brought from some other part of the plant, and, as a rule, this does not take place.

ExPT. 143.- Remove a branch from a woody plant, such as the Beech, and at about nine inches from the base remove a ring of tissue down to the new wood. Place the branch in water. Remove another branch, and place it in water without injurying it. Note-

(i) New roots are produced from the portion of the stem above the place where the ring of tissue has been removed.

(ii) No adventitious roots are produced from the portion below the wound, because no elaborated sap can pass through the wound because it can only travel through the phloem, and this has been removed.

(iii) The branch from the tree which was placed in water without being injured produces roots from the tip of the stem.

\section{SUMMARY.}

Absorption of Water and Minerals. - All materials (with the exception of carbon) which plants require for their growth are taken in by the root-hairs and uncuticularised portions of the root.

Absorption. - That roots absorb is shown by placing the roots of a plant in a solution of eosin, when their internal parts are stained.

Osmosis. - The mixing of fluids through a permeable membrane is called osmosis ; for osmosis to take place it is necessary for the fluids to have different densities.

The sap given out by roots can dissolve some of the insoluble constituents of the soil.

Conditions necessary for Absorption. -

(I) The air surrounding the plant must have a certain temperature.

(2) The soil or solution in which the plant is growing must also have a certain temperature.

(3) The strength of the solution has a decided effect on absorption.

Plants give out Moisture. - Places with a prolific vegetation have a moist atmosphere. An Oak tree gives out many gallons of water on 
bright summer days; a Sunflower during its active life gives out 200 times its dry weight of water.

Transpiration is the giving out of water vapour by a plant. Only those parts of a plant in contact with the atmosphere can transpire.

The Organs of Transpiration.-Stomata and lenticels are the organs by which plants lose the greater portion of the water vapour which they give out.

Conditions favourable to Transpiration.-(I) A certain intensity of light; (2) a dry atmosphere; (3) a windy day.

Why Plants Transpire. - (I) To get rid of the excess of water taken in by the roots; $(2)$ to aicl the distribution of salts throughout the plant ; (3) to aid absorption of water and salts by the roots.

Liquid Water given out by Plants. - Plants like the Lady's Mantle, Buttercup, and Arum give out liquid water through water pores, stomata, or epidermis.

Root Pressure is the power which roots possess of forcing water up the stem.

How Root Pressure is Set Up.-Root-hairs are very active in spring, and take in large quantities of water until all the cells of the roots are filled. The water from the cells exudes into the vessels of the xylem, and it is then forced up the stem to the leaves.

Water Travels in Plants up the interior of the vessels of the new wood.

The Transpiration Current is the current of water which passes up the stem to make good that lost by transpiration. It either passes up the younger and outer rings of the wood (woody plants), or through separate vascular bundles (herbaceous plants).

Elaborated Sap has been acted on by the chlorophyll anci protoplasm in the leaves. It travels in the following ways-(I) The proteid substances in it pass along the sieve tubes; $(2)$ the sugars move through the parenchyma cells round the vascular bunclles; (3) a slow movement occurs from cell to cell to make goorl the loss due to growth.

\section{Questions on Chapter XI.}

(I) What part of its food does a green plant obtain by means of roots? How does the root absorb food ? (I 897.)

(2) What do you know about-

(a) The materials found in a fertile soil?

(b) The substances found between the particles of a soil ?

(i) The way in which water travels in a soil?

(3) Define the term osmosis. Explain the part which osmosis plays in the nutrition of a plant.

(4) What conditions are necessary for absorption?

(5) What are the functions of the root? Briefly explain the relation between the structure and functions of a root. (I893.)

(6) Explain why it is that plants droop on a hot day and recover their freshness in the evening. (1889.)

(7) What is the "transpiration current"? State by what tissue it 
travels in the plant, and describe an experiment proving your statement. (1897.)

(8) What is the chief function of the wood? Give experimental evidence in support of your answer. (I89I.)

(9) Explain what is meant by " root-pressure." What manifestation of it occurs in nature? (1892.)

(I0) Give an account of the absorbent organs of roots, and of the process of absorption. (I892.)

(II) The trunk of an Oak tree, when in full leaf, is sawn all round so deeply as to cut through the sap-wood. State and explain the effect of this operation. (I893.)

(12) Describe the effect of a tight ligature upon a growing hazel stem.

(I3) What is meant by transpiration? In what circumstances do plants transpire most? Give experiments which demonstrate how transpiration takes place.

(14) Why does a branch when removed from a plant begin to flag? How may this be prevented? (1885.) 


\section{CHAPTER XII}

\section{THE PHYSIOLOGY OF GROWTH AND MOVEMENT}

Growth.-The permanent change of form which takes place in living plants is called growtl. The change of size in a dead seed which takes place when it is placed in water is not a permanent change, for if the water is removed it returns to its original size. On the other hand, if a living seed is supplied with water, the young embryo it contains commences to develop. Root, stem and leaves are produced, and a permanent change in shape and size takes place, or in other words, it grows. It is only living things which can grow.

Conditions which are necessary for Growth.I. Heat. The plant and surrounding air must be at a certain temperature. In winter the temperature of the soil is too low for absorption to take place, and growth is arrested. The lowest temperature at which plants can grow is said to be the minimum temperature of growth. There is a temperature above which no growth can take place. This cessation of growth may be caused either by the activity of the protoplasm being arrested, or by the cells losing water so that they are no longer turgid. The highest temperature at which plants can grow is called the maximum temperature of growth. The extremes of temperature above and below which no growth can take place vary for different plants. Between the minimum and maximum temperatures there is one at which plants grow best ; this is said to be the optimum temperature for growth.

2. Water.-No plant can grow without water, since this substance enters into the composition of all protoplasm. Water is also necessary as a medium for carrying nutritive materials to those parts of the plant where growth is taking place, and it is 
the means by which the green parts of plants are kept fresh, and the cells turgid.

3. Oxygen.-Those parts of the plants where growth is proceeding require oxygen, for without it no energy can be produced. No growth can take place without energy. Energy is produced when a plant respires (p. 125).

4. Food Materials. - There must be suitable food materials present. Food may either be stored up in seeds, or it may be taken along with water from the soil, or be obtained by the leaves.

5. Cells in an Embryonic Condition.-The cells of some parts of the plant must be in such a condition that they can divide and increase in size.

6. Light.-While light is not absolutely essential for growth, it is still necessary for healthy growth. Plants will grow faster in the dark than in the light, as is well seen in the case of Rhubarb, which when forced in the dark, has small leaves and long and slender stems. When grown in the light the stem of Rhubarb is short and thick, and its leaves large. Speaking generally, it may be said that most plants grown in the dark have soft stems, which are very much elongated, and of a pale colour. The leaf-blades, in similar circumstances, are small, and yellow in colour, and the tissues of the plants have thinner walls, and contain more water than those grown in the light, or, light may be said to retard growth.

If wheat seeds are sown too close together so that light cannot pass between the plants, the stems become long and so slender that they can no longer support the ears of corn, and the stems bend under the weight. This constitutes the so-called laying of wheat. It can be prevented by leaving a sufficient space between the rows to enable light to pass between the plants, when the growth will be normal.

The rapid growth of shoots produced from bulbs, tubers, rhizomes, and seeds is especially valuable, for the light is thus reached very quickly, and the plants are then capable of independent nutrition.

Plants grow more rapidly during the night than day. During the day assimilation goes on and the materials then stored are used up during darkness in producing a permanent change in the plant. 
ExPT. 144.-Fill two plant pots with soil, and sow a few Mustard seeds in each. Keep the soil moist. Place one pot in a window and the other in a dark cupboard. Measure the length of the plants in each pot from time to time. Note-

(i) The plants kept in the dark cupboard are yellow in colour ; those exposed to light are green.

(ii) Those grown in the dark increase in length nearly three times as fast as those grown in the light.

(iii) The leaves of the plants grown in the dark are very small, but those produced in the light are far larger.

(iv) The plants kept in the dark begin to droop and soon die ; those grown in the light are healthy and strong.

(v) The plants in the dark are often attacked by fungi.

(vi) Iight is necessary for the healthy growth of plants, but they grow faster in the dark.

Growth in Length of Plants.-At the apex of a shoot or root are two zones of growth. At the extreme apex of the stem there is a meristematic layer where new cells are produced by division. Just behind this region the cells increase in size, but little cell division takes place.

Most herbaceous plants from time to time show a change in the vigour of the growing point. If a plant like the Deadnettle is examined, the nodes at the base are seen to be crowded together ; that is, the internodes are short. Higher up the internodes are longer, while again towards the apex the nodes are crowded together and the internodes are short. The variation in the length of the internodes depends upon the strength of the growing point. At first the growing point is not very vigorous and it produces short internodes; as it gains strength, longer and longer internodes are produced. Later, its strength or activity again declines, and the internodes become shorter until the period of growth has ceased. Similarly in the life of most plants there is a grand period of growth.

Monocotyledonous plants, like the Indian Corn, show this increase in the vigour of the growing point to perfection. If the plumule of a germinating seed of Indian Corn be examined it will be found to be about $\frac{1}{8}$ of an inch in diameter. If the diameter of a mature stem be measured it will be found to be many times larger. How has this increase in size been produced? The growing point at first could only form a thin stem, but as its strength increased, a larger and larger stem was produced. But, here again, the vigour of the growing point declines later in life and the stem produced has a smaller diameter. 
ExPT. 145.-Obtain a well-developed Deadnettle and examine it. Note-

(i) The leaves are crowded together at the base and apex; between these two regions they are further apart.

(ii) The leaves are produced at the nodes in pairs; where the internodes are long the leaves are a greater distance apart.

(iii) That part of the stem where the internodes are longest were produced during the grand period of growth.

EXPT. 146. - Sow a few seeds of the Indian Corn in a pot. Keep the soil moist and warm, and exposed to light in a window. Measure with a tape-measure both the growth in length and thickness of the seedlings from time to time. Measure and record-

(i) The circumference of the plumule when it first appears above the ground.

(ii) The length of the plumule when it first appears above the ground.

(iii) Repeat the above measurements every day during the growth of the plant.

(iv) Preserve the record of the series of measurements for future reference.

EXPT. 147.-Germinate a Bean seed, and when the radicle is welldeveloped wash it. Measure off half an inch from the tip of the radicle, and divide it into ten equal parts by marks with Indian ink. Pass a fish hook through the seed, and suspend it to a cork in a bottle which contains a little water. Examine at the end of twenty-four hours. Note-

(i) The amount of growth. Measure from the tip of the radicle to the mark nearest the base.

(ii) The grand period of growth is well illustrated by the amount of elongation between mark (3) near the tip and mark (4) from the base.

(iii) The differences in the amount of growth in the different parts of the root are due to the two zones of growth. The greatest amount of elongation takes place in the zone where the cells are increasing in size.

Irritability.-Living protoplasm possesses many properties, but one of the most important is its power of responding to external stimuli. This property is called irritability or sensitiveness. The response to these external agencies very commonly produces movements.

Growing organs possess the property of irritability to a far greater extent than the older parts of plants. The irritability of growing organs must be distinguished from the irritability of mature organs. 


\section{ThE IRRITABILITY OF GROWING ORgans.}

The principal stimuli which act on the growing organs and produce movements are light, gravitation and water. The agencies which act on protoplasm, and the movements which they produce, will here be considered.

The Action of Light on the direction of Growth.The importance of light to plant life cannot be overestimated. We have seen how necessary it is for assimilation, and for the healthy growth of a plant. The various parts of plants react in different ways when exposed to light. The aërial portions generally turn towards the light, while those parts which under normal conditions develop in the dark, turn from it. In the case of the former light is necessary for their full development, but the latter can grow without light.

Heliotropism.- The action of light is well shown by window plants. The stems of such plants are not erect as in the open air, but are inclined towards the source of light. This turning of a portion of a plant either towards or away from the light is called heliotropism.

Positive Heliotropism.-The portions of a plant which turn towards the light are said to be positively heliotropic. The stems and leaf-stalks incline towards the source of illumination so as to place their long axis parallel with the rays of light. But the leaf-blades arrange themselves at right angles to the illumination and so receive the maximum amount of light.

Negative Heliotropism.-Those parts of the plant which turn from the light are said to be negatively heliotropic. Roots, rhizomes, and bulbs turn from the light and are consequently negatively heliotropic. Aërial roots like those of the Ivy also turn from the light.

ExpT. 148. - Place a pot containing a Castor Oil plant on a window sill, and observe it from day to clay. Note-

(i) The sten and leaf-stalks bend towards the sun; the divided leaves arrange themselves at right angles to the winclow.

(ii) If the pot is turned, the leaf-stalks and leaf-blades move round until they occupy their old position.

ExPT. 149. - Examine a piece of Ivy which is clinging to the wall or to the trunk of a tree. Note-

(i) Most of the clinging roots are developed on the shady side of the stem.

(ii) The roots developed in the light are turned away from it. 
Exp1. 150.-Obtain a box which will just cover a pot of Musk. Cover the pot with the box, and so arrange matters that the light from a window can shine on the plant. Examine in twenty-four hours. Note-

(i) The plants turn towards the light.

Turn the box so that the light can only shine into one corner.

(ii) On the following day the plants will have turned again to seek the light.

Turn the box so that the plant can only receive light from the room.

(iii) At the end of another day the plants turn once more to catch the diffused light.

(iv) Plants like Musk are light-seekers. They always arrange themselves so as to receive the maximum anount of light.

\section{Constituents of White Light which Produce} Heliotropism.-If a plant is grown so that the red and yellow rays of the spectrum (p. 123) can fall on it, there is either only a little curvature or none at all. But under the influence of the blue and violet rays nearly as much curvature takes place as in white light.

ExPT. 151. - Obtain two boxes similar to the one used in Experiment 150. Make grooves in each, so that the open sides of the boxes can have slips of glass inserted. Germinate three pots of Cress and mark them A, B, C. Place pot A on a window sill exposed to white light. Cover $\mathrm{B}$ with a box and slide a piece of red glass into position, so that red rays can only fall on the plants. Cover $\mathrm{C}$ with the other box and slide a piece of blue glass into position, so that blue rays can only pass to the plants. Note-

(i) The plants in pot A turn towards the window in the same way as the Musk did.

(ii) The plants in pot B grow erect; they do not curve in any direction.

(iii) The plants in pot $\mathrm{C}$ curve towards the source of light just as do the plants in pot $\mathrm{A}$.

Experimental Results. - It must consequently be concluded :-

(1) That plants growing in a window, and more strongly illuminated on one side than the other, bend towards the source of light.

(2) That plants which receive only red rays grow erect, and do not curve towards the source of light. Or, they grow as they would in the open air. The rays from the red end of the spectrum are not instrumental in producing curvature. 
(3) That plants which receive blue rays bend towards the side where the strongest light falls, just as plants do which grow in white light.

(4) That the curvature of positively heliotropic organs is due to the rays from the blue end of the spectrum.

Why Heliotropic Movements take Place.-The movements which plant organs show when acted on by light is due to the elongation of the side in the shade. Either the side in the shade grows faster than that exposed to the brighter light, or a different distribution of water occurs in the cells of the organs. It must be distinctly understood, that no matter what the external agency may be which produces the curvature, it is the protoplasm of the plant cells which responds to it.

Geotropism.-We have seen that most shoots either grow erect or bend towards the light, but that roots grow away from the light. There is, however, another external agency in addition to light, which acts on the various parts of plants. This force plays a very important part in determining the direction of the organs of plants and is spoken of as gravitation. ${ }^{1}$

The property which enables plants to take up a definite position under the influence of gravitation is called geotropism. Some organs grow in opposition to the attractive force of the earth, others grow in the same direction as gravitation acts. As in the case of heliotropism, we use the terms negative and positive in describing the two conditions of growth.

Positive Geotropism.-Those parts of plants which grow towards the centre of the earth are said to be positively geotropic. Tap roots, aërial roots, and a few cotyledonous sheaths, grow downwards and are positively geotropic. Lateral roots and stems grow outwards, and are described as being diageotropic. In some cases the tap root has become injured, and one of the secondary roots has developed a positively geotropic growth.

Negative Geotropism.-All those parts of a plant which grow upwards or away from the centre of the earth are said to be negatively geotropic. This is the rule with erect stems, flower-stems, and a few leaves.

I As the student will probably know, by gravitation is meant the mutual attraction between material hodies separated from one another. This mutual attraction between the earth and bodies near it gives rise to the weight of bodies. 
ExpT. 152.-Germinate a few Peas in damp sawdust. Place one on damp soil. Place another with the radicle and plumule in a horizontal position on a piece of glass which is covered with damp blotting paper. Note-

(i) The radicle of the Pea in the damp soil bends downwards and the plumule upwards.

(ii) The plumule of the Pea on the piece of glass grows straight upwards, but the root grows along the piece of glass until it reaches the edge, when it turns so as to make nearly a right angle with the rest of the root, and then grow downwards.

(iii) This shows that the root is positively geotropic and the stem negatively geotropic.

Expт. 153.-Make a hole in the bottom of a glass tumbler for drainage. This can be done by striking a blow at the centre with a sharp pick. The tumbler may crack, but if it holds together anyhow it will do. Fill with soil (p. 13), and put a quick growing plant in it. Expose to light. Note-

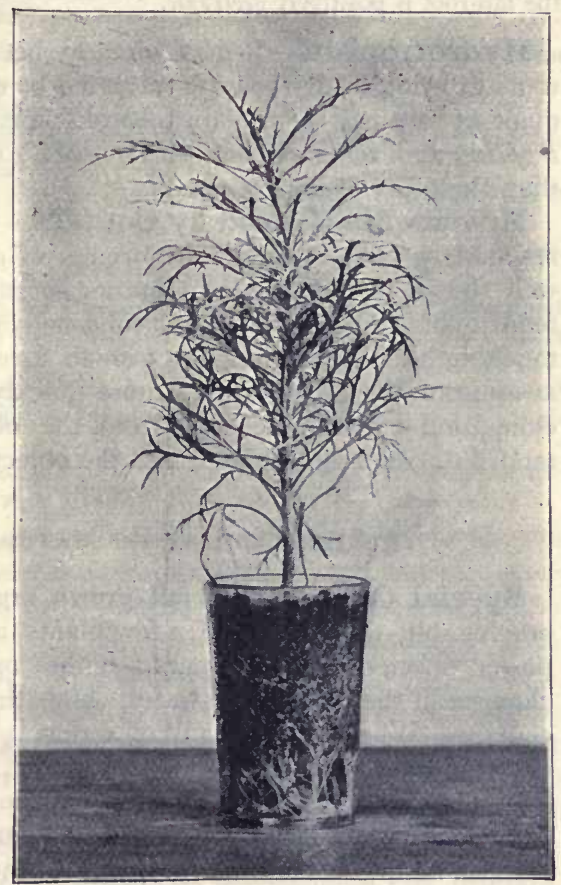

Fig. 162.- Photograph of a plant grown in a tumbler to show the distribution of the roots. The white roots are close to the side of the tumbler. During the growth of the plant the tumbler was covered with brown paper. The plant produced both flowers and fruits.

(i) No roots will be

seen near the glass (Fig. 162), or, if they should appear there, they will soon bend away from the light.

Cover the tumbler with brown paper to prevent the light from affect ing the roots. Examine in a few days.

(ii) The soil near the glass is packed full of roots.

(iii) If the plant and soil are turned out, and a sharp knife is used to 
cut a slice of soil away near the centre, it will be found full of roots with the tap-root growing downwards.

(iv) This shows that the ordinary roots are negatively heliotropic and the tap-root is positively geotropic.

Hydrotropism.-It has already been seen (p. 59) that roots growing in dry soil are attracted by moisture. The movement of any part of a plant towards moisture is termed hydrotropism, and roots possess this property to a far greater extent than the other organs of plants.

Movements Caused by Contact.-Just as animal bodies respond to contact so do the organs of a few plants. This is well shown in the case of climbing organs (p. 26). When a tendril comes in contact with a solid body the side of the tendril touching the object has its growth arrested, while the side away from the object grows more quickly. This produces an elongation of the side away from the object and causes the tendril to curve and twine round the object.

\section{The Irritability of Mature Organs.}

Special Cases.-Most full grown organs are incapable of moving, but the organs of a few plants are endowed with the power of vigorous movement. These movements are due to changes in the amount of water which the cells of the organs contain. When cells are full of water, it presses on the elastic walls and they become greatly distended, their cavities becoming enlarged. If the cells lose water, the walls shrink and the cavities are diminished. It is to the changes in the size of the cells of an organ that the movements under consideration are due.

The amount of water in the cells depends upon the temperature and amount of light which they receive. The change in the position of leaves and the opening and closing of flowers are due to changes in the turgidity of the cells on different sides of the leaf. The turgidity, depending as it does upon the amount of water absorbed, is evidently produced by the amount of light and by the temperature. Many flowers and leaves show a periodic movement.

The Opening and Closing of Flowers.-Many flowers and some inflorescences (p. 156) change their position from day 
to night. It is a general rule that flowers are open during light and closed at night ; but a few open at night and close during the day. The closing of the flowers during darkness is called the sleep of the flowers.

EXPT. I 54.-Collect a few flowers of the Dandelion, and place them in a tin box so that they receive no light. Note-

(i) At the end of an hour they are all closed up.

Now place their cut ends in water and expose them to a bright light.

(ii) They will open again.

This shows that the amount of light which they receive causes them to open and close.

EXPT. 155.-Bring a Tulip plant with fully developed flowers, which are closed, into a warm room. Note-

(i) If the temperature of the room is about ten degrees Fahrenheit higher than the external air whence the plant was obtained, the flowers open.

Now expose the flowers to a lower temperature, either by placing them outside in the cold, or by surrounding the pot with a mixture of salt and ice.

(ii) The flowers will close. The closing of the flowers is due to the decrease in the amount of heat which they receive.

The Sleep of Leaves.-If the compound leaves of the Wood Sorrel or Clover are examined during early morning they are found to be folded so as to expose the least amount of surface to the atmosphere. If the same leaves are noticed at noon they will be seen to be fully expanded.

The Utility of Plant Movements.-The heliotropic and geotropic movements of organs place them in the most favourable position for performing their functions.

Thus, when leaves are placed at right angles to the rays of light, they receive the maximum amount of light and energy, and are thus able to assimilate to perfection. The primary root being positively geotropic, carries the secondary roots into new soil from which food is obtained. The primary stem growing erect, places the aërial organs in a good position for receiving light. The roots being both geotropic and hydrotropic, they are placed in a good position to obtain food, and to fix the plant firmly in the soil. The flowers close at night to protect the internal organs from losing heat by radiation, and to prevent them from being washed by rain and dew. They open in warm sunshine so that insects can visit them, and close in the cold to prevent loss of heat. Those flowers which open during darkness and close during light are visited by night-flying insects. 
The change from the diurnal to the nocturnal position, which many leaves undergo, protects them from rain, snow, hail, changes in temperature, and prevents loss of heat by radiation. The leaves are folded so as to expose the minimum amount of surface to the air during their nocturnal position, and during the diurnal as much surface as possible is exposed for assimilation.

\section{Summary.}

Growth means a permanent change of form. It is only living things which grow.

Conditions necessary for Growth.-(I) A certain temperature which varies for different plants. For every plant there is a minimutm temperature below which no growth can take place, and a maximum above which growth will be arrested. Between these points the optimum temperature occurs.

(2) Moisture nust be present, because it enters into the composition of the protoplasm.

(3) Oxygen is necessary for most plants.

(4) Suitabie food materials must be present.

(5) Light is necessary for the healthy growth of all green plants. Light prevents too rapid growth.

Irritability means the property of protoplasm to respond to external influences. Most growing and some mature organs possess this property. Light, gravitation, and moisture are the principal agents which produce movements in growing plants.

The Action of Light on Growing Organs.-Heliotropism refers to the power of turning either towards the light or away from it which plants possess. Most shoots bend towards the light and are said to be positively heliotropic. Roots, rhizomes, and bulbs turn from the light and are said to be negatively heliotropic.

Heliotropic movements take place as a result of changes in the length of one side of the organ in comparison to the other. This produces curvature.

Geotropism is the property which enables the organs of plants to take up a definite position in regard to gravitation.

Movements caused by Contact. - When a tendril comes in contact with a support, the side which touches it has its growth arrested, and the opposite side grows more quickly. This causes curvature, and enables the tendril to twine round the support.

The Sleep of Flowers and Leaves. - Many flowers and leaves change their position from day to night. The movements are produced by changes in the amount of water which the cells of the various parts of foliage leaves or floral leaves contain.

The Utility of the Movements. - All the movements which the various parts of plants perform are to bring the plants into touch with their surroundings. 


\section{Questions on Chapter XII.}

(r) Define the term growth. What conditions are necessary for growth?

(2) Why does Rhubarb grow faster in the dark than in the light ?

(3) Give an account of an experiment which proves that plants grow faster in the dark than in the light.

(4) Explain, and illustrate by an experiment what is meant by "a grand period of growth" in the life of a plant.

(5) The protoplasm is said to possess the property of irritability. Explain this.

(6) Why do the stems and leaves of window plants take up a definite position with regard to the light?

(7) Explain the term heliotropism. Aërial stems are said to be positively heliotropic and roots negatively heliotropic. Explain this.

(8) A plant is covered with a blue glass. How will its method of growth differ from one grown under red glass?

(9) Explain why it is that, when a seed germinates, the stem grows upwards and the root downwards. (1889 and I897.)

(10) Describe, and briefly explain, the influence of light upon the direction of growth of stems and of roots. (I89i.)

(I I) What is the effect of light upon the direction of growth of stems and leaves? (I896.)

(12) Most flowers are open in the light and closed during darkness. Explain how this change is produced, and of what service it is to the flower. 


\section{CHAPTER XIII}

\section{FLOWER AND INFLORESCENCES}

Floral Leaves. - In addition to the foliage leaves p. 3I), stipules (p. 45), and bracts (p. 46), which have already been dealt with, certain modified leaves which go to build up the flowers of a flowering plant, and are called floral leaves, now

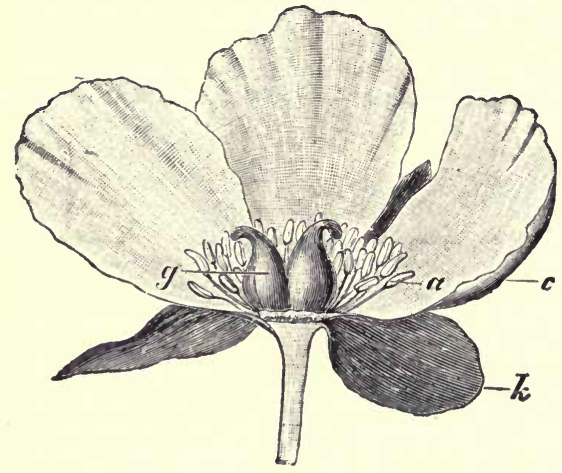

FIG. I63.-Diagram of Flower in longitudinal section. $k$, calyx ; $c$, corolla ; $a$, andrœcium ; $g$, gynœcium. (S.)

call for consideration. The successive whorls or rings of floral leaves are, commencing with the external whorl, as follows.

1.- The Calyx, built up of separate leaves which receive the name of sepals. Each sepal is a modified leaf and is, as a general rule, green.

2.-The Corolla, built up of petals. Each petal is also a modified leaf, which may be brightly coloured and of a peculiar shape.

3.-The Androcium is built up of stamens which form the male organs of reproduction and produce a substance called pollen. Each stamen is, like a sepal and petal, a modified leaf ; it 
performs a special work in connection with the reproduction of plants.

4.-The Gynocium, or pistil, is built up of carpels. The pistil constitutes the female organ of reproduction and always occupies the centre of the flower. It produces ovules, which under healthy conditions form the future seeds. The following experiments will make clear what is meant by floral leaves.

ExpT. 156.-Examine a Wallflower. Note-

(i) The calyx on the outside of the flower. In this case it is built up of four sepals, each of which is long and hairy. The two inner sepals are swollen at the base. Each sepal, which is either yellowish or brownish-red in colour, can be pulled off without tearing it from its fellows.

(ii) Standing just within the calyx, and alternating with the sepals, four yellow or reddish-brown leaves will be found. These form the corolla. The petals are arranged in the form of a cross and are the largest leaves of the flower.

(iii) Within the corolla six stamens occur. Four are long and two short. Remove one : it consists of $(a)$ a stalk, called a filament; $(b)$ a head-the anther. Open the anther: it contains a number of microscopic pollen grains.

(iv) The centre of the flower is occupied by two carpels joined together, which form the pistil, and is divided at the apex into two lobes. The long somewhat swollen body forming the lower part of the pistil is called the ovary. The lobes at the apex of the ovary form the styles, and the tips of these form the stigmas.

(v) Open the ovary: a number of rounded bodies are seen-the ovules.

ExpT. 157.- Examine the flower of a Buttercup. Note-

(i) The five sepals (green and leaf-like in appearance) on the outside forming the calyx.

(ii) Five yellow petals, constituting the corolla, are found just within the calyx, filling the gaps between the sepals.

(iii) A number of yellow stamens, each consisting of a filament and an anther. The anthers, if ripe, are full of pollen.

(iv) Many small green carpels - not united together as in the wallflower-make up the pistil. Each carpel possesses at its base a swollen portion-the ovary-and above this the style and stigma can be distinguished.

(v) In each ovary a small egg-shaped ovule is to be found.

Flower.-The following reasons lead us to believe that a flower is a modified shoot.

I. - The flowers are produced either at the apex of a shoot or in the axil of foliage leaves. This is just the position in which we find branches or shoots (p. 16). 
2.- The floral leaves are arranged either in a lateral (p. 17) or in a spiral (p. 37) manner. This is just what we find in the case of foliage leaves (p. 36-7).

3.-The floral leaves are very often leaf-like in form, markings, and colour.

4.--In many cases the intermediate forms between floral leaves and foliage leaves can be seen on one plant. Thus, in the White Water-Lily there are numerous intermediate forms between carpels, stamens, petals, and sepals. In the Christmas Rose, too, all the various stages between foliage leaves and carpels can be made out.

5.-Under cultivation, or change of surroundings, the floral leaves may become changed. Thus, in the cultivated Rose, the stamens and carpels have been converted into petals. In some cases wild flowers can be collected possessing green leaves instead of carpels.

A flower is a branch which has become modified for the special work of producing seeds for the reproduction of its kind.

Inflorescence.-An inflorescence is a collection of flowers produced from a common stalk. The common stalk upon which the flowers are borne is called a peduncle or rachis. (Fig. 164). If the flowers possess stalks which connect them to the peduncle the stalks are called pedicels. When the flowers spring from the peduncle without stalks they are said to be sessile.

Many inflorescences are produced in the axils of leaves, when they are said to be axillary. When found at the apex of a shoot the flower is said to be terminal.

Indefinite Inflorescences.-If the flowers at the base of an inflorescence open first, as in the Wallflower and Lily of the Valley, the inflorescence is called indefinite. In such an inflorescence the apex keeps on producing flowers, and we cannot tell where it is going to stop flowering.

Spike.-There are a number of such indefinite inflorescences, all bearing a certain relation to one another. When the flowers are arranged on the peduncle in a sessile manner, i.e., without pedicels, the inflorescence is said to be a spike. Examples-Ribgrass or Plantain, Bistort, and Verbena. (Fig. 165). 
Raceme.-When the flowers are connected to the peduncle by pedicels they form a raceme. This is a very common form
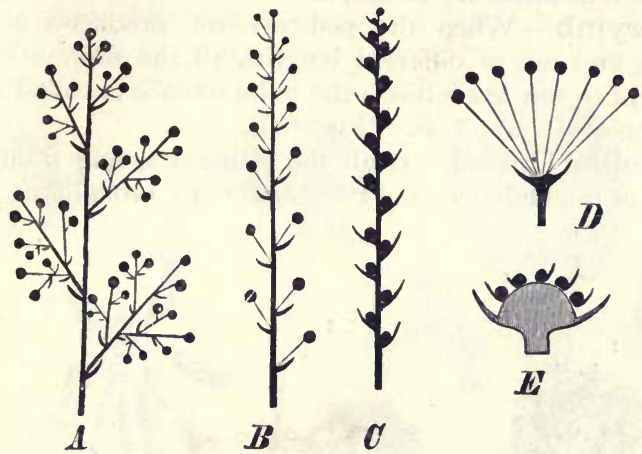

F1G. 164.-Diagram of Indefinite Inflorescences. $A$, panicle ; $B$, raceme ; $C$, spike ; $D$, umbel ; $E$, head. (S.)

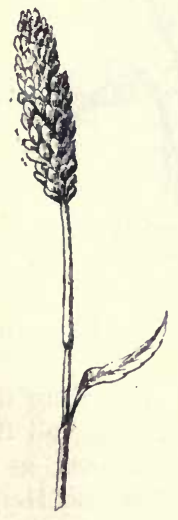

FIG. I65.-Spike of Bistort. (Onetenth nat. size.)

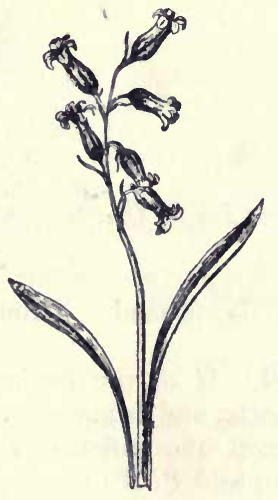

F1G. 166. - Raceme of Wild Hyacinth. (One tenth nat. size.)

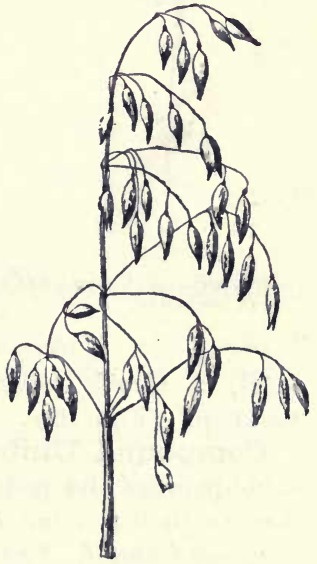

Fig. 167.-Panicle of Oats. (Reduced.)

of inflorescence. Examples - Wallflower, Foxglove, and Hyacinth. (Fig. 166). 
Panicle.-When the pedicels themselves branch, so that there are two or more flowers produced from a single pedicel, a panicle is formed. Examples-Rhubarb, Oats. (Fig. 167).

Corymb. - When the pedicels are produced at different levels, and are of different lengths, all the flowers being thus brought to the same level, the inflorescence is called a corymb. Example-Candy Tuft. (Fig. I68).

Simple Umbel.--If all the pedicels spring from the same point of the peduncle and the flowers are brought to the same

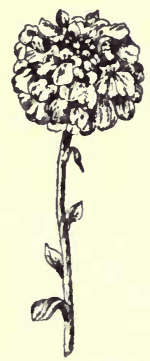

A

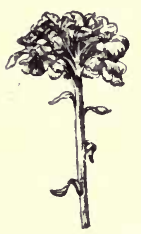

B

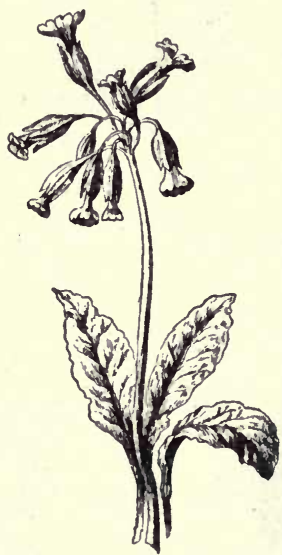

FIG. 168.-A, Corymb of Candy Tuft ; FIG. 169.--Simple umbel of Cowslip.

$\mathrm{B}$, section of. (One-fifth nat. size.)

level, a simple umbel is formed. Examples-Cherry and Cowslip. (Fig. 169).

Compound Umbel.-If all the pedicels spring from the same point of the peduncle, and branch so as to bring all the flowers to the same level, the inflorescence is known as a compound umbel. Examples-Fool's Parsley, Carrot, and Hemlock. (Fig. 170).

Head or Capitulum.-An inflorescence in which the peduncle is shortened and flattened out, and the flowers are fixed to it either by pedicels or are sessile, is called a head or capitulu:n. The flattened-out peduncle is called a common 
receptacle. The capitulum is very common in the order of plants called the Compositæ. The florets of the head open on the outside first, the inner ones opening last. Examples-Daisy, Dandelion, and Clover. (Fig. 172).

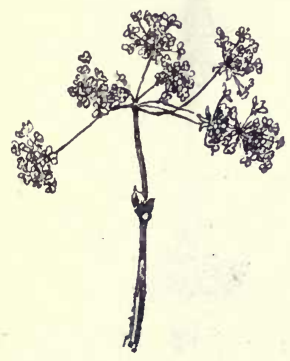

Fig. 170. - Compound umbel of Sweet Cicely.

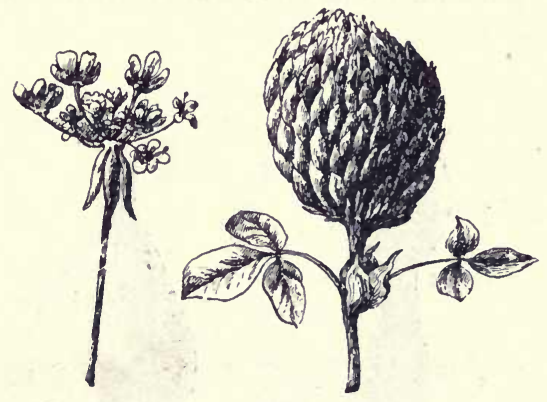

FIG. 172.-Head of Clover. (One-fifth nat. size.) view of portion of compound umbel of Sweet Cicely

ExPT. 158.-Examine the inflorescence of the Wallflower. Note-

(i) The peduncle, or axis upon which the flowers are placed.

(ii) The pedicels by which the flowers are connected to the peduncle.

(iii) The kind of inflorescence. The pedicels spring from different parts of the peduncle and thus form a raceme.

ExPT. 159.-Obtain a Plantain and examine it. Note-

(i) The large number of green flowers which hide the peduncle from view.

(ii) The flowers do not possess stalks, or are sessile on the peduncle.

(iii) The arrangement of the sessile flowers shows that the inflorescence is a spike.

ExPT. 160.-Strip off the flowers from an inflorescence of the Daisy. Note-

(i) The common receptacle upon which the flowers are placed.

(ii) The flowers are sessile, as in the spike.

(iii) The inflorescence is a head or capitulum.

Expт. 16r.-Compare the simple umbel of the Cowslip or Oxlip with the compound umbel of the Fool's Parsley. Note-

(i) In the simple umbel of the Cowslip the pedicels are not branched, while in the compound umbel of Fool's Parsley each pedicel is branched; and at the apex of each branch a flower is produced.

(ii) The flowers in both come to the same level. 
Other Indefinite Inflorescences.--There are a few more indefinite inflorescences which remain to be considered.

Spadix. - The spadix is a spike of male and female flowers. The peduncle is fleshy and is continued for a distance above the place where the flowers are inserted. It is enclosed by a large
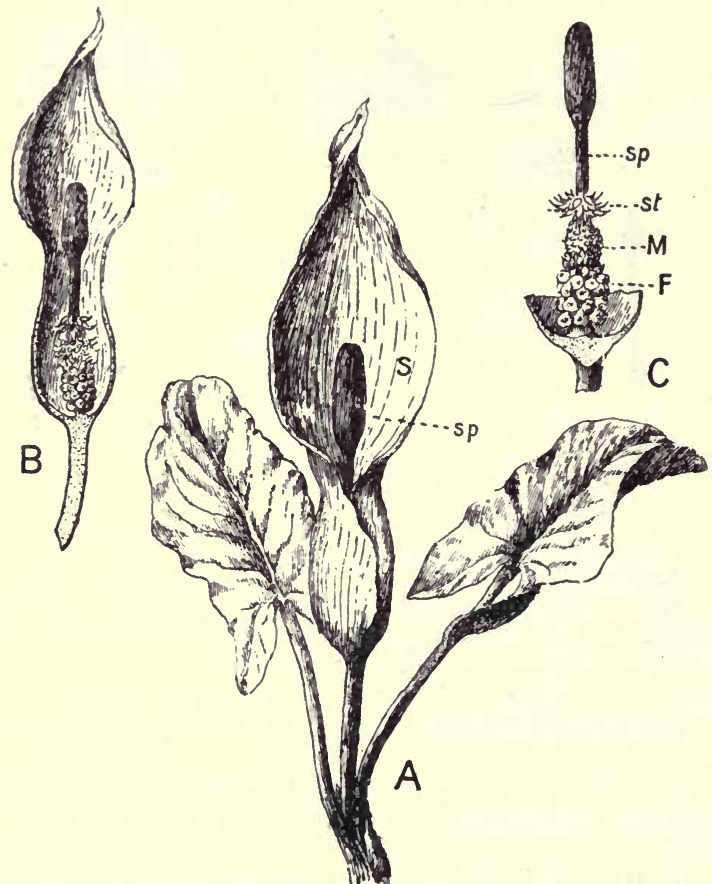

FIG. I73.-A, Arum (one-fourth nat. s1ze). B, Spadix of Arum, with the front of spathe cut away. C, Spadix, with the whole of the spathe cut away; $S$, spathe ; $s p$. spadix ; $F$, female flowers ; $M$, male flowers ; $s t$, undeveloped male flowers.

leaf called the spathe, which in the wild form is green, but in a cultivated state is white. Example-Arum. (Fig. 173).

Catkin.-The catkin is a crowded spike of inconspicuous sessile male or female flowers. When it consists of male flowers alone, it drops off after flowering. The male flowers of the Oak, 
Hazel, and Sweet Chestnut are arranged in catkins. Both the male and female flowers of the Willow, Poplar, and Birch form catkins.

Expт. 162.-In either April or May obtain an Arum and examine it. Note-

(i) The yellowish-green spathe which surrounds the spadix. It is longer than the spadix.

(ii) Cut away the spathe. Notice the inside is, as a rule, full of small flies. The spadix, which is thick and fleshy, is seen within and is generally of a purple colour above the flowers.

(iii) The female flowers are at the base of the spadix and the male flowers are just above these. There is a ring of undeveloped male flowers just above the fertile male flowers.

Expr. 163.-Collect a few catkins of the Hazel. They are produced in the months of February and March. Examine one. Note-

(i) The external appearances of the inflorescence. It is pendulous.

(ii) Renove a single flower with a pin. Observe each flower is connected by a very short stalk or is sessile on the peduncle. Only stamens are found in each flower.

(iii) The inflorescence is a spike of male flowers.

Relation between Indefinite Inflorescences.-The raceme only differs from a spike in having pedicels which separate the flowers, so that they make a better show and are more likely to be seen by insects than the sessile flowers on a spike.

The panicle, which is a compound raceme, generally bears only small flowers, and the arrangement of these on the ends of small stalks causes them to be seen for a great distance. It differs from both the spike and raceme; from the former in possessing stalks, and from the latter in having these branched.

The corymb differs from the raceme in having the pedicels of unequal length, and in the flowers being all brought to the same level. Thus, a more or less flat surface, upon which insects love to rest and collect honey, is formed.

In the head the same result is obtained by the flowers being crowded together on a flat receptacle, an arrangement which also makes them very conspicuous.

Both the catkin and the spadix are spikes; the former is a catkin of male flowers, while the latter bears both male and female flowers. The catkins are produced before the leaves, and by their pendulous position aid in the distribution of the pollen by the wind. 
Definite Inflorescences.-A definite inflorescence is one where the uppermost flower opens first and the lower ones in

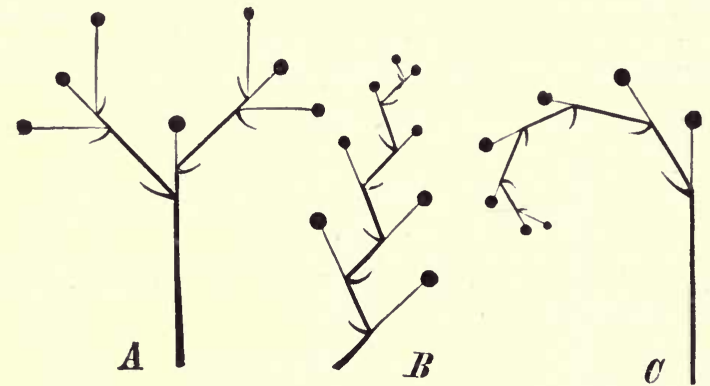

F1G. 174.-Diagram of definite inflorescences. $A$, dichotomous cyme; $B$, helicoid cyme ; $C$, scorpioid cyme.

regular order, beginning at the top. In such an inflorescence it is possible to say where the flowering will cease. Such inflorescences are also called cymose. As a rule the apex of the shoot

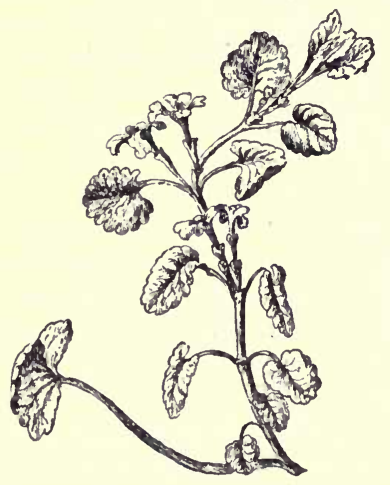

FIG. 175.-Axillary flowers of Ground Ivy. (One-fourth nat. size.) produces a flower, which develops first, the flowering being continued by secondary or tertiary branches. The following are the principal forms of definite inflorescences.

Solitary Flowers.-In the few cases where the apex of the peduncle produces a single flower, the flower is said to be solitary. Example-Tulip.

The solitary flower may be produced in the axil of a leaf, when it is said to be solitary and axillary. Example-Poor Man's Weather - glass, and Ground Ivy. (Fig. I75.)

Dichotomous Cyme.-In the dichotomous cyme the apex of the peduncle is occupied by a flower, which opens first. From beneath this flower new branches are produced, and the apex of each branch also 
produces a flower. Thus, in a dichotomous cyme each apical growing point eventually produces a flower. Examples-Stitchwort and Sandwort. (Fig. 176.)

Scorpioid Cyme.-When the cyme is developed on one side only of the peduncle, and is in the young state rolled up in

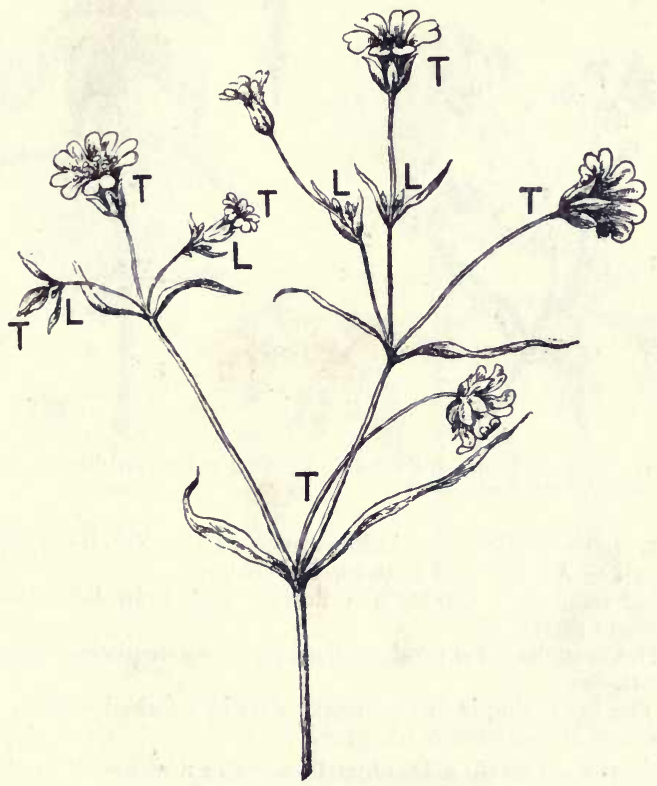

FIG. 176.-Dichotomous cyme of the Stitchwort. T, terminal flower; L, lateral flower.

a spiral manner, it is called a scorpioid cyme. Example--Forget-me-not. (Fig. 177.)

Verticillaster.--If the flowers are produced on opposite sides of the stem, in the axils of leaves, and they stand tier above tier, the inflorescence is called a verticillaster. Some botanists call it a whorled inflorescence, but if it is examined with care the flowers will be seen to grow from the axils of leaves, and only appear to be whorled. Example-Deadnettle. (Fig. I78.) 
Glomerule.-When the flowers belonging to a number of cymes are crowded and rolled together so as to form a head, the inflorescence is called a glomerule. Examples-Nettle, Box, Valerianella.

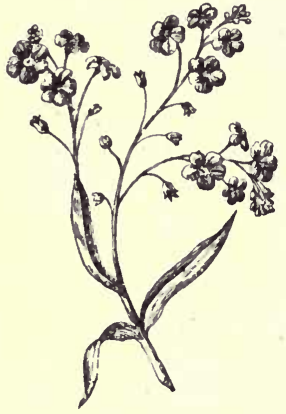

FIG. 177.-Scorpioid cyme of Forgetme-not. (Half nat. size.)

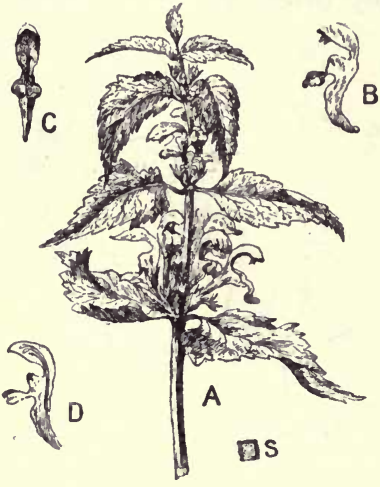

FIG. 178.-Verticillaster of the Deadnettle.

ExPT. 164.-Collect the inflorescence of the Stitchwort (it flowers from April to August) and examine it. Note-

(i) The main axis produces a flower, and from beneath this the branches are produced.

(ii) The branches also produce flowers, new ones being formed from beneath these.

(iii) The branching is dichotomous, i.e., in a forked manner, and the inflorescence is a dichotomous cyme.

ExPT. 165.-Obtain a Deadnettle when in flower. Note-

(i) The way in which the flower springs from the axil of opposite leaves.

(ii) Each pair of leaves produces flowers, those in the lower ones opening first.

(iii) The inflorescence is a verticillaster.

Relation between the Definite Inflorescences.The variation in the different kinds of inflorescences depends upon the mode of branching of the shoot. This is shown in the dichotomous cyme of the Stitchwort. In the Forget-menot the axis is produced from lateral buds, the apical buds in each case producing a flower. The lateral buds only develop on one side. Thus, the scorpioid cyme of the Forget-me-not 
differs from the dichotomous cyme in which the lateral buds produce branches on both sides of the apex. In the glomerule the branching brings the flowers to the same level and appears to form a head.

Bracts.-The bracts are borne upon the inflorescence (p. 46). They are leaves in the axils of which the flowers are produced.

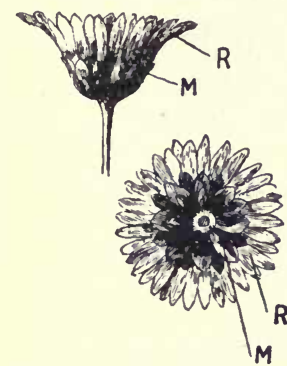

FIG. r79.-Two views of involucre of Daisy. R, ray flowers; $M$, bracts of involucre.

There may be one large bract only, which surrounds the inflorescence as the spathe of the Arum. (Fig. I73.) In some cases these bracts are brightly coloured. Very

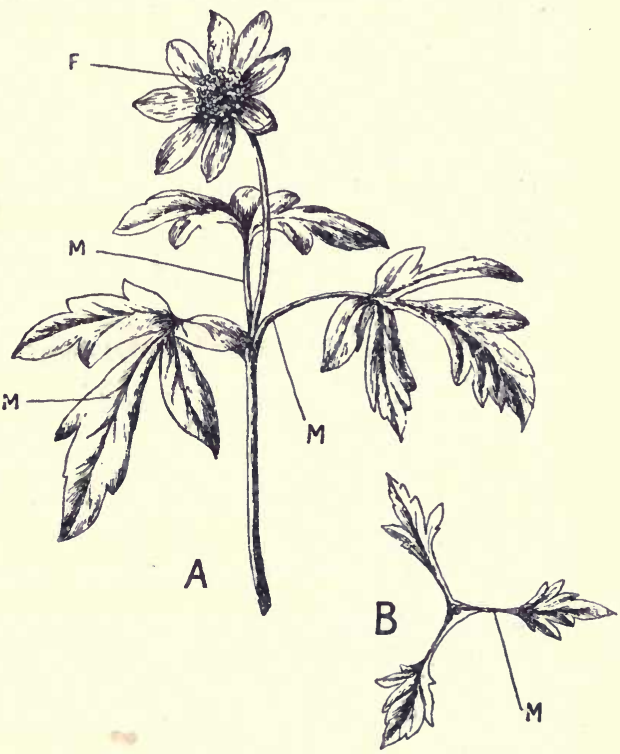

FIG. I80.-A, Anemone; B, involucre ; M, M, M, bracts of involucre; F, flower. small bracts are often found at the base of each pedicel, as in the Hyacinth, when they are termed bracteoles.

Involucre.-When the bracts are arranged around the flowers in a whorl, as in the Daisy and Dandelion, they form an involucre. (Fig. 179.) The bracts of the involucre may be leafy, scaly, or partly leafy and scaly. They may be imbricated like the tiles on a house, or simple.

The Anemone has an involucre of three bracts, just below the flower. (Fig. I80.) 


\section{SUMmary.}

Floral leaves are modified leaves which build up the flowers. They form a number of whorls, as follows -

(I) The sepals, which form the calyx.

(2) The petals, which form the corolla.

(3) The andrœcium, or male organs of reproduction, is built up of stamens.

(4) The gynœcium (pistil), or female organ of reproduction, is built up of carpels.

Stamens consist of a stalk - the filament, and a head-the anther.

Pistils are built up of one or more carpels; they consist of ovary, style, and stigma.

The Flower is supposed to be a modified shoot or branch, for the following reasons-

(I) The flowers are produced in the same positions as the buds, viz., at the apex of the main shoot and in the axils of leaves.

(2) The floral leaves are arranged either in a lateral or spiral manner.

(3) The floral leaves may be leaf-like.

(4) The intermediate forms between foliage leaves and the various kinds of floral leaves are known.

(5) The floral leaves change under cultivation.

An inflorescence is a collection of flowers produced from a common stalk. The common stalk upon which the flowers are borne is called a peduncle, and the smaller stalks by which the flowers are attached to it are termed pedicels. There are two kinds of inflorescences, $(a)$ indefinite, (b) definite.

Indefinite inflorescences. - The flowers open at the base first and at the top last.

Definite inflorescence. - The top flower opens first.

Indefinite inflorescences are-Spike, Raceme, Panicle, Corymb, Simple Umbel, Compound Umbel, Capitulum, Spadix, Catkin.

Definite inflorescence are-Solitary, Dichotomous Cyme, Verficillaster, Glomerule.

Bracts are greatly modified leaves in the axil of which the flowers are produced. When the bract is large and surrounds the inflorescence it is called a spathe. An involucre is a collection of bracts which generally enclose the flowers of the inflorescence.

\section{Questions on Chapter XIII.}

(I) Distinguish between a "flower" and an " inflorescence." Illustrate your answer by reference to the Daisy. (I897).

(2) Explain, with examples, the following terms-bracts, stipules, petiole, peduncle. ( 1896.$)$

(3) What is a flower? What structures compose it ?

(4) Explain the differences between definite and indefinite inflorescences, giving examples of each. 
(5) Give examples of the following kinds of inflorescences, and explain their relation to each other-spike, raceme, panicle, head, umbel. (1890.)

(6) Describe and compare the inflorescences of the Wallflower, Parsley, and Daisy. (1893.)

(7) Briefly describe, giving examples, the following forms of inflorescences, and point out the relation which exists between themSpike, Spadix, Catkin.

(8) Fully describe the inflorescence of any three of the following plants-Chickweed (Stellaria), Wallflower (Cheiranthus), Forget-me-not (Myosotis), Deadnettle (Lamium), Foxglove (Digitalis). (I89I.)

(9) Describe the inflorescence of the Arum.

(I0) What is an involucre? What plants possess involucres?

(I I) Explain how a bracteole differs from a spathe. 


\section{CHAPTER XIV.}

The Terms Used in Describing the Flower

Terms. - In describing the structure of a flower it is necessary to use a number of terms or names to define the appearances which the organs of a flower may present. It must be distinctly understood that the mere learning of such terms without knowing how to apply them is of little use. In all cases the flowers themselves should be examined and their peculiarities of structure noted. The principal terms used in describing the flower are :-

The Torus. - The upper portion of the flower stalk upon which the floral leaves are fixed is called the torus or receptacle. It is usually thicker than the portion below, and may expand between the stamens and the pistil into a disc. The disc may be club- cup- or urn-shaped. Upon the shape of the receptacle will depend the appearance of the flower.

Complete and Incomplete Flowers. - If the flower is built up of calyx, corolla, stamens, and pistil, it is said to be complete. When one or more of these parts are absent the flower is said to be incomplete.

The Buttercup, Wallflower, and Primrose are examples of complete, and the Anemone, Hazel, and Oak of incomplete flowers.

Perfect and Imperfect Flowers. - When the flower possesses both stamens and pistil it is said to be perfect. The Anemone, Pea, and Rose are examples of perfect flowers. If either the stamens or pistil is absent the flower is said to be imperfect. The Hazel, Dog's Mercury, and Oak are examples of imperfect flowers.

Regular and Irregular Flowers.-When the flower can 
be divided into equal halves in any plane, it is said to be regular or actinomorphic. If the flowers of the Hyacinth and Wallflower are examined they are seen to be regular or actinomorphic, for if a sharp knife is used they can be cut into equal halves in any

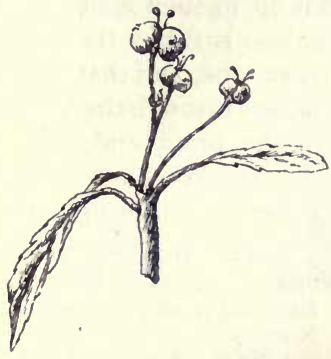

Fig. 181.-Female flowers Dog's Mercury.

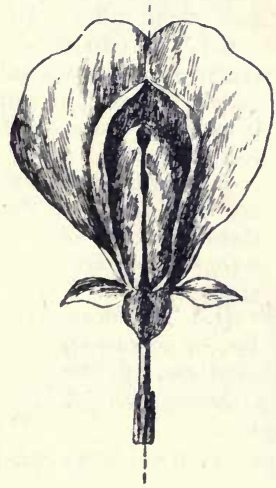

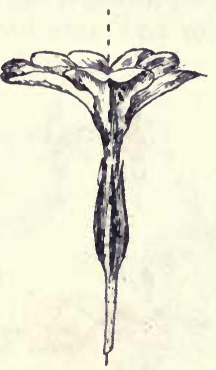

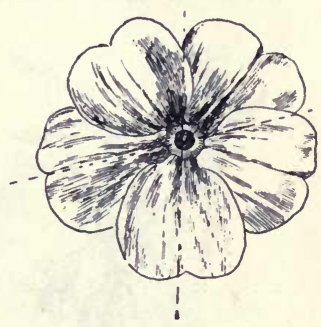

FIG. 182.-Actinomorphic flower of the Primrose ; the dotted lines show the planes of division.

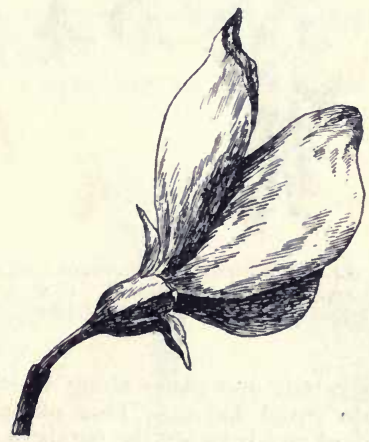

Fig. 183.-Zygomorphic flower of the Pea; the dotted lines show the plane of division.

plane which passes through the centre of the flowers. (Fig. 182). The flowers of the Pea and Deadnettle can only be divided into equal halves in one plane. Flowers of this kind are said to be irregular or zygomorphic (Fig. 183). If a flower cannot be 
divided into equal halves in any plane it is said to be asymmetrical, as in a few plants which belong to the Pink family.

The portion of the flower which faces the bract in the axil or which it stands is called the anterior part; while the portion which faces the axis of the inflorescence is the posterior part. The plane which passes through the flower in such a way as to divide it into posterior and anterior halves is called the trans-

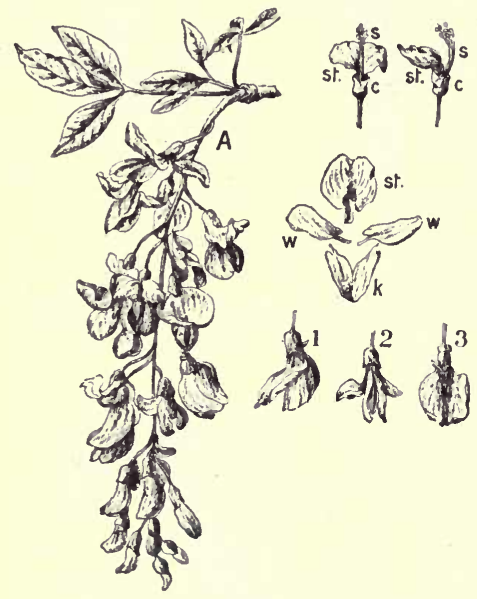

FIG. 184.- $A$, Raceme of Laburnum ; st, standard; $w$, wings; $k$, keel. $1,2,3$, the flower from different points of view. verse one, and that which passes through the middle of the bract and axis of the inflorescence is said to be the median plane.

ExP' I66. - Obtain a flower of the Gorse or Laburnum and examine it. Note-

(i) The large petal which receives the name of the standard is posterior, because it is the nearest to the axis of the inflorescence.

(ii) The two petals which slightly adhere, and are called the keel, are anterior, because they are the nearest to the bracts.

(iii) The two petals, one on each side of the standard, receive the name of wings; they are lateral, i.e., at the sides.

(iv) The flower is irregular, or zygomorphic, because there is only one plane along which a section can be made to divide it into equal halves. This plane passes through the centre of the standard and between the petals of the keel.

Expт. 167.-If the flower of the Apple or Blackberry can be obtained, examine it. Note-

(i) The flower consists of five sepals and five petals.

(ii) It can be divided into equal halves in any plane, therefore it is regular or actinomorphic.

Shape of Flower.-There are a number of terms which are used in describing the shape of the flower. It is said to be-

1.-Cruciform, when the petals are arranged in the form of a cross, as in the Wallflower and Cabbage. (Fig. 185). 
2.-Papilionaceous, when butterfly-shaped as in the Pea and Gorse. (Fig. I 86).

3.- Spurred, when a spur is formed either from the corolla or calyx. This spur may be used for storing up honey. Examples -Monkshood, and Toadflax. (Fig. I87).

4.-Tubular, when a tube is formed as in the florets of the Thistle. (Fig. I 88 ).

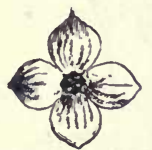

Fig. 185 .

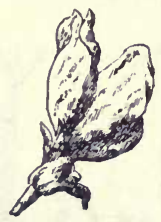

FIG. 186.

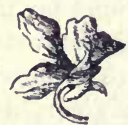

FIG. 187.

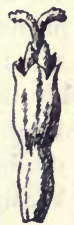

FIG. 188 .

Cruciform flower. Papilionaceous flower. Spurred flower. Tubular flower.

5.- Rotate, when the tube of the flower is short and the lobes flat and spreading, so that it resembles a wheel. ExamplesPotato, and Forget-me-not. (Fig. 189).

6.-Funnel-shaped, when it is shaped like an inverted cone, as in the Convolvulus. (Fig. I90).

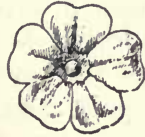

Fig. 189.

Rotate flower.

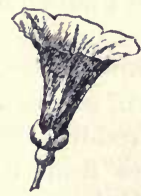

FiG. 190. Funnel-shaped flower.

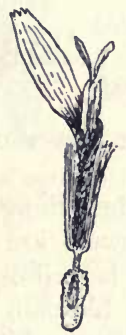

FIG. I9I. Ligulate flower.

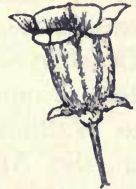

Fic. 192. Campanulate flower.

7.-Ligulate, when strap-shaped, as the floret of the Dandelion. (Fig. I9I).

8.-Campanulate, when bell-shaped, as in the Harebell and Clustered Bluebell. (Fig. I92). 
9.-Personate, when the throat of the flower is masked, as in the Snap-dragon. (Fig. I93).

Io.-Labiate, when the flower is two-lipped, as in the Deadnettle and Sage. (Fig. I94).

Size of Flower.- The flowers may be very small, so that it is necessary to use a hand-lens to make out their different parts, or they may be large. If a plant bears small flowers, it is the rule for a large number to be produced. When large flowers are produced by a plant, only a few are formed. The diameter of the flower should be given when describing it, For instance the diameter of the flower of the Wallflower is given as $1 \frac{1}{3}$

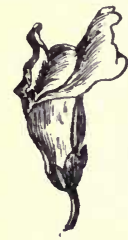

FIG. 193. Personate flower.

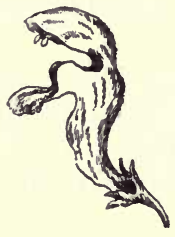

FIG. 194. Labiate flower.

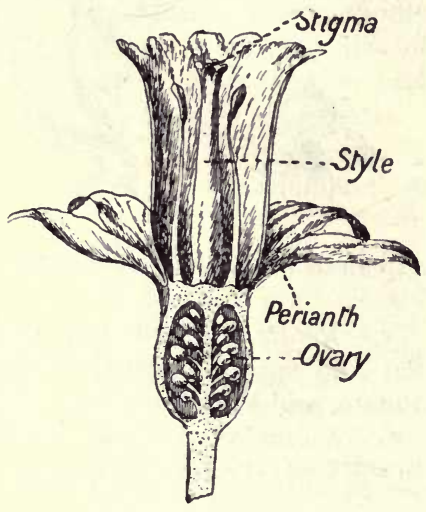

FIG. r95.-A longitudinal section of the flower of the Daffodil ; showing inferior ovary and superior perianth:

inches; while the flower of the Fool's Parsley is $\frac{1}{4}$ of an inch in diameter.

Colour.-In describing a flower its colour must always be noted. Some flowers are green, others are brightly coloured. The Wallflower is yellow or reddish brown, the Hare-bell is blue, the Apple blossom varies from white to pink, and the Anemone is generally white. If the flower possesses any peculiarities such as markings, hairs, \&c., they must be described.

Perfume.-Those flowers which are visited by insects may be sweet-scented or without perfume. Green flowers, as a rule, have no perfume, but if the flowers open at night they are very sweet scented. The characters of the flowers as to perfume, must be recorded when writing the description of the flower.

Cohesion and Adhesion.-The term cohesion is used 
to note union between similar members, as sepal to sepal or petal to petal. Adhesion is used to note union between dissimilar members, as sepals to petals, stamens to petals, \&c.

Calyx.-The sepals which form the calyx may be separated from each other, or may grow together by their edges to form a cup. If the sepals are distinct, as in the calyx of the Buttercup, the calyx is said to be polysepalous. (Fig. 163). If the sepals are united so as to form a cup the calyx is gamosepalous, as in the Deadnettle and Primrose. (Fig. 182).

When the calyx is fixed below the pistil it is inferior, as in the Wallflower and Buttercup. (Fig. I63). If the calyx is above the pistil it is superior, as in the Currant and Parsley. (Fig. I95).

The number of the sepals is noted and the number of

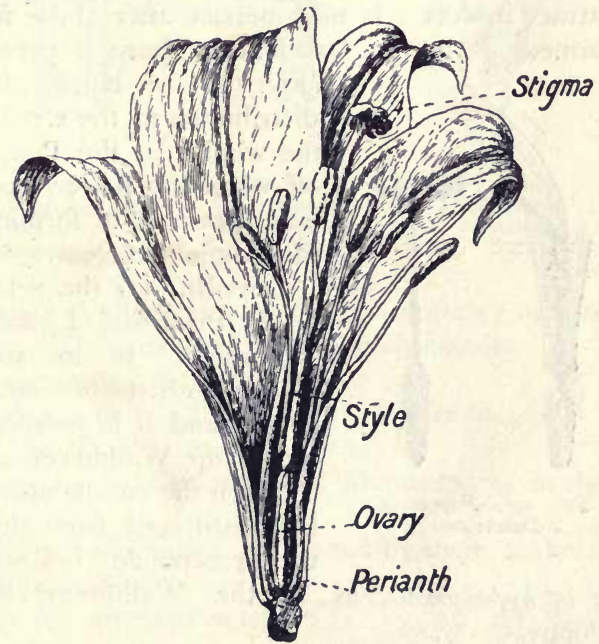

FIG. 196.-A longitudinal section of the flower of the White Lily; showing superior ovary and inferior perianth. whorls they make. In the gamosepalous calyx the number of the sepals can be inferred from the number of the divisions to be made out. If there are five lobes to the calyx it is a five-lobed calyx, as in the Primrose and Toadflax. The number of rows of the sepals must also be noted in describing the calyx. There may only be one row, as in the Buttercup, or two, as in the Wallflower. The shape of the sepals or lobes of the calyx is of importance. The sepals may be shaped like the leaves, (p. 38-40), and the same terms are used in describing both. The limb or free portion of the calyx may be entire, toothed, or lobed. The 
lobes may be shaped like the tips of the leaves, (p. 44), and the same terms are used as in describing leaves.

The colour of the calyx and whether it is hairy or smooth, must be recorded. If the calyx is coloured it is said to be petaloid, as in the Christmas Rose and Anemone. In most cases. it is green.

The function of the calyx is to protect the stamens and pistil from injury. In those cases where it is coloured it serves to attract insects. It may persist after those functions are performed, as in the Dandelion, where it persists as a pappus

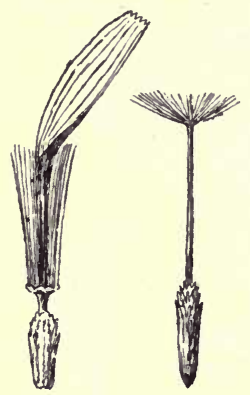

FIG. 197.- Pappus of Dandelion. (Fig. 197) of hairs which aids in the distribution of the seeds by the action of the wind. In the Poppy the sepals fall off when the flower opens. The calyx may take part in forming the fruit, as in the Apple and Pear.

Corolla.-If the petals are united, as in the Primrose, a gamopetalous corolla is formed. In its simplest form the corolla consists of a number of separated petals, and it is polypetalous, as in the Buttercup, Wallflower, and Stitchwort.

When the corolla springs from beneath the pistil and from the thalamus, as the receptacle is sometimes called, it is hypogynous, as in the Wallflower, Rock Cress, and Poppy.

If the petals are fixed on the calyx the corolla is perigynous, as in the Pea, Rose and Apple.

[If the flower has the corolla and stamens hypogynous, it is a hypogynous flower ; if the corolla and stamens are perigynous, it is a perigynous flower; and when both corolla and stamens are inserted on the ovary it is an epigynous flower.]

The corolla may spring from the top of the ovary, when it is said to be epigynous, as in the Cow-Parsnip and Sea Holly.

The number of the petals or the lobes of the corolla, the shape of the petals, or the lobes, must be observed and the terms used for the calyx may be employed to describe them.

Androcium.-The whole collection of stamens of a flower constitute the andracium. In describing the stamens the union 
or cohesion is of importance. When the stamens are distinct or separate they are said to be free, as in the Buttercup and Rock Cress. If there are four stamens and two of them are short and two long, they are didynamous, as in the Deadnettle

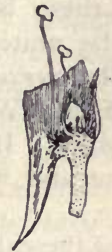

FIG. r98.-Section of flower to show didynamous sta. mens.

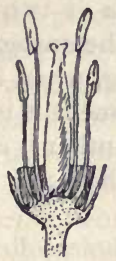

Fig. 199.-Section of flower to show tetradynamous stamens.

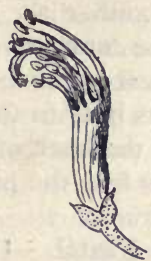

FIG. 200.

Monadelphous stamens.

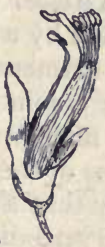

FIG. 20r.

Diadelphous stamens.

and Foxglove. In the Wallflower there are six stamens ; two are short and four long. They are said to be tetradynamous.

If the filaments are united they may be :-

Monadelphous, all in one bundle, as in the Laburnum.

Diadelphous, in two bundles, as in the Pea.

Polyadelphous, several bundles of united filaments, as in the St. John's Wort.

Syngenesious, when the stamens are united by their anthers, as in the Daisy and Dandelion.

The adhesion of the stamens must be described in the following terms :-

Hypogynous, when they spring from beneath the pistil, as in the Buttercup, Wallflower, and Stitchwort.

Perigynous, when they are inserted on the calyx, as in the Pea, Rose, and Apple.

Epigynous, when inserted on the top of the ovary, as in the Fool's Parsley and

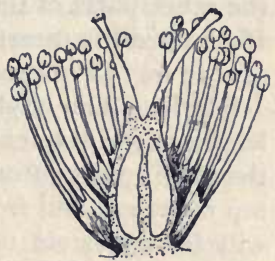

FIG. 202.-Polyadelphous stamens. Hemlock.

Epipetalous, when united to the corolla, as in the Primrose, Mint, and Borage.

Gynandrous, when the stamens are joined to the pistil, as in the Spotted Orchis. 
Filament.-The relative length of the filaments and pistil must be noted. The stamens are long if longer than the pistil, and short if shorter than the pistil. The filament may be broad, hairy, or petaloid. If the filament does not bear an anther the stamen is called a staminoid.

Anther.-The anther as a rule is two-lobed, these being joined by a rib-the connective. The anther may be united to the filament so that it is free to swing, when it is called versatile. If it is joined by its base to the filament it is basifixed. When the filament enters the back of the anther it is dorsifixed. If the lobes of the anthers face the pistil they are introrse and when they turn away extrorse.

Gynœcium or Pistil.-The whole collection of the carpels of a single flower constitute the gynœcium. The cohesion of the carpels is included in describing a flower. There are three kinds of pistils :-

Monacarpous, when the pistil consists of a single carpel, as in the Pea and Gorse. (Fig. I84).

Apocarpous, when there are two or more carpels and they are separate or distinct, as in the Buttercup and Strawberry. (Fig. I63).

Syncarpous, when there are two or more carpels and these are united together, as in the Wallflower, Deadnettle, and Hyacinth. (Fig. 196).

The adhesion of the pistil is superior when it is inserted above the other parts of the flower, as in the Buttercup and Foxglove. If the pistil is inserted below the other parts of the flower it is said to be inferior, as in the Fool's Parsley and Daffodil.

Style.-The style may be long or short according to the length of the stamens. It may be hairy, angular, or round. If the style springs from the side of the ovary it is lateral, from the top terminal, and from the base it is called gynobasic. There will be one style to each carpel of an apocarpous pistil. In syncarpous pistils, the styles may be separated along their whole length or along part of their length, or united along their whole length.

Stigma.-The apocarpous pistil will, as a rule, have one stigma to each carpel, and in most syncarpous pistils the number of the carpels can be obtained by noting the number of the stigmas. Thus if there are three stigmas - the number of carpels 
in the pistil will be three. The stigmas will, according to the number present, be 2 -fid, 3-fid, 4-fid, \&c. They may be round, square, feathery, or petaloid. When the style is absent the stigmas are sessile.

Placentation.-The place where an ovule is fixed to the ovary is known as the placenta, and the way in which they are arranged and connected to the ovary by the placentas is called placentation. The arrangement of the ovules in the ovary can be determined by cutting across the ovary, and if it is small by using a hand-lens to examine the section made. There are several kinds of placentation, which are known as :-

Parietal Placentation, when the ovules are attached to the walls of the ovary, as in the Poppy, Wallflower, and Pea. In such an ovary there is generally one chamber, but in the Wallflower there are two. (Fig. P, 203).

Axile Placentation, when the ovary is syncarpous, and the carpels meet in the centre and from this longitudinal axis the
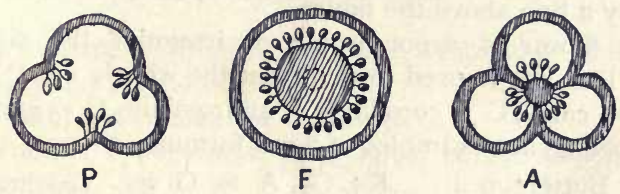

FIG. 203.-P, parietal ; F, free-central ; A, axile placentation. (Diagrammatic.)

ovules grow, as in the Daffodil, Hyacinth and Tulip. The ovary generally possesses as many cells as there are carpels; the ovules are attached to the axis. (Fig. A, 203).

Free-Central Placentation, when the ovary is one-chambered, and the carpels form a swelling or column in the centre of the ovary to which the ovules are fixed, as in the Primrose, Stitchwort, and Chickweed. (Fig.F, 203).

Basal Placentation, when the chamber of the ovary contains only a single ovule and this springs from the base, as in the Buttercup.

Marginal Placentation, when in an ovary which is formed from a single carpel the ovules are arranged along the ventral margin, as in the Larkspur and Hellebore.

Perianth.-When the two outer whorls of the flower are alike in colour and appearance it is called a perianth. The 
How to describe a Flower.-In describing a flower the following plan should be followed, taking the organs in the order shown.

Flower.-(a) Whether complete or incomplete.

(b) Whether actinomorphic or zygomorphic.

(c) Shape.

(d) Diameter, colour, perfume.

Calyx.-(a) Whether polysepalous or gamosepalous.

(b) Number of sepals or lobes of calyx.

(c) Whether inferior or superior.

(d) Shape of calyx or sepals, markings, colour, smooth or hairy.

Corolla.- (a) Whether polypetalous or gamopetalous.

(b) Number of petals or lobes of corolla.

(c) Whether superior, hypogynous, perigynous, or epigynous.

(d) Shape of petals or lobes of corolla.

Andrœcium.-(a) Whether free, monadelphous, diadelphous, or polyadelphous.

(b) Number of stamens or indefinite.

(c) Whether hypogynous, perigynous, epigynous, epipetalous, or gynandrous.

(d) Shape and length of filaments.

(e) Whether anther two-lobed, and how fixed to filament, introrse or extroise.

Gynœcium.-(a) Whether monocarpous, apocarpous, or syncarpous.

(b) Number of carpels.

(c) Whether inferior or superior.

(d) Whether style long or short.

(e) Whether stigmas terminal, 2-fid, 3-fid, 4-fid, \&c.

$(f)$ Whether ovary one, two, three, or more celled.

Ovules. - (a) How many?

(b) Placentation-axile, parietal, free-central, marginal, or basal.

Then represent the parts and arrangement of the flowers in floral formulæ and floral diagram. 
Expr. I68.-Examine a flower of the Anemone and describe it, taking its organs in the following order-

(i) Flower. - Incomplete, perfect, actinomorphic, $I \frac{1}{2}$ inches in diameter, white, faintly scented.

(ii) Calyx.-Polysepalous, six in two series, inferior, sepals lanceolate and reticulate veined.

(iii) Corolla. - Absent.

(iv) Andrœcium. - Free, indefinite, hypogynous, filaments long, anther two-lobed, basifixed, extrorse.

(v) Gynœcium.-Apocarpous, carpels numerous, superior, styles short, stigmas terminal.

(vi) 0vules.-One in each carpel, pendulous (suspended).

(vii) Floral formula. $-\mathrm{K}_{3}+3 \mathrm{Co}, \mathrm{A} \infty, \mathrm{G} \infty$.

ExpT. 169.-Examine a Wallflower and describe it, taking its organs in the following order-

(i) Flower.-Complete, actinomorphic, cruciform, $I \frac{1}{2}$ inches in diameter, reddish-brown, sweet scented.

(ii) Calyx.-Polysepalous, four in two series, inferior, inner sepals saccate (p. I83) lanceolate, hairy.

(iii) Corolla.-Polypetalous, four, hypogynous, petals clawed, limb obovate, claw linear.

(iv) Andrœcium.--Free, six in two series, tetradynamous, hypogy-

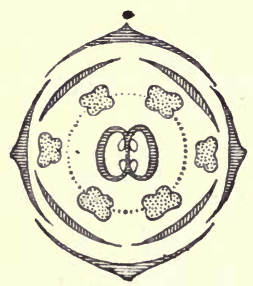

FIG. 204.-Floral diagram of Wallflower. nous, filaments thick, anthers two-lobed, dorsifixed, introrse.

(v) Gynœcium.--Syncarpous, carpels two, superior, ovary long, spuriously two-celled, style short, stigma 2-fid.

(vi) Ovules.-Numerous, parietal placentation.

(vii) Floral formula. $-\mathrm{K}_{2}+2, \mathrm{C}_{4}, \mathrm{~A}_{2}+4$, $\mathrm{G}(2)$.

ExpT. 170--Examine the flower of the Furze (Whin or Gorse), and describe it, taking its organs in the following order-

(i) Flower.-Complete, zygomorphic, one inch in diameter, papilionaceous, yellow.

(ii) Calyx. - Gamosepalous, two-lobed, inferior, green.

(iii) Corolla.-Polypetalous, five (consisting of standard, wings and keel), perigynous.

(iv) Andrœcium. - Monadelphous, ten, perigynous, anthers two-lobed, versatile.

(v) Gynœcium.-Monocarpous, superior, style long, stigma terminal.

(vi) Ovules. - Parietal placentation.

(vii) Floral formula. - $\left[\mathrm{K}(2), \mathrm{C}_{5}, \mathrm{~A}(10),\right] \mathrm{G}_{1}$.

ExpT. 171.- Examine the flower of the Deadnettle and describe it, taking its organs in the same order as before. 
ExpT. 172. - Examine the flower of the Daffodil and describe it, taking its organs in the same order as above.

\section{SUMMARY.}

Terms used to describe the shape and arrangement of the organs of flowers-

The torus is the upper part of the flower stem upon which the floral leaves are placed. Its shape varies.

A complete flower is one in which calyx, corolla, stamens and pistil are all present.

An incomplete flower is one where one or more of the floral whorls are absent.

A perfect flower will contain stamens and pistil.

An imperfect flower will only contain stamens or pistil.

An actinomorphic flower is one which can be divided into equal halves in any plane.

A zygomorphic flower can only be divided into equal halves in one plane.

The anterior parts of the flower face the bract in the axis of which the flower stands. The posterior parts of the flower face the axis of the inflorescences.

Shapes of flowers.-The following list gives the principal shapes of the flowers-

Cruciform, papilionaceons, spurred, tubular, rotate, funnel-shaped, ligulate, campanulate, personate, labiate.

Cohesion is a term used to describe union between similar parts. Adhesion is used to describe union between dissimilar parts.

The calyx may be polysepalous or gamosepalous; inferior or superior.

The corolla may be polypetalous or gamopetalous; hypogynous, perigy. nous, or epigynous.

The andrœcium is composed of the whole collection of stamens of a single flower.

The collesion of the stamens may be monadelphous, diadelphous, polyadelphous, syngenesious.

The adhesion of the stamens may be hypogynous, perigynous, epipetalous, epigynous, gynandrous.

The filament may be long or short.

The anther may be versatile, basifixed, dorsifixed.

The gynœcium is composed of the whole collection of carpels of a single flower. There are three kinds of pistils-monocarpous, apocarpous, syncarpous.

The Placentation, or the arrangement of the ovules in the ovary may be parietal, axile, free-central, basal, marginal.

The term perianth is used when the two outer whorls of a flower are alike as in most monocotyledons.

The floral formula represents by letters, figures, lines and brackets, the parts of a flower and their position. 
The floral diagram is a graphic way of representing the flower in ground plan.

\section{Questions on Chapter XIV.}

(I) Explain the term "torus." What is its shape in the Daisy and the Buttercup?

(2) Define the terms "complete" and "perfect." Mention flowers which are perfect but incomplete, and others which are imperfect.

(3) What do you understand by hypogynous, perigynous and epigynous flowers? Give two examples of each. (I898.)

(4) Describe and compare the perianth of Helleborus (Christmas Rose), Anemone, and Ranunculus (Buttercup). (1898.)

(5) Describe the position and the general structure of the ovary in the Buttercup, the Primrose, and the Daffodil. (1897.)

(6) Explain, with examples, the meaning of the terms-marginal, axile, and parietal placentation. (I894.)

(7) Explain, with examples, the meaning of the following terms applied to stamens-diadelphous, tetradynamous, didynamous, syngenesious, epipetalous. (1890.)

(8) Describe and compare the flowers of the Narcissus and the Hyacinth. (1893.)

(9) Describe, with examples, the papilionaceous, the labiate, and the personate types of corolla. (I89i.)

(I0) What is meant by "zygomorphic symmetry"? Give examples. 


\section{CHAPTER XV}

THE DEVELOPMENT AND MORPHOLOGY OF THE FLOWER

The Development of the Flower.-The young flower buds appear on the stem as rounded outgrowths, and if a series of these is examined by cutting transverse sections through them, the order of development of the floral whorls can be ascertained. If a series of flower buds of different ages is examined from the inflorescence of the Wallflower, the very young bud will show the calyx just appearing. The first sepal to appear is the anterior one, then the two lateral ones are developed, and last of all the posterior one. In a little older bud the corolla will be found as four little projections just within the sepals, and alternating with them. All four petals appear at once. In buds a little older still the stamens will be seen inside the corolla. The order of the appearance of the stamens is as follows :-

I. - The anterior pair of long stamens appear first.

2. - The lateral pair of short stamens next.

3.-The posterior pair of long stamens last.

The pistil is the last floral organ to appear; the two carpels arise together, and can be seen as small projections in the centre of the bud.

The order of the development of the floral whorls can be far better made out in those flowers which are closely associated in large numbers in inflorescences, like the capitulum or head. (p. 168). Thus, in the young inflorescence of the Daisy or the Sunflower, nearly all the stages of development can be seen in a single section. If a young capitulum of the Daisy is examined with a hand-lens, the youngest flowers can be seen 
near the centre, and the oldest towards the edge. From the centre to the edge all stages in the development of the floral organs can be made out. If a section is cut through a young capitulum, and the section treated with potash solution for a short time, and then mounted in glycerine and examined with a high power-the central flowers will show the corolla appearing as five small lobes. In an older flower, just within the corolla, five projections will be seen-these are the stamens. In a still older flower the centre of the stamens will be filled in with two carpels, which form the pistil.

Thus, in the Daisy the corolla appears first, then the stamens, and last of all the pistil. In the Sunflower the corolla and stamens appear as in the Daisy, then the calyx, and last of all the pistil. In the large majority of plants the appearance of the floral whorls is the same as in the Wallflower, but as we have seen there are exceptions.

Expr. I73.-From the raceme of the Wallflower cut off the young buds from the apex and lay them in regular order, placing the oldest at one end and the youngest at the other end. With a sharp knife or razor cut the buds into halves transversely, beginning with the oldest. Examine with a hand-lens. Note-

(i) The oldest bud shows the petals, stamens and pistil coiled up inside the calyx, the parts being very distinct.

(ii) The anthers show small openings. These are called the pollen sacs.

(iii) The pistil is two-celled, and within it the ovules can be seen.

(iv) From the oldest onwards the parts are less distinct.

(v) In the younger buds the pistil is the least distinct, then stamens and corolla ; the calyx is the best developed of all the parts.

(vi) This shows that the calyx is developed first and the pistil last.

ExpT. I74.-Collect a number of inflorescences of the Daisy or Dandelion, and examine them with a hand-lens. Note-

(i) The shape of the inflorescence. It forms a cone which is irregular in outline.

(ii) The younger inflorescences show the central flowers just appearing.

(iii) The largest and oldest flowers are near the edge of the inflorescence, and the younger and smaller flowers in the centre.

(iv) This shows that the growing point cuts off floral leaves from the outer part of the torus first and from near the apex last of all.

The Structure and Functions of the Sepals.-The green sepals resemble the foliage leaves in structure and appearance. They are covered with an epidermis, which contains 
stomata, and between the upper and lower epidermis comes the mesophyll, which is penetrated and strengthened with vascular strands.

The Texture of the Sepals. - The texture of sepals varies considerably. They may be delicate, firm, membranous, or scaly. The duration of the sepals will depend upon their texture. They may fall off when the flower opens, when they are said to be caducous; if they last until the seeds begin to ripen and then fall off, they are deciduous; and when they remain until the seeds are ripe, they are persistent. The surface of the sepals is frequently provided with hairs for protection.

Functions of the Sepals.-When the sepals are green they perform the same functions as foliage leaves. They also serve to protect the other floral leaves from injury. If they are petaloid they may serve to attract insects, as in the Anemone and Lilies.

The Structure and Functions of the Petals. - The petals and petaloid sepals are covered with a delicate epidermis. Within the epidermis come one or more layers of spongy parenchyma; this is traversed with a number of delicate vascular strands, which, as in foliage leaves, gives it a veined appearance.

The Texture of the Petals. - The texture of the petals is usually delicate. They are deciduous, i.e., they fall off as the seeds ripen. The surface of the corolla may be smooth or glabrous (p. 29), or present certain hair structures or hair-like outgrowths.

The Colour of Petals and Sepals. -When the sepals and (less often) the petals are green, the colour is due to chlorophyll. The petals are, however, as a rule coloured, the colour being due either to coloured sap or to chromoplasts (p. 84). In a few cases the colouring is due to both.

The Functions of the Petals. - The colour, markings, shape, and perfume of the corolla are all designed to attract insects, so as to ensure the distribution of the pollen (p. 198). The petals also protect the essential organs (stamens and pistil) of the flower from injury. Petals may be modified to form nectaries or glands for the preparation of honey. Petals thus have a twofold function, attractive aud protective.

EXPT. 175. - From a flower of the Geranium strip off a petal, and with a sharp knife pull away the surface tissue. Mount the petal in water 
with the torn surface below, and examine under a low power. Note-

(i) The conical-shaped outline of the cells.

(ii) The cells contain coloured cell-sap. There are no chromoplasts present.

EXPT. I76. - Cut transverse sections through a sepal of the Wallflower, mount the thinnest in water, and examine with the high power. Note-

(i) The epidermis on both the upper and lower surfaces.

(ii) The mesophyll between the upper and lower epidermis, it contains vascular bundles.

ExpT. I77.- Harden a few petals of the Wallflower in alcohol, and cut transverse sections. Select the thinnest and mount in glycerine. Examine under the low power. Note-

(i) The short hairs growing out from the epidermal cells. These give the characteristic appearance to the petals because they reflect the light.

(ii) The vascular bundles are slender, but consist of xylem and phloem.

(iii) The mesophyll is built up of parenchyma cells.

(iv) The epidermis contains no stomata.

ExPT. 178. - Examine with the hand-lens the base of a single petal of the Buttercup. Note-

(i) The pocket-like nectary which secretes honey.

Place it in alcohol for a short time, and mount in water. Examine it with a low power and reflected light. Note-

(ii) The vascular bundles, which give to the petal a veined appearance.

(iii) The epidermis, which consists of small but regularly arranged cells.

(iv) The colouring matter has nearly all disappeared.

The Essential Floral Organs.-The andrœcium and gynœcium form the essential floral organs. They are called the essential organs of the flower, because without them no seeds can be produced. The calyx and corolla are not essential for the formation of seeds, since many plants which have only stamens and pistil produce seeds. The calyx and corolla do, however, perform useful work in protecting the essential organs from loss of heat as well as from dew and rain; they also by their colour, perfume, and shape attract insects to the flower.

The Structure of the Andrœcium.-The andrœcium or a flower consists of modified leaves, which bear very little resemblance to foliage leaves. Each stamen is, as a rule, filiform in shape, and consists of a filament or stalk bearing an anther at the apex. They have no vegetative function to perform, but are 
modified for special work-that of producing pollen. The filament represents the petiole of the foliage-leaf, and it is traversecl by one or more vascular bundles, which is surrounded with endodermis. The vascular cylinder is surrounded by parenchyma cells, and these again by an epidermis. As a rule therc are no stomata in the epidermis of the filament.

The anther represents the blade of the foliage leaf folded to form four cavities - the pollen sacs. Up the centre of the anther, and dividing it into two lobes is a midrib-the connective. In the centre of the connective runs a vascular bundle, continuous with the bundles of the filament, and bringing nutritive matter to the anther. The walls of the mature anther, as seen in a transverse section, consist of the following parts ;-

I.- The epidermis, the outer walls of which have a well-developed cuticle, and may contain a few stomata.

2.- The fibrous layer consisting of several

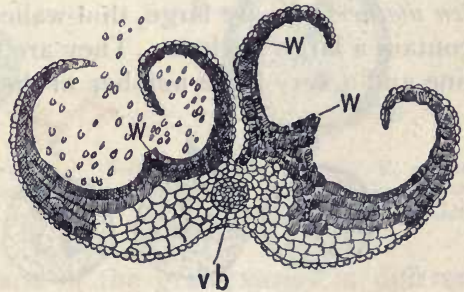

FIG. 205.-Transverse section oi anther of Wallflower. $W$, wall of pollen sacs; $v, b$, vascular bundle. layers of cells, which present a stratified appearance, due to the thickening of the walls.

3.-The tapetum layer, sometimes represented by nearly disorganised cells, for it is used for the nutrition of the pollen grains. The young anther contains four pollen sacs, but the mature one only two; this is owing to the two pollen sacs in each lobe of the anther uniting just before it becomes ripe. The pollen sacs contain pollen. Each pollen grain is a male reproductive cell.

The Development of the Stamens. - The first part of the stamen to appear is the anther, and this is formed by the division of a number of cells just below the epidermis. These cells-are, because of their position, called hypodermal cells; they form what is called the archesporium or meristem layer from which the anther and pollen grains are formed. The cells of the archesporium divide at four points in the young anther, which 
correspond to the four pollen sacs. The cells formed by their division give rise to

I. - The cells of the fibrous layer.

2. - The cells of the tapetum layer.

3. - The pollen mother cells, formed from the inner cells.

4.-The epidermis of the anther, formed from the cells above the hypodermic layer.

The filament is the last portion of the stamen to be produced; as a rule, it is not fully developed until just before the pollen is ripe.

The Development of Pollen.-Dicotyledons.-The pollen mother-cells are large, thin-walled, filled with protoplasm and contain a large nucleus. They are more or less rounded in outline and a very large number of them occur in each pollen sac.
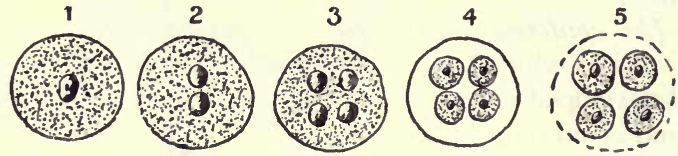

FIG. 206.-Diagram illustrating the development of pollen in a dicotyledonous anther.

Each mother-cell divides into four pollen grains in the following manner. The nucleus divides (p. 89) into two, and each half again divides into two, so that there are four nuclei in the mother-cell. The protoplasm becomes rounded off so as to form separate masses round each nucleus. (Fig. 206). A new cell wall is produced round each nucleus from the protoplasm, thus separating the daughter-cells, as they are called. Each cell after ripening forms a pollen grain. The pollen grains are set at liberty by the breaking down of the wall of the mothercell. This method of formation of pollen is the common one for all dicotyledonous plants.

Monocotyledons. - In monocotyledonous plants the formation of pollen differs from the method just described. The nucleus of the mother-cell divides into two parts, and between these parts a cell wall is formed which extends right across the cell. Each nucleus again divides and new cell walls are formed between them. Thus, out of the mother-cell four daughter-cells 
are formed. The principal difference, then, is the division by a wall of the cell into two after the division of the nucleus. (Fig. 207). The pollen grains of dicotyledonous plants are formed by free cell formation, but in monocotyledonous plants by a method which comes between this and vegetative division. (p. 89).

The Structure of a Pollen Grain.-The pollen grain is at first surrounded by a very thin cell-wall which with age increases in thickness. The outer layer becomes cuticularised and forms the extine; the inner layer consists of cellulose and
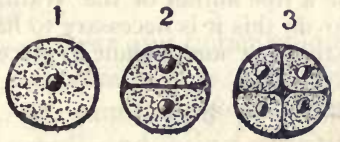

FIG. 207.-Diagram illustrating the development of pollen in a monocotyledonous anther.

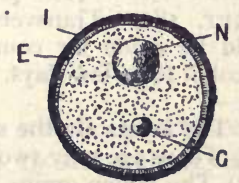

FIG. 208.-Pollen grain. E, extine ; $\mathrm{I}$, intine; $\mathrm{N}$, vegetable nucleus ; $\mathrm{G}$, generative nucleus. (Dia: grammatic.)

forms the intine. The shape of the grain varies in different plants. The extine, too, may be raised into knobs, spines, and ridges or be perfectly smooth. Most pollen grains have thin places in their extine and out of one of these places the intine grows to form the pollen tube.

The interior of the grain is filled with granular protoplasm, in which two nuclei may with great difficulty be made out. The smaller nucleus is the generative one, and the larger one the vegetative nucleus. When the pollen grain is placed under suitable conditions (p. 152) germination takes place, and the intine breaks through the extine to form a long tube called the pollen tube, which is of service in carrying the generative nucleus to the ovule.

EXPT. 179. - Cut a transverse section from the filament of any welldeveloped stamen. Mount in water and examine, first with a low, then with a high power. Note-

(i) The outside epidermal layer.

(ii) A few rows of parenchyma within the epidermis which represent the cortex of the petiole.

(iii) One or more vascular bundles in the centre of the section; these are continuous with the bundles of the stem, and bring nutritive materials to the anther and pollen grains. 
ExpT. 180. - Cut transverse sections of the young flower bud of the Wallflower. Mount the thinnest in water and examine with a low power. Neglecting the other parts of the flower, look for an anther. Note-

(i) A single layer of cells, the epidermis, the outer walls of which possess a well-developed cuticle.

(ii) The flbrous layer, which is several layers of cells in thickness and appears striated.

(iii) The tapetum layer. This is represented by a layer of cells in all stages of disorganisation.

(iv) The four pollen sacs.

(v) The pollen grains. Some are in the pollen sacs, others in the water.

ExpT. I8I. - Transverse sections of a ripe anther of the Wallflower should be made for comparison. To do this it is necessary to harden in alcohol for a few days. Select the thinnest and mount in glycerine. Note-

(i) The layers are the same, but better developed.

(ii) There are only two pollen sacs.

(iii) The pollen grains are ripe.

Examine a pollen grain with a high power. Note-

(iv) The thin places in the wall through which the intine grows to form the pollen tube.

(v) The nuclei, the largest, is the vegetative one, and the two smaller ones are the generative ones. These will be seen with difficulty.

ExPT. 182.--Mount in water and examine the pollen grains of the following flowers as they appear-Rock Cress, Sunflower, Hyacinth, Apple, Deadnettle, \&c. Note-

(i) Their shape and external markings.

(ii) The thin places in their walls.

(iii) Their comparative sizes.

ExPT. 183. - Cut a piece of cardboard the size of a microscopic slip, and out of the centre remove a circular piece the size of a cover-glass. Fix the cardboard to the glass slip with a thin layer of Canada balsam and dry ; place a drop of a six per cent. solution of sugar in the cell you have formed in the cardboard. Mount a few pollen grains from the Wallflower in the sugar solution, and cover with a cover-glass. Examine with the high power of microscope. Note-

(i) The thin places in the wall of the grains.

Damp the cardboard and put in a dark warm place for a few hours. Note-

(ii) Many of the grains have sent out pollen tubes filled with granular protoplasm.

(iii) One or more nuclei may be detected in the pollen tube.

How the Pollen is liberated from the Anther.-When the anther is ripe, the pollen sacs open so as to set the pollen grains at liberty. The anther lobes may open by one split 
marking the line of junction between two pollen sacs, when the opening is called longitudinal dehiscence. In other cases the anther opens by small pores, as in the Heath and Potato, when the dehiscence is porous. In the Barberry, the anthers open by small doors or valves when the dehiscence is valvular.

The Structure of the Gynœcium.-The gynœcium consists of modified foliage leaves which depart even more widely than the stamens from the ordinary foliage leaf type. The structure of the carpels, as these modified leaves are called, can be macle out if transverse sections are cut and examined by the microscope. Each carpel is found to consist of the following parts :-

I.--Lower and upper epidermis.

2.- Several layers of mesophyll.

3.-A number of vascular strands which penetrate the mesophyll, and bring nutritive material to the carpel and its ovules.

The gynœcium may consist of a single carpel, as in the Pea ; or of several carpels, as in the Poppy and Lily. In every case the carpel or carpels are united so as to form a cavity or cavities - the ovary. In the ovary the ovules are developed, and they receive the materials necessary for their further growth from the ovary.

The Structure of an Ovule.-An ovule consists of the following parts :-

I. - The funiculus or stalk by which it is attached to the placenta or swelling on the wall of the ovary (p. Io).

2.- The integuments or coverings of the ovule, which are several layers of cells in thickness. There is a small opening through the integuments, the micropyle. (p. 1o).

3.-The nucellus, an oval mass of tissue within the integuments.

4.- The embryo-sac embedded in the nucellus.

The Embryo-Sac.-The embryo-sac is a large oval cell which contains:-(i) The embryo-sac nucleus placed in the centre of the sac. (ii) The egg-apparatus, which consists of three cells at the micropyle end of the embryo-sac. One of these receives the name of the ovum or oosphere and is the cell from which the embryo is developed. The other two form the Synergida, and direct the pollen tube to the oosphere. (iii) The 
antipodal cells, which consist of three cells which are placed at the posterior end of the embryo sac. In many cases these disappear before the ovule is ready for fertilisation. (iv) The granular protoplasm, in which the above structures are embedded. (v) The vacuole, which is filled with cell-sap.

The funiculus unites the ovule to the wall of the ovary and contains a vascular strand which carries the nutritive materials necessary for the development of the ovule and embryo or young plant. The integuments protect the nucellus and embryo-sac from injury. In a few plants the integuments may not be developed. The most important part of the ovule is the embryo-sac with its contents.

ExpT. 184.-Cut transverse sections through the open flower of the Marsh Marigold. Wash the section from the razor with water into a watch-glass. Mount a section containing ovules in dilute glycerine. Examine under a low power. Note-

(i) The ovules connected to the carpel by short stalks - the funicles.

(ii) 'The embryo-sac, which is very large.

Examine the embryo-sac under a high power. Note-

(iii) 'The egg apparatus, which consists of synergidxe and oosphere.

(iv) The antipodal cells at the far end of the embryo-sac from the micropyle,

(v) The embryo-sac nucleus.

The Development of the Gynœcium :- The gynœcium is the last part of the flower to appear, and it always occupies the apex of the floral axis. The carpels may be separate as they are developed and afterwards unite, or they may remain separate (as in an apocarpous gynœcium). (p. 186). The zone of tissue just below the carpels begins to develop and carry up the carpels with it. The union of the carpel or carpels forms the ovary. Ridges appear on the wall of the ovary. These are the placentas from which the ovules will be developed.

The Development of the Ovules. - The ovules are formed as outgrowths of the placentas. Each ovule at first consists of two layers of cells belonging to the epidermis of the wall of the ovary, and to a deeper layer just below it. One cell is larger than its neighbours and from this the embryo-sac and its contents are formed. The integuments and the nucellus are formed from the cells at the base of the projection. The funicle is also formed from the cells at the base of the ovule and fixes it to the placenta. 
The large cell which we may call the embryo-sac continues to grow, and its nucleus, - that is, it must be remembered the primary embryo-sac nucleus-divides and the two daughter nuclei move to the ends of the embryo-sac. They both divide again. There are thus two at each end of the sac. These again divide, so that there are eight nuclei in the embryo-sac, four near each end. The protoplasm now forms around three of the nuclei at each end. The three at the end nearest the micropyle form the egg-apparatus, and those at the opposite end the antipodal cells. One nucleus from each end passes towards the middle of the sac. These unite and form the secondary embryo-sac nucleus.

Kinds of Ovules.-There are three common types of ovules, and the names which they receive depend upon the relative positions of the funiculus and body of ovule. These are explained by the figures given. They are as follows :-

I. - The ovule is Orthotropous (atropous) when the funiculus and the axis of the ovule forms a continuous line (Fig. 209, A).

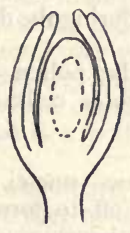

A

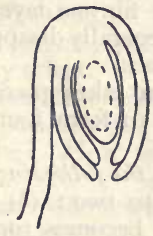

B

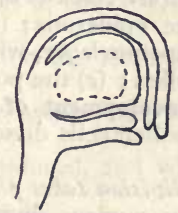

C

Fig. 209.-Diagrams of Ovules. A, orthotropous ; B, anatropous ; C, campylotropous. (After Strasburger.)

The nucellus is then straight, and the micropyle is at the greatest possible distance from the funiculus.

2.-The ovule is Anatropous when the funiculus curves sharply, so that it lies side by side with the body of the ovule. (Fig. 209, B).

3.-The ovule is Campylotropous when the ovule is itself curved so that the micropyle and the chalaza, or basal portion of the ovule, do not lie in the same straight line. (Fig. 209, C). 


\section{SUMMARY.}

The floral whorls are developed in the following order-

The calyx. - The anterior sepal appears first, next the lateral, and finally the posterior sepal.

The corolla. - All the petals appear together.

The stamens. - The anterior pair appear first, next the lateral pair, and finally the posterior pair.

The pistil. - The carpels appear together.

The sepals resemble foliage leaves in structure and appearance. They protect the essential organs from injury, and if petaloid may attract insects.

The petals differ from foliage leaves in colour and texture. Their principal function is to protect the essential organs, and by their shape, colour, and perfume to attract insects.

The essential floral organs consist of andrœcium and gynœcium. These are essential for the production of seeds. The androecium produces pollen, and the gynœcium ovules.

The structure of the andrœcium. - It consists of modified leaves, bearing very little resemblance, however, to foliage leaves. Its function is to produce pollen and liberate it. The filament of an anther represents the petiole of a foliage leaf and the anther lobes the blade.

The anther consists of the following layers of cells-

(a) The epidermis; (b) the fibrous layer; $(c)$ the vascular bundle; (d) the tapetum layer, which generally disappears during the development of the pollen; $(e)$ the pollen sacs.

The development of pollen takes place in the pollen sacs. The mother pollen cells divide up to form four daughter cells-the pollen grains.

This division takes place in the following way-

(a) The nucleus divides into two; $(b)$ the two nuclei divide into two each; $(c)$ the protoplasm becomes rounded off to form four cells round the protoplasm; $(d)$ the mother cell-wall becomes disorganised and the daughter cells are set at liberty as pollen grains.

The pollen grain consists of a cell-wall, the outer part of which is cuticularised to form the extine; the inner, or intine, is very delicate and consists of cellulose. The interior of the grain contains-

(a) A large nucleus-the vegetative one; (b) a small nucleus-the generative one. These are embedded in the protoplasm.

The anther may liberate its pollen-(a) by longitudinal slits, when the dehiscence is longitudinal ; (b) by pores, when the dehiscence is porous; (c) by valves, when the dehiscence is valvular.

The gynœcium is built up of carpels. Each carpel is a modified leaf, and it consists of -

(a) The epidermis; (b) mesophyll; (c) vascular bundles. The carpel may contain ovules.

The parts present in an ovule are-

(a) The funiculus or stalk; $(b)$ the integuments or coverings of the ovules; $(c)$ the nucellus in which $(d)$ embryo-sac is embedded. 
In the embryo-sac the parts present are-

$(a)$ Egg apparatus-synergidæ, oosphere ; $(b)$ antipodal cells ; $(c)$ embryo-sac nucleus ; $(d)$ protoplasm.

The first part of the gynœcium to be developed is the stigma. This is carried up by the growth of the tissue beneath. The ovary is the last part to appear. The union of the carpel or carpels forms the ovary.

The kinds of ovules are as follows-

(i) The orthotropous; (ii) the anatropous ; (iii) the campylotropous.

\section{Questions on Chapter XV.}

(I) State what you know about the development of $(a)$ the calyx, $(b)$ the corolla, $(c)$ the stamens, and $(d)$ the pistil, in any flower of your own selection.

(2) What is the structure of $(a)$ the calyx, and $(b)$ the corolla of any flower? Of what use are they to the plant?

(3) Describe the structure of an anther and of a pollen grain. (1890.)

(4) What is pollen? Give an account of its development and its function. (1893.)

(5) How are the pollen grains set at liberty? Give examples.

(6) Describe the contents of the embryo sac at the time when fertiisation is about to take place. (1891.)

(7) Give a description of the successive stages in the development of the embryo-sac in any plant. (1894.)

(8) Explain the use of the stigma, and describe the structure of the stigma of any flower you may select.

(9) Describe, giving an example of each, the anatropous, the orthotropous, and the campylotropous ovule. (1898.)

(10) What is a pollen tube? How is it produced, and what is its use?

(11) Of what parts does an ovule consist? Where are ovules found, and how are they held in position?

(12) Explain with diagrams the following terns - anatropous, tapetum, synergidæ, antipodal cells. 


\section{CHAPTER XVI}

\section{POLLINATION AND FERTILISATION}

Flowering Plants.-There is one feature in which all flowering plants differ from non-flowering plants-that is, the production of seeds. They are often spoken of as seed plants in contradistinction to seedless plants. If certain conditions are fulfilled, the ovules become changed into seeds. There is no other way in which seeds can be produced, except by changes in the ovules which convert them into seeds. The ovules of to-day become the seeds of to-morrow, and the seeds of to-morrow form the plants of the future.

The conditions which are necessary for the conversion of an ovule into a seed are as follows :-

(1) The pollen grain formed in the anther must find its wav on to the stigma of the pistil. This transference of the pollen from the andrœcium to the gynœcium is called pollination.

(2) The pollen grain must germinate and form a pollen tube, which must grow down the style and enter the micropyle of the ovule. The generative nucleus of the pollen grain must be set at liberty and unite with the oosphere in the embryo-sac. The union of the generative mucleus of the pollen grain with the oosphere is called fertilisation.

(3) The oosphere after fertilisation is called an oospore or egg-spore, and must develop into an embryo or young plant (p. II).

(4) Food materials must be removed from the leaves of the plant into the embryo-sac, there to be used up by the developing embryo during its early growth, or to be stored until the germination of the seed takes place. 
Pollination.-Pollination may take place in two different ways.

(I) Cross-Pollination.-When the pollen of a flower is distributed to the pistil of another flower it is said to be crosspollinated.

(2) Self-Pollination.-When the pollen of a flower is distributed to the pistil of the same flower it is said to be selfpollinated.

Cross-Pollination.-It has been proved with many plants that cross-pollination produces a better crop of seeds ; and that the plants produced from these seeds are stronger and better able to survive in the struggle for existence. It was pointed out by the late Charles Darwin ${ }^{1}$ that cross-pollinated flowers produce offspring which possess $(a)$ greater strength; $(b)$ the habit of earlier flowering; $(c)$ greater diversity of colour, than the self-pollinated flowers. Cross-pollination can take place in two ways :-

(I) By the pollen being carried from the anther of one flower to the pistil of another flower by insects. Those plants which possess flowers which are pollinated by insects are called entomophilous or "insect-loving" plants.

(2) By the pollen being carried from the anther of one flower to the pistil of another flower by the rvind. Those plants which possess flowers which are pollinated by the wind are called anemophilous, or "wind-loving" plants.

Why Insects visit Flowers. - Insects are attracted to flowers by their shape, colour, and perfume. Many flowers also produce honey which the insects use for food. Organs which produce honey are called nectaries or honey-glands (p. 195). These nectaries occupy different positions in different plants. Thus, in the flowers of the Wallflower there are two nectaries, which occur at the base of the short stamens, and the sugar solution or honey which they produce is stored up in the saccated lateral sepals. In the Christmas Rose, the modified petals, which are tubular in shape, bear neciaries. The nectary in the spotted orchid is in the twisted spur, and it is necessary for the bee to put its tongue or proboscis down this spur in order 
to reach the honey. In fact any part of the flower may be modified for the secretion and reception of honey.

Insects cannot live on honey alone for it contains no nitrogen, and nitrogen is just as necessary for the life of animals as for plants. Many coloured flowers do not produce honey, but plenty of pollen, the pollen being collected by insects for their food. The pollen, since there is a fair amount of protoplasm in it, contains nitrogen. Bees, for instance, possess small brushes, on the end of their appendages or limbs, which are used to brush the pollen from the surface of the body. The pollen is then moistened and rolled up into little balls, which are stored in a little sac in one of the limbs until the hive is reached. The Broom is a plant which does not produce honey, but which is visited by crowds of bees for the sake of its pollen, which it produces in large quantities. Insects are of service to plants because they distribute the pollen from flower to flower, and the plants in return supply them with honey and pollen for food.

Contrivances to Prevent Self-Pollination.-The importance of cross-pollination to many plants has produced many contrivances to prevent self-pollination, and to enable the far more successful cross-pollination to take place. The principal arrangements by which flowers facilitate cross-pollination must now be described.

(I) The stamens and carpels may be produced in different flowers. In such a case it is necessary for the pollen to be carried from flower to flower. Such flowers are said to be diclinous. The stamen-bearing flowers and the carpel-bearing flowers may be produced on the same plant, as in the Birch, Hazel, and Pine, when it is said to be monocious. The stamenbearing flowers may be produced on one individual, and the carpel-bearing flowers on another individual plant, as in the Dog's Mercury and Willow, when the plant is said to be diocious.

(2) Both stamens and carpels are present in most of the common flowers, and the flower is said to be monoclinic. In such a flower self-pollination may be prevented by the stamens and carpels ripening at different times. If the stamens ripen and distribute their pollen before the carpels of the flower bearing them are ready for pollination, the flower is said to be protandrous, as in the Dog Daisy, Stitchwort, and Harebell 
When the carpels ripen and are pollinated before the stamens of the same plant are ready to distribute their pollen, the flower is said to be protogynous, as in the Plantain (Fig. 212).

(3) The arrangement of the stamens and stigma may be different in the same flower, as in the Cowslip and Primrose. The style of one flower may be long and the stamens short, and in another flower the stamens long and the style short. Thus, the pollen of a short-styled flower would reach the stigma of a long-styled flower, and the pollen of a long-styled one would reach the stigma of a short-styled flower (p. 2 10).

(4) The pollen of a flower may have no effect on the ovules of the same flower, as in most Orchids.

Cross-Pollination by Insects.-We have seen that insects visit flowers in search of honey and pollen. They also aid in the distribution of pollen from flower to flower. Most entomophilous plants produce flowers which have the following characters :-

I.-They are brightly coloured, sweet-scented, and very prominent.

2.-They produce honey and pollen, or pollen only, the insects visiting them to collect food.

3.- They produce pollen-grains which are generally sticky so that they will adhere to the body of insects and to the stigma.

4.- They produce stigmas which are generally sticky, and are placed so that insects must brush them as they pass into the flower in search of honey or pollen.

We will now consider how cross-pollination is produced by insects by taking a few typical examples.

I.-Dimorphic Plants.-If the flowers from a few Cowslip plants are examined the stamens in one will be found at the top of the corolla tube, and the stigma half-way down the tube. In another specimen the stigma will be at the top of the tube, and the stamens half-way down the tube. The first flower has short style and long stamens, and the second, a long style and short stamens. The Cowslip, and all other plants the individual flowers of which vary in the lengths of their styles and stamens, are said to be heterostyled. If there are only two lengths of styles, the plants are called dimorphic. (See Primulacæ, p. 268). 
ExPT. I85.-Collect a few flowers of the Cowslip or Primrose and examine them. Select one where the stigma appears at the top of the corolla tube, and another where the stamens occupy a similar position. Open each corolla by inserting a knife at the bottom of the tube, and making a vertical cut so as to lay them open. On the long-styled. one, note-

(i) The stamens are half way down the tube, and the style at the top of the corolla tube.

On the short-styled one, note-

(ii) The style is half way down, and the stamens at the top of the corolla tube.

Place the flowers side by side, and measure the relative lengths of styles and stamens, note-

(iii) The long style is on the same level as the stamens in the shortstyled flower, and the stamens in the long-styled flower are on the same level as the short style.

(iv) The honey which is at the base of the corolla tube.

In the two forms of the Cowslip, the size of the pollen grains are different, and the structure of the top of the stigma varies. The difference of the two forms is seen below in a tabular form.

$$
\text { Long-Styled. Short-Styled. }
$$

Flowering... A little later ............. Earlier

Stamens ... Short ................... Long

Pollen ...... Grains smaller ........... Grains larger

Style ......... Long .................... Short

Stigma ..... Globular hairs long..... Flattened hairs short.

The larger pollen grains of the short-styled flowers are necessary because they have to pollinate the long-styled flowers, and a longer pollen tube will be necessary to reach the ovule in the ovary. Thus they contain materials for the production of a longer pollen tube. The longer hairs on the stigma of the longstyled form are to prevent the pollen grains from being blown away by the wind.

The Work of the Insect. - When the insect visits the Cowslip for honey, its proboscis or tongue is passed down the tube of the corolla to reach the nectary at its base. If the flower is a longstyled one, the tongue is dusted with pollen at a certain point, and if the next flower visited is a short-styled one, the pollen is placed on the top of the flattened stigma. In the short-styled flower the tongue of the insect is dusted with pollen higher upthis is deposited on the stigma of the long-styled flower. Thus the proboscis of the insect is the medium for the distribution of the pollen, and so produces cross-pollination. 
This description will do for most dimorphic plants, among which the Primrose, Lungwort, and Common Flax are examples.

2.-Trimorphic Plants.-If a few flowers of the Purple Loosestrife are collected from different plants and examined 'they will be found to be heterostyled, and in addition trimorphic, i.e., with styles of three different lengths. The arrangement of the styles and stigmas is seen from the following description :-

(A) Flowers, where the stamens are in two sets-a short set and a long set - the top of the style (stigma) coming between the two.

(B) Flowers, where the stamens are in two setsone set of the same length as the short stamens in $\mathrm{A}$, the other of the same length as the style in A. The style is longer than the two

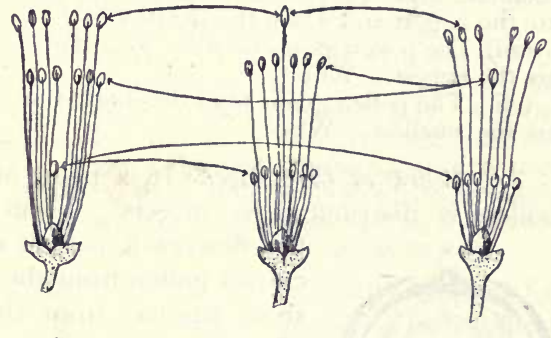

C
B

A

Fig. 210 -Diagram of trimorphic forms of the Loosestrife. sets of stamens.

(C) Flowers, where the stamens are in two sets-one set on the same level as in the long style in B, and the other set level with the style in A. The style is shorter than the two sets of stamens.

Thus, there are short-styles, medium-styles, and long-styles.

There are short-stamens, medium stamens, and long-stamens. (Fig. 210).

ExPT. I 86. - Collect flowers of the Purple Loosestrife from different plants. They can be found in damp places in July and August. Examine them. Note-

(i) The long tubular calyx, near the top of which the distinct, crumpled, purple petals are inserted.

(ii) The stamens inserted in the calyx tube, but much lower down than the petals.

(iii) The syncarpous (p. I86) pistil of two carpels, which possesses one style and one stigma.

Now dissect with care a number of the flowers, and arrange them into three series according to the comparative lengths of the stamens 
and stigmas. Separate the petals from the calyx, and open the tube of the calyx so as to show the position of the stamens and stigma. Note-

(iv) Those flowers where the stigma comes between the two sets of stamens. The style is of mid-length, the stamens are long and short.

(v) Those flowers where the stigma is long-the two sets of stamens coming below it. The stigma is long, the stamens are of mid-length and short-length.

(vi) Those flowers, where the stigma is short - the two sets of stamens are inserted above it. The stigma is short-the stamens are of midlength and long-length.

Now mount pollen from the different sets of stamens in water. Examine with low power. Measure the size of each, and note which are the largest and which the smallest.

(vii) The pollen grains from the long stamens of the short-styled form are the largest. Why?

(viii) The pollen grains from the shortest stamens of mid-styled form are the smallest. Why?

The Work of the Insect-In a plant of this description the pollen is distributed by insects. From the examination of

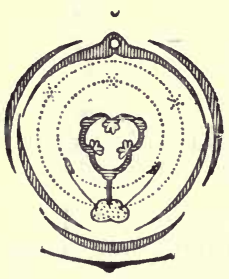

FIG. 211.-Floral Diagram of Orchid. the flowers it is seen at once that the insect carries pollen from the short stamens to the short stigma; from the mid-stamens to the mid-stignı; from the long-stamens to the long-stigma.

3.--British Orchids. - The most highly developed of all entomophilous plants are the orchids. They are noted for their peculiar shapes and the beauty of their flowers. Representatives of this order of plants are found in nearly all parts of the world, and men are constantly engaged in tropical and sub-tropical climates in looking for new specimens. One of the common British representatives is the Spotted Orchis, which makes gay many a lane and bog in the North, and decorates the Sussex Downs and most sea-cliffs in the South.

ExPT. 187.-Dig up a single plant of the Spotted Orchis when in flower, and examine it. Note-

(i) From the tuberous root rise several smooth, parallel-veined, spotted leaves.

(ii) From the centre of the leaves springs the peduncle, which bears a nearly pyramidal head of many purple flowers.

(iii) From the peduncle carefully remove one of the flowers and hold it in the same position as that assumed by it when on the stem. A 
twisted stalk to all appearance connects it to the peduncle. Cut across this supposed stalk-it is full of ovules - in fact, it is the ovary.

Now examine the flower, it is zygomorphic (p. 179). Note-

(iv) The perianth is gamophyllous (p. I88), six-lobed, and superior (p. 183). The largest leaf of the perianth is called the labellum, and is roughly divided into three lobes; it forms a spur below, which contains a nectary.

(v) The single stamen, the anther of which is united with the pistil, and is consequently said to be gynandrous. The stamen terminates below in a little knob called the rostellum or little beak, and this stands over the opening into the spur, so that an insect must push it on one side to obtain honey. The anther contains two pollen-masses.

(vi) The ovary, at the top of which the shiny, sticky stigma is seen. This is protected by the rostellum, which stands in front of it.

(vii) The pollen-masses can be extracted in the following way: With a fine pointed pencil press the rostellum, and keep it pressed for about twenty seconds. Now draw the pencil away slowly. On the tip of the pencil the pollen-masses which have been extracted from the anther lobes will be seen. Observe the pollen-masses; at first they are erect, but at the end of two or three minutes they incline forwards, and if the pencil with the pollen-masses is placed in a second flower they strike the stigma, and some of the pollen will adhere to it.

The flowers of the Spotted Orchis are splendidly adapted for cross-pollination, as the last experiment shows. The smallest quantity of pollen will obtain the maximum of results. If a bed of this plant is watched on a bright day in June or July, the bees will be seen to work the flowers for food, and if some of the insects are caught and examined the pollen-masses will be seen to adhere to their heads.

The Working of the Parts.-The bee or other insect which is attracted to the Orchid flower lands upon the labellum on the lower side of the flower. He passes his proboscis down into the spur in search of honey. The head of the insect thus comes in contact with the rostellum, which gives way before the pressure and the bee's head now rests against the anther. The base of the pollen-masses comes in contact with the head of the insect and begins to set there. This process requires time-several seconds at least. The time necessary for this to take place is gained by the honey being stored up in the thickness of the walls of the spur. To get the honey the proboscis has to dig and penetrate the walls of the spur. This takes time, during which the pollen-masses set on the head of the insect. When the honey has been extracted, the insects fly away with the pollen-másses, which change their position, as they did on the 
pencil ; and when the next flower is visited, they come in contact with the stigma and pollinate it.

4-Flowers Pollinated by the Humble-Bee.-Flowers like the Clover, Vetch, and Pea are pollinated by the humble-bee, which possesses a longer proboscis than most insects. In flowers of this description the honey is stored deep down the tube formed by the diadelphous (p. 185) stamens.

ExpT. I88. - Obtain a few inflorescences of the Clover and examine them. Note-

(i) The inflorescence is a head of numerous flowers.

(ii) Each flower is zygomorphic (p. 179).

(iii) The calyx is gamosepalous (p. 183).

(iv) The corolla is polypetalous (p. 183), and consists of a standard, wings, and a keel.

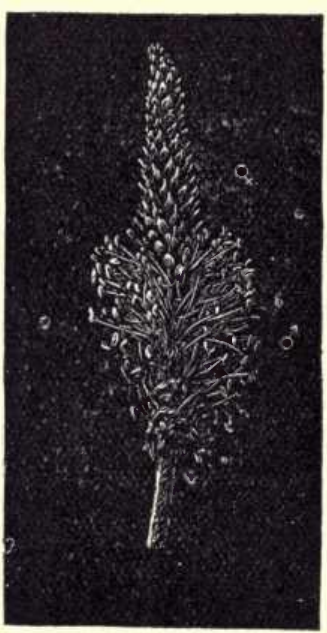

FIG. 212.-Inflorescence of Plantain, with protogynous flowers. The upper flowers are closed, and the styles hang out; the lower flowers have lost their styles, and the stamens hang out. (S.)

(v) The stamens are diadelphous (p. 185), and ten in number.

(vi) The pistil is monacarpous (p. 186).

(vii) The free stamen and small opening down which the humble-bee can pass its proboscis.

(viii) If the standard is pressed downwards, the stamens move so as to discharge their pollen in a certain way.

(ix) There is only one way in which honey can be extracted from the nectary at the base of the tube formed by the stamens.

\section{Cross-pollination by the} Wind.-A large number of plants are pollinated by the wind. They include the great class of Grasses, the.Hazel, Yew, Oak, and Plantain. The chief characteristics of windpollinated flowers are as follows :-

I. The flowers are small, simple, and inconspicuous, thus presenting a great difference to the brightlycoloured insect-pollinated flowers.

2. The flowers have no scent and do not secrete honey; in fact, they have none of the characters by which the entomophilous flowers attract insects. 
3. The flowers produce great quantities of pollen, which is powdery and can easily be distributed by the wind.

4. The versatile anthers are fixed on to slender filaments, which hang out of the flowers so that a little wind can shake them. (Fig. 212) The Nettle, for instance, can distribute its pollen from the anthers by uncurling its filaments with a sudden movement and scattering the pollen in a minute explosion.

5. The stigmas are large and possess structures for holding the pollen which comes in contact with them.

(Fig. 212)

Comparison of Insect-Pollinated and Wind-Pollinated Plants. -

\section{Insect.Pollinated.}

( $\mathrm{r})$ The pollen is carried in a definite direction, i.e., from flower to flower.

(2) Less pollen is produced, for it is more certain of performing its work.

(3) The pollen is better protected from rain, dew, and marauding insects.

(4) Less material is used in producing pollen.

(5) The maximum number of seeds are produced with the minimum amount of material.

\section{Wind-Pollinated.}

(I) The pollen is.carried in all directions, and the great bulk of it is lost.

(2) Large quantities of pollen are produced, most of which never reaches the stigma of a flower.

(3) The pollen is not so well protected from the rain and dew.

(4) Less material is used in producing showy flowers and honey.

(5) The maximum number of seeds are produced with the maximum amount of material.

Self-Pollinated Plants.-By self-pollination is meant where the pollen of a flower A pollinates the stigma of the same flower A. There is a number of plants which produce flowers that are always self-pollinated. Self-pollination is easily secured, and seems in these flowers to give good results. The selfpollinated plant is more likely to be pollinated than any other, because the pollen is near at hand and only needs a little movement to bring it on to the stigma. Either the wind or insects may produce self-pollination, by distributing the pollen from the anthers to the stigma. Several flowers, which are near relations of the Daisy, have stigmas which curl downwards until the pollen-ladened anthers are reached and self-pollination takes place. The Poor-man's Weatherglass produces flowers which may be cross-pollinated during the first three days after opening. If not pollinated during this interval, the flowers 
close up and never open again, but the anthers come in contact with the stigma and self-pollination takes place.

A very large number of plants produce two kinds of flowersthe ordinary open ones and minute closed ones.

The small closed flowers, called Cleistogamic flowers, are selfpollinated and produce large quantities of seeds. The structure and advantages of cleistogamic flowers must now be considered.

The Structure of Cleistogamic Flowers.-They are very small and never open. The petals are rudimentary or absent, the stamens few in number, the anthers small, the pollen grains are few, producing their tubes while in the anthers, the pistil is small, and the stigma almost absent. Pollination takes place by the pollen tubes passing from the anthers down the short style to the ovules in the ovary.

Advantages of Cleistogamic Flowers.-They seem to furnish the following desirable results to the plant.

I. They produce seeds in seasons when the ordinary flowers which are insect-pollinated might be able to produce none.

2. They produce seeds with the smallest consumption of matter, and the energy used is reduced to a minimum. The amount of pollen used in the cleistogamic flowers of the Violet is only the $\overline{24} \frac{1}{6} \overline{0}$ part of that used by a Dandelion. Just as many seeds being produced as in a perfect flower of the Violet.

3. They belong to plants which also produce zygomorphic flowers which are pollinated by insects. But insects, in this strange climate of ours, are very variable quantities. Hence seasons might occur, and do occur, when the necessary insects not being present no seeds would be formed but for the cleistogamic flowers.

Among the plants which produce cleistogamic flowers are the Wood-Sorrel, Violet, and Pansy.

Fertilisation.-When the pollen grains are deposited on the stigma, they are generally held fast by its sticky surface. The grains take up moisture and nutritive materials from the stigma, and germination commences. Pollen tubes are produced, and these pass between the superficial cells of the stigma and bore their way down the style. They feed, as they grow, upon the tissue of the style, and enter the ovary. In the ovary they find their way to the micropyles of the ovules. Each 
ovule requires one pollen grain to form a tube to bring its generative nucleus to the oosphere. Why the pollen tubes enter the micropyle is not fully understood at present, but there must be some substance which attracts them. The pollen tube is guided to the oosphere by the egg-apparatus (p. 20r), the tip of the tube is broken off, and the generative nucleus and some of the protoplasm is set at liberty. The liberated generative nucleus fuses with, and fertilises, the oosphere.

In the Lily, the large size of the pollen grain and tube enables all the stages in the production of a pollen tube and in the process of fertilisation to be followed. The vegetative nucleus passes into the pollen tube first, the generative nucleus following on. The vegetative

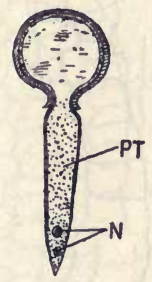

FIG. 213.-PT, pollen tube ; $N$, nuclei. (Dia. grammatic.) nucleus is used up during the growth of the pollen tube, and the generative nucleus or cell divides into two. When the micropyle is reached, the tube passes in between the eggapparatus, and the leading generative nucleus passes out at the end of the tube along with some of the protoplasm. The nucleus travels on until it reaches the nucleus of the oosphere, when it fuses with it, the protoplasm uniting with the protoplasm of the oosphere. After fertilisation, the oosphere becomes the oospore or egg-spore, and it surrounds itself with a firm cellwall.

Development of the Embryo.-The development of the embryo can be studied in a little wayside weed, the Shepherd's Purse. This plant is self-fertilised and produces a very large number of seeds, and as a rule, all stages can be obtained on one plant, from the oospore up to the mature embryo.

The oospore divides into two cells. The one nearest the micropyle is called the upper cell. The upper cell produces a row of cells called the suspensor; the lower cell by division gives rise to nearly all the embryo. The suspensor supports the embryo and fixes it to the wall of the ovule. The embryonic or lower cell divides into eight cells. The four which are the greatest distance from the suspensor form the cotyledonis and plumule, the four nearest the suspensor form the radicle. The tip of the radicle and the root-cap are formed by the upper cell of the 
suspensor. (Fig. 214) The outer cells of the embryo, as it can be called, divide up to form the dermatogen (p. I I2), which
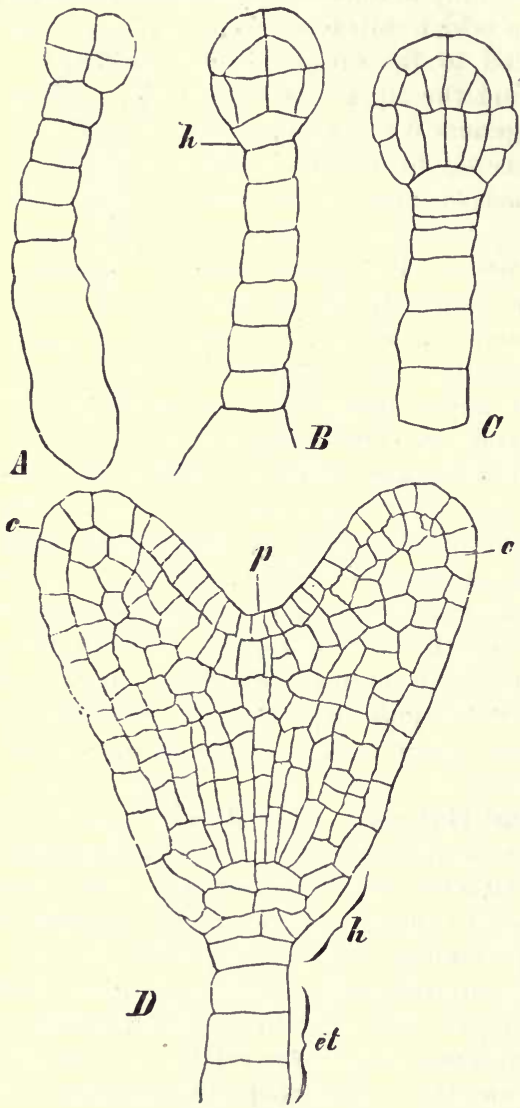

FIG. 214.- - Stages in the development of embryo of the Shepherd's Purse. $c$,.cotyledons ; $p$, plumule; et, suspensor; $h$, hypophysis. (Magnified.) (S.) forms the whole epidermis of the plant. The inner cells divide up to form the plerome, from which the central cylinder of the main stem is formed. Cells are produced between the dermatogen and plerome, from which the cortex is produced. These form the periblem.

Expт. 189.-From the Shepherd's Purse pull off a number of ovaries in different stages of development. Remove the wall from a young ovary, and with needles separate some of the ovules from the replum or central dividing wall of the ovary. Soak some of the ovules in potash solution for ten minutes, or until they are almost transparent.

Mount them in a drop of glycerine on a slide and place on a cover-glass. Press, or give the coverglass a sudden tap, to burst the ovules and force out the embryos. Use the low power for the older stages and for the younger ones the high power. Note-

(i) The suspensor, which consists of several cells, at the end of which the embryonic cell will be seen.

(ii) The embryonic cell in an older specimen will have divided into a number of cells. 
(iii) In a still older specimen the cells have become so arranged that the following layers can be seen-(a) Dermatogen, covering most of the embryo ; $(b)$ plerome, forming the central mass of embryo; $(c)$ periblem, between the two.

(iv) In still older stages the cotyledons will have appeared. They will be seen as lateral outgrowths from the upper part of the embryo.

ExPT. 190. - Collect a few inflorescences of the Water Plaintain (Alisma Plantago). They are in full flower in June, July, and August. The flowers are small and pink in colour. Remove some of the ovules, and treat with potash solution. Mount in glycerine, and with the cover-glass force out some of the embryos. Note-

(i) The suspensor and embryonic cell.

(ii) The embryonic cell divides up into four cells.

(iii) The cells divide into dermatogen, plerome, periblem.

iv) Try and make out the following structures-

(a) The single cotyledon which is formed from the free end of the embryo; $(b)$ the radicle and apex of root which are formed from the lower cells.

Changes in Embryo-Sac.During the development of the em-

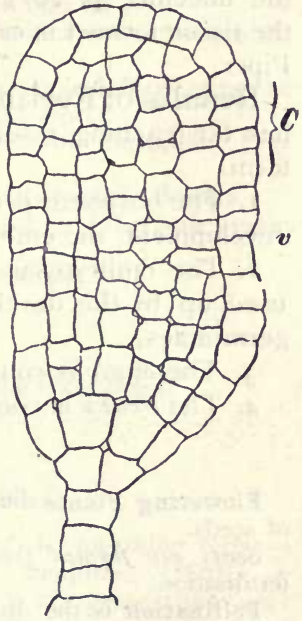

FIG. 215.-Young embryo of the Water Plantain. $C$, cotyledon ; $v$, growing point. (Magnified.) (S.)

bryo, changes are taking place in the embryo-sac. The embryo-sac nucleus (p. 203), divides up and produces a number of nuclei. When hundreds of nuclei have been produced, and the embryo-sac has been enlarged, cell-walls begin to be formed between them. Thus, a tissue of parenchyma cells is produced in the embryo-sac, in which starch and proteids in the form of aleurone grains are stored up for the use of the embryo. This tissue receives the name of endosperm. In Wheat, Barley, and Rye, the endosperm is stored up in such quantities that it is not all used up in the development of the embryo, but is utilised when the seed germinates and the embryo begins to grow. If the ripe seed contains endosperm it is said to be albuminous. If the endosperm is all used up by the developing embryo, so that the embryo-sac is filled with the embryo, the seed is said to be exalbuminous. Wheat, Barley, and Rye are 
examples of albuminous seeds, and Peas and Beans of exalbuminous seeds. In a few cases, reserve material is formed from the nucellus (p. 20I), which is around the embryo-sac, when the tissue formed is called perisperm. Examples-Henbane and Piper.

Results of Fertilisation.--The fertilisation of the oosphere has far-reaching results. These are shown below in a tabular form.

I. The oosphere is converted into an oospore, from which, by development, the embryo is produced.

2. The embryo-sac is filled with endosperm, which may be used up by the developing embryo or stored up until the seed germinates.

3. The ovule is converted into a seed.

4. The ovary is converted into a fruit.

Summary.

Flowering Plants differ from non-flowering plants in the production of seeds.

Seeds are formed from ovules by the changes which go on after fertilisation.

Pollination is the distribution of the pollen from the anther to the stigma. It can take place in two different ways-(i) Cross-pollination, when the pollen of A finds its way to the stigma of B ; (ii) Self-pollination, when the pollen of A finds its way to the stigma of A.

Contrivances to Prevent Self-Pollination. These are-(i) The flowers may be diclinous (p. 208); (ii) the plants may be monœcious or diœcious (p. 208); (iii) the flowers nuay be protandrous or protogynous (p. 209); (iv) the plant may produce two or three kinds of flowers ; (v) the pollen of A may have no effect on the stigma of A.

Insect-Pollinated flowers are-(i) Brightly coloured, sweet scented, and very prominent; (ii) they produce either honey, or plenty of pollen, or both; (iii) their pollen is sticky; (iv) their stigmas are small.

Dimorphic Plants produce two kinds of flowers; these are-(i) Flowers with short-styles; (ii) flowers with long-styles.

The pollen of the short-styled form pollinates the stigma of the longstyled form, and the pollen of the long-styled flower the stigma of the short-styled form.

Trimorphic Illants produce three kinds of flowers; these have three lengths of style.

Humble-Bee Flozvers, such as the Clover, Vetch, and Pea, cannot be pollinated by any other insect because their tongues are not long enough.

Wind-Pollinated Plant s produce flowers which possess the following characters-(i) The flowers are small, and generally green; (ii) the 
flowers have no scent; (iii) the flowers produce great quantities of pollen which is dry; (iv) the anthers are versatile and hang out of the flower ; (v) the stigmas are very large.

Self-Pollinated Plants produce flowers which may be-

(a) Pollinated by the wind blowing the pollen from the anthers to the stigma of the same flower.

(b) Pollinated by insects creeping over the flower and distributing the pollen from the anthers to the stigma of the same flower.

(c) Pollinated by the stigma coming in contact with the anther of the same flower.

(d) Pollinated by the flower never opening-cleistogamic flowers.

Fertilisation is the union of the generative nucleus of the pollen grain with the oosphere in the ovule.

The Embryo Develops from the oospore by division.

The Results of Fertilisation are-

(i) The oosphere changes into the oospore.

(ii) The oospore changes into the embryo.

(iii) The embryo-sac is filled with a tissue-the endosperm.

(iv) The ovule is converted into a seed.

(v) The ovary is converted into a fruit.

\section{Questions on Chapter XVI.}

(I) Explain, giving examples, the meaning of the following termsdiøecious, monœecious, diclinous, hermaphrodite, complete. (1897.)

(2) What is meant by self-fertilisation and by cross-fertilisation? Mention any plants in which the rvind is the agent in pollination. (1891.)

(3) Describe the structure of the flower of any British Orchid, and explain how pollination takes place. (I890.)

(4) Mention three different flowers which are not pollinated by insects, and explain in what respects they differ from flowers which are so pollinated. State the means by which the pollination of these three flowers is effected. (1894.)

(5) Explain the way in which insects are of use to flowers, and the means by which flowers attract them.

(6) In what important respects do wind-fertilised flowers differ from insect-fertilised flowers? Give examples of both. (1898.)

(7) Explain briefly the biological significance of (a) brightly coloured, and $(b)$ irregular flowers, as compared with $(c)$ inconspicuous and $(d)$ regular flowers. Give examples.

(8) What is the use of the spurs formed from floral leaves? Give examples.

(9) What is meant by heterostyled plants? Give examples.

(I0) Mention plants which produce cleistogamic flowers, and explain of what use they are to the plant.

(I I) How do dimorphic plants differ from trimorphic plants? Explain what advantage (if any) the trimorphic plants will have over the dimorphic plants.

(12) Why are the pollen-grains larger in the short-styled flower of the Primrose than in the long-styled form? 


\section{CHAPTER XVII}

\section{The Morphology of Seeds and Fruits, and their}

DISTRIBUTION

Seeds.-A seed is the result of the changes which take place in an ovule after fertilisation. The changes can be shown thus :-

(I) The oospore develops into an embryo.

(2) The embryo-sac nucleus divides up to form endosperm.

(3) The coverings or integuments of the ovule change and become fit for the protection of the embryo, and in the seed are called the spermoderm (p. I I.)

Structure of Seeds.-Each seed is covered with a layer, the testa. It is formed from the integuments of the ovule. The central portion of the seed consists of the embryo and the endosperm when it is present. The opening through the testa is called the micropyle (p. Io), and represents the micropyle of the ovule. The parts present in albuminous and exalbuminous seeds may be shown thus :-

\section{Seeds.}

Albuminous.

Testa.

Embryo.

Endosperm.
Exalbuminous.

Testa.

Embryo.

Comparison of an Ovule with a Seed.-The corresponding parts of the ovule and seed may be easily compared :- 


\section{Ovule.}

Funiculus.

Integuments.

Micropyle.

Nucellus.

Embryo-sac.

Contents of sac.
Seed.

Funiculus.

Testa.

Micropyle.

Perisperm.

Embryo-sac.

Embryo and Endosperm.

Examples of Various Kinds of Seeds.-Some examples of the different kinds of seeds will be useful :-

Albuminous.
Wheat.
Barley.
Violet.
Rye.
Tulip.
Castor Oil.
Buttercup.
All Grasses.

Exalbuminous.

Pea.

Bean.

Mustard.

Apple.

Chestnut.

Oak.
With Perisperm.

Stellaria.

Piper.

White Water Lily.

Henbane.

The Aril.-The seeds of some plants have appendages which may be variously produced from the funiculus, hilum, or micropyle. Such new growths are called arils. In the Willowherb a tuft of hairs is produced which aids in the distribution of the seeds. In the Water Lily the aril is produced from the funiculus, and grows round the seed, producing an outer covering often mistaken for the integument. This method of the formation of an aril also takes place in the Yew and Passion flower. In the seed of the Castor Oil plant the aril appears as a small wart-like swelling at its base. The Willow produces a tuft of woolly hairs formed from the funiculus, and hence called a funiculus aril. Among other plants which produce an aril Milkwort, Violet, Celandine, and Spindle-tree may be mentioned.

Expт. 191.-Examine the structure of the seeds given in the table on p. 223. Note-

(i) The nature of the testa.

(ii) The position of the hilum and micropyle.

(iii) The kind of seed-whether albuminous or exafouminous.

(iv) The nature of the endosperm or perisperm.

(v) The number of cotyledons present. 
Fruits.-Fertilisation not only stimulates the ovule and its contents so that a seed may be produced, but its influence also extends to the carpels, and in some cases to other parts of the flower, so that a fruit is formed. Other parts of the flower which do not take part in the formation of the fruit drop off sooner in cases where fertilisation has not occurred. A fruit is the direct result of the changes which go on in a flower as a result of fertilisation.

Definition of a Fruit.-A true fruit is the result of the changes which go on in a single gynacium due to fertilisation. When other parts of the flower take part in the formation of
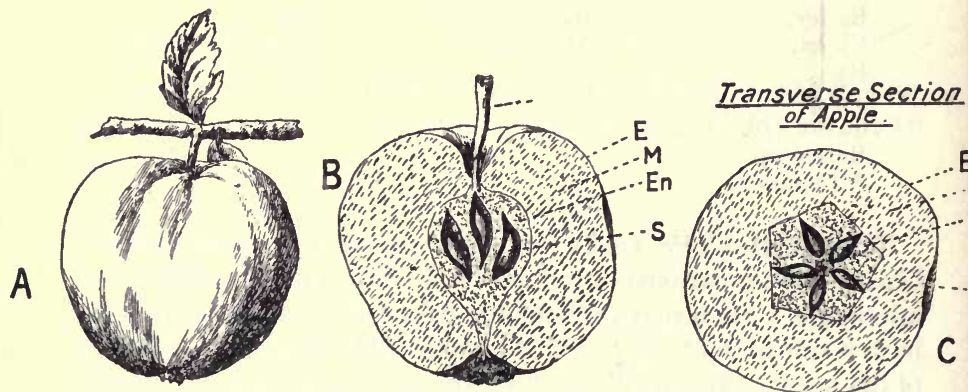

FIG. 216.-A, Apple; B, longitudinal section of Apple; C, transverse section of Apple. $E$, endocarp; $M$, mesocarp ; En, endocarp; $S$, seed.

the fruit, the organ produced is called a spurious fruit or pseudocarp. The apple is formed by the receptacle growing up round the gynœcium after fertilisation, and so forming the whole of the succulent part of the fruit. When an apple is used as food, it is the altered receptacle and calyx which we eat. The central part is formed from the gynœcium and is called the core. The pips are the seeds. (Fig. 216.)

In the strawberry the receptacle becomes succulent after fertilisation, and carries up the true fruits - the hard grains which the fruit contains (Fig. 217). Fruits can thus be divided according to the parts of the flower which take part in their formation into true fruits and spurious fruits. 
Structure of a Fruit.-The wall of the fruit is called the pericarp, and in most instances it can be divided into three different layers :-

The epicarp, or outer layer of the fruit. (Fig. 218).

The mesocarp, or middle layer of the fruit.

The endocarp, or inner layer of the fruit.

The pericarp may be hard and dry, or soft and succulent; in a few cases a portion may be succulent and the remainder hard. In the Plum and Cherry the epicarp and mesocarp are succulent, and the endocarp is hard (Fig. 218). The Hazel-nut possesses a very hard pericarp which is broken off when the seed within is used for food (Fig. 22I).

When the fruit is formed from a single carpel, as in the
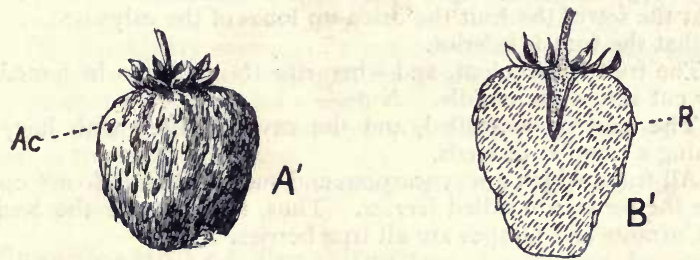
Fig. 217.-A $\mathbf{A}^{1}$, Strawberry ; $\mathbf{B} 1$, longitudinal section of Strawberry; Ac, carpel ;
R, swollen receptacle.

Bean and Pea, it is called a monocarpous fruit. If two or more separate carpels take part in the formation of the fruit, as in the Buttercup and Raspberry, the fruit is apocarpous. A syncarpous fruit is formed from a syncarpous gynœcium, as in the Poppy, Lily, and Wallflower.

Fruits may dehisce or open to liberate the seeds, when they are called dehiscent fruits. If the fruits do not open to liberate the seeds, but the seeds germinate within, and the young plant break through the wall of the fruits, they are called indehiscent fruits.

When the fruit is the result of a single gynoecium it is called a simple fruit, and when produced from a number of carpels it is said to be a compound fruit. Thus, both monocarpous and syncarpous fruits are simple, while apocarpous fruits are compound. 
ExPT. 192. - Select a ripe Cherry and examine it. Note-

(i) It is fixed on the top of a stalk-the peduncle.

(ii) Just below the fruit a scar is present ; this is where the stamens were attached. The calyx must have been inferior.

(iii) Just on the top of the fruit a small spot is present ; this is where the style was fixed.

(iv) The Cherry must be a true fruit because it is formed from the gynœcium only.

Cut the fruit across. Note-

(v) The hard stone in the middle; the hard part is the endocarp.

(vi) The pulp, or succulent part, which consists of two layers; the outer of these is the epicarp, and the inner the mesocarp.

Now break open the stone. Note-

(vii) The seed in the centre; it is protected from injury by the hard endocarp.

(viii) Stone fruits like the Cherry, Plum, and Peach are called drupes.

ExPT. 193.-Obtain a ripe Gooseberry and examine it. Note-

(i) At the top of the fruit the dried-up lobes of the calyx occur. This shows that the fruit is inferior.

(ii) The fruit is succulent, and when ripe the pulp can be forced out. Now cut across the middle. Note-

(iii) The fruit is one-celled, and the cavity is filled with juicy pulp containing a number of seeds.

(iv) All fruits which are syncarpous and succulent, and do not open to liberate the seeds, are called berries. Thus, the fruits of the Red and Black Currants and Grapes are all true berries.

Exr'T, 194. - Obtain a Poppy head from a chemist and examine it. Note-

(i) The external markings on the fruit; these represent the carpels from which the syncarpous fruit was formed.

(ii) If the fruit is shaken, seeds fall out through pores which are near the apex. When fruits liberate their seeds by pores, they are said to dehisce by pores.

Now cut across the fruit. Note-

(iii) The syncarpous fruit is one-celled and contains many seeds.

(iv) A dry syncarpous fruit which dehisces by pores, valves, or teeth is called a capsule.

ExP'. 195.-Examine an Apple. Note-

(i) The remains of the lobes of the calyx on the top of the fruit: The fruit is inferior.

Now make a section of the Apple so as to pass through the dried lobes of the calyx and the peduncle. Note-

(ii) The skin, which is peeled off when the Apple is eaten, is the epicarp.

(iii) The succulent part of the pericarp, which is eaten, is the mesocarp.

(iv) The core is the endocarp and contains the seeds. 
(v) The calyx tube, or receptacle, has grown up and surrounded the gynocium, thus forming a spurious fruit. The spurious fruits like the Apple are called pomes.

Expт. 196.-Obtain a number of Strawberries in different stages of development, and examine them. Note-

(i) The ripe Strawberry consists of a pulpy mass which is surrounded at its base by the persistent calyx.

(ii) The surface of the fruit is covered by numerous small bodies which are the carpels of the apocarpous gynœecium. Each one bears a a style or shows the scar where the style was fixed.

Now examine the series of Strawberries. Note-

(iii) The least ripe Strawberry will have a very small receptacle, while in riper ones the receptacle increases in size. Thus, the fruit of the Strawberry is spurious, and is formed by the receptacle becoming succulent.

(iv) It is an apocarpous spurious fruit.

ExpT. 197.-Examine a Blackberry and compare it with the Strawberry. Note-

(i) The Blackberry consists of a number of succulent druplets, which are arranged on a slightly enlarged receptacle.

(ii) Each druplet contains a seed.

(iii) It differs from the Strawberry in having the carpels succulent instead of the receptacle.

(iv) The Blackberry is an apocarpous fruit, and may be called a compound drupe.

Classification of True Fruits.-Fruits can be arranged according to the characters of the ripe pericarp into :-

(I) Succulent fruits (simple), when some portion or the whole of the pericarp is succulent.
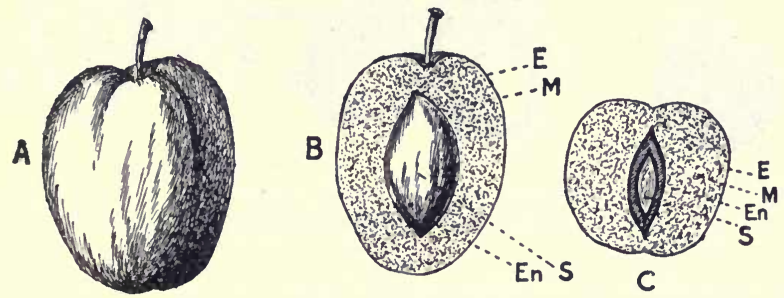

FIG. 218.- A, Plum ; B, longitudinal section; C, transverse section. $E$, epicarp ; $M$, mesocarp ; En, endocarp ; $S$, seed.

(a) The drupe, when the epicarp and mesocarp are succulent, but the endocarp is hard and stone-like (Fig. 218). Examples -Cherry, Plum, Peach, and Apricot. 
(b) The berry, when the whole of the pericarp is soft and succulent (Fig. 219). Examples-Gooseberry, Grape, Currant, Orange, and Cucumber.
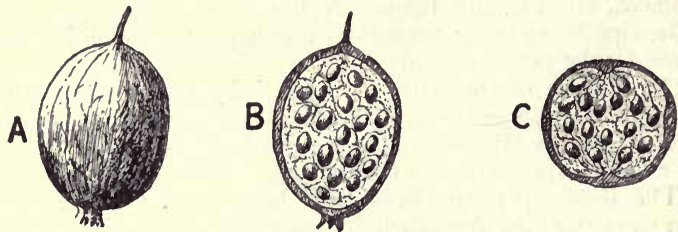

FIG. 2r9.-A, Gooseberry ; B, longitudinal section ; C, transverse section.

Collective Fruits.--(c) The compound druplets, when the carpels of an apocarpous gynœcium are succulent, separated, and each contains a seed (Fig. 220). Examples-Blackberry and Raspberry.

(2) Dry fruits, when the pericarp is hard and dry. If they do not open to liberate the seeds they are indehiscent; if they open, they are dekiscent.

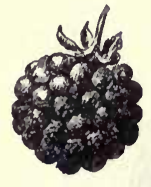

FIG. 220.-Black. berry.
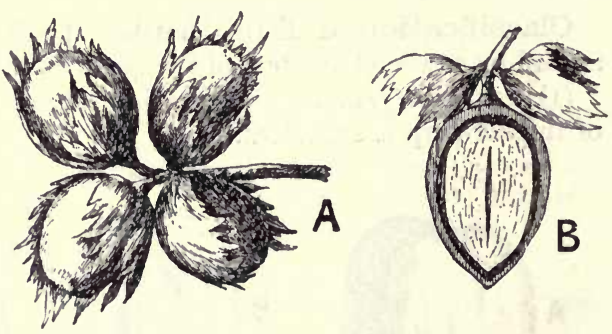

Indehiscent Fruits.-(a) The nut is hard, inferior and syncarpous (Fig. 221). Examples-Acorn, and Hazel-nut.

(b) The achene is hard, superior, and consists of one carpel (Fig. 222). Examples-Buttercup and Rose.

(c) The schizocarp is a many-seeded fruit, which splits into 
many one-seeded fruits, and these enclose the seeds until germination (Fig. 223). Examples-Fool's Parsley, Maple, and Geranium.
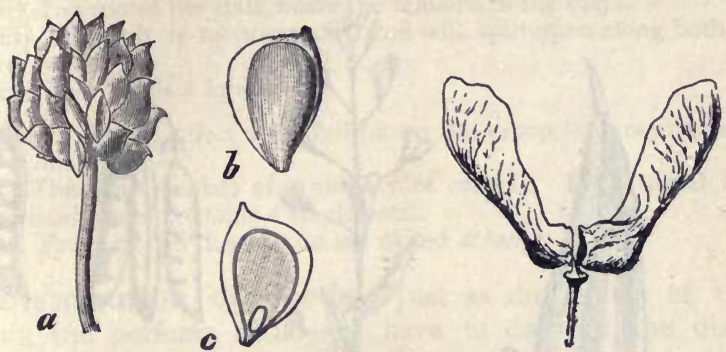

Fig. 222.-Achenes of Buttercup. (S.) Fig. 223.-Schizocarp of Sycamore.

Dehiscent. - (a) The capsule is a dry, syncarpous fruit which opens by pores, valves, or teeth (Fig. 224). Examples-Poppy, Lily, Foxglove, and Stellaria.

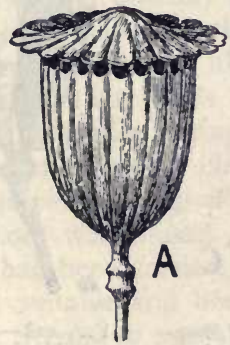

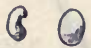
(3)

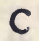

FIG. 224.-A, Capsule of Poppy ; B, transverse section of capsule ; C, seeds. (Onefourth nat. size.)

(b) The siliqua is formed of two carpels ; it is superior and syncarpous (Fig. 226). Examples - Wallfower, Rape and Mustard.

If the siliqua is short and wide it is called a Silicula. Example-Shepherd's Purse (Fig. 227).

(c) The legume or pod is composed of a single carpel which 
dehisces along both the ventral and dorsal sides (Fig. 225). Examples-Pea, Bean, Vetch, and Clover.

(d) The follicle consists of a single carpel which dehisces

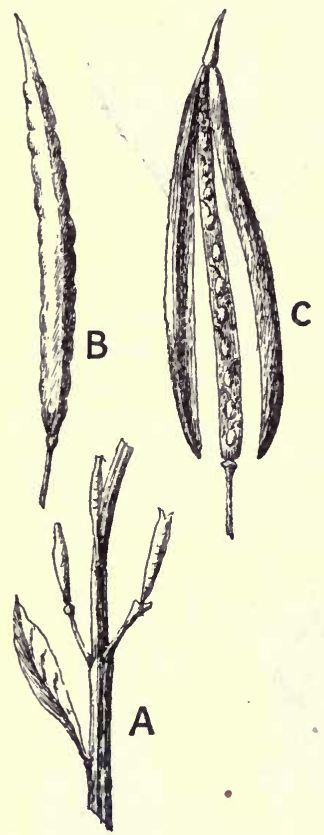

FIG. 226.-A, Fruits of Wallfower ; B, siliqua ; $\mathrm{C}$, siliqua open.
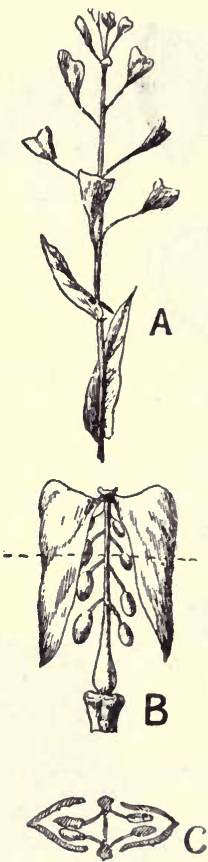

FIG. 227.-A, Fruits of Shepherd's Purse ; $\mathrm{B}$, silicula ; C, transverse section across $\mathrm{B}$.

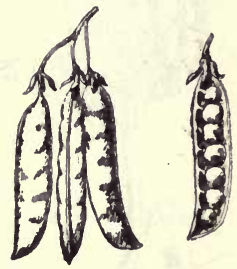

FIG. 225.-Legume of
Pea.

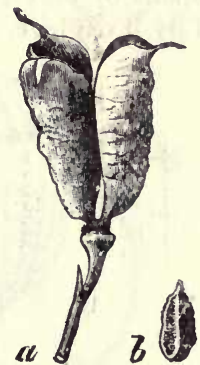

FIG. 228.-Follicles of Monkshood.

along the ventral side only (Fig. 228). Examples-Columbine, Aconite, Pœony, and Larkspur.

Expr. 198. - Collect a few Hazel-nuts and examine one. Note-

(i) The hard, dry pericarp which encloses the seed.

(ii) The pericarp, if broken open, shows three layers, which represent the epicarp, mesocarp, and endocarp.

(iii) The fruit is syncarpous and indehiscent. 
Expr. 199. - Collect a few fruits from the Broom and examine them. Note-

(i) The fruit is superior, and often bears at the tip the remains of the style.

(ii) The top of the stalk bears the remains of the calyx.

(iii) The fruit is monocarpous, and will split open along both sides, or sutures.

(iv) The fruit is a legume.

ExPT. 200.-Collect a few full-blown Buttercup flowers and examine the fruit. Note-

(i) The fruit consists of a number of carpels. Each carpel is dry, indehiscent, and contains a single seed.

(ii) Fruits of this description are called achenes.

Distribution of Seeds.-Just as the variety of colour, form, and perfume of flowers have to do with the distribution of the pollen, so the variety of texture, colour, and shape in fruits have to do with the distribution of seeds. Plants are stationary objects, and to give the young plants a chance in the struggle for existence, it is necessary that the seeds should be distributed as widely as possible from the parent plant. When it is considered that only a few seeds out of the large number produced can possibly find suitable conditions for germination, it will be realised that the distribution of seeds is an important branch of the natural history of plants.

The fact that seeds are distributed from place to place is shown by plants springing up in unlikely localities, such as ruined buildings, on churches, and old walls. Some time ago in examining the top of a church, a number of the seeds of the Sycamore were found. These were germinating, and most likely had been carried for a considerable distance by the wind. Had a suitable soil been present, it seemed possible for some of the Sycamore seeds to have taken root and flourished. So numerous are the plants which sometimes grow in such places that lists have been prepared of the vegetation found on Cologne Cathedral, the Coliseum at Rome, and for many other places.

How Seeds are Distributed.-Seeds may be distributed in many ways :-

(1) The seeds or fruits may be scattered by the wind.

(2) The seeds may be scattered by the fruit exploding, and so sending individuals for a considerable distance from the parent tree. 
(3) The seeds or fruits may be scattered by clinging to the wool or hair of animals.

(4) The seeds and portions of the fruits may be scattered by animals swallowing them; after passing through their bodies, the seeds may germinate.

Seeds Scattered by the Wind.-The seed or fruit often has wing-like appendages which make their superficial area greater and so much lighter in proportion to their bulk. When seeds or fruits of this kind are liberated from the parent plant, they fall slowly through the air, not straight down, but in zigzag lines, like the movements of a rook or lapwing, through the air.

The pappus of hairs which is produced from the calyx in the Dandelion aids in the dispersal of the fruits. In the Poppy and Larkspur the seeds lay loose at the bottom of the fruits, and when the wind blows the fruit from side to side the seeds are gradually distributed far from the parent plant. The following table shows how a number of common seeds and fruits are scattered by the wind :-

I. The fruits of the Ash, Sycamore, Elm, and Birch, have appendages which carry them for a long distance from the parent plant.

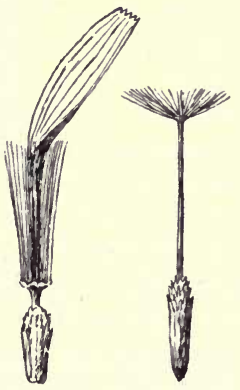

FIG. 229.-Fruit of Dandelion.

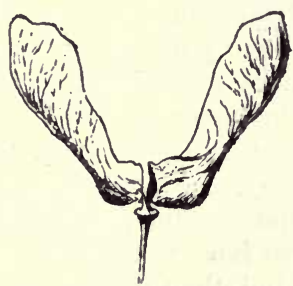

FIG. 230.-Ripe fruit of Sycamore.

2. The fruits of the Dandelion, and most Compositæ possess a pappus of hairs, and are in this way carried through the air by the wind. 
3. The seeds of the Willow, Poplar, and Willow-herb, have tufts of hair, which act like the pappus of the Dandelion.

4. The seeds may be winged, as in the Begonia.

5. The seeds may be small or flattened in form, as in the Orchid, Poppy, Larkspur, and Wallflower, when they are scattered by the wind blowing them out of the fruits.

Seeds Scattered by Explosive Fruits.-Explosive fruits are not common, but the following examples will illustrate their action. In the Box, the seeds are smooth, and are discharged by the pericarp contracting and forcing the seeds out like

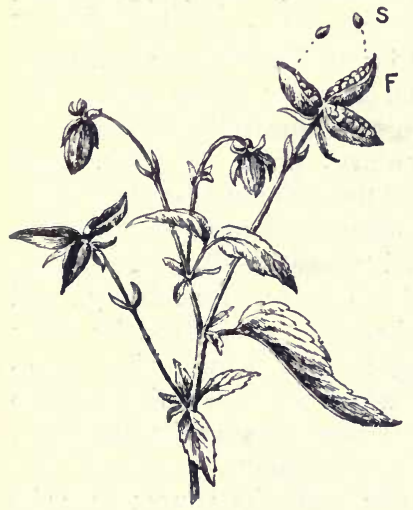

FIG. 231.-Violet. F, explosive fruit ; $\mathrm{S}$, seeds being shot out of fruit.

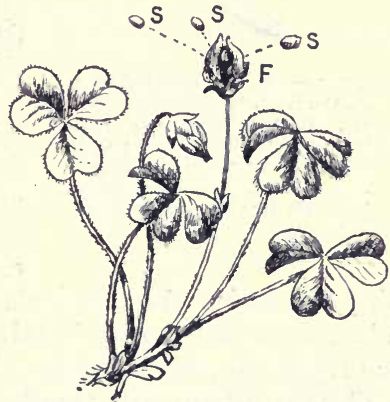

FiG. 232.-Wood Sorrel. F, sling fruit; $S$, seeds being slung out of fruit.

a bean shot from between the fingers. The capsule of the Violet splits open, and, as the valves dry, they contract and fling out the seeds. In the Wood-Sorrel and Squirting Cucumber, the fruit dehisces suddenly, and ejects the seeds for a considerable distance.

Seeds Scattered by Clinging to Animals.-Plants may produce fruits, and in a few rare cases seeds, which are armed with hooks, by which the seeds adhere to the hair or wool of animals. A most familiar example is the Galium, which grows in many of the hedgerows in the country lanes throughout the United Kingdom. Fruits which are armed with hooks 
receive the name of burrs. The hooked fruit of the Wood Avens clings to animals, and is carried for great distances. A
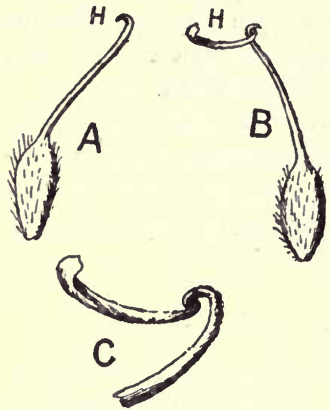

FIG. 233.-Fruit of Wood Avens. $A$, the fruit, showing the hook $\mathrm{H}$; $\mathrm{B}$, the fruit, with both style and stigma; $\mathrm{C}$, the style and stigma more highly magnified. The hook is formed from the style by the stigma break. ing away. country walk through a district where these plants grow will best show how their fruits are distributed by animals.

Seeds Scattered by Animals.-When seeds are distributed by passing through the alimentary canal of animals, they must possess two characters. (a) The seed must be protected by a hard portion of the fruit, which is not acted upon by the digestive juices during the passage of the fruit through the alimentary canal. (b) The hard part of the fruit must be surrounded by something eatable to tempt the animal to swallow it. The drupes of the Cherry, Blackberry, and Raspberry, are scattered by birds eating them and afterwards dropping the seeds. As a rule, plants which produce fruits that are adapted for distribution in this way produce succulent fruits, as the Apple, Strawberry, Rose-hips, and Currant.

Germination of Seeds.-The conditions necessary for the germination of seeds have already been considered (p. 152). That seeds have their vital functions arrested by drying is familiar to everyone ; but when seeds are placed under suitable conditions germination soon begins. Seeds and fruits are able to find a permanent lodgment in the soil by the structure of their surfaces. Thus, the fruits of the Geranium and Grasses are enabled to bury themselves in the ground by movements which are produced by changes in the amount of moisture they contain. The Ivy-leaved Toadflax, or Mother of Thousands, buries its seed capsules in the crevices of walls and cliffs. Nuts, Acorns, and similar seeds are often buried in the ground by animals, such as the squirrel, and forgotten. Afterwards they may germinate. Some seeds have mucilaginous coverings, which not only fix them to the soil but absorb water. 
EXPT. 201.-Place some seeds of the Pumpkin on damp sawdust, and examine them from time to time. Note-

(i) The seed is flattened, oval in outline, and possesses a thickened border. At one end the hilum and micropyle occur. Split open the cotyledons ; observe it is an exalbuminous seed.

(ii) The young radicle (when it appears through the micropyle) grows downwards and fixes itself in the soil.

(iii) The young radicle possesses a peg or projection on the lower side which pins down the seed-coats while the cotyledons are extracted.

(iv) The hypocotyledonous portion, when it comes out of the seed, is arched; this enables it to lift the soil far better than if it came up straight.

(v) The cotyledons increase in size, open out, and perform the work of assimilation.

EXPT. 202.-Compare plants in various stages of germination. Note-

(i) The embryo swells and bursts the testa.

(ii) The radicle comes out of the micropyle and curves downwards and enters the soil.

(iii) The hypocotyledonous stem, or portion beneath the cotyledons, comes up curved.

(iv) The cotyledons are green even beneath the ground. They elongate and spread when exposed to light.

(v) The plumule develops and produces the foliage leaves.

\section{SUMMARY}

Changes in the Embryo-sac form the endosperm, and convert the ovule into a seed. Seeds may be albuminous, i.e., have endosperm and embryo in the embryo-sac ; or exalbuminous, i.e., have only the embryo in the embryo-sac.

The Seed is covered with a testa which encloses the embryo and also the endosperm if it is present.

The Aril is a growth formed from some part of the ovule.

Fruits are divided into true fruits and spurious fruits. A true fruit is formed from a single gynœcium. In a spurious fruit some other portion of the flower takes part in its formation. The wall of fruits is called the pericarp, which can be divided into epicarp, mesocarp, and endocarp. Fruits may either dehisce or open to liberate the seeds, or they may not dehisce.

True fruits may be succulent or dry, and can be arranged into-

Succulent.

The drupe.

The berry.

The druplets.

$\begin{array}{ll}\begin{array}{l}\text { The nut. } \\ \text { The achene. } \\ \text { The schizocarp. }\end{array} & \begin{array}{l}\text { The siliqua. } \\ \text { The legume. } \\ \text { The follicle. }\end{array}\end{array}$

The capsule. 
Seeds may be distributed by the wind; by explosive fruits; by clinging to animals ; by the digestive process of animals.

Fruits or seeds may have appendages which act the part of a parachute. Fruits may be armed with hooks which cling to the hair and wool of animals ; or they may be succulent and so get eaten by animals, the seed being afterwards dropped uninjured.

Seeds germinate when placed under suitable conditions. Some plants bury their seeds, others provide the seeds with coverings which enable them to bore their way into the soil.

\section{Questions on Chapter XVII.}

(I) Explain precisely in what points of structure a seed differs from an ovule. (I880.)

(2) What is a fruit? How does a true fruit differ from a spurious fruit?

(3) What is a berry? What are the advantages to a plant to have this kind of fruit? (1877.)

(4) Describe and compare the fruits of the following plants:-the Buttercup, the Cabbage, the Gooseberry, the Orange. (1890.)

(5) Draw and describe the fruit of a field Geranium, and point out the uses of some of its peculiarities.

(6) Describe the structure of the seed of the Buttercup, of the Apple, and of the Onion. (1891.)

(7) Distinguish between albuminous and exalbuminous seeds, giving an example of each. What is the use of the albumin? (1894.)

(8) What is meant by the "dehiscence" of a fruit? Describe the dehiscence of the fruit of the Marsh Marigold, the Pea, and the Primrose.

(9) Describe and compare $(a)$ the capsule and the berry, $(b)$ achene and drupe, giving an example of each. (1898.

(10) From what part of a flower may the fruit be developed? Describe an achene, a follicle, and a nut, giving examples. (1889.)

(I I) Describe and compare the fruits of the Strawberry, the Raspberry, and the Gooseberry. (I893.)

(12) What is the aril? Describe the different forms of this structure which are found in British plants. (I89r.)

(13) Give examples of fruits and seeds which are dispersed by the aid of birds and other animals, explaining in each case how the dispersal is effected. (1893.) 


\section{CHAPTER XVIII}

\section{THE PHYSIOLOGY OF REPRODUCTION}

Necessity for Reproduction.-Hitherto the means by which plants maintain their individual lives have alone been considered. The limited duration of the life of a single plant is known to every one. Plants are not only preyed upon by slugs, but larger animals also use them for food, and countless parasites, too, live on them. Plants also struggle among themselves for food and light. Extremes of cold and heat have to be contended with. Plants live, die, and new ones take their place. Given this fact that plants die, the subject of reproduction becomes of vital interest, because it is the only way-as far as is known - by which these new individuals can be produced. All existing plants are the descendants of ancestral forms.

By reproduction is meant the production of new individuals by an existing plant. This can take place in two ways: ( $\mathrm{I}$ ) By a portion of the vegetative part of a plant being cut off from the parent plant, thus forming a new individual. This method of reproduction is called asexual or vegetative reproduction. (2) By the union of two cells, one the male, the other the female. These cells, by their fusion, form a single cell which is capable of developing into a new individual. This method of reproduction is called sexual reproduction.

Vegetative Reproduction.-This form of reproduction is comparatively simple, and almost any part of the plant may become separated to form a new individual. The branches of the Gooseberry bend down, and roots are formed at the ends of the branches, which become detached, and form independent plants. The runner of the Strawberry creeps over the surface of the soil for a considerable distance, and roots develop at its 
nodes. This ultimately fornis an independent individual by the intervening portion dying away. The off-set of the House-leek becomes similarly detached, and forms a new plant. The stolon of the Couch Grass performs the same function. In the axil of a leaf of the bulb of the Tulip a new bud is formed which eventually exhausts the whole bulb, and carries on the life of the plant. The Potato produces tubers at the ends of the stolons. These tubers after a resting period develop into new plants.

The Pilewort and some of the Lilies produce small buds, which receive the name of bulbils, in the axil of foliage leaves. These bulbils contain stores of reserve material, and drop off the parent plant to produce new individuals. The leaves of the Begonia and other plants will, if they come in contact with the soil, produce buds which develop into new plants.

The Biological Importance of Vegetative Reproduction.-As long as the food supply is plentiful, and the surroundings are favourable, vegetative reproduction suffices. It is an easy way of ensuring the propagation of the particular races of plants in which it is possible. Gardeners use this method on a large scale for the production of any favourable character which a plant may show. It is said that if vegetative reproduction is indulged in for a long time by a particular race of plants there is a tendency for the race to degenerate. Most plants, however, also reproduce their kind by organs which are produced in a sexual manner.

Sexual Reproduction.-The male reproductive cell is the generative nucleus of the pollen grain, and the female cell the oosphere in the embryo-sac. The former is called the male pronucleus, and the latter the female pronucleus. Neither of these cells can alone produce a new plant, but the actual reproductive cell is formed by their union. The union of the male cell with the female cell stimulates the cell formed, and it develops into a new individual which combines the good or bad characters of the parents. Sexual reproduction differs from vegetative reproduction in the fact of the cells, which produce the new plant, being formed in special organs - the pollen grain and embryo-sac. The most important fact in sexual reproduction is that in a single cell there should be stored up the potentiality of the future plant, or in other words, a single cell should be able to produce a perfect plant. 
The Biological Importance of Sexual Reproduction.-The biological importance of sexual reproduction cannot be overestimated. As long as the surroundings of a plant are favourable, vegetative reproduction suffices, but under unfavourable conditions, the life of the particular race of plants can only be continued over the hard time by sexually produced bodies. The seed produced as the result of sexual union is capable of retaining its vitality under external conditions which would destroy the mature plant. During a period of drought the vitality of the young embryo within the seed is only suspended, not destroyed, and when the necessary conditions agrain occur, it germinates and produces a perfect plant.

Life-History. - All the changes which a plant undergoes from birth to death are called its lifehistory. The life-history of an anmual plant consists of the germination of the seed, the production of the seedlings, its growth to maturity, when it flowers and produces

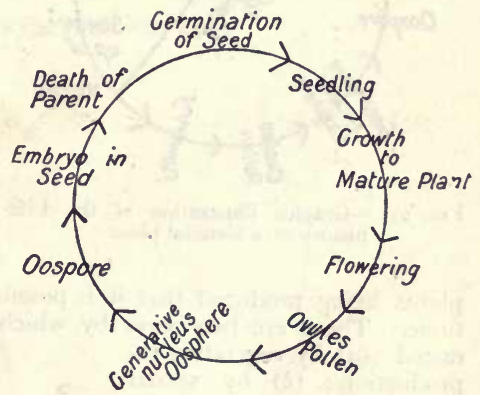

FIG. 234--Graphic illustration of the Lifehistory of an annual plant. pollen and ovules. The generative nucleus of the pollen grain unites with the oosphere in the ovule, and the oospore is formed. The oospore develops into the embryo, and a seed is produced. The parent dies, but the life of the particular race of plants is carried on by the embryo in the seed.

The life-history of a biennial plant consists" of the germination of the seed and the production of the seedling; its growth and the storing up of reserve material, which ends the first year of its life; then during the second year growth recommences, and a flower stem and flowers are produced; pollen and ovules are formed; these produce seeds, and the parent dies too.

The life-history of a perennial plant takes three or more years for its completion. It consists of the germination of the 
seed, the production of the seedling, and its growth until maturity is reached. Flowering then takes place, once or many times, and seeds are formed. The plant may only live a few years, or for a thousand years. It is a common thing to see

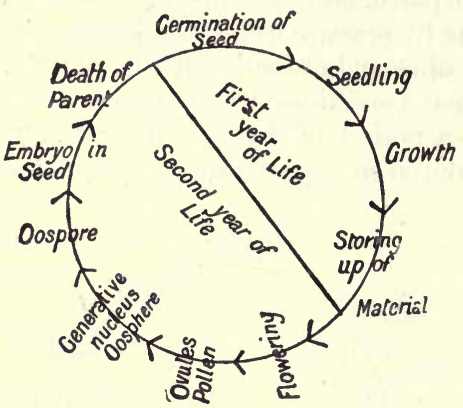

Fig. 235,-Graphic illustration of the Lifehistory of a biennial plant.

trees with several hundred rings, which mark so many years of growth, and a section of the Sequoia in the British Museum has 1330 annual rings. The life-history of such a plant is shown in a graphic manner in Fig. 236.

\section{SUMMARY.}

The Necessity for Reproduction is shown by the death of the individual plant. It is only by new plants being produced that it is possible for a race of plants to continue. There are two ways by which new individuals can be produced $-(a)$ by vegetative reproduction; $(b)$ by sexual reproduction.

Vegetative Reproduction of a plant takes place by a portion of the vegetative part of the plant being severed from the parent; this leads an independent life as a new individual.

The Sexual Reproduction of a plant is brought about by the union of two cells; these by their union produce one cell which develops into the embryo.

The Biological importance of Reproduction is

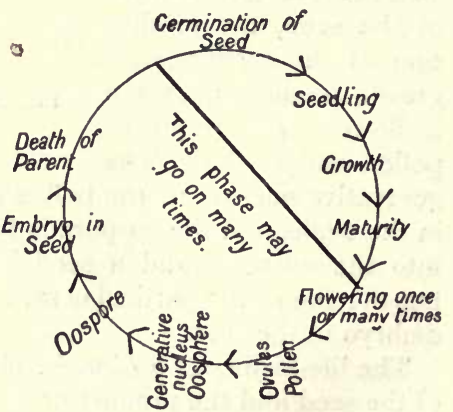

F1G. 236.-Graphic illustration of the Lifehistory of a perennial plant. shown in the multiplication of the individual, and by the better chance it gives the offspring by the distribution of the seeds far away from the parent. The seeds produced can stand extremes of climate better than the mature plant.

The Life-History of a plant consists of all the changes which it undergoes from birth to death. 


\section{Questions on Chapter XVIII.}

(I) Give an account of the different ways in which plants propagate themselves otherwise than by seed. (1898.)

(2) Why is reproduction necessary in plants? Enumerate the two ways by which plants propagate themselves.

(3) Define what is meant by "sexual reproduction." How does it take place?

(4) What is the biological importance of sexual reproduction?

(5) Explain what is meant by the life-history of a plant.

(6) Trace the history of an annual plant from the time of the germination of the seed until it dies.

(7) How does the life-history of an annual plant differ from the lifehistory of a biennial plant?

(8) Show in a graphic manner the life-history of-

(a) An annual plant.

(b) A biennial plant.

(c) A perennial plant. 


\section{CHAPTER XIX}

\section{THE CLASSIFICATION OF PLANTS}

Natural System.--The natural system of botanical classification is based on the resemblances and differences in plants, on the structure, in fact, of both their vegetative and reproductive organs. The whole plant kingdom can be divided into two sub-kingdoms (i) Phanerogams, and (ii) Cryptogams. All plants belonging to the former division produce flowers and seeds, while those of the latter produce neither flowers nor seeds. The Phanerogams are again divided into $(a)$ Angiosperms and (b) Gymnosperms. The Angiosperms have their ovules enclosed in an ovary, but the Gymnosperms have naked ovules. The Angiosperms include two main classes $(a)$ Dicotyledons, and (b) Monocotyledons.

Dicotyledonous plants have the following characters :-

The seedling possesses two seed leaves or cotyledons.

The foliage leaves are reticulate. veined.

The vascular bundles are open and arranged to form a circle.

The parts of the flowers occur either in fives, fours, or multiples of these numbers.
Monocotyledonous plants have the following characters :-

The seedling possesses but one seed leaf or cotyledon.

The foliage leaves are parallel. veined.

The vascular bundles are closed and scattered.

The parts of the flowers are in threes, or multiples of this number.

Divisions of Dicotyledons. - The dicotyledonous plants can be arranged into four sub-classes, according to the structure and arrangement of their floral whorls.

I. - Thalamifloræ.-All dicotyledonous plants which have the stamens hypogynous (p, 185), and the pistil superior (p. 183). 
(2) Calycifloræ.-All dicotyledonous plants which have the stamens perigynous (p. 185) or epigynous, and the pistil either superior or inferior.

(3) Gamopetalæ.-All dicotyledonous plants with gamopetalous (p. 184) corolla, and epipetalous stamens, the pistil is either superior or inferior.

(4) Incompletæ.-All dicotyledonous plants with the corolla absent.

Divisions of Monocotyledons.-The monocotyledons are arranged into three sub-classes, according to the structure and arrangement of their floral whorls.

(I) Petaloideæ.-All monocotyledonous plants with coloured perianths (p. 187).

(2) Spadicifloræ.-All monocotyledonous plants with the Howers enclosed in a spathe.

(3) Glumifloræ.-All monocotyledonous plants with the flowers in glumes.

Each of these sub-classes into which the dicotyledons and monocotyledons are divided includes a number of orders, and each order consists of a number of familiar plants which are closely related. The orders dealt with in this chapter are shown below in a tabular form :-

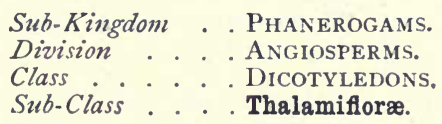
Natural Order.
Distinguishing Characteristics.
(a) Ranunculaceæ
(i) Stamens indefinite (p. 188), hypogynous, (p. I85).
(ii) Pistil apocarpous (p. 186).
(b) Cruciferæ
(i) Sepals and petals in the form of a cross.
(ii) Stamens 6, tetradynamous (p. 185).
(iii) Pistil, syncarpous (p. 186), carpels 2.
(c) Caryophyllex.
(i) Leaves, opposite and entire ; nodes swollen.
(ii) Stamens Io, in two series.
(iii) Pistil syncarpous. 


\section{Suh-Class . . Calycifloræ.}

Natural Order.

(a) Leguminosæ .

(b) Rosaceæ

(c) Umbelliferæ
Distinguishing Characteristics.

(i) Flowers zygomorphic (p. I79).

(ii) Stamens IO, either monadelphous or diadelphous (p. 185).

(iii) Pistil monocarpous (p. 186).

(i) Flowers actinomorphic (p. 179).

(ii) Stamens indefinite, perigynous (p. 185).

(iii) Pistil apocarpous (p. 186) or monocarpous.

(i) Flowers in compound umbels (p. I68).

(ii) Stamens 5, epigynous (p. I85).

(iii) Pistil.

\section{Sub-Class . . . Gamopetalæ.}

Natural Order.

(a) Compositæ.

(b) Primulaceæ

(c) Boragineæ .

(d) Scrophularineæ.

(e) Labiatæ. . . .
Distinguishing Characteristics.

(i) Flowers in heads.

(ii) Stamens 5, syngenesious (p. 185).

(iii) Fistil syncarpous, carpels 2 ; ovary onecelled, and stigma 2-fid.

(i) Flowers actinomorphic.

(ii) Stamens 5, opposite to corolla lnbes.

(iii) Pistils syncarpous, carpels 5 .

(iv.) Placentation, free central (p. I87).

(i) Leaves entire and hairy.

(ii) Flowers rotate and actinomorphic.

(iii) Stamens 5, alternating with corolla lobes.

(iv) Pistil syncarpous, carpels 2; ovary fourcelled, style gynobasic (p. I86).

(i) Stem round.

(ii) Flowers zygomorphic.

(iii) Stamens 4, didynamous (p. 185).

(iv) Pistil syncarpous, carpels 2 ; ovary twocelled, ovules numerous, axile placentation (p. 187).

(i) Stem square, leaves opposite.

(ii) Flowers two-lipped, zygomorphic.

(iii) Stamens 4, didynamous.

(iv) Pistil syncarpous, carpels 2 ; ovary fourlobed and four-celled, with one ovule in each cell. 
Sub-Class . . . Incompletæ.

Natural Order.

(a) Cupuliferæ
Distinguishing Characteristics.

(i) Male flowers in catkins.

(ii) Female flowers sessile in an involucre of bracts.

Sub-Kingdom . Phanerogams.

Division. . . AngIOSPERMS.

Class . . . . Monocotyledons.

Sub-Class . . . Petaloideæ.
Natural Order.
Distinguishing Characteristics.
(a) Liliaceæ
(b) Amaryllideæ.
(i) Perianth either gamophyllous or poly- phyllous.
(ii) Ovary superior; ovules axile placentation.
(i) Perianth generally with a corona (p. 28I).
(ii) Ovary inferior.

Meaning of a Natural Order.-A natural order is built up of a number of genera, each possessing some common characters. The genus in its turn includes several plants resembling each other in one or more respects. The narrowest systematic conception is the species. A species includes plants so closely related that they must have descended from a common ancestor.

Naming of Plants.-Each plant receives two scientific names; the first indicates the genus, the second the species. Thus, for instance, the Tormentil, Potentilla tormentilla, and the silver-weed, Potentilla anserina, are two species of the genus Potentilla.

The following scheme indicates how each plant is arranged in its true position in the natural system of classification ;

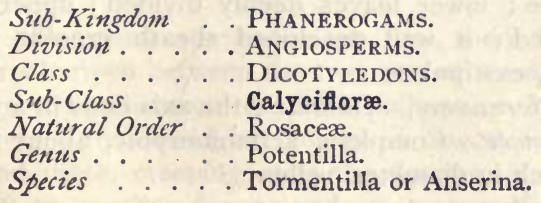




\section{DESCRIPTION OF NATURAL ORDERS.}

Sub-Kingdom. . . PhaneRogams.
Division. . . . . Angiosperms.
Class . . . . Dicotyledons.
Sub-Class . . . . Thalamifloræ.

Natural Order; Ranunculaceæ (Buttercup Family).The plants balonging to this natural order are usually mediumsized herbs. The leaves are radical or cauline; if the latter they are alternate. The flowers are showy and actinomorphic. The stamens are indefinite and hypogynous. The pistil is apocarpous. The fruits consist of one-seeded achenes (p. 228), or many seeded follicles (p. 230).

Floral formula.-K 5, C 5, A $\infty, \mathrm{G}$ i $10 \infty$.

Description of a Typical Buttercup (Ramunculus Acris).

Habit.-A hairy perennial plant with erect stem and straight rootstock. It grows in meadows, and flowers from April to September.
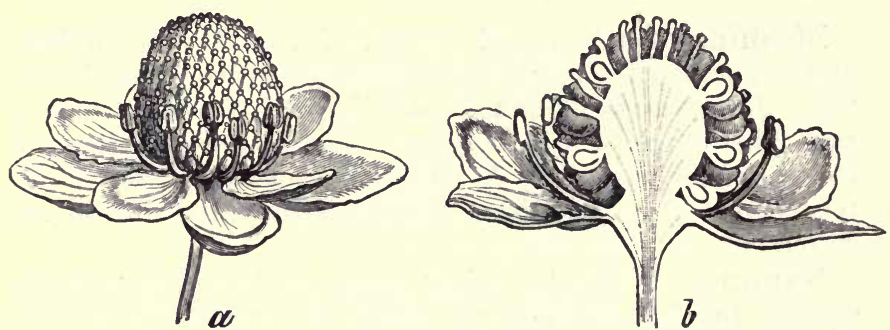

FIG. 237.-Hypogynous flower of Ranunculus, with numerous superior carpels on the receptacle. (Magnified.) (S.)

Root.-A branched tap-root.

Stem.-Herbaceous, erect, round, hollow, hairy, green.

Leaves.-Both radical and cauline; cauline leaves alternate, simple; lower leaves deeply divided; upper, narrow and not divided; a well developed sheath present, reticulate-veined, hairy, exstipulate.

Inflorescence.-Definite; the axis ends in a flower.

Flower.-Complete, actinomorphic, about three quarters of an inch in diameter, yellow. 
Calyx.-Polysepalous 5, inferior, hairy, green.

Corolla.-Polypetalous 5, hypogynous, each petal with a nectary at base.

Andracium.-Free, indefinite, hypogynous ; filament long.; anther two-lobed and basifixed.

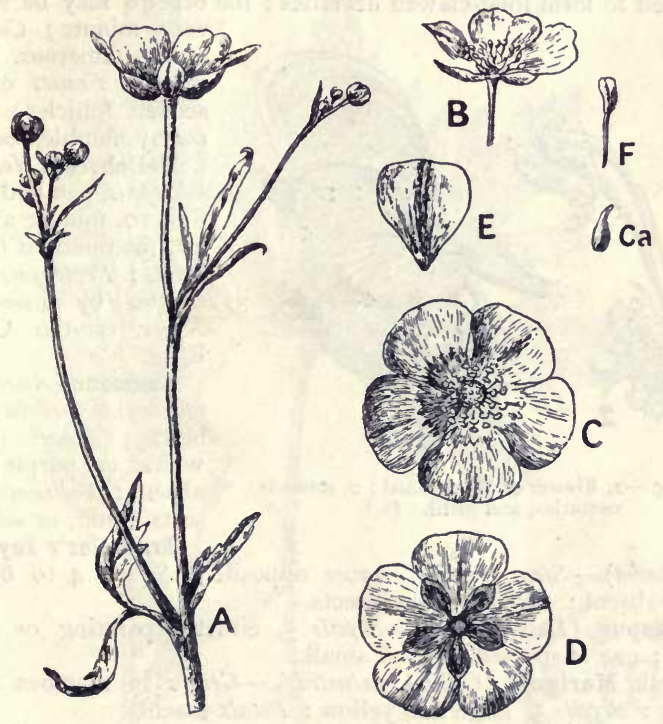

Fig. 238.-Buttercup (Ranunculus). A, branch with flowers: B, longitudinal section of flower; C, flower from above; D, flower from below; E, petal; F, stamen ; $\mathrm{Ca}$, carpel. (One-third nat. size.)

Gynocium.-Apocarpous ; carpels numerous, spirally arranged on a conical receptacle ; superior.

Fruits.-Achenes with a single seed in each ; seeds possess endosperm.

Pollination.-The outer stamens ripen first, then the inner ones. The carpels ripen between the two sets of stamens. In this way either self-pollination or cross-pollination can take place. The flowers are visited by crowds of insects for honey and pollen, and these, creeping over the flowers, may either bring pollen from another flower, and so cross-pollinate; or 
they may distribute the pollen from the stamens to the pistil of the same flower and produce self-pollination.

Exceptions to THE above Type.

Monkshood (Aconitum napellus).-Flowers in racemes, zygomorphic; Calyx blue, sepals 5, the posterior one hood-like; Petals 8, 2 are modified to form long-clawed nectaries; the other 6 may be absent or

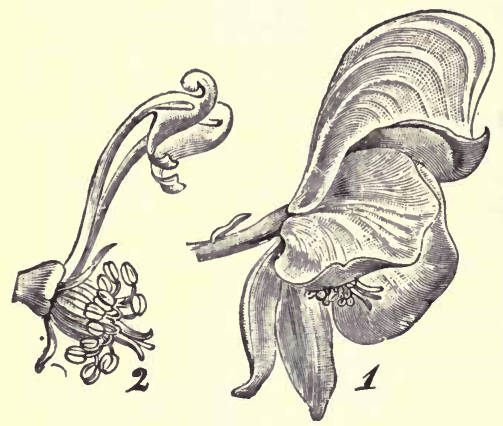

FIG. 239.-I, Flower of Monkshood ; 2, stamens nectaries, and pistil. (S.) very minute; Carpels 3 ; ovules numerous. Protandrous; Fruits of manyseeded follicles; Pollinated by humble-bees.

Hellebore (Hellebornis). - Sepals petaloid; Petals 8 to 10, minute and tubular, modified to form nectaries ; Protogynous; Pollinated by insects; $H$. Niger is the Christmas Rose.

Anemone (Anemone nemorosa).-Involucre of 3 bracts; Sepals (petaloid) white or purple ; Petals absent; Pollinated by insects, wind, or self.

Traveller's Joy (Clematis vitalba).-Stem woody, leaves opposite; Sepals 4 to 6, white; Petals absent ; Pollinated by insects.

Larkspur (Delphinium). - Sepals 5, either separating or cohering below; one is spurred; Petals small.

Marsh Marigold (Caltha palustris). - Grows in marshes and wet ditches; Sepals 5, large and yellow ; Petals absent.

Columbine (Aquilegia vulgaris).--Flowers purple and solitary or in panicles; Sepals 5, petaloid and regular; Petals 5, spurred; Protandrous; Pollinated by insects.

Properties of Ranunculaceæ. - The plants of this order are very rich in substances that possess poisonous properties. The most poisonous plants are Aconitum (all species). The root of this genus has been mistaken for the Horse-radish. It can be distinguished by the following characters :-

\section{Aconitum.}

The rootstock is from two to three inches in length, and ends in a point.

It is coffee coloured, and possesses no pungent smell.

If scraped when fresh it turns pink.

\section{Horse-radish.}

The rhizome is from three to four times as long as the root of Aconitum.

It is of a light yellow colour, and possesses a pungent smell.

It does not turn pink when scraped.

The root of Aconitum is largely used in medicine. 
Ranunculus.-All species are more or less poisonous. The Celery. leaved Crowfoot is probably most poisonous. $R$. acris frequently causes poisoning in cattle. The Marsh Marigold is a source of danger to children, who are attracted by its large yellow flowers.

All species of Anemone and Helleborus are poisonous.

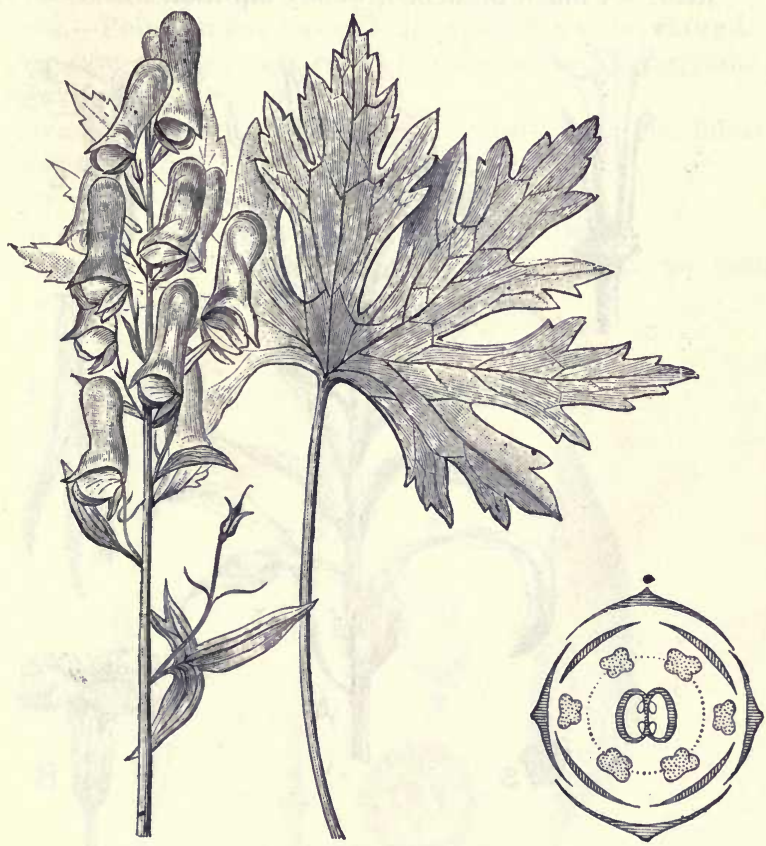

FIG. 240.-Monkshood (Aconitum). (One-third nat. size). (S.)

Fig. 241.-Floral diagram of Cruciferæ.

Natural Order: Cruciferæ.-(Wallflower Family). The plants of this order have either radical or cauline leaves, which are exstipulate. The flowers are in racemes and are cruciform. Sepals $2+2$, the two lateral ones saccate. Petals 4, Stamens 6 , tetradynamous. Pistil syncarpous, carpels 2. Ovary twocelled. Ovules numerous, parietal placentation. Fruit either a siliqua or silicula.

NoTE. - This is the only order with tetradynamous stamens.

Floral formula. $-\mathrm{K}_{2}+2, \mathrm{C}_{4}, \mathrm{~A}_{2}+4, \mathrm{G}(2)$. 
Description of a typical Crucifer. Cheiranthus Cheiri.-(Wallflower).

Habit.-A perennial plant which grows on old walls, and is largely cultivated in gardens.

Root.-A much branched, woody tap-root.

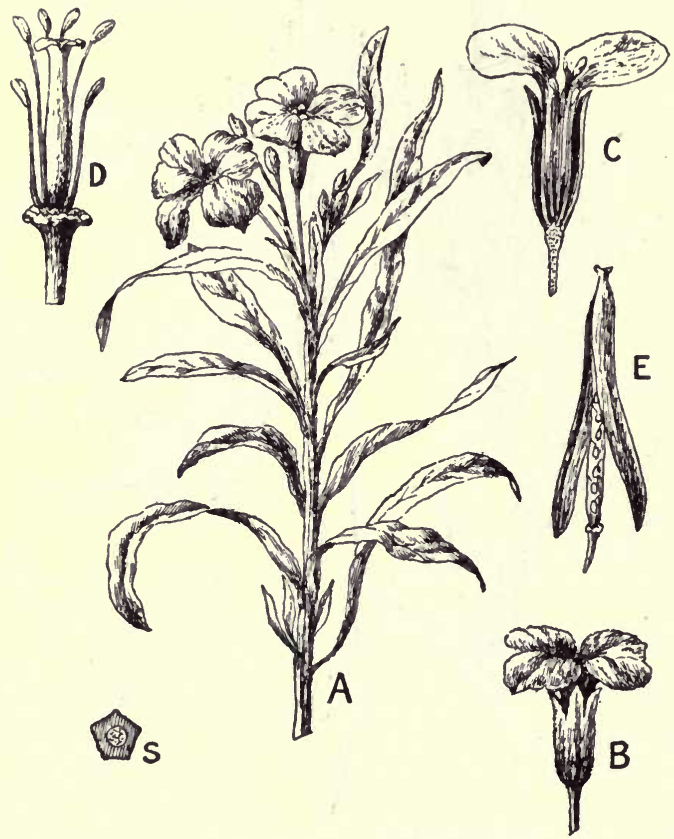

FIG. 242.-Wallflower (Cheiranthus). A, Branch and inflorescence; B, flower; C, longitudinal section of flower; D. stamens and pistil : E, fruit ; S, transverse section of stem. (One-fourth nat. size.)

Stem.-Woody below and herbaceous above, erect, branched, ribbed; the lower part is covered with pale brown bark, and the upper portion is coloured green and is hairy.

Leaves.-Cauline, alternate, sessile, lanceolate, acute, entire and reticulate-veined. Upper side dark green and slightly hairy; the lower side pale green and more hairy ; exstipulate. 
Inflorescence..-Indefinite, erect, raceme.

Flowers.-Complete, actinomorphic, cruciform. Diameter $1 \frac{1}{2}$ inches. Yellow or reddish-brown in colour and sweet scented.

Calyx.-Polysepalous $2+2$, inferior; inner sepals saccate ; sepals lanceolate and hairy.

Corolla.-Polypetalous ; petals 4, hypogynous and clawed.

Androcium.-Free ; stamens 6, tetradynamous, hypogynous; filaments thick, anther two-lobed.

Gyncecium.-Syncarpous ; carpels 2 ; ovary superior, linear, spuriously two-celled; style short ; stigma 2 -fid.

Ovules.-Numerous, parietal placentation.

Fruit.-A siliqua. Seeds with a little endosperm.

Pollination.-The flowers are visited by insects for their honey, which is stored in the saccate sepals.
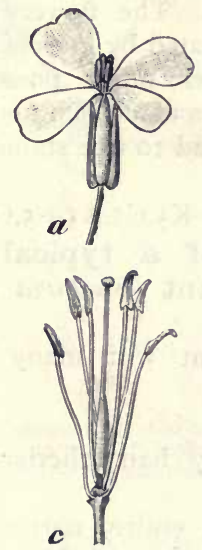
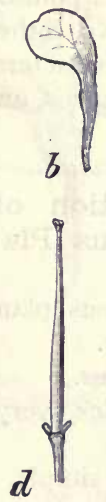
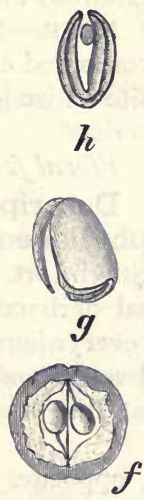

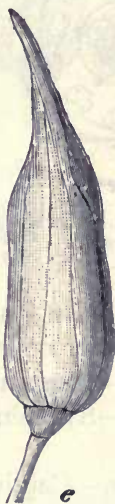

FIG. 243.-Wild Radish (Raphanus Sativus. $a$, flower (nat. size); $b$, petal ; $c$, androecium and gynœcium; $d$, pistil with glands; $e$, fruit ; $f$, transverse section of fruit; $g$ and $h$, embryo. (S.)

Properties of Cruciferæ.-All Cruciferce are wholesome, being largely used for food. Many are valuable because of the organic acids they contain.

The principal plants of this order cultivated for food are: $(a)$ For their roots, Turnip (Brassica campestris). (b) For their leaves, Cabbage (Brassica). "Brussels-Sprouts" is a variety of Cabbage which produces large axillary buds. The young seedlings of the Cress (Lepidium sat- 
ivum), and the White Mustard (B. alba) are used for salads. (c) For their inflorescences-Cauliflower and Broccoli are varieties of Cabbage. Their inflorescences are branched and very succulent. The flowers are very minute. (d) For their seeds, Black Mustard ( $B$. nigra), from which the mustard of commerce is produced. (e) For their oil, Rape and Colza (varieties of Brassica). The oil is obtained from their seeds.

Natural Order: Carophylleæ, (Stitchwort family).The plants belonging to this order have swollen nodes, opposite leaves which are entire and narrow. The flowers are solitary or in dichotomous cymes. The calyx consists of five united or free sepals. The corolla is made up of five petals, each deeply cut or entire. There are Io stamens in two series which ripen five at a time. The pistil is syncarpous, the

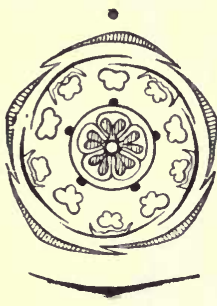

FIG. 244.-Floral diagram. carpels varying in number from 3 to 5 . The placentation of the ovules is axile. Fruit is a capsule. The flowers are protandrous and pollinated by insects.

NoTE.-No other order possesses the combined characters of swollen nodes, opposite entire leaves, and to free stamens in two series.

Floral formula.- $\mathrm{K}_{5}, \mathrm{C}_{5}, \mathrm{~A}_{5}+{ }_{5}, \mathrm{G}(2$ to 5$)$

Description of a typical Caryophyllaceous Plant (Stellaria media).Stitchwort.

Habit.--An annual herbaceous plant with many branches, which grows nearly everywhere.

Root.-Short, and very slender.

Stem.-Swollen at the nodes, very hairy, herbaceous and green.

Leaves.-Cauline, opposite, simple, entire, narrow. Lower leaves possess petioles, while the upper are sessile; exstipulate.

Inflorescence.-Definite, forming dichotomous cymes.

Flowers.-Complete, actinomorphic, stellate, small, white.

Calyx.-Polysepalous ; 5 inferior green sepals.

Corolla.-Polypetalous ; 5, hypogynous, petals split.

Andracium.-Free ; 10 stamens in two series; hypogynous; the outer whorl of stamens is opposite the petals, and the others alternate with them ; filament slender; anther two-lobed.

Gynacium.-Syncarpous : carpels 3; superior ; styles 3 ; stigmas 3 . 
Ovary.-One-celled; ovules axile placentation.

Fruits.-A capsule which opens by valves. Seeds with perisperm.

Pollination.-Honey is produced in five nectaries, forming small knobs outside the stamens. The flowers are cross-pol-

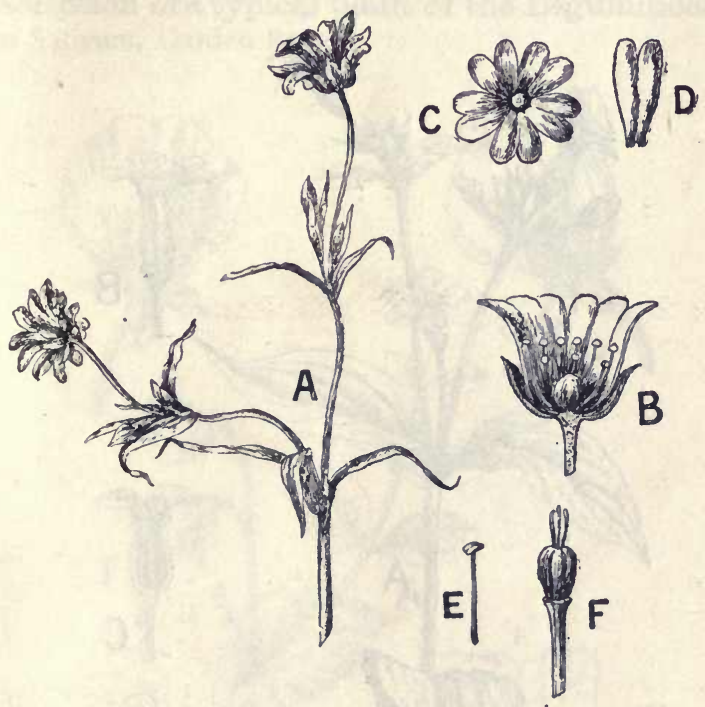

FIG. 245.-Stitchwort (Stellaria). A, branch, with inflorescence; B, longitudinal section of flower; C, corolla, as seen from above; D, petal; E, stamen; F, pistil. (One-fourth nat. size.)

linated by insects. Some of the flowers never open and are self-pollinated. These are not cleistogamic.

NOTE.-This plant is most variable. In some cases the sepals may be 6 . The stamens opposite the petals may be absent, and in a few cases all the stamens may be wanting. The flowers of the Pink, Catchfly, and Campion have the calyx gamosepalous and the petals are clawed.

Properties. - A few plants of this order possess poisonous properties. The most dangerous plants are:-Lychnis githago, the Corn Cockle, which grows in cornfields. Its leaves are very narrow, flowers violet. 
coloured, and the seeds are produced in capsules. It is harvested along with the corn, and is separated from it by machinery. If the flour should contain large quantities of the seeds of this plant bad results may follow from its use. Saponaria officinalis, the common soap-wort, is a stout perennial plant with rose-coloured flowers. All parts of this plant possess a poisonous substance.

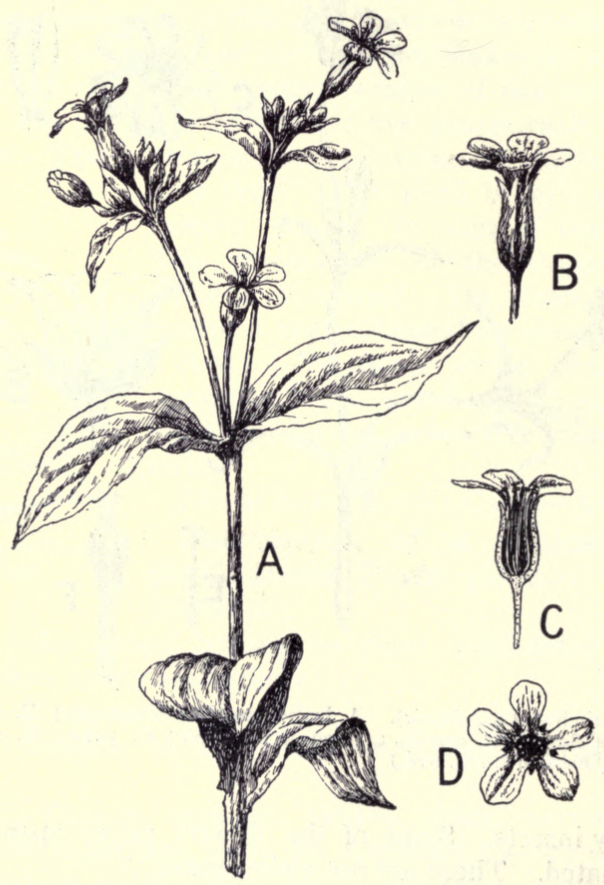

FIG. 246.-A, branch of Campion ; B, a separate flower ; C, longitudinal section of flower; $\mathrm{D}$, flower seen from above.

\section{Sub-Class. Calycifloræ.}

Natural Order: Leguminosæ (Pea Family).-The plants belonging to this natural order may be either herbs, shrubs, or trees. The leaves are alternate, being usually compound and stipulate. The flowers are zygomorphic and papilionaceous. The calyx 
is gamosepalous. The corolla is polypetalous and consists of a standard, wings, and keel. The ro stamens are either diadelphous or monadelphous. The pistil is monocarpous. The fruit is a legume while the seeds are exalbuminous.

Floral formula. $-\mathrm{K}(5), \mathrm{C}_{5}, \mathrm{~A}(9)+\mathrm{I}$ or (10), G I.

Description of a typical plant of the Leguminosæ. (Pisum Sativum, Garden Pea). -

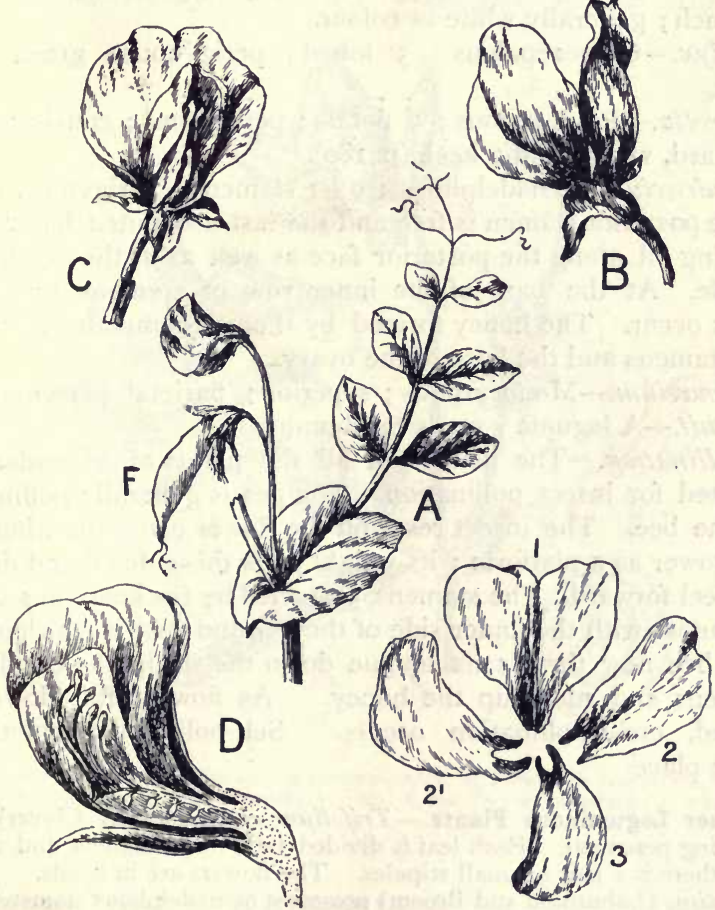

FIG. 247.-A, leaf and flower of Pea; B, a side view of flower; C, flower from above; D, longitudinal section of flower; 1 , standard ; $2,2^{\prime}$, wings ; 3 , the two petals which form the keel.

Habit.-A weak annual plant which climbs by means of tendrils. 
Root.-A branched tap-root with a large number of nodules on the branches. These nodules are caused by bacteria (p. 132).

Stem.-Herbaceous, ribbed, solid, hairy, green.

Leaves.-Cauline, alternate, pinnately compound, stipulate ; the stipules are large, green, and persist; some of the leaflets are converted into tendrils.

Inflorescence.-Axillary and two flowered.

Flower.-Complete, zygomorphic, papilionaceous ; diameter one inch; generally white in colour.

Calyx.-Gamosepalous ; 5 lobed; perigynous; green and hairy.

Corolla.-Polypetalous; 5 petals; perigynous; consists of a standard, wings, and a keel. (p. 180).

Androcium.-Diadelphous ; 9+ I stamens; perigynous ; the single posterior stamen is free and the rest are united, having an opening all along the posterior face as well as at the top of the bundle. At the base of the inner row of stamens five nectaries occur. The honey formed by them accumulates between the stamens and the base of the ovary.

Gynocium.-Monocarpous ; superior ; parietal placentation. Fruit.-A legume; seeds exalbuminous.

Pollination. - The flowers of all the plants of this order are adapted for insect pollination. The pea is generally pollinated by the bee. The insect rests on the flower using the wings of the flower as a platform ; its weight pulls these down and draws the keel forward. The stamens, protected by the keel, thus come in contact with the under side of the bee and dust it with pollen, The bee now thrusts its tongue down the slit in the bundle of stamens and sucks up the honey. As flower after flower is visited, cross-pollination occurs. Self-pollination sometimes takes place.

Other Leguminous Plants. - Trifolium repens (Dutch Clover) is a creeping perennial. Each leaf is divided into three leaflets and at its base there is a pair of small stipules. The flowers are in heads.

Cytisus (Laburnum and Broom) possesses monadelphous stamens.

Vicia faba (Broad Bean) possesses a strong erect stem.

Phaseolus coccineus (Scarlet Runner) has a left-handed twinging stem by means of which it climbs around slender supports.

Properties of Leguminosæ. - Many are largely used in medicine; some are poisonous, others are largely cultivated for food.

Laburnum. - The seeds of Laburnum are poisonous. The plant can 
be recognised by its ternate leaves, its racemes of large yellow flowers, and many seeded legumes. Most of the other plants belonging to the genus Cytisus are poisonous.

Leguminous Plants Cultivated for Food. - The following are the principal plants which are cultivated for food in the United Kingdom :-

Garden Peas-Pisum.

Beans-Phaseolus.

Clovers-Trifolium.

Medick-Medicago.

Sainfoin-Onobrychis.

Vetches or Tares-Vicia.

Bird'sfoot Trefoil-Lotus.

Kidney-Vetch-Anthyllis

Common Melilot-M. officinalis.

Furze, gorse, or whin-Ulex.

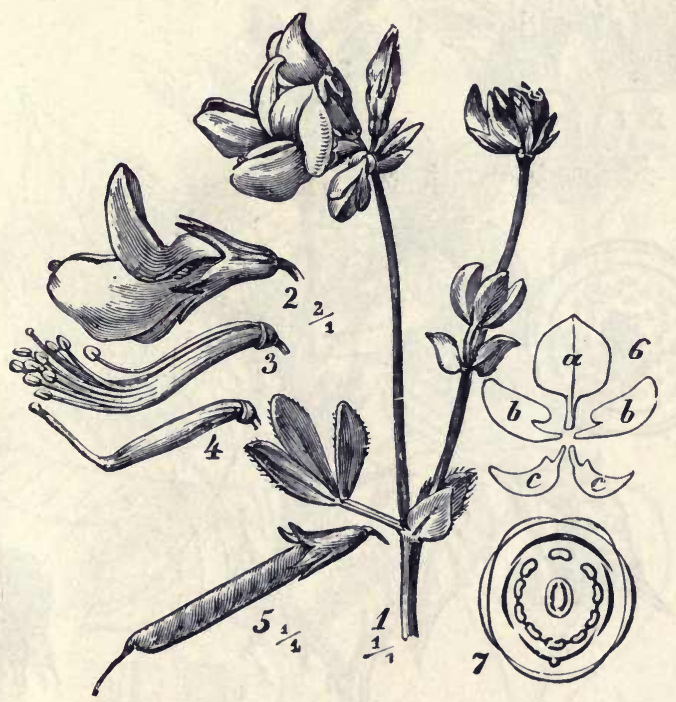

Fig. 248.-Bird's-foot Trefoil (Lotus corniculatus.) I, Flowering branch ; 2, flower ; 3 , pistil and stamens : 4 , carpel ; 5 , fruit ; 6 , corolla; $a$, standard; $b$, wings ; $c$, keel ; 7 , floral diagram.

Natural Order : Rosaceæ (Rose Family).- The plants of this order are either herbs or woody plants. The leaves are generally alternate and stipulate. The flowers are actinomorphic and perigynous. The sepals and petals are usually four or five in number and the stamens are indefinite and perigynous. The pistil is either apocarpous or monocarpous while the number 
of carpels varies from one to many. Fruit various. Seeds either with or without endosperm.

NOTE.-The difference between the plants of this order and those of the natural order Ranunculaceæ consists in their perigynous stamens.

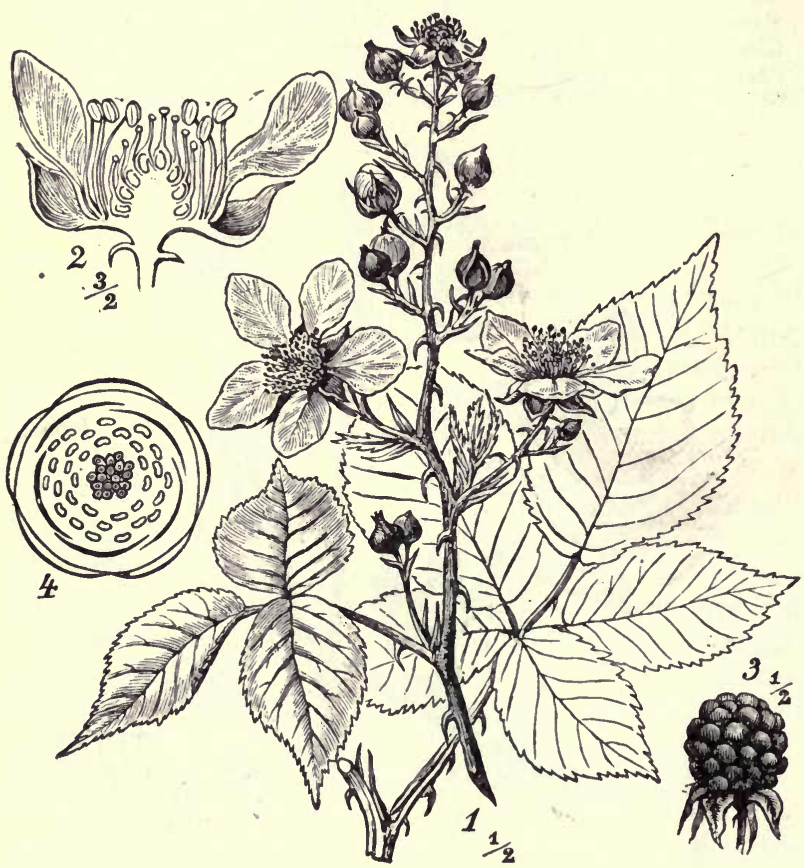

FIG. 249.-Blackberry (Rubus fruticosus). I, Flowering branch ; 2, longitudinal section of flower; 3 , fruit ; 4 , floral diagram. (S.)

Floral formula. $-\mathrm{K}(5), \mathrm{C}_{5}, \mathrm{~A} \infty, \mathrm{G}$ I to $\infty$.

Description of a typical plant of Rosaceæ (Rosa canina, Dog Rose).-

Habit.-A prickly shrub with large coloured flowers.

Root.-A tap-root with woody branches.

Stem.-Woody, prickly, and covered with bark. 
Leaves.-Cauline, alternate, pinnately compound, with a terminal leaflet. The margin of the leaf is serrate. Leaves are stipulate, and these are adnate (p. 46).

Inflorescence.-Definite. The flower is produced at the end. of a branch (in some cases other flowers may be produced in subjacent bracts).

Bract.-Bracteate.

Flower.-Complete, actinomorphic, large, coloured, and sweetscented.

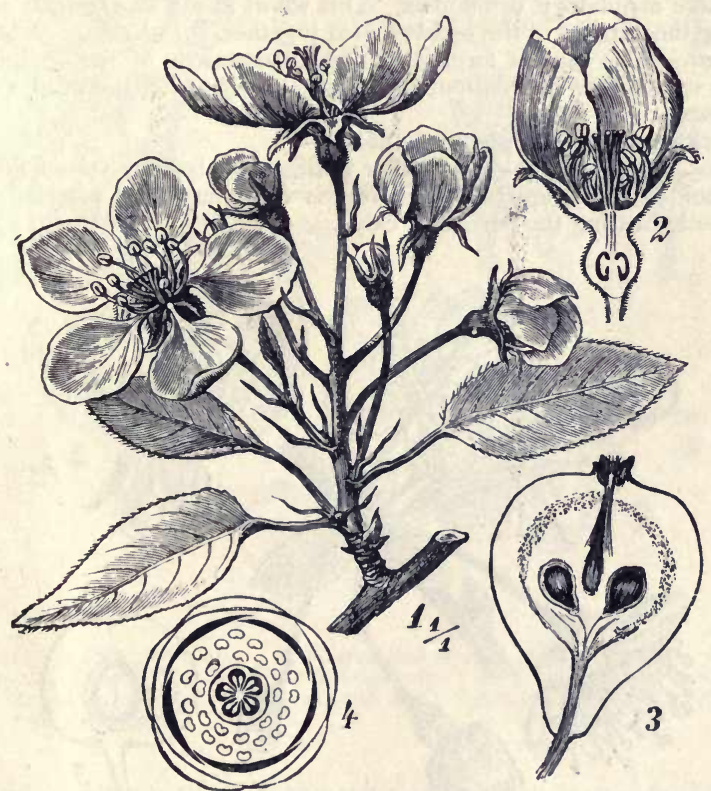

FIG. 250.-Pear (Pyrus communis). 1, Flowering branch ; 2, longitudinal section of flower : 3 , longitudinal section of fruit ; 4 , floral diagram. (S.)

Calyx:-Gamosepalous, 5 lobed, sepals inferior.

Corolla-Polypetalous; 5 perigynous petals.

Androcium.-Free, indefinite, perigynous stamens.

Gynocium.-Apocarpous; carpels numerous and superior. Each carpel contains a single ovule. 
Fruit.-A pseudocarp concealing a number of achenes. Seeds have no endosperm.

Pollination.-By insects.

\section{Exceptions to THE above Type.}

The order Rosaceæ is a very large one, and contains a number of plants differing in some respects from the Dog Rose.

Strawberry (Fragaria vesca) -

Calyx.-Under the calyx, and alternating with the sepal, a whorl of sepal-like members is developed. This whorl forms an epicalyx, representing the stipules of the sepals joined together.

Frnit.-The fruit is formed by the enlargement of the receptacle, which swells after pollination, becoming at first white, then red, sweet, and juicy.

Blackberry and Raspberry (Rubus)-

Fruit.-The carpels enlarge after fertilisation, become succulent, and form one-seeded druplets. The fruit is compound and inserted on a receptacle bearing the persistent calyx.

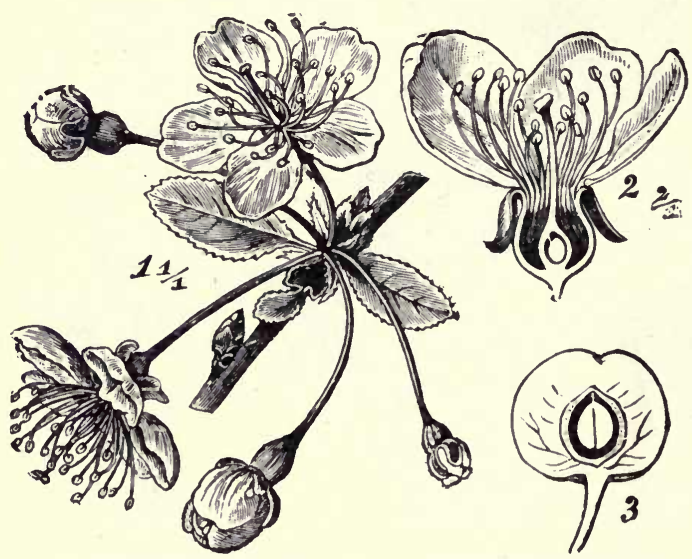

Fig. 251.-Cherry (Prunus cerasus). x, Flowering branch ; 2, longitudinal section of flower ; 3 , longitudinal section of fruit. (S.)

Cherry, Plum and Apricot (Prunus) -

Pistil. - The pistil is monocarpous ; after pollination the single carpel swells up and a one-seeded fruit is produced. This is a drupe which is a simple fruit. 


\section{Apple and Pear (Pyrus) -}

Pistil. - The pistil consists of five carpels which are united to one another along their sides. In the Apple the five styles are united at their base, but in the Pear they are free.

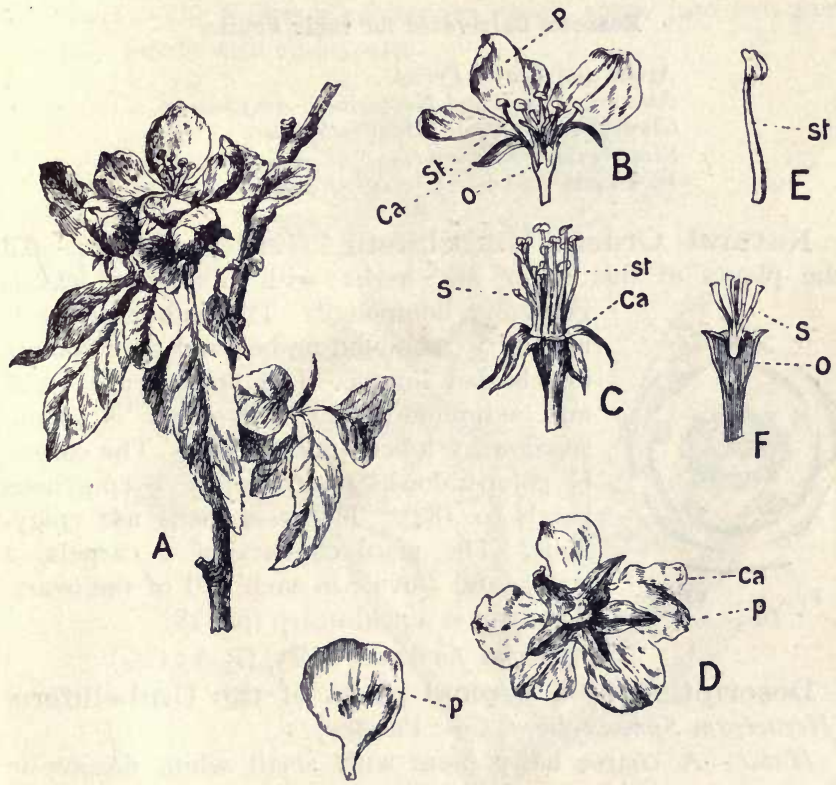

F1G. 252.-A, Twig of Apple; B, longitudinal section of flower ; C, flower, with corolla absent ; D, view of flower from below ; E, a single stamen; F, pistil, with portion of calyx. (One-fourth nat. size.) $C a$, calyx; $p$, petal ; st, stamens; $s$, style ; o, ovary.

Fruit.-After pollination the calyx tube which surrounds the pistil swells up and produces an inferior fruit known as a pome.

Hawthorn (Cratagus) -

Pistil.-The pistil differs from that of the Apple in consisting of only two carpels and in being two-celled.

Fruit.-The portion of the receptacle surrounding the carpels becomes hard and forms a stony endocarp. Thus, the fruit is a stonefruit with two stones.

Ladies' Mantle (Alchemilla)-The stamens are definite, and the anthers are une-celled. 
Properties of Rosaceæ. - The seeds of many species contain prussic acid in small quantities. The Cherry Laurel contains this acid in the leaves, and if these are eaten they produce intoxication. A very large number of the plants of this order are used in medicine.

\section{Rosaceæ Cultivated for their Fruits.}

Apple and Pear-Pyrus.

Almond, Peach and Nectarine-Amygdalus.

Cherry, Apricot and Plum-Prunus.

Strawberry-Fragaria.

Raspberry and Blackberry-Rubus.

Natural Order: Umbelliferæ (Parsley Family).-All the plants of this order are herbs with alternate leaves,

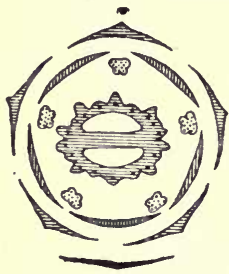

Fig. 253.-Floral Diagram. generally compound. The inflorescence is usually a compound umbel, and an involucre of whorled bracts. The flowers are small and actinomorphic. The calyx is gamosepalous, 5 lobed and superior. The corolla is polypetalous, there being 5 epigynous petals (p. 184). The 5 stamens are epigynous. The pistil consists of 2 carpels, 2 styles, and I ovule in each cell of the ovary. The fruit is a schizocarp (p. 228).

$$
\text { Floral formula.- } \mathrm{K}(5), \mathrm{C}_{5}, \mathrm{~A}_{5}, \mathrm{G}(\overline{\mathrm{z}}) \text {. }
$$

Description of a typical plant of the Umbelliferæ (Heracleum Sphondylium, Cow Parsley).

Habit.-A coarse hairy plant with small white flowers in compound umbels.

Root.-A tap-root with numerous branches.

Stem.-Herbaceous, erect, hollow, ribbed, hairy, and green.

Leaves.-Cauline, alternate, deeply divided, with large sheaths which clasp the stem; exstipulate.

Inflorescence.-Indefinite, compound umbels.

Bracts.-Bracteate, forming an involucre at the base of the main umbel, and partial involucres at the base of the secondary umbels.

Flower-Complete, actinomorphic, small, white or yellow ; the outer flowers may be zygomorphic.

Calyx.-Gamosepalous, 5 lobed, superior, green and hairy.

Corolla.-Polypetalous, 5, epigynous. 
Androcium.-Free, 5, epigynous, alternating with the petals.

Gyncecium.-Syncarpous, carpels 2, inferior, ovary two-celled, with one ovule in each cell.

Fruit.-The fruit is a schizocarp which splits into two mericarps. Seeds with endosperm.

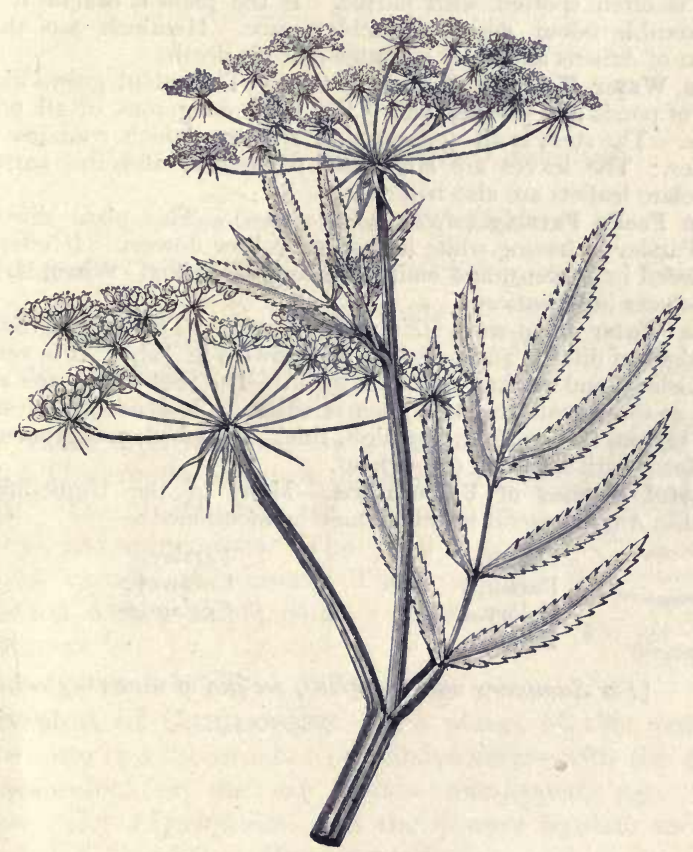

FıG. 254.-Water-Parsnip (Sium latifolium). (Half nat. size.) (S.)

Pollination.-The flowers are small and crowded together. Honey is produced by an enlarged disc, the nectary. The honey being freely exposed, the flowers are visited by shorttongued insects, which cross-pollinate the flowers. The principal insects which visit the flowers are flies, beetles, and wasps. 
Properties of Umbelliferæ. - Many are noted for their poisonous properties. Some are very dangerous in the wild state but harmless when cultivated. Thus, wild Celery is poisonous, but when blanched by being deprived of light the poisonous matter is not produced; light seems to be necessary for its production. The principal poisonous plants of this order are :-

Poison Hemlock (Conium maculatum).-A glabrous herb, often more than a yard high, with hollow stems. The lower portion of the stem is often spotted with purple. If the plant is bruised it enits a disagreeable odour which resembles mice. Hemlock was the State poison of Athens and by it Socrates met his death.

The Water Hemlock (Cicuta virosa). - This plant grows along the sides of ponds and ditches, and is the most dangerous of all poisonous plants. The stem is an underground rhizome which contains internal cavities. The leaves are large and tripinnate, and the narrow and lanceolate leaflets are also tripinnate.

The Fool's Parsley (Aethusa cynapium). - This plant differs from true Parsley in having white instead of yellow flowers. It often grows as a weed in gardens, and emits an odour of garlic. When it is eaten it produces intoxication.

The Water Drop-wort (Enanthe crocata).--This plant grows along the edges of ditches and marshes, and flowers in July. It is very much like Celery, and is often mistaken for it. The root fibres are about as thick as the thumb, and the juice is either yellow or colourless. The stem is from two to three feet high, thick, branched, and grooved. The petioles sheath the stem throughout.

Useful Species of Umbelliferæ.-Many of the Umbelliferæe are useful. Among useful members may be mentioned :-

$$
\begin{aligned}
& \text { Carrot. } \\
& \text { Parsnip. } \\
& \text { Celery. } \\
& \text { Fennel. }
\end{aligned}
$$

Parsley.

Caraway.

Coriander.

[For Summary and Questions, see end of next chapter]. 


\section{CHAPTER XX}

\section{CLASSIFICATION OF PLANTS (Continued)}

Sub-class :-Gamopetalæ.

Natural Order: Compositæ (Compositæ Family).The plants of this order which belong to the British flora are herbs. Their leaves are various and exstipulate. Flowers small and occur in heads. The calyx is small or absent ; in some cases it is replaced by a pappus of hairs. The corolla consists of from 3 to 5 petals. The 5 stamens are syngenesious (p. 185), and epipetalous. The pistil is syncarpous, carpels 2, inferior. The ovary is one-celled with a single ovule. Seeds exalbuminous.

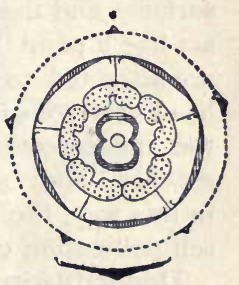

FIG. 255.-Floral Diagram.

Floral formula. $-\mathrm{K}(5-0) \mathrm{C}(5,) \mathrm{A}(5), \mathrm{G}(\overline{2})$.

Division of Compositæ.-The plants of this order are divided into two sub-orders: (a) Tubuliflora-with the flowers actinomorphic, or the ray florets one-lipped, e.g., Daisy, Thistle. (b.) Liguliflora - with the flowers ligulate or strapshaped, e.g., Dandelion, Hawk's-weed.

Description of a Typical member of Tubulifloræ (Bellis perennis, Daisy).--

Habit.-A perennial herbaceous plant, growing in meadows.

Stem.-An underground rootstock.

Leaves.-Radical, petiolate, toothed, green.

Inflorescence.-Indefinite, head or capitulum (p. 168).

Flowers. - The central flowers are termed disc flowers, and 
those on the outside, ray flowers. The disc flowers are incomplete but perfect (p. 178), actinomorphic, tubular, and minute. The ray flowers are incomplete, imperfect, zygomorphic, ligulate, and minute.

Caly.x.-Absent in both disc- and ray-flowers.

Corolla.-The disc-flowers are gamopetalous, 5 lobed,epigynous.

The $r a y$-flowers are gamopetalous, 3 lobed (may consist of five petals), epigynous.

Andrecium.-The disc-flowers-stamens, syngenesious, 5, epipetalous.

The ray-flower, stamens absent.

Gynacium.-In both ray- and disc-flowers-Syncarpous, carpels 2 , inferior, style 2 -fid.

Pollination.-The disc-flowers are protandrous. The pollen from them accumulates in the tube formed by the united anthers. The style branches possess hairs on their outer surfaces and these, when the style pushes its way up the tube, act like a paint brush and sweep the pollen out. The insects are attracted to the head by the ray-flowers, which make the head very conspicuous. The insects creeping over the surface of the inflorescence carry pollen from inflorescence to inflorescence, and cross-pollination takes place. If not pollinated in this way, the style turns down and touches the pollen, and self-pollination takes place.

Description of a typical member of - Ligulifloræ. (Taraxacum Dens-leonis, Dandelion.)

Habit.-A perennial herb which contains a milky fluid; radical leaves, and a hollow radical peduncle, carrying a head of bright yellow flowers.

Stem.-A short tap-root, is capped with a short erect rhizome.

Leaves.-Radical, simple, runcinate.

Inflorescence.-Indefinite, head of from 100 to 200 flowers.

Bracts.-The Bracts form an involucre.

Flower.-Complete, zygomorphic, ligulate, small, yellow.

Calyx.-Represented by a pappus of hairs.

Corolla.-Gamopetalous, 5 lobed, epigynous.

Andracium.-Syngenesious, 5, epipetalous.

Gynocium.-Syncarpous, carpels 2, inferior, style 2, stigma 2-fid. 
Fruit.-The fruit is a one-sided indehiscent achene and carries a pappus of hairs, which is a modified calyx.

Pollination.-The description of the pollination of the Daisy holds good for the Dandelion.

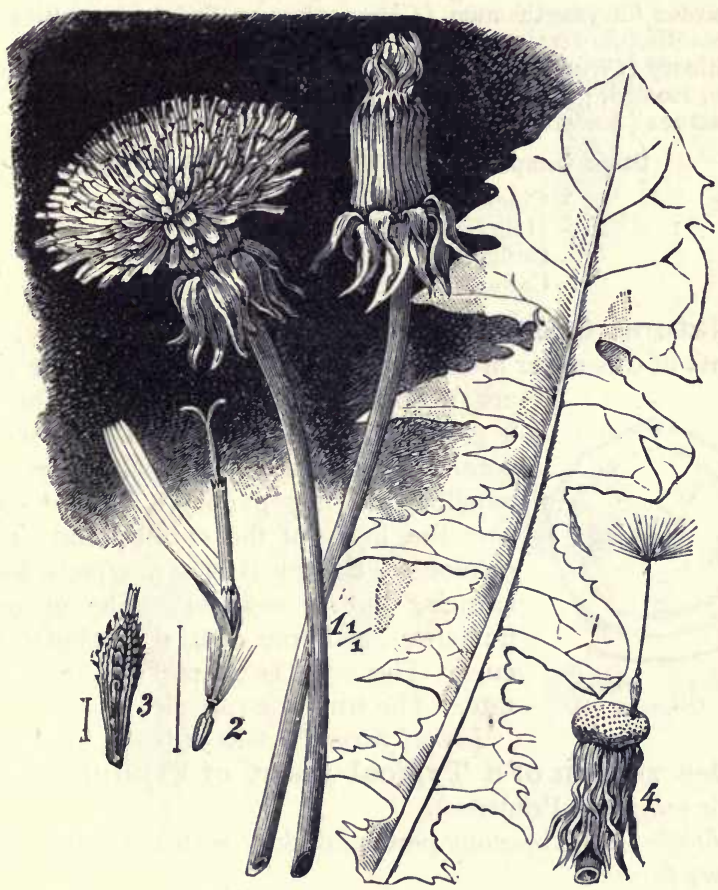

FIG. 256.-Dandelion (T. Dens-leonis). I, Two inflorescences and a leaf; 2, a flower ; 3 , fruit ; 4 , receptacle, with one fruit. (S.)

Properties of Compositæ. - Many are used in medicine, and a few only are poisonous. Lactuca virosa, the Lettuce, contains an illsmelling latex which is slightly poisonous.

Further remarks on the Compesitæ. - This order is the largest in the vegetable kingdom, and the best defined of all the natural orders. There are some 12,000 species, all agreeing in having their flowers in heads and their stamens syngenesious. A few plants of this order are 
cultivated either for food or for ornamental purposes. The following are of service to man :-

Sunflower (Helianthus annuus), cultivated for its seeds, which yield a valuable oil.

Jerusalem Artichoke ( $H$. tuberosus), cultivated for its tubers. It only flowers in the United Kingdom during very hot summers.

Garden Chrysanthemum (Chrysanthemum indicum), cultivated for its beautiful flowers.

Chicory (Cichorium intybus), useful for its roots, which are dried in kilns, roasted, ground, and mixed with coffee.

Lettuce (Lactuca).- - Its leaves are used for salad.

\section{Other Compositæ which are Cultivated in Gardens.}

\begin{tabular}{l|l} 
Cineraria. & Chamomiles. \\
Helichrysum. & Daisy. \\
Gaillardia. & Dahlia. \\
Calliopsis. & Senecio.
\end{tabular}

Natural Order: Primulaceæ (Primrose Family).-The plants of this order are herbs with radical leaves. The flowers

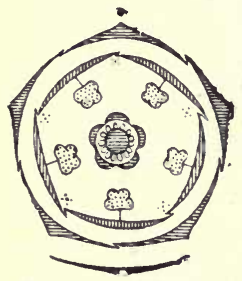

Fig. 257.-Floral Diagram. are actinomorphic and showy. The calyx is gamosepalous, 5 lobed, and inferior. The corolla consists of 5 petals, which are gamosepalous and hypogynous. The five stamens face the lobes of the corolla, and are epipetalous. The pistil is syncarpous, has five carpels, and is superior. The ovules are numerous, and free central placentation occurs. The style is simple, and stigma capitate. The fruit is a capsule.

$$
\text { Floral formula.- } \mathrm{K}(5),\left[\mathrm{C}(5), \mathrm{A}_{5},\right] \mathrm{G}(5) \text {. }
$$

Description of a Typical Plant of Primulaceæ (Primula vulgaris, Primrose).

Habit.-A herbaceous perennial plant with radical leaves and showy flowers.

Root.-Fibrous, forming a dense mass.

Stem.-A stout erect rhizome.

Leaves.-Radical, simple, spathulate, reticulate-veined; margin crimped ; dark green above and light green below ; exstipulate.

Inflorescence.-Definite, solitary.

Flower.-Complete, actinomorphic, tubular; I inch in diameter; dimorphic pale yellow, and sweet scented.

Calyx.-Gamosepalous, 5 lobed, inferior, apex of lobes acute, ridged, green and hairy. 
Corolla.-Gamopetalous, 5 lobed, hypogynous, lobes divided. Andracium.-Free, 5, facing the lobes of corolla, epipetalous. Gynoecium.-Syncarpous, carpels 5, superior, style long or short, stigma capitate, ovules numerous, free central placentation.

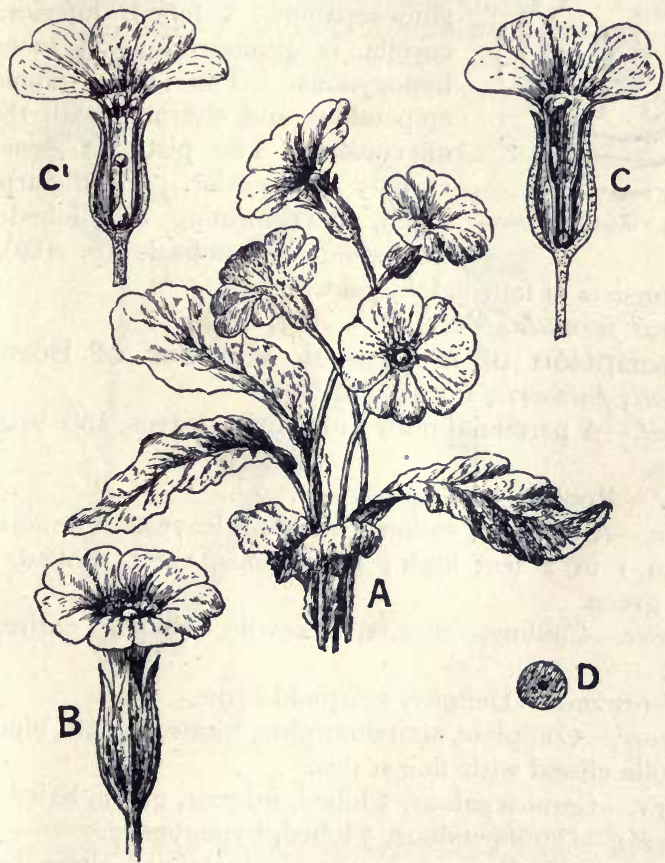

Fig. 258.-Primrose (Primula). A, R adical leaves and flowers; B, flower; C, long-styled flower; $\mathrm{C}^{1}$, short-styled flower; D, section of stem. (One-fifth nat. size.)

Fruit.-A capsule. Seeds with endosperm.

Pollination.-Cross-pollinated by insects (p. 209-1o). Selfpollination is possible in the short-styled form.

Properties of Primulaceæ. - The properties of the plants of this order are unimportant. The tubers of Cyclamen are poisonous, but after cooking they are perfectly harmless. 


\section{Natural Order: Boragineæ (Borage Family).-The} plants can be easily recognised by their succulent stems covered

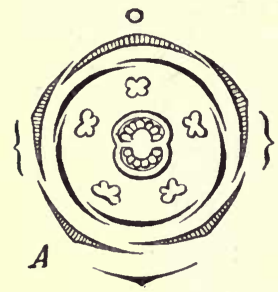

Fig. 259.-Floral diagram. with hairs, their entire leaves and scorpioid cymes. The flowers are generally blue and actinomorphic. The calyx is gamosepalous, 5 lobed, inferior. The corolla is gamopetalous, 5 lobed, and hypogynous. The five stamens are epipetalous and alternate with the lobes of corolla. The pistil is syncarpous, carpels 2, superior. Each carpel is 2 lobed, thus forming a 4 lobed ovary. The style is gynobasic (p. 186). The fruit consists of four indehiscent nutlets.

\section{Floral formula. $-\mathrm{K}(5),[\mathrm{C}(5), \mathrm{A} 5] \mathrm{G}(2)$.}

Description of a Typical Member of Boragineæ (Myosotis palustris, Forget-Me-Not).

Habit.-A perennial herb with entire leaves, and bright blue flowers.

Root.-Rootstock creeping.

Stem.-A creeping stolon with small leaves. The aërial stem is from I to 2 feet high; herbaceous, erect, ribbed, hollow, hairy, green.

Leaves.-Cauline, alternate, sessile, simple, entire, hairy, green.

Inflorescence.-Definite, scorpioid cyme.

Flower.-Complete, actinomorphic, rotate, minute, blue, throat of corolla closed with fine scales.

Calyx.-Gamosepalous, 5 lobed, inferior, green, hairy.

Corolla.-Gamopetalous, 5 lobed, hypogynous.

Androcium.-Free, 5 stamens, epipetalous, alternating with lobes of corolla, filament short.

Gynœcium.-Syncarpous, 2 carpels, superior ovary, 4 lobed, style gynobasic, stigma capitate.

Fruit.-Four indehiscent nutlets.

Pollination.-By insects.

Properties of Boragineæ. - The properties of the plants of this order are unimportant. The dried root of Alkanet, cultivated throughout the south of Europe, is used in medicine. 
Other Boragineæ which should be noticed.

Viper's Bugloss-Echium vulgare.

Borage-Borago officinalis.

Comfrey-Symphytum officinale.

Cromwell-Lithospermum officinalis.

Lungwort-Pulmonaria augustifolia.

Madwort-Asperugo procumbens.

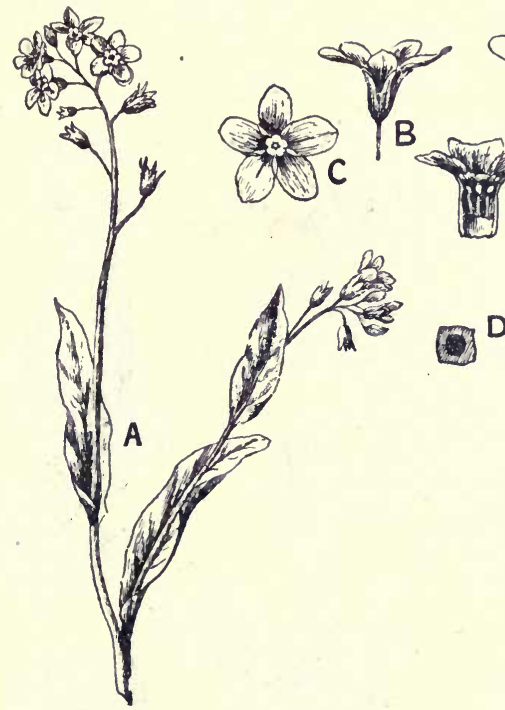

FIG. 26o. - Forget-me-not (Myosotis). A, branch, with inflorescence; B, flower ; $\mathrm{C}$, corolla and scales from above ; $\mathrm{D}$, section of stem ; E, longitudinal section of flower. (Half nat. size.)

Natural Order: Scrophularineæ (Foxglove Family).The plants of this order are herbs, with simple toothed leaves, which as a rule are alternate. The inflorescence may be solitary, axillary, or a raceme. The flower is zygomorphic, and very often showy, The calyx is gamosepalous, 5 lobed, inferior. The corolla is gamopetalous, 5 lobed, hypogynous. The stamens are usually 4 ( 2 in Veronica), didynamous (p. 185), epipetalous. The pistil is syncarpous, carpels 2, superior; style terminal, 
ovary two-celled, ovules axile placentation. The fruit is a capsule.

Floral formula.-K(5), [C(5), $\left.\mathrm{A}_{4}\right] \mathrm{G}(2)$, or $\mathrm{K}(4),[\mathrm{C}(4), \mathrm{A} 2 \mathrm{G}](2)$. Description of a Typical Plant of the Scrophularineæ.-(Digitalis purpurea, Foxglove).

Habit.-A tall perennial herb, which flowers from July to September.

Stem.-Herbaceous, erect, round, green.
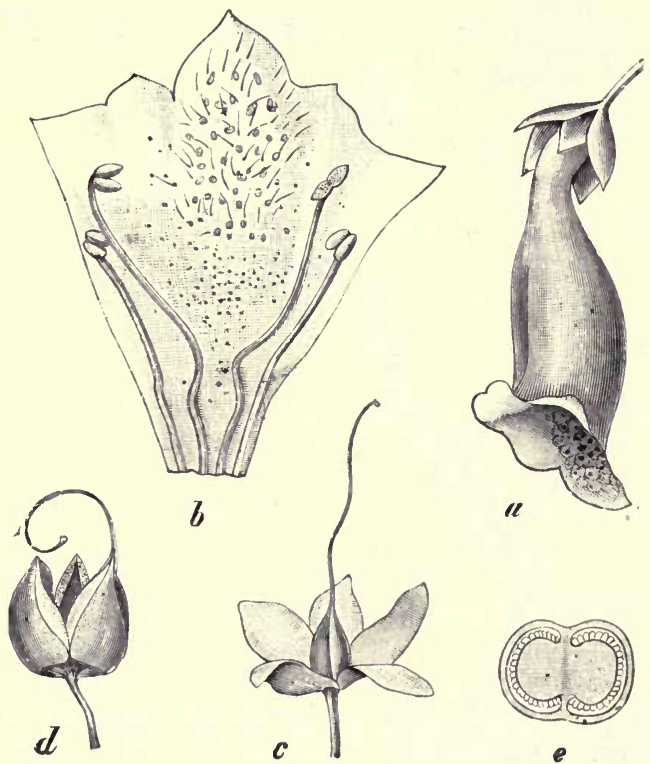

c

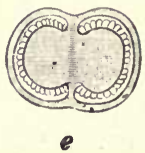

Fig. 26r.-Foxglove (Digitalis purpurea). $a$, Flower $; b$, corolla cut open and spread out ; $c$, calyx and pistil ; $d$, fruit ; $e$, section of fruit, (S.)

Leaves.-Lower ones radical and stalked; upper ones cauline and sessile.

Inflorescence.-Indefinite ; raceme.

Flower.-Complete, zygomorphic, tubular, large, purple, with spots inside.

Calyx.-Gamosepalous, 5 lobed, inferior. 
Corolla.-Gamopetalous, 5 lobed, hypogynous ; the lower lip of corolla is longer than the upper lip.

Androcium.-Free, 4 stamens, didynamous, epipetalous, filaments various, anthers 2 lobed.

Gynocium.-Syncarpous, 2 carpels, superior, style terminal ; stigma 2-fid ; ovary 2 -celled; ovules numerous; axile placentation.

Fruit.--A two-valved capsule.

Pollination.-The flower is protandrous, and is pollinated by humble-bees, which creep into the flower and are dusted with pollen on their backs.

\section{Exceptions to the above Type.}

Speedwell (Veronica)-Leaves.-Opposite ; Inflorescence.-Either an axillary or a terminal raceme; Corolla.-Petals 4, lobes unequal;
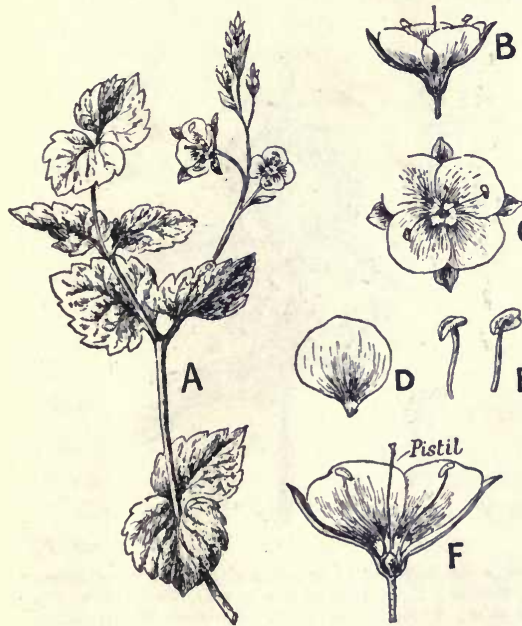

Stamens. -2 only.

Mullein (Verbas. (uim)-Stamens. - 5.

Properties of Scroph ularineæ.Several of the plants of this order are poisonous, and are used in medicine. The most poisonous is the Foxglove, all parts of which are poisonous.
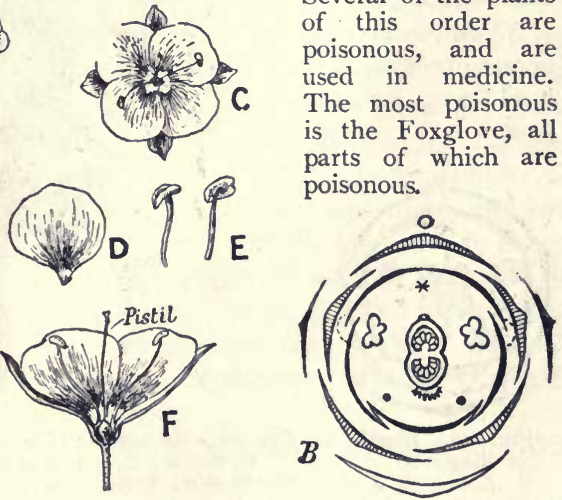

FIG. 262.-Speedwell (Veronica). A, flowering branch ; $B$, flower; C, flower, viewed from above; D, petal; $\mathrm{E}$, stamens; F, section of flower.

Fig. 263.-Floral diagram of Speedwell."

Many of the plants are root-parasites, and are provided with suckers which penetrate into the roots of the host plant, e.g., Yellow Rattle, Cow-Wheat, Eye-bright, and Lousewort. 
Natural Order: Labiatæ (Labiate Family).-The plants of this order can be recognised by their square stem and opposite leaves. The inflorescence is a verticillaster (p. 173). The flower is zygomorphic. The calyx is gamosepalous, 5 lobed, and inferior. The corolla is gamopetalous, 5 lobed, hypogynous, and two-lipped. The stamens ( 2 or 4 ) are epipetalous ; if four, didynamous. The pistil is syncarpous, carpels 2, superior, style gynobasic, ovary 4 lobed. The fruits consist of 4 nutlets.

NOTE.-The Labiatæ can be distinguished from the Scrophularineæ by their square stem and opposite leaves, and by the 4 lobed ovary and gynobasic style ; from the Boragineæ by the stamens being fewer in number than the lobes of corolla, and by the zygomorphic flowers.

Floral formula. $-\mathrm{K}(5),[\mathrm{C}(5), \mathrm{A} 4], \mathrm{G}(2)$.

Description of a Typical Plant of the Labiatæ (Lamium album, White Deadnettle).

Habit.-A perennial herb with square stem and coarse foliage.

Stem. - Herbaceous, erect, square, hollow, hairy, green.

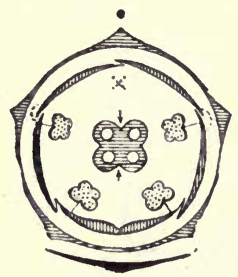

FIG. 264.-Floral diagram.

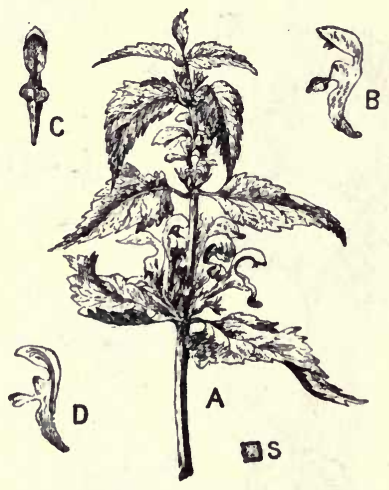

Fig. 265.-Deadnettle (I Lamium). A, flowering branch ; B, flower ; C, section of flower ; D, flower viewed from the side; S, section of stem. (One-sixth nat. size.)

Leaves.-Cauline, opposite, simple, cordate, serrate, hairy. Inflorescence.-Definite; verticillaster.

Flower.-Complete, zygomorphic, $\frac{1}{4}$ of an inch in diameter labiate, white, faintly scented. 
Calyx.-Gamosepalous, 5 lobed, inferior, lobes acute, hairy green.

Corolla.-Gamopetalous, 5 lobed, hypogynous, very hairy.

Androcium.-Free, 4, didynamous, epipetalous, filament round and hairy, anthers 2 lobed.

Gynocium.-Syncarpous, carpels 2, superior, style gynobasic ; stigma 2 -fid, ovary 4 lobed; I ovule in each cell of ovary.

Fruit.-Four nutlets.

Pollination.-Pollinated by humble-bees, which creep into the flower to suck the honey from the nectary. As the bee creeps into the flower its back touches the stigma, and is afterwards dusted with pollen from the anthers. Thus cross-pollinais effected.

Properties of Labiatæ. - None of the plants of this order are poisonous, but many species possess essential oils which are formed by glands in the tissues of the leaves. The oil can be separated by distillation. Many of the plants of the order are used for cooking purposes, such as Mint, l'ennyroyal, Marjoram, Thyme, Sage, and Balm.

\section{Sub-Class : Incompletæ.}

Natural Order: Cupuliferæ (Oak Family).--The plants of this order include most of the shrubs and trees found in the temperate regions of the globe. The leaves are simple, monœcious (p. 208). The male inflorescence is generally a catkin. The flowers are small and inconspicuous. The perianth is either absent or small and green, The stamens vary in number from 4 to 6 . The pistil is syncarpous, carpels from 2 to 6 , ovary either 2 or 3 celled, with 1 or 3 ovules in each, The fruit is often I-seeded, indehiscent-a mut. Many plants of this order possess a cupule. Seeds are without endosperm.

Description of a typical Member of the Cupuliferæ.-(Corylus Avellana, Hazel).

Habit.-A deciduous shrub, with monœcious flowers; the main stem breaks up into branches just above the ground.

Root.-The primary root of the seedling grows only for a short time, then gives off several lateral roots which run along just beneath the surface soil in a horizontal manner.

Stem.-The base of the stem beneath the ground gives off suckers (p. 2I) which grow upwards, and from their lower side adventitious roots are produced. If from any reason the 
connecting portion between the old plant and the new shoots is destroyed, new plants are formed.

Leaves.-Cauline, alternate, simple, cordate, serrate; the small stipules fall off as the leaf expands.

Inflorescence.-The male flowers are arranged in a spike known as a catkin (p. 170).

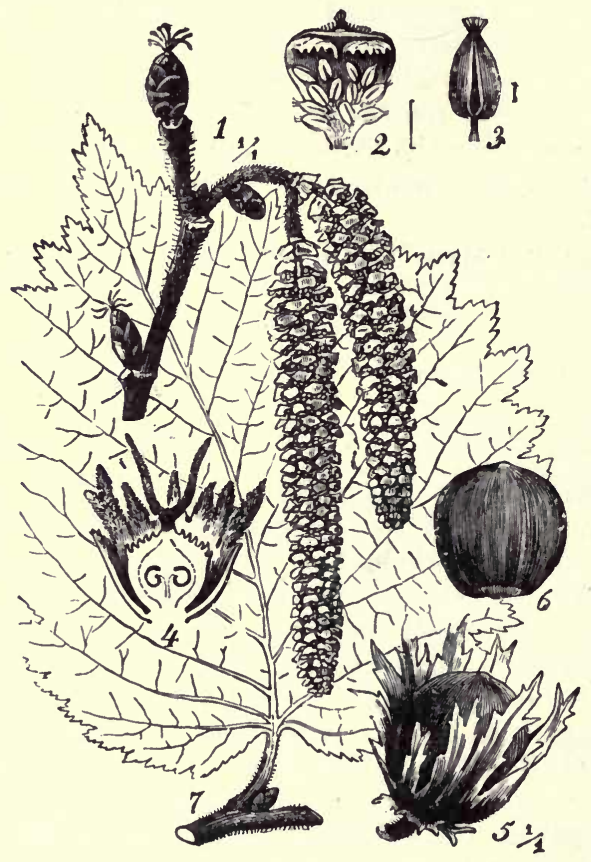

FiG. 266.-Hazel (Corylus). - 1, Flowering branch ; 2, a male flower; 3, a stamen ; 4 , a female flower ; 5 and 6 , fruit ; 7 , a foliage leaf. (S.)

The female flower appears as a small bud, recognised by the coloured stigmas protruding from its apex.

Flower.-The male flower is incomplete, imperfect (p. 178), and very minute.

The female flower is imperfect, incomplete, and minute. 
Perianth.--The male flower possesses no perianth; the stamens are fixed on a bract.

The female flower possesses a minute gamophyllous perianth inserted on the ovary and therefore epigynous.

Andracium.-Male flower-free, 4, united to bract, each anther is deeply lobed, so that there appear to be eight stamens.

Gynocium.-Female flower-syncarpous, carpels 2, inferior style long, stigmas red ; the ovules develop after pollination.

Fruit. - A nut.

Pollination.-The Hazel and its relations are pollinated by the wind. That this may take place without difficulty the flowers are produced before the foliage leaves. The Hazel flowers in February, March, and early April.

Properties of Cupuliferæ. - The bark of a few species of Oak, and acorns, are used in medicine. The plants of the order are harmless, and their properties are unimportant.

Economic importance of Cupuliferæ. - This order is of great econonic value. The wood of the Oak is used very largely because of its hardness, density, and durability. Its bark and acorn cupules are used for tanning. Cork is also obtained from the Oak. The Beech produces seeds-Beech Nuts-from which oil is obtained. The Hazel produces nuts which are largely used for food. The seeds of the Chestnut are edible, and form a most important article of food in the South of Europe.

\section{Class : MoNocotyledons.}

Sub-class : Petaloideæ.

Natural Order: Liliaceæ (Lily Family).-The plants of this order are succulent herbs with perennial bulbs or rhizomes. The leaves are generally long, narrow, and entire. The inflorescence may be solitary or a raceme. The flowers are large, actinomorphic and coloured. The perianth consists of six leaves arranged in two series. The 6 stamens are arranged in two series. The pistil is syncarpous, carpels 3 , ovary superior, style unbranched, stigmas 3-fid, ovules in axile placentation. The fruit is a capsule.

Floral Formula. $-\left[\mathrm{P}_{3}+3, \mathrm{~A}_{3}+3\right] \mathrm{G}(3)$.

Description of a Typical Flower of the Order Liliaceæ.-(Hyacinthus Nonscriptus, Wild Hyacinth or Bluebell.) 
Habit.-A perennial herb with an underground bulb, narrow radical leaves, and a raceme of sweet-smelling blue flowers.

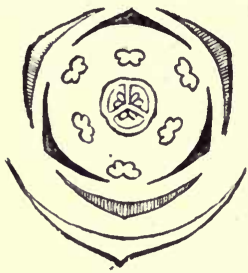

Fig. 267.-Floral diagram.

Root.-Adventitious roots are given off from the lower surface of the bulb.

Stem.-An underground bulb (p. 23).

Leaves. -Radical, simple, narrow, entire, green.

Inflorescence.-Indefinite, raceme.

Bracts.-Bracteate, blue, one at the base of each pedicle.

Flower.--Complete, actinomorphic, bellshaped, blue.

Perianth.-Gamophyllous (base only), 6 lobed, inferior.

Andracium.-Free, 6, in two series, epipetalous; filament blue, anther 2-lobed, versatile.

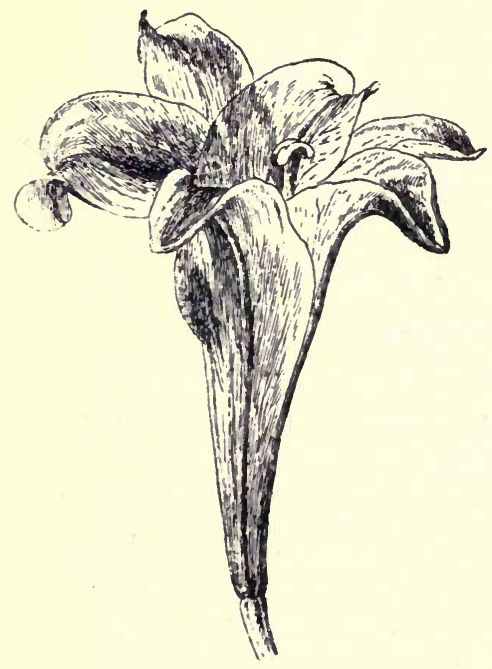

FIc. 268.-Flower of White Lily.

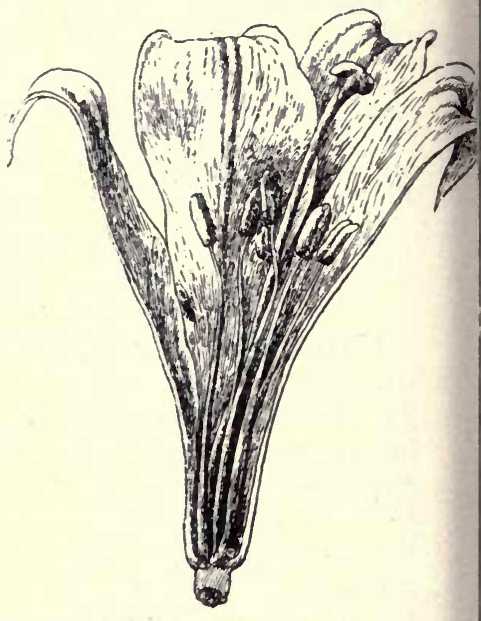

FIG. 269.-Longitudinal section of flower of White Lily.

Gynccium.-Syncarpous, carpels 3, superior, style long, stigma 3-fid, ovary 3 -celled, ovules axile placentation. 
Fruit.-A capsule, seeds albuminous.

Pollination. - The flowers may be pollinated by insects, or

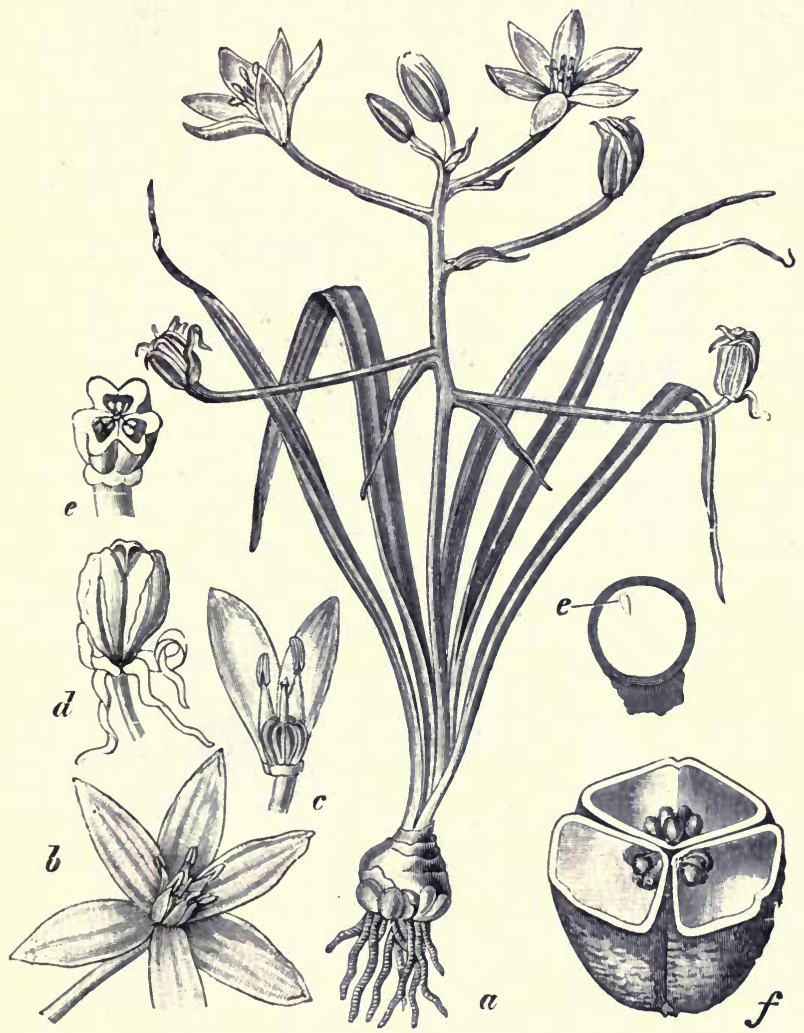

Fig. 270.-Star of Bethlehem (Ornithogalum umbellatum). $a$, entire plant; $b$, flower ; $c$, section of flower; $d$, fruit ; $e$, section of fruit ; $f$, ovules and ovary. (S.)

self-pollination may take place. The stamens and pistil riper at the same time. 


\section{Exceptions to the above Type.}

This order is a very large one, and there are many species which depart more or less from the above iype.

Butcher's Broom (Ruscus aculeatus). - This is the only British monocotyledonous shrub. Stem. - It grows in thickness by the production of a new meristem layer in the cortex ; Leaves. - The leaves are very minute, bearing in their axils leaf-like branches (cladodes);

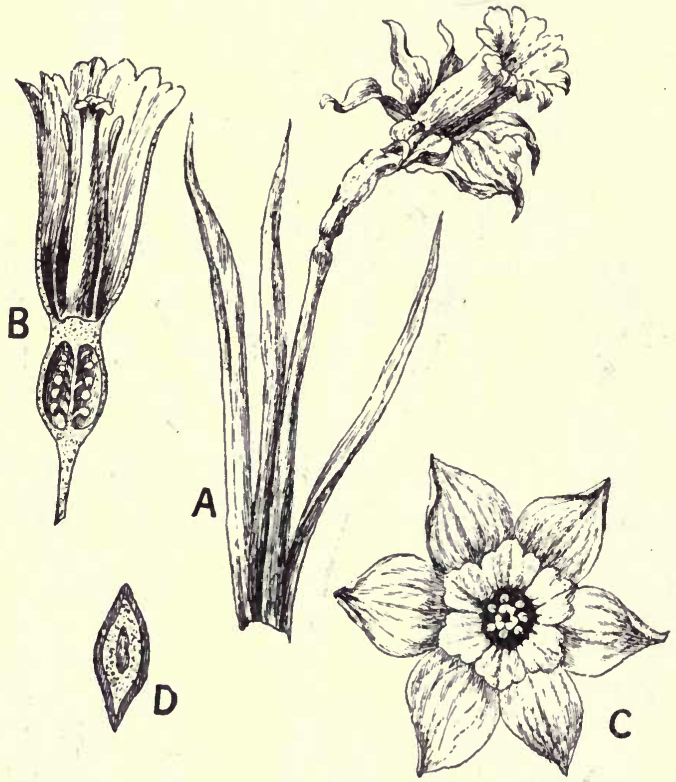

FIG. 27r.-Daffodil (Narcissus). A, leaves and flower; B, longitudinal section of flower; C, flower viewed from above; $D$, transverse section of stem. (Onefourth nat. size.)

Flowers. - The flowers are minute, and are produced on the face of the cladode; Stamens. - There are only 3 stamens, and the filaments are united into a short stout column.

Herb-Paris (Paris quadrifolia). - This plant differs from monocotyledonous plants in having the parts of the flower in fours, and its leaves whorled. Perianth. - The perianth consists of 8 segments in 2 series, but varies from 3 to 5 in each whorl ; Stamens. - There are usually 8 stamens, but these vary from 6 to 10 ; Pistil. - There are 4 carpels. 
Properties of Liliaceæ. - Many of the plants in this order are poisonous, and a few are used in medicine. The principal poisonous plants are

Meadow Saffron (Colchicum autumnalt). - This plant possesses a subterranean tuber, which gives rise to rose-coloured flowers, which appear in August and September ; the fruit and leaves follow in spring. The whole plant is poisonous, but the seeds and tubers contain the largest quantity of the poisonous material.

Herb Paris ( $P$. quadrifolia) and Lily of the Valley (Convallaria majalis), are also poisonous.

Tulip (Tulipa). - The bulbs of the Tulip are poisonous, and also the bulbs of Crown Imperial (Fritillaria imperialis).

Natural Order : Amaryllideæ (Daffodil Family).-These plants have the same characters as the Liliaceæ, with the exception of the pistil, which is inferior. Many of the members of this order have a well developed corona, which is an outgrowth of the perianth.

Floral formula. $-\left[\mathrm{P}(3+3) \mathrm{A}_{3}+3\right] \mathrm{G}(\overline{3})$.

Plants belonging to Amaryllideæ.-The plants of this order do not need any special description, they are so much like the Liliaceæ in every respect except the pistil. Well known plants from among the Amaryllideæ are the Daffodil or Lent Lily (Narcissus Pseudo-narcissus), and the Snow-drop (Galanthus nivalis), Snow-Flake (Leucojum astivum).

\section{SumMary.}

The Natural System of classification is based on the resemblances and differences of plants.

Classification. -

The Plant Kingnom.

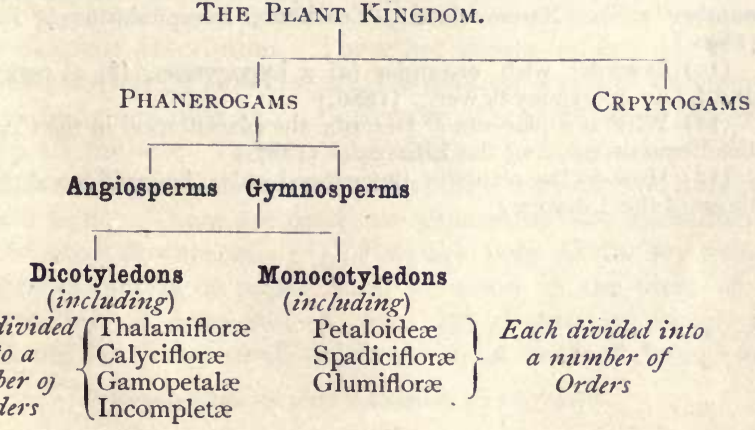

Each divided Thalamifloræ into a Calycifloræ number of Gamopetalae Orders Incompletx

Petaloide Spadicifloræ Glumiflorx
Each divided into

Orders 
A natural order consists of a number of genera which possess some common character.

A genus consists of one or more species which resemble one another in one or more respects.

A species includes plants which must have descended from a common ancestor.

\section{Questions on Chapter XIX AND XX.}

(I) What are the chief distinctions between Monocotyledons and Dicotyledons? (1898.)

(2) Describe and compare the corollas of any three of the following plants, and mention the natural order to which each plant belongsLarkspur (Delphinium), Monkshood (Aconitum), Sweet Pea (Lathyrus), Deadnettle (Lamium), Snapdragon (Antirrhinum). (I892.)

(3) Describe and compare the fruits of the Wallflower (Cheiranthus) and the Pea (Pisum), and those of the Parsley (Petroselinum) and the Dandelion (Taraxacum). To what natural orders do these plants respectively belong? (I892.)

(4) Describe the general structure, position, and placentation of the ovary in the Umbelliferæ, the Leguminosæ, and the Labiatæ. (I89I.)

(5) Describe the position, number, and arrangement of the stamens in the flowers of the Cruciferæ, the Compositæ, and the Primulaceæ. (I891.)

(6) Give a general account of the structure of the flower of a I.eguminous plant. (I 899.)

(7) Describe carefully the structure of a leaf bud in any member of the natural order Cupuliferæ. (1899.)

(8) Describe the arrangements of the stamens in the flowers of the Buttercup, the Deadnettle, and the Sweet Pea. Refer these plants to their natural orders. (1894.)

(9) Mention instances from the following natural orders of flowers, in which the number of the stamens is $(a)$ less than, or $(b)$ greater than, that of the petals, explaining in each case how the difference in number arises-Ranunculaceæ, Cruciferæ, Scrophularineæ, Labiatæ. (1890.)

(I0) Describe with examples $(a)$ a hypogynous, (b) a perigynous, and $(c)$ an epigynous flower. (i 886.)

(I I) What is a placenta? Describe the placentation in the Cruciferæ, the Leguminosæe, and the Liliacex. (1887.)

(12) How do the plants of the natural order Amaryllidex differ from those of the Liliacex? 


\section{CHAPTER XXI}

\section{PLANT DESCRIPTION}

The Importance of Plant Description.-The importance of practical work in all branches of science is now universally admitted, and in Natural Science it is the only way to obtain sound useful knowledge. In fact, this book is mainly written for those persons who are willing to verify the principal facts of botany by an appeal to Nature herself. Plant description forms one of the most agreeable methods of approaching Nature. The collection of plants (not with the idea of having so many plants in a Herbarium), but to learn direct from Nature her secrets, is always interesting. It is only by constant intercourse with nature that true knowledge of living things can be obtained. The able naturalist Goethe made the following remark: "Man Sieht nur was man weiss," the trained naturalist goes about and sees living things everywhere.

Apparatus Necessary for Plant Description.-The apparatus necessary to examine the external parts of plants are of the simplest description. These are shown below :-

(I) A sharp knife is necessary for making sections of stems, flowers, buds, and ovaries. (2) Needles ; the three-sided glover's needles are the best. These can be mounted in handles by forcing the blunt end into fresh twigs ; when the twigs dry the needles are held tight. These are used for separating the constituent parts of small flowers, etc. (3) Pins are very useful for fixing the parts of flowers on paper, cork, or wood in the form of a diagram. (4) $A$ hand-lens (p. 63). (5) A pair of forceps is very useful for lifting small objects. (6) $A$ book of forms ${ }^{1}$ for

1 Evans's forms for plant description are very useful. 
plant description is very useful, because it keeps the attention of the student fixed on the most essential points. (7) A blank drazving book and pencils will enable the student to make sketches of the different parts of the plant.

How to Describe a Plant. - With a little practice a good description of any ordinary plant should be made in about three-quarters of an hour. Slovenliness should always be avoided, and care must be taken to describe only those parts which are present. To make certain that a good method of work is ensured the following plan should be followed.

\section{A Plan for Describing Plants}

(I) Habit.-Whether annual, biennial, or perennial ; herbs, shrubs, or trees (p. 19) ; size and general appearance.

(2) Root.-Kind (p. 53). Whether a tap-root ; size, shape, and branching, and adventitious, if present. Special roots, such as aërial.

(3) Stem. - (a) Kinds, such as herbaceous, or shrubby, or woody.

(b) Direction of growth-erect, creeping, underground, \&c.

(c) Shape-round, ribbed, square, \&c.

(d) Internal appearances-solid or hollow.

(e) Covering and colour-hairy or smooth, green, or other colour.

(4) Leaves. - (a) Kind of leaves-radical or cauline (p. 38 ).

(b) Phyllotaxis (p. 36)-alternate, opposite, whorled, or spiral arrangement.

(c) Simple or compound (p. $3^{8}$ ).

(d) Composition of leaf-perfect, petiolate, sessile.

(e) Shape of leaf (p. 39).

(f) Vernation of leaf (p. 34).

(g) Colour and covering of leaf-hairy or smooth, dark or light green.

(h) Stipulate or exstipulate (p. 45).

(5) Inflorescence.-(a) Whether definite or indefinite (p. 166-172).

(b) Kind (p. 166-174).

(6) Bracts. - $-(a)$ Whether present or absent.

(b) Describe like foliage leaves.

(7) Flower.-(a) Whether complete or incomplete (p. 178).

(b) Whether actinomorphic or zygomorphic (p. 179).

(c) Shape.

(d) Diameter, colour, perfume.

(8) Calyx. - (a) Whether polysepalous or gamosepalous (p. 183).

(b) Number of sepals or lobes of calyx.

(c) Whether inferior or superior (p. 183).

(9) Corolla. - (a) Whether polypetalous or gamopetalous.

(b) Number of petals or lobes of corolla.

(c) Whether superior, hypogynous, perigynous, or epigynous.

(d) Shape of petals or lobes of corolla. 
Andrøcium.-(a) Whether free, monadelphous, diadelphous, or polyadelphous (p. I85).

(b) Number of stamens or indefinite.

(c) Whether hypogynous, perigynous, epigynous, epipetalous, or gynandrous (p. 185).

(d) Shape and length of filaments.

(e) Whether anther two-lobed, and how fixed to filaments, introrse or extrorse.

Gynœcium.-(a) Whether monocarpous, apocarpous, or syncarpous (p. I8б́).

(b) Number of carpels.

(c) Whether inferior or superior (p. 186).

(d) Whether style long or short.

(e) Whether stigmas terminal, 2-fid, 3-fid, 4-fid, \&c.

$(f)$ Whether ovary one, two, three, or more celled.

Ovules. - (a) How many.

(b) Placentation-axile, parietal, free-central, or basal (p. 187).

Floral Formula (p. 188).

Floral Diagram (p. I88).

Classification.-Place the plant in its true position in the natural system, as follows :-

$\left.\begin{array}{l}\text { Sub-Kingdom . } \\ \text { Division . . } \\ \text { Class . . . } \\ \text { Sub-Class. } . .\end{array}\right\}$ (p. 245).

Natural Order.

Genus.

Species. [If possible name the plant.]

Common Name.

\section{EXAMPLE OF PLANT DESCRIPTION}

Habit.-An erect perennial herb, with radical leaves, growing in damp ditches or marshy places.

Root.-Absent.

Stem.-Herbaceous, erect, ribbed, twisted, solid, hairy, brownish purple.

Leaves.--Radical leaves crowded, petiolate, pinnate, reticulate-veined, cauline leaves alternate, compound, ternate; the terminal leaflet large, upper part of leaflet crenate, hairy, upper side dark green and under side light green, stipulate, stipules adnate, small and lobed.

Inflorescence.-Definite, two-flowered cyme, drooping.

Flower.-Complete, actinomorphic, roughly campanulate, $\frac{3}{4}$ of an inch in diameter, honeyed, dull orange, protandrous. 
Calyx.-Gamosepalous, Io lobes, 5 alternating, lobes small, inferior, lobes toothed, hairy, reddish brown.

Corolla.-Polypetalous, 5 lobed, perigynous, petals triangular in shape, veined, alternating with lobes of calyx.

Andrœcium (Stamens).-Free, indefinite, perigynous, filaments short, anthers 2 lobed and versatile, introrse, the outer whorl ripening first.

Gynœcium (Pistil).-A A pocarpous, carpels numerous,superior, styles long, filiform, stigmas terminal and coloured.

Ovules. - One ovule in each carpel, placentation basal.

Fruit.-Not developed.

Floral formula. - $[\mathrm{K}(5)$ c $5, \mathrm{~A} \infty] \mathrm{G} \cong$.

Floral Diagram.-(p. 258.)

\section{Classification}

Sub-Kingdom: Phanerogams. I place this plant in the above sub-kingdom because it is a flowering plant.

Division: Angiosperms. I place the plant in this division because the ovules are enclosed in carpels.

Class: Dicotyledons. I place this plant in the above Class because the leaves are reticulate-veined, and the parts of the flower are in fives.

Sub-Class : Calycifloræ. This plantbelongs to this sub-class because the petals and stamens are inserted on the calyx and are perigynous.

Natural Order: Rosaceæ. This plant belongs to this natural order, because of the indefinite stamens (which are perigynous), and its apocarpous pistil; the perigynous stamens distinguish it from a Ranunculus.

Genera: Geum.

Specics : Rivale.

Common Name: Water Aven.

For other examples see Chapters on Classification. 


\section{INDEX}

Absorption, by roots, 137$14^{\circ}$

Absorption of gases, 121

Acacia, 42

Achene. 228

Acicular, 39

Actinomorphic, 179

Adhesion, 182

Adventitious, 25, 53

Aërial roots, 54 stems, 8

Air" bubbles, 63

Air chamber, 112

Albuminous, 2 I9

Alchemilla, 26r

Aleurone grains, 86

Amaryllidex, 281

Anatomy, 4, 16

Anatropous, 203

Androcium, 164, 184 ; structure of, 196

Anemone, 248

Anemophilous, 207

Angiosperms, 242, 243

Annual, 19; rings, 68, 107

Anterior, 180

Anther, 186 ; structure of, 197

Apocarpous, 186

Apple, 26r

Aquilegia, 248

Aril, 223

Arum, 170

Ash, 117

Assimilation, 121

Axil of leaf, 9

Axillary, 66

Axis, 8; descending, $5 \mathbf{r}$

BACTERIA, 132

Barberry, 146

Bark, $107-108$

Basal placentation, 187

Basifixed, 186

Bast, 99, 100

Bean, Io

Beech, 17

Bellis, 265

Berry, 228

Biennial, 19
Blackberry, 26o

Blade, 34

Biadderwort, ${ }^{3} 3$ I

Bleeding, 145

Borage, 270

Boragineæ, 270

Bordered pits, 78

Botany, I

Branches, 9 ; formation of, $\mathrm{It}_{3}$

Bugloss, 271

Bulbs, 23

Bundles, 66, 98

Butcher's broom, 280

Buttercup, 246

Butterwort, 130

Calcium, 117

Callus, 97

Caltha, 248

Calycifloræ, 243, 254

Calyx, 164,183

Cambium, 98, 99, r05 ; interfascicular, 104; ring, 104

Campanulate, $18 \mathrm{t}$

Campion, 253

Campylotropous, 203

Candy tuft, 168

Cane sugar, 88

Capitulum, 168

Capsule, 229

Carbohydrates, 76

Carbon, 117,120

Carbonaceous food. See carbon

Carbon dinxide, I 9, 121, 123

Carnivorous plants, $128-13^{2}$

Carpel, 165

Carrot, 56

Caryophylleæ, $2 \% 2$

Catkin, r 70

Cauline bundles, 10o

Cell, 65,74 ; contents of, $8 \mathrm{I}$; kinds of, 92 ; mature, 81 ; structure of 74 ; young, 8 r

Cell-sap, 8 r, 82

Cellulose, 76

Cell-wall, 65, 74 ; chemical changes in, 76 ; composition of, 75
Cherry, 26o

Chicory, 268

Chlorine, 117

Chlorophyll, 8r

Chloroplast, $8 x, 84$

Chromoplast, 84,86

Circulation of protoplasm, $8 \mathrm{c}$

Classification, 3, 4, 242

Cleistogamic, 216

Clematis, 248

Climbing plants, $25-28$

Closed bundles, 98

Closing of flowers, 160

Closing membrane, 77

Clover, 133

Cohesion, 182

Colour of flowers, 182

Combustible elements, 117

Comfrey, 27 I

Common bundles, 100

Companion celis, 93

Complete flower, 178

Compositæ, 265

Compound leaves, 38,40

Convolute, $4^{8}$

Convolvulus, 181

Cordate, 39

Cork, 67 ; cambium, 107

Corm, 23

Corolla, 164, 184

Corona, 28x

Cortex, 66, Iur

Corylus, 275

Corymb, 168,

Cotyledons, 1 I

Creeping-stem, 8

Cruciferæ, 249

Crystal, 2, 81

Crystalloid, 86

Cupuliferæ, 275

Cuticle, 77

Cutin, 76

DAFFODIL, 281

Dahlia, 146

Daisy, 265

Dandelion, 266

Daughter-cell, 89, 198 
Deadnettle, 274

Delphinium, 248

Dermatogen, I 12

Description of plants, 283

Diadelphous, 185

Diastase, 122

Dichotomous, 172

Diclinous, 208

Dicotyledon, 12, 68, 224

Didynamous, 185

Digitalis, 272

Dimorphic, 209

Dodder, 129

Dorsal. See posterior

Dorsifixed, 186

Drupe, 227

Druplet, 228

Dry substance of plants, II 7

Ebracteate, 46

Egg-apparatus, 20I

Elaborated sap, 148

Elements of plant food, $\mathbf{1 r} 8$; essential, I 18; non-essential, I 34

Elm, 18

Embryo, II, 12, 217 ; sac, 201

Emergencies, 30, 96

Endocarp, 225

Endodermis, 103, 105

Endosperm, 12, 219

Entomophilous, 207

Epicalyx, 260

Epicarp, 225

Epidermis, 94

Epigynous, 185

Epipetalous, 185

Epiphyllous, 188

Epiphyte, 54

Essential organs, 196

Extine, 199

Extrorse, 186

FATs, $8 \mathbf{r}, 87$

Female flower, 179

Ferment, 122

Fertilisation, 216 ; results of, 220

Fibrous roots, 53

Filament, 186

Floral diagram, 188

,, formulæ, 188

"leaves, 164

Flowering plants, 206

Flower, 178

Foliage leaves, 34

Follicle, 230

Food of plants, 120

Fool's parsley, 264

Forget-me-not, 270

Foxglove, 272

Free-cell formation, 90

Free-central placentation, 187
Fruits, 224 ; classification of, 227 ; kinds of, 224

Functions, 116

Funiculus, 201, 223

Fusiform, 57

GaMOPETALE, 243, 265

Gamopetalous, 183

Gamophyllous, 188

Genus, 245

Geotropism, 158-159

Germination, 12

Glabrous (see smooth)

Glands, 96

Glandular hairs, 96

Globoid, 86

Glomerule, 174

Gorse, 180

Growing point of root, $\mathrm{II}_{3}$; of stem, 108

Growth, 152

Growth by apposition, 75 ; by intussusception, 75

Guard-cells, 94

Gynandrous, 185

Gynœecium, $165,186,201$

Gynobasic, 186

Gymnosperms, 242

HAB1T, 284

Hairs, 95

Hand-lens, $6_{3}, 6_{4}$

Hard bast, 99, roo

Harebell, I8I

Hazel, 275

Head, r68

Heat due to respiration, 125

Helianthus, 268

Heliotropism, 156-1 58

Helleborus, 248

Herbaceous, 19

Herb Paris, 280

Heterostyled, 209

Histology, 4 ; of the cell, 7491 ; of the tissues, 92-102 ; of the shoot and root, 102I 15

Hook-climbers, 25

Hop, 26

House-leek, 20

How to describe a plant, 284

Humble-bee flowers, 214

Hyacinth, I Io

Hydrogen, 117

Hypogynous, 185

1 MBRICATED, 175

Incompletæ, 243,275

Incomplete flowers, 178

Indehiscent, 228

Inferior, 183

Inflorescence, 166

Integuments, 201

Intercellular spaces, II I
Interfascicular cambium, 104

Internode, 19

Intine, 199

Introrse, 186

Intussusception, 75

Involucre, 175

Iodine solution, 75

Iron, 117,1 18, 134

Irregular, 178

Irritability, 155; of growing organs, 156; of mature organs, 160

LABIATE, 182

Labiateæ, 274

Ladies' mantle, 26r

Lamina. See blade

Lanceolate, 39

Larkspur, 248

Leaf structures, 8 ; apex of, 43 ; climbers, 26 ; margin of, 42 ; perfect, 34 ; reticulate and parallel, 34 ; scar, 67

Leaves, 31 ; bracteate, 3r, 46 ; floral, 31, 47, 164; foliage, 31 ; formation of, II $_{3}$; opposite, 37 ; radical, 38 ; shapes, $39-42$

Legume, 229

Leguminosæ, 254

Leguminose plant, ${ }_{32}$

Lenticel, 108, 142, 143

Lettuce, 268

Leucoplast, 8 r, 82, 84, 85

Life-history, 5, 239

Light, 122, 153

Lignification, 77

Ligulate, 181

Ligulifloræ, 266

Lilac, 47

Liliaceæ, 277

Lily of the valley, $28 \mathrm{r}$

Lime, 68

Longitudinal section, 6 I

Magnesium, 117,134

Maize, 68

Male flower, 178

Marsh marigold, 248

Median plane, $x$ so

Medullary rays, 104

Members, 8

Meristem, 99

Mesocarp, 225

Mesophyll, II

Micropyle, 10

Microscope, 71, 72

Mid-rib of leaf, 35

Mineral salts, 134

Monadelphous, 185

Monkshood, 248

Monocarpous, 186 
Monocotyledon, 12, 242; stem, rog; root, 1 Io

Monœcious, 208

Morphology, 3, 4, 8-15

Mother pollen cell, 198

Mounting specimens, 62

Movements of protoplasm, 79

Mustard seeds, 12, 52

NAming of plants, 245

Napiform, 57

Natural history, 5

Natural system, 5

Nectary, 207

Nettle, 96

Net-veined. See reticulate

Nitragin, 133

Nitrates, 128

Nitrogen, II7, 128

Node, rg

Non-essential organs, $x g 6$

Nucellus, 2or

Nucleolus, 8I

Nucleus, 8I

Nutrition, 116

OA K, 17, 147

Obovate, 39

Offset, 20

Onion, 23

Oosphere, 201

Oospore, 217

Open bundle, 98

Opening of flowers, $x 60-16 x$

Order, 245

Osmosis, 139

Ovary, 165

Ovule, I65; development of 202 ; kinds of, 203

Oxygen, I 17,126

\section{Palisade tissue, it I}

Palmate, 43

Panicle, 168

Papilionaceous, I8I

Pappus, 184

Parasites, 24, 123

Parenchyma, 92

Parietal placentation, 187

Peach, 227

Pear, 26r

Pedicel, r66

Peduncle, 166

Perennial, 19

Perfect flower, 178

Perianth, 187

Periblem, II

Pericycle, $\mathrm{IO}_{3}, \mathrm{IO}_{5}$

Periderm, 107, 108

Perigynous, 184,185

Perisperm, 220, 223

Personate, 182

Petal, I64
Petaloid, 188

Petaloideæ, 243, 277

Petiolate, 34

Phanerogam, 242

Phelloderm, 107, 108

Phellogen, 107, 108

Phloem, 98, 99, 100

Phosphorus, II 7, 132

Phyllotaxis, $36-38$

Physiology, 4 ; of movement, $4, \mathrm{I}_{52}-\mathrm{I} 6_{3}$; of nutrition, 4 , I $6-136$; of reproduction, 4, 235-24I

Pine, 70

Pinnate, $4 \mathrm{I}$

Pistil, 165

Pitcher plant, 132

Pitted vessel, 93

Placenta, 187

Placentation, 187 ; kinds of, I07

Plant description, 283

Plantain, r66

Plasmolysis, 8I

Plerome, II 2

Plumule, II

Pod. See legume

Pollen grain, r64 ; development of, rg9; structure of, Ig8

Pollen sac, 197

Pollen tube 217

Pollination, 206-207

Polyadelphous, 185

Polypetalous, 184

Polyphyllous, I 88

Polysepalous, 183

Pome, 227

Poppy, 226

Posterior, 180

Potassium, 107, 134

Prickles, 30

Primrose, 268

Primulaceæ, 268

Prœefoliation, 47

Properties of Boragineæ, 270 ; of Caryophylleæ, 253 ; of Cruciferæ, 25I ; of Compositæ, 267 ; of Cupuliferæ, 277; of Labiatæ, 275; of Leguminosæ, 256 ; of Liliaceæ, $28 \mathrm{I}$; of Primulaceæ, 260 ; of Ranunculaceæ, 248 , of Rosaceæ, 262 ; of Scrophularineæ, 273 ; of Umbelliferæ, 264

Proteids, 79

Protandrous, 208

Protogynous, 209

Protoplasm, 79-80

Prunus, 260

Pseudocarp, 224

Pulmonaria, 27I

Pyrus, 26r
RACEME, 167

Radial longitudinal section, 6r

Radical leaves, 38

Radicle, Ir

Ranunculaceæ, 246

Ranunculus, 246

Raphides, 87

Raspberry, 260

Receptacle, 178

Regular, 178-r79

Reniform, 39

Reproduction, 89 , 237-238

Reserve material, $\mathrm{x} 2$

Respiration, $124-128$

Resting or dormant buds, I7

Reticulate leaves, 34

Rhizome, 2I, 22

Roots, adventitious, I4, 53 ; aërial, 54; clinging, 53 ; conical, 57 ; fusiform ; 57 movements of, $5^{8}$; uses of, $5^{8}$

Root-cap, II3, 52

Root-climbers, 53

Root-hair's, 52, 95, I 37

Root-pressure, 145-146

Rosaceæ, 257

Rose, 257

Rotation of protoplasm, 80

Rubus, 260

Saccate, $190,25 x$

Sagittate, 39

Saprophyte, 123

Scale leaves, 46

Scarlet runner, 26

Schulze's solution, 88

Sclerenchyma, 104, ro5

Scorpioid, 173

Scrophularineæ, 27 I

Secondary growth, Io5

Sections, how to prepare, $6 \mathrm{r}-$ 73

Seeds, examples of, 223 ; distribution of, 23I ; germination of, 234

Seedlings, 13-14

Self-fertilisation, 215

Sepal, 164, 183, 194

Serrated, 42

Shepherd's purse, 217, 218

Shoot, I6-50

Shrub, 20

Sieve-plate, 93

Sieve-tube, 93

Silica. See silicon, I I7, I 35

Silicula, 229

Silqua, 229

Sleep of plants, $160-16 r$

Smooth, 29

Sodium, II 7, 135 ,

Solomon's seal, 22 
Spadicifloræ, 243

Spadix, 170

Spathe, 170

Spatulate, 39

Species, 245

Spectrum, 122

Speedwell, 273

Spermoderm, II

Spike, 166

Spine, 30

Spiral vessel, 93

Spongy parenchyma, III

Spotted orchis, 212

Spurious fruit, 224

Spurred flower, I8I

Stamen, 184, 196

Starch, 85

Stigma, 186

Stinging nettle, 96

Stipulate, 256

Stipule, 45

Stitchwort, 252

St. John's wort, 185

Stolon, 21

Stomata, 94, r42

Strawberry, 260

Structure of dicotyledonous stem, 102, ${ } 03$

Style, 186

Subterranean stems, 8, 2I

Succulent fruits, 227

Sucker, 2 I

Sugars, 88

Sulphur, II7

Sundew, 128

Sunflower, 66, 68, 268
Superior, 183

Symbiosis, 133

Syncarpous, 186

Syngenesious, 185

TAngential sections, 61,62

Taproot, 52

Taraxacum, 266

Tegmen, I I

Tendril, 27

Testa, II

Tetradynamous, 185

Thalamifloræ, 242, 246

Thalamus. See torus

Thorn, 30

Tillering, $\mathbf{I} 7$

Tissue, $6 \epsilon$

Tissues, epidermal, 65, 94 ; vascular, $65,94,98$; ground, 66, 94, 101

Tormentilla, 245

Torus, 178

Transpiration, I40- 147

Transverse plane of flower, 180

Transverse sections, $6 \mathrm{r}, 62$

Traveller's joy, 248

Tree, 20

Trimorphic, 2I I

Tuber, 22

Tubercular root, 57

Tubular flowers, I8I

Tubulifloræ, 265

Tulipa, 28I

Turnip, 57

Twining stems, 26
UMBLE, compound, $\mathbf{I} 68$; simple, I68

Umbelliferæ, 262

Unicellular hairs, 95

Unicostate, 35

VACUOLES, $8 \mathbf{r}$

Vascular bundles, roo

Vascular cylinder, 69

Vegetable marrow, 69

Venation, 34

Venus's fly-trap, ${ }^{32}$

Vernation, 47

Veronica, 273

Versatile, 186

Verticillaster, $\mathbf{1 7 3}$

Vessels, kinds of; 93

Vine, 145

Violet, explosive fruits of, 233

W ALLFLOWER, 250

Water culture, II 8 , II9; so. lution for, $\mathrm{Ir} 8$

Water dropwort, $26_{4}$

Water hemlock, 264

Water pore, 95, I45

White light, composition of 122

Whorled leaves. See phyllo. taxis

Wild hyacinth, 27?

Willows, 233

Wood sorrel, 233

XYLEM, 98, roo

ZYGOMORPHIC, I79

THE END 


\section{MACMILLAN \& CO.'S SCIENCE CLASS BOOKS Adapted to the South Kensington Syllabuses.}

\section{PRACTICAL PLANE AND SOLID GEOMETRY.}

Practical Plane and Solid Geometry. By J. HARRISON, M. Inst. M.E., etc., Instructor in Mechanics and Mathematics, and G. A. Baxandall, Assistant Instructor Royal College of Science, London. Part I. Elementary. 2s. $6 d$. Adapted to the Elementary Stage of the South Kensington Syllabus. Part II. Advanced.

[In the Press.

Test Papers in Practical Plane and Solid Geometry.

Elementary Stage. By GeORGE GRACE, B.Sc. (Lond.). 24 Tests printed on Cartridge Paper. 2s.

\section{BUILDING CONSTRUCTION.}

Building Construction for Beginners. Adapted to the Elementary Stage of the South Kensington Syllabus. By J. W. RiLEy, Rochdale Technical School.

\section{MATHEMATICS.}

An Elementary Course of Mathematics. Comprising Arithmetic, Algebra, and Euclid. Adapted to the Elementary Stage of the South Kensington Syllabus. By H. S. HALl, M.A., and F. H. Stevens, M.A., Masters of the Military Side, Clifton College. 2s. $6 d$.

Graduated Test Papers in Elementary Mathematics. Adapted to the Elementary Stage of the South Kensington Syllabus. By WALTER J. Wood, B.A. Is.

Practical Mathematics. Adapted to the South Kensington Syllabus. By F. Castle, M.I.M.E.

[In the Press.

\section{THEORETICAL MECHANICS.}

Mechanics for Beginners. By W. Gallatly, B.A. 2s. $6 d$. Adapted to the Elementary Stage of the South Kensington Syllabus.

Mechanics for Beginners. By Rev. J. B. Lock, M.A. Part I. Mechanics and Solids. 2s. 6d. Adapted to the Elementary Stage of the South Kensington Syllabus.

Hydrostatics for Beginners. By F. W. Sanderson, M.A. 2s. $6 d$.

\section{APPLIED MECHANICS.}

Lessons in Applied Mechanics. By Prof. J. H. Cotterill, F.K.S., and J. H. Slade. 5s. $6 d$.

\section{SOUND, LIGHT, AND HEAT.}

Elementary Lessons in Heat, Light and Sound. By D.

E. Jones, B.Sc., Inspector of Science Schools under the Science and Art Department. Adapted to the Elementary Stage of the South Kensington Syllabus. 2s. $6 d$.

Heat for Advanced Students. Adapted to Advanced

Stage of South Kensington Syllabus. By E. Edser, A.R.C.Sc. [In the Press. MACMILLAN AND CO., LTD., LONDON. 


\section{MACMILLAN \& CO.'S SCIENCE CLASS BOOKS Adapted to the South Kensington Syllabuses.}

Elementary Physics. By Balfour Stewart, F.R.S. New Edition, thoroughly Revised. 4s. 6d. Questions, 2s.

IX. MAGNETISM AND ELECTRICITY.

Electricity and Magnetism for Beginners. Adapted to the Elementary Stage of the South Kensington Syllabus. By F. W. SANDERSON, M.A. 2s. $6 d$.

Magnetism and Electricity for Beginners. Adapted to the Elementary Stage of the South Kensington Syllabus. By H. E. HadLev, B.Sc. (Lond.).

[In the Press.

Elementary Lessons in Electricity and Magnetism. By Prof. Silvanus P. Thompson, F.R.S. New Edition, r895. 4s. $6 d$.

\section{$X$. and $X I$. CHEMISTRY.}

INORGANIC CHEMISTRY--THEORETICAL.

Chemistry for Beginners. Adapted to the Elementary Stage of the South Kensington Syllabus. By Sir Henry Roscoe, F.R.S., Assisted by J. Lunt, B.Sc. New Edition, revised. 2s. 6 d.

The Elements of Chemistry. Adapted to the South Kensington Syllabus. By Prof. IrA Remsen. 2s. $6 \mathrm{~d}$.

Inorganic Chemistry for Advanced Students. By Sir H. E. RoscoE, F.R.S., and Dr. A. HARDEN.

[In the Press.

Chemical Problems. By Prof. T. E. THORPE, F.R.S.

With Key, 2s.

Chemical Arithmetic. By S. Lupton, M.A. With I200 Problems. 4s. $6 d$.

Inorganic Chemistry. By Prof. Ira Remsen, 6s. 6d. INORGANIC CHEMISTRY-PRACTICAL.

Chemistry for Organised Schools of Science. By $S$. PARRISH, B.Sc., A.R.C.S. (Lond.), with Introduction by Dr. Forsyth.

IIn the Pres:

Practical Inorganic Chemistry. By G. S. Turpin, M.A.,

D.Sc. Adapted to the Elementary Stage of the Soutb Kensington Syllabus, and to the Syllabus for Organised Science Schools. 2s. $6 d$.

Practical Inorganic Chemistry for Advanced Students. By Chapman Jones, F.I.C., F.C.S. $25.6 d$.

The Junior Course of Practical Chemistry. By F. Jones,

F.C.S. 2s. $6 d$. The New Edition of this book covers the Syllabus of the South Kensington Examination.

ORGANIC CHEMISTRY-THEORETICAL.

Organic Chemistry for Beginners. By G. S. TURPIN, M.A.,

D.Sc. Adapted to the South Kensington Syllabus. 2s. $6 d$.

Organic Chemistry. By Prof. Ira Remsen. 6s. $5 d$. MACMILLAN ANI) CO., LTD., LONDON. 


\section{MACMILLAN \& CO.'S SCIENCE CLASS BOOKS \\ Adapted to the South Kensington Syllabuses.}

\section{GEOLOGY.}

Geology for Beginners. By W. W. Watts, M.A., F.G.S. Adapted to the Elementary Stage of the South Kensington Syllabus. 2s. 6d.

\section{HUMAN PHYSIOLOGY.}

Physiology for Beginners. By Sir Michael Foster and Dr. L. E. Shore. Adapted to the Elementary Stage of the South Kensington Syllatus. 2s. $6 d$.

Physiology for Advanced Students. Adapted to the Advanced Stage of the South Kensington Syllabus. By A. Stanley Kent, M.A. (Oxon.).

In preparation.

Lessons in Elementary Physiology. By the Right Hon. T. H. HuXLEY, F.R.S. 4s. 6d. Questions, Is. $6 d$.

XVII. BOTANY.

Botany for Beginners. Adapted to the Elementary Stage of the South Kensington Syllabus. By ERnest Evans, Burnley Technical School.

\section{METALLURGY.}

A Text-Book of Elementary Metallurgy. By A. H. Hiorns, Principal of the School of Metallurgy, Birmingham and Midland Institute. 3s. Questions, Is.

\section{PHYSIOGRAPHY.}

Experimental Science (Section I. Physiography). By Prof. R. A. Gregory and A. T. Simmons, B.Sc.

[In the Pre is

Physiography for Beginners. By A. T. Simmons, B.Sc. 2s. $6 d$. Adapted to the Elementary Stage of the South Kensington Syllabus.

Physiography for Advanced Students. By A. T. Simmons, B.Sc. 4 s. $6 d$.

Elementary Lessons in Astronomy. By Sir NoRMAN Lock Yer. New Edition. 5s. 6d. This book contains all the Astronomy re. quired for the Advanced and Honours.

XXIV. THE PRINCIPLES OF AGRICULTURE.

Agriculture for Beginners. Adapted to the Elementary Stage of the South Kensington Syllabus. By A. J. COOPER, Harris Institute, Preston.

[In preparation.

Elementary Lessons in the Science of Agricultural PRACTICE. By H. TANNER, F.C.S. 3s. $6 d$.

\section{HYGIENE.}

Hygiene for Beginners. By E. S. Reynolds; M.D.

Adapted to the Elementary Stage of the South Kensington Syllabus. 2s.6d.

Handbook of Public Health and Demography. By E.

F. Wrllovgriby, M.B. New and Revised Edition. 4s. $6 d$.

$$
\text { MACMILLAN AND CO., LTD., LONDON. }
$$




\section{MACMILLAN \& BOOKS FOR STUDENTS OF BOTANY.}

LABORATORY PRACTICE FOR BEGINNERS IN BOTANY. By William A. Setchell, Ph.D., Professor of Eotany in the University of California. Globe 8vo. 4s. $6 d$. net.

PRACTICAL BOTANY FOR BEGINNERS. By Prafessor F. O. Bower, D.Sc., F.R.S., Author of "A Course of Practical Instruction in Botany." Globe 8vo. 3s. 6 d.

A COURSE OF PRACTICAL INSTRUCTION IN BOTANY. By F. O. Bower, D.Sc., F.R.S., Regius Professor of Botany in the University of Glasgow. Crown 8vo. Ios. $6 d$.

FIRST LESSONS IN PRACTICAL BOTANY. By G. T. Betrany, M.A., B.Sc., F.L.S. Putt 8vo. rs.

BOTANY. Dy Sir J. D. Hooker, F.R.S. With Illustrations. Pott 8 vo. Is.

[Science Primers.

L.ESSONS IN ELEMENTARY BOTANY. By DANIEL Oliver, F.R.S. The Part on Systematic Botany based upon material left in manuscript by the late Professor HensLow. With numerous Illustrations. Third Edition. Fcap. 8vo. 4s. 6 d.

FIRST BOOK OF INDIAN BOTANY. By DANIEL Oliver, F.R.S. With numerous Illustrations. Globe 8vo. 6s. $6 d$.

A TEXT-BOOK OF BOTANY. By Dr. E. Strasburger, Dr. Fritz Noll. Dr. H. Schenck, Dr. A. F. W. Schimper. Translated from the German by H. C. PORTER, Ph.D. With 594 Illustrations, in Part Coloured. Medium 8vo. I8s. net.

THE STUDENT'S FLORA OF THE BRITISH ISLANDS. By Sir J. D. Hooker, F.R.S. Third Edition. Globe 8va. Ios. $6 d$.

GRAY'S BOTANICAL TEXT-BOOKS. Sixth Edition.

Vol. I. Structural Botany: or, Organography on the Basis of Morphology. To which is added the Principles of Taxonomy and Phytography, and a Glossary of Botanical Terms. By Asa Gray. 8vo. Ios. 6d.

Vol. II. Physiological Botany.-r. Outlines of the History of Phrnogamous Plants. II. Vegetable Physiology. By G. Lincoln Goodale, A.M., M.D., Professor of Botany in Harvard University. 8vo. ros. $6 d$.

AN INTRODUCTION TO THE STUDY OF SEAWEEDS. By G. MURray, F.R.S.E. Illustrated. 7s. 6 d.

THE STRUCTURE AND DEVELOPMENT OF THE MOSSES AND FERNS (Archegoniata). By Douglas Houghton CampBELL, Ph.D., Professor of Botany in the Leland Stanford Junior University. Medium 8vo. I4s. net.

THE HERB OF THE FIELD. By Charlotte $M$. YONGE. New Edition, revised. Crown 8vo. 5s.

LECTURES ON THE EVOLUTION OF PLANTS. By Professor Douglas H. Campbell, Ph.D. Crown 8vo. 4s. 6 d. net.

THE YEW-TREES OF GREAT BRITAIN AND

IRELAND. By John Lowe, M.D. Ed., Honorary Physician to His Royal Highness the Prince of Wales, \&c., \&c. Illustrated, 8vo. ros. net. MACMILLAN AND CO., LTD., LONDON. 


\section{MACMILLAN \& CO.'S BOOKS FOR STUDENTS OF BOTANY.}

BRITISH FOREST TREES AND THEIR SYLVICUL'TURAL CHARACTERISTICS AND TREATMENT. BY JOHN NisBet, of the Indian Forest Service. Crown 8vo. 6s. net.

TIMBER AND SOME OF ITS DISEASES. By $\mathrm{H}$. Marshall WARD, M.A., F.R.S., F.L.S., late Fellow of Christ's College, Cambridge, Professor of Botany at the Royal Indian Engineering College, Cooper's Hill. With Illustrations. Crown 8 vo. 6s. [Nature Series. TEXT-BOOK OF THE DISEASES OF TREES. By Professor R. Hartig. Translated by Dr. W. Somerville, Professor of Agriculture and Forestry at Durham College of Science. With a Preface by Professor H. Marshall Ward, F.R.S. With numerous Illustrations. 8vo. ros. net.

TIMBER AND TIMBER TREES, NATIVE AND FOREIGN. By Thomas LAsLetr, Timber Inspector to the Admiralty. New Edition. Revised by Professor H. Marshall Ward, F.R.S. Crown 8vo. 8 s. $6 d$.

THE BOOK OF THE ROSE. By the Rev. A. FosterMelliar. Illustrated. Extra Crown 8vo. 8s. 6 d. net.

FLOWERS, FRUITS, AND LEAVES. By Sir John LuBbock, Bart., F.R.S. With numerous Illustrations. Crown 8 vo. 4 s. 6 d.

[Nature Series.

ON BRITISH WILD FLOWERS, considered in relation to Insects. With numerous Illustrations. By Sir JoHN LUBBOCK, Bart., F.R.S. Crown 8vo. 4 s. $6 d$.

[Nature Series. THE COLOURS OF FLOWERS, as Illustrated in the British Flora. ¿By Grant Allen. With Illustrations. Crown 8vo. 3 s. $6 d$. [Nature Series.

A PRIMER OF PRACTICAL HORTICULTURE. Ten Lectures delivered for the Surrey County Council. By J. WRIGHT, F.R.H.S. Pott 8vo. Is.

THE CHEMISTRY OF THE GARDEN. A Primer for Amateurs and Young Gardeners. By Herbert H. Cousins, M.A., Oxford Lecturer in Chemistry at the South-Eastern Agricultural College, Wye, Kent. Pott 8vo. Is.

GARDEN FLOWERS AND PLANTS. A Primer for Amateurs. By J. WRIGHT, F.R.H.S. With 50 Illustrations. Pott 8vo. Is. GREENHOUSE AND WINDOW PLANTS. A Primer for Anateurs. By Charles Collins. Edited by J. Wright, F.R.H.S. With 38 Illustrations. Pott 8 vo. Is.

FARM AND GARDEN INSECTS. By WILLIAM Somerville, D.CEc. (Mon.), D.Sc. (Dun.), B.Sc. (Edin.), F.R.S.E., F.L..S. With 46 Illustrations. Pott 8vo. Is.

VEGETABLE CULTURE. A Primer for Amateurs, Cottagers, and Allotment Holders. By A. DeAN, F.R.H.S., Member of the Fruit and Vegetable Committee of the Royal Horticultural Society. Edited by J. Wright. With 38 Illustrations. Pott 8vo. rs.

$$
\text { MACMILLAN AND CO., LTD., LONDON. }
$$




\section{MACMILLAN \& CO.'S PUBLICATIONS.}

MACMILLAN'S ELEMENTARY COMMERCIAL CLASS ROOKS. Edited by James Gow, Litt.D., Head Master of the High School, Nottingham.

History of Commerce in Europe. By Rev. H. de B. GIBBINS, M.A. 3s. 6 .

Commercial Geography. By E. C. K. Gonner, M.A., Professor of Pul tical Economy in University College, Liverpool. ${ }_{3} s$.

Commercial Arithmetic. By S. Jackson, M.A. 3s. 6 d.

Commercial German. By F. Coverley Smith, B.A. 3s. $6 \pi$.

Commercial Spanish. By Prof. Delbos, Instructor, H.M.S. Britannia, Dartmouth. 3 s. 6 d.

Commercial Law. By J. E. C. Munro, LL.D., late Prof. of Law and Political Economy in the Owens College, Manchester. $3 s .6 d$. Marine Insurance. By W. Gow, M.A., (Glasgow), Ph.D. (Heidelberg) 4s. $6 d$.

\section{COMMERCIAL CORRESPONDENCE AND OFFICIAL ROUTINE.}

MODERN BUSINESS METHODS. By F. HoOpER and J. Graham. I. The Home Trade. $2 s .6 d$. II. Import and Export Trade. $3 s .6 d$. The Teacher's Companion to I. The Home Trade. 2s. $6 \mathrm{~d}$. net.

A Beginner's Guide to Office Work. Sewed, is. Book of Facsimile Modern Business Forms. $6 d$. Modern Business Letters. [In the Press.

\section{FIRST LESSONS IN BOOK-KEEPING. By J.} Thornton. 2s. $6 d$. Key. IOS. $6 d$.

Exercise Books to First Lessons IN BOOK-KeEPING. No. 1, for Lessons I.-IX., $9 d$.; No. 2, for Test Exercises, $9 d$.; No. 3, for Test Exercises, rs. 6d.; No. 4 , for Lessons XIII. and XIV., is. $6 d$. ; Case to contain all the above, $6 \%$. Complete set with case, $5 s$. No. 3 , Condensed Edition for working out a selection on all the Lessons, 2s. ; No. 6, Journal, 6d.

Examination Papers in Book-Keeping. $9 d$.

Key to Examination Papers. $2 s$.

Advanced Examination Papers in Book-Keeping. is. Key to Advanced Examination Papers in BookKEEPING. 2s. $6 d$.

Primer of BOOK-K Eeping. Is. Key. 2s. $6 d$.

Exercise Books to Primer of Book-Keeping. Part I., Ledger; Part II., Journal. The Set, Is.

Easy Exercises in Book-KeEping. I $s$.

Manual of Book-Keeping. 7s. $6 d$. MACMILLAN \& CO., LTD., LONDON. 




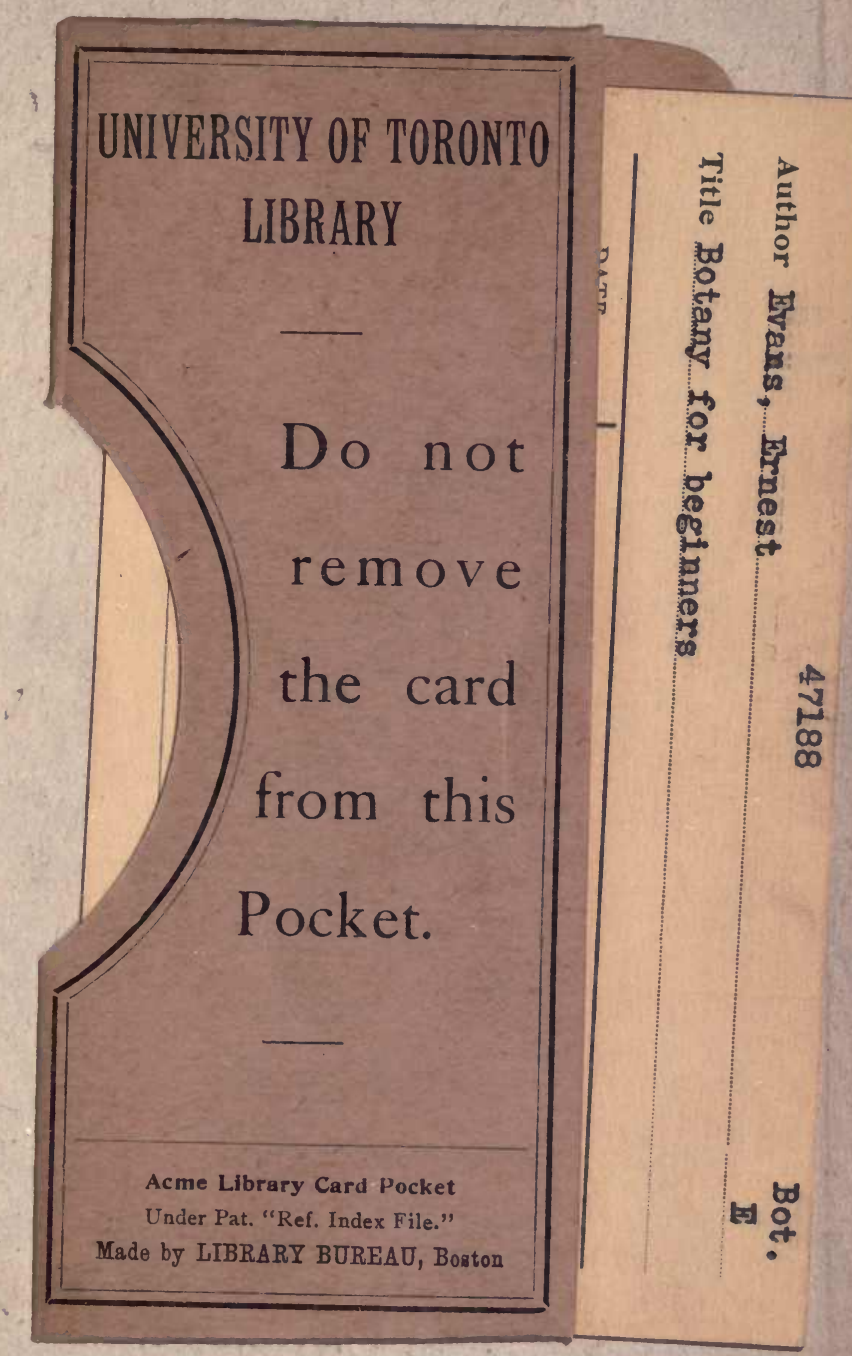


